\title{
Conservation
}

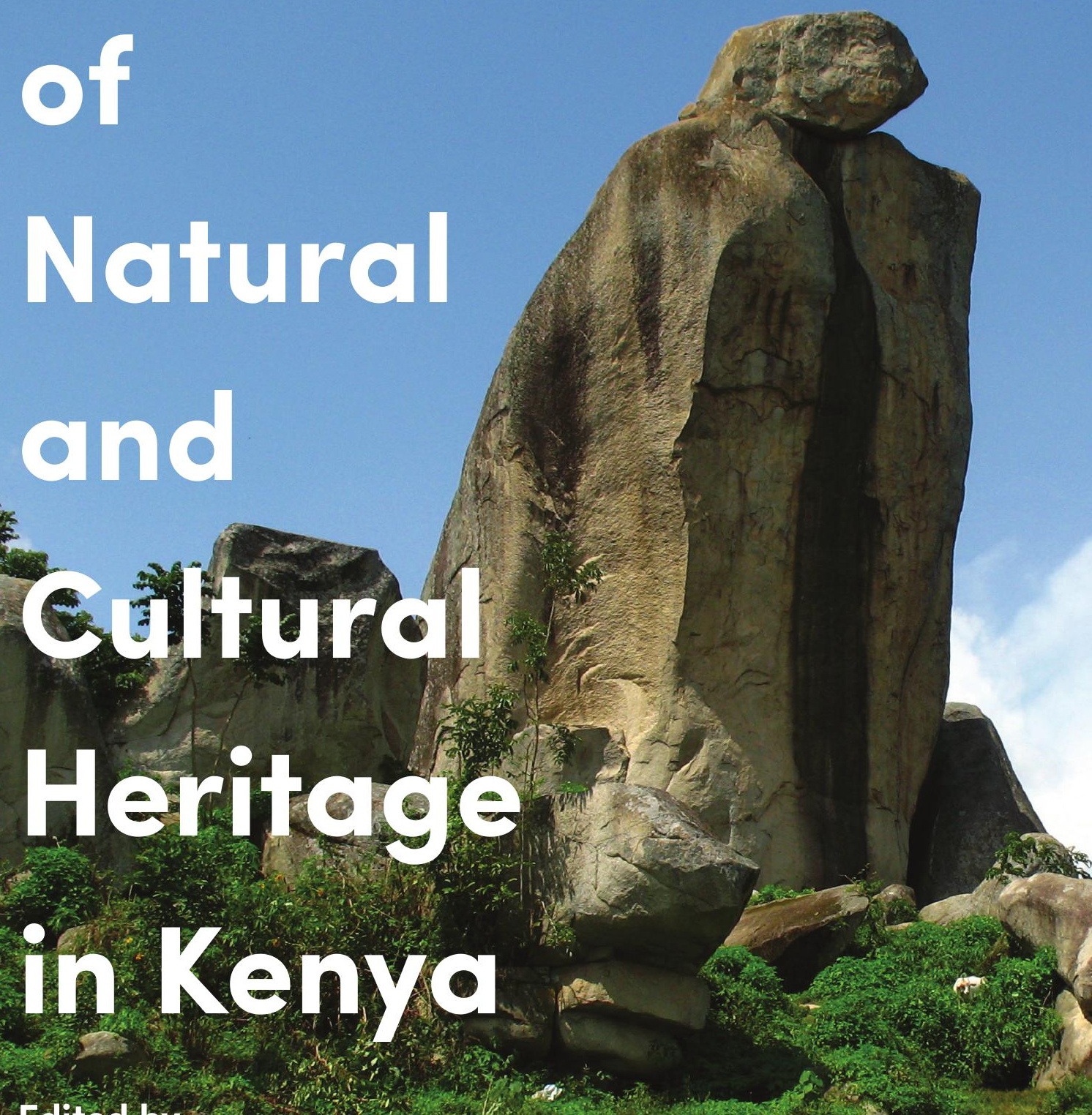

Edited by

Anne-Marie Deisser

Muguima Nuguna 
Conservation of Natural and Cultural

Heritage in Kenya 



\section{Conservation of \\ Natural and Cultural Heritage in Kenya}

A cross-disciplinary approach

Edited by

Anne-Marie Deisser

Mugwima Njuguna

${ }^{\star}$ UCLPRESS 
First published in 2016 by

UCL Press

University College London

Gower Street

London WC1E 6BT

Available to download free: www.ucl.ac.uk/ucl-press

Text (C) Contributors, 2016

Images (C) Contributors and copyright holders named in captions, 2016

A CIP catalogue record for this book is available from The British Library.

This book is published under a Creative Commons Attribution Non-commercial Non-derivative 4.0 International license (CC BY-NC-ND 4.0). This license allows you to share, copy, distribute and transmit the work for personal and non-commercial use providing author and publisher attribution is clearly stated. Further details about CC BY licenses are available at http://creativecommons.org/ licenses/

ISBN: 978-1-910634-82-0 (Hbk.)

ISBN: 978-1-910634-83-7 (Pbk.)

ISBN: 978-1-910634-84-4 (PDF)

ISBN: 978-1-910634-85-1 (epub)

ISBN: 978-1-910634-86-8 (mobi)

ISBN: 978-1-911307-32-7 (html)

DOI: $10.14324 / 111.9781910634844$ 


\section{Foreword}

Dr Mzalendo Kibunjia, Director General, National Museums of Kenya

As scientists, historians and archaeologists continue to uncover, study and promote access to tangible and intangible cultural heritage, there are ever increasing challenges that pervade conservation efforts. Heritage conservation is threatened as the world globalizes and African economies open up to new realms of growth in the international markets while increased building construction, infrastructural expansion as well as terrorism destroy existing heritage assets. Kenya in particular prides itself as a prodigious habitat for abundant and various natural and cultural heritage assets including archaeological sites, wildlife, landscapes and folklores. However, the different forms cultural and natural heritage take and the complexity of the conservation challenges are not congealed; their constant and respective evolution requires continuous regeneration of competence, technology and value systems. Conservators must therefore seek to expand existing principles and practices in the management of cultural and natural heritage, including the assessment of values attributed to the heritage, questions of reversibility and replica as well as access and security issues.

Cultural heritage conservation is not one of the subjects that have been accorded great attention in Kenya over the past century. The editors and contributors aim, however, to highlight and expand conservation studies from the confines of technical and scientific management expertise into the strata of matters engrained in local populations and the intrinsic links between communities, and their cultural and natural environment within the Kenyan legal framework. An in-depth discussion on contradictions in existing laws in Kenya exposes the difficulties in implementing conservation guidelines.

This book gives voice to subjects and highlights heritage uncared for, which helps to tell and understand the national narrative. The heritage mentioned includes monuments, trafficking of African antiquities, wildlife, cultural tourism, indigenous methods of conservation, the participation and empowerment of communities as immediate beneficiaries and 
makers of the culture. Consequently, ownership rights and utilization of heritage resources is presented as an issue of human rights and democracy. This book also introduces rural landscapes from the dimension of aesthetics and how these can be understood and used as a socio-cultural resource. It is a book that opens up conversations on 'esoteric' historical issues such as colonization and the influence of religion on cultural practices.

Kenyan scholars have for a long time relied on foreign knowledge in seeking to understand and explain the issues affecting cultural heritage in the country and the continent at large. The foreign principles, concepts and theories when applied in solving local problems are limited and in many cases incoherent to the cultural values, economic status and politics of Kenya. It is therefore pleasing to see a book developed through intense research by local academics and professionals that will be very useful to graduate students as well as conservation practitioners in Kenya and abroad.

As the complexity of challenges increases and other disciplines advance, with their handlers seeking an ear in the administration of public knowhow, the need for cross-disciplinary approaches is inevitable. It is therefore important that we finally have a book that takes a multi-faceted approach to conservation through the contributions of various experts to expound on these issues. The perspectives of historians, curators, landscape architects, environmentalists and other heritage professionals in this book configure a holistic understanding of the different challenges and how collaboration can bring untold solutions to the issues undermining heritage conservation in Kenya. Experts may be inclined to give excessive import and supremacy to their faculties at the expense of both competing and complementary approaches but it is the mingling of these works that filters inconsistencies and overrides unnecessary jargon for the lay reader to deduce simple concepts that drive the discourse beyond the scholarly fronts.

The research in this book recognizes the complementarity of works of art such as landscape architecture to efforts by historians and archaeologists in conserving cultural heritage. The role of designers in built heritage, as well as redevelopment of areas in line with original principles in urban conservation districts, is highlighted through case studies in Nairobi and the Kenyan coast and deepens the understanding of how integration of historical structures into contemporary buildings and settlements can be carried out coherently. With its many case studies, the book presents an undoubtedly comprehensive approach that analyzes heritage and its constituent elements in detail. The book nourishes 
the reader in breadth and in depth with a heightened exposure to the urgency of multi-disciplinary solutions in conservation.

Even though none of the issues presented here are purely new, the book unequivocally ascends past the elementary view of heritage into the stratum of how the different faculties are interwoven and the conflicts that bloom. This book is timely: it comes at a critical time when Kenya is struggling with slackening tourism and stiff competition from other countries in the region such as Seychelles, Mauritius and Botswana; it will arouse new interest on how cultural heritage can diversify tourism opportunities. Politicians and activists have been helpful in raising awareness about cultural items although they are disposed towards quick fixes and short-lived advocacies and interventions. Academics in this book are, however, establishing articulate prognoses and informed forecasts that direct the course of action with regard to heritage conservation. This is a major step in opening avenues for further discussions that will create concrete interventions in synchronizing existing laws, ensuring best practices in heritage conservation, establishing legal conservation guidelines, human resource capacity development and advancement of relevant curricula in Kenyan universities. 



\section{Acknowledgements}

This publication is the result of a truly participatory process extending over three years. It draws heavily on the creation of the Heritage Conservation and Human Rights (HCHR) network. In the early stages of HCHR, a group of people from different institutions and professional backgrounds engaged in brainstorming sessions with the objective of broadening the concept of heritage conservation in Kenya and to promote its association with the concept of human rights. The idea to develop a publication around the main themes inspired by these encounters was initiated by Dr Mugwima Njuguna.

Amongst the HCHR network participants, 14 papers were selected. However, many other members contributed to this publication through their sharing of knowledge and expertise and their contributions deserve special mention: Dr Mary Mwiandi, chair of the department of history and archaeology, University of Nairobi (UON); Gilbert Wafula, lecturer of archaeology and tourism in the department of history and archaeology (UON); Patrick Nyabul, lecturer at the department of philosophy and religious studies in the college of humanities and social sciences (UON); Dr Owakah Francis, university lecturer and researcher in philosophy (UON); Brenda Kamande, landscape architect with a passion for history and people; Carolyne Wanza, landscape architect, urban designer and assistant lecturer at Jomo Kenyatta University of Agriculture and Technology; Daniel Kipkorir, lecturer at the department of anthropology and human ecology, Moi University; Dr Joseph Wasonga, lecturer at the department of history, archaeology and political studies, Kenyatta University; Dominic Kinyua, landscape architect and lecturer at Kenyatta University; Kariuki Kamaru, architect and lecturer at Jomo Kenyatta University of Agriculture and Technology and Paul Mwau, landscape architect with an interest in urban design.

The publication of this book would not have been possible without the support of the universities that have produced the various authors, the University of Nairobi, Jomo Kenyatta University of Agriculture and 
Technology, Kenyatta University, Moi University and University College London. Technical support was received from the department of history and archaeology, UON, both directly and through the associate dean of the faculty of arts, Professor Ephraim Wahome, who over the years invited the authors to UON, and shared his knowledge and worked tirelessly.

The editors enjoyed the support and good spirit of Dr Ambreena Manji and Dr Christian Thibon, the directors of the British Institute in Eastern Africa (BIEA) and the French Institute for Research in Africa (IFRA) respectively, who made it possible to have a workshop where all the authors met and charted the way forward.

The language editing was handled by Dr Godwin Siundu, department of literature, UON and editor of Eastern African Literary and Cultural Studies. 


\section{Contents}

List of figures $\quad$ xiii

List of tables $\quad$ xvi

List of contributors $\quad$ xvii

Introduction $\quad 1$

1. Access to heritage conservation as a human right in Kenya 17 Anne-Marie Deisser and Ephraim Wahome

2. Assessment of legislation on cultural heritage resources in Kenya 30

Mwanzia Kyule

3. The concept of intangible cultural heritage in Kenya 45 Orinda Shadrack Okumu

4. The conservation of public monuments as a tool for building collective identity in Nairobi 59 Lydia Muthuma

5. Reflections on architectural morphology in Nairobi, Kenya: implications for conservation of the built heritage Muhoro Teckla, Munala Gerryshom and Mugwima Njuguna

6. The bao: a board game in Africa's antiquity Mwanzia Kyule

7. Traditional technologies: a conservation challenge Freda M'Mbogori

8. Wildlife heritage ownership and utilization in Kenya the past, present and future Francis Mwaura 
9. Evaluating rural heritage conservation in Kenya: the case of Karue Hill, Embu County

Anthony Njeru Murithi

10. Development of cultural heritage tourism in Kenya:

a strategy for diversification of tourism products

Evaristus Irandu and Parita Shah

11. Significance of traditional oral information and natural artefacts for heritage conservation at the Kit-Mikayi cultural site

Okello Benter, John Bosco Mukundi, Arnold Onyango Watako and Ochieng' Aggrey Adimo

12. Community participation in conservation of gazetted cultural heritage sites: a case study of the Agikuyu shrine at Mukurwe wa Nyagathanga

Robert Rukwaro

13. Fisheries as heritage: indigenous methods of fishing and conservation among the Luo fishers of Lake Victoria, Kenya Paul Opondo

14. Tracing a forgotten heritage: the place of Mau Mau memory and culture in Kenya

Ephraim Wahome, Felix Kiruthu and Susan Mwangi

References

Index 


\section{Figures}

Figure 1.1 Kenyan inter-censual urban growth rates \% (adapted from KNBS 1999)

Figure 1.2 National and coastal population trends since 1948 (adapted from KNBS 2009)

Figure 1.3 Coastal population trend since 1948 (adapted from KNBS 2009)

Figure 4.1 Monuments described in this chapter and their locations (Muthuma 2014)

Figure 4.2 Dedan Kimathi wa Waciuri by Samuel Wanjau. This is the sculpture that was commissioned in the 1970s, but never installed. It lies in the garden of Paa-ya-Paa (Muthuma 2014)

Figure 4.3 Statue of King George V in front of Nairobi High Court (Railway Museum, Nairobi 2014)

Figure 4.4 Fountain where a plaque of King George VI was mounted (Muthuma 2014)

Figure 4.5 The Carrier Corps (African War Memorial) on Kenyatta Avenue (Muthuma 2014)

Figure 5.1 Colonnaded façades of City Hall (wikimedia.org, accessed 22 February 2016)

Figure 5.2 Symmetry, use of pediments, rustication, quoining and cornice on Panafric House (http://nairobians.net/, accessed February 2016)

Figure 5.3 Masonry construction, vertical proportions and carved stone ornaments (https://gregorycrofford. com/, accessed 6 March 2016)

Figure 5.4 Old Provincial Commissioner's Office (http:// theglobalgrid.org/, accessed 22 February 2016)

Figure 5.5 Norfolk Hotel (http://www.beglinwoods.com/, accessed 22 February 2016) 
Figure 5.6 Kenwood House (http://4.bp.blogspot.com/, accessed 22 February 2016)

Figure 5.7 Sheria House (http://www.travel-images. com/, accessed 22 February 2016)

Figure 5.8 Singh Sabha Temple (http://i0.wp.com/, accessed 22 February 2016)

Figure 6.1 Maasai men playing bao on a wooden board at Olenkuluo near Ntuka, Narok County, Kenya (Kyule, M. 2004)

Figure 6.2 Temporary pits scraped by Akamba herd-boys on the ground to make a four-row, 32-pit bao game board platform at Kwethelu Village, Emali, Kenya (Kyule, C. 2013)

Figure 6.3 A four-row, 60-pit bao board complex on exposed rock surface near Leshota, Narok County, Kenya (Ambrose, S. 2005)

Figure 6.4 A two-row, 26-pit bao board cut into natural rock formations at archaeological site GvJh115, Narok County, Kenya (Ambrose, S. 2005)

Figure 6.5 A prehistoric bao board curved on natural rock formation at Hyrax Hill archaeological landscapes, Nakuru, Kenya (Kyule, M. 2012)

Figure 6.6 Remains of a bao board on one of the blocks used to build the Hyrax Hill site museum on the left side of the door leading to the building's west wing (Kyule, M. 1992)

Figure 7.1 Locations of the interviewed potters (M'Mbogori 2015)

Figure 7.2 Pottery forms of Jareer (M'Mbogori 2015)

Figure 7.3 Pottery making chaîne opératoire of the Cushitic speakers (M'Mbogori 2015)

Figure 7.4 Pottery forms of Coastal Bantu speakers (M'Mbogori 2015)

Figure 8.1 Dr Rosendo Ribeiro on a zebra ride in Nairobi (Smart 1950)

Figure 9.1 Developing positive theory (adapted from Lang 1987)

Figure 9.2 Developing normative theory (adapted from Lang 1987)

Figure 9.3 A view of Karue Hill (Murithi 2011) 
Figure 9.4 Unique rock formations on Karue Hill (Murithi 2011)

Figure 9.5 Discordant constructions at the peak (Murithi 2011)

Figure 9.6 Deforestation on Karue Hill (Murithi 2011) 151

Figure 10.1 Lamu (Shah 2014) 161

Figure 10.2 The Kenyatta International Conference Centre (worldpress.com 2016) 162

Figure 10.3 Swaminarayan Temple on Forest Road, Nairobi (Shah 2014)

Figure 10.4 Age of tourists at the respective sites (Irandu \& Shah 2014)

Figure 10.5 Types of visitors (Irandu \& Shah 2014) 166

Figure 10.6 Preferred type of tourism (Irandu \& Shah 2014) 167

Figure 10.7 Perceived value of respective sites to tourists (Irandu \& Shah 2014)

Figure 11.1 Map showing location of study site of Kit-Mikayi (Benter 2013)

Figure 12.1 Map of Central Region showing the Kikuyu Holy Mountains and Mukurwe wa Nyagathanga site (adapted from George Phillip Ltd 1991)

Figure 12.2 Location of Mukurwe wa Nyagathanga site (Survey of Kenya 1968)

Figure 12.3 Mukurwe wa Nyagathanga: the place where God directed Gikuyu, the founder of the Agikuyu Nation, to settle (Rukwaro 2015)

Figure 12.4 Mukurwe wa Nyagathanga: the stalled tourist hotel (Rukwaro 2015)

Figure 12.5 Mukurwe wa Nyagathanga: the pseudo-Kikuyu traditional forms of the stalled tourist hotel at the mythical site (Rukwaro 2015) 190

Figure 14.1 Transformation of war trenches (Wahome 2013) 223 


\section{Tables}

Table 3.1 Levels of vitality for endangered languages of Kenya (adapted from Moseley 2010)

Table 4.1 Tabulation of monuments according to the subject depicted

Table 5.1 Status of selected historic buildings in Nairobi (adapted from National Museums of Kenya 2003)

Table 7.1 Forbidden acts in Cushitic pottery making (M'Mbogori 2015)

Table 7.2 Potters' tools, techniques and tutors of the Coastal Bantu speakers (M'Mbogori 2015)

Table 8.1 Wildlife heritage property rights and functions (Mwaura 2015)

Table 10.1 Existing and potential cultural heritage products of Nairobi (Irandu \& Shah 2014)

Table 10.2 Ranking of priorities by tourists (Irandu \& Shah 2014)

Table 10.3 SWOT analysis of the potential of Nairobi

Table 12.1 Summary of conservation activities carried out by different stakeholders at the Agikuyu shrine during the Wangari Maathai period (Rukwaro 2015)

Table 12.2 Suggested areas of material and non-material cultural knowledge (Rukwaro 2015) 


\section{List of contributors}

Anne-Marie Deisser joined the Textile Conservation Centre, University of Southampton, UK, in 2000 where she took her master's degree in Textile Conservation and her $\mathrm{PhD}$ research, which investigated 'conservation partnership' between local and institutional communities. She taught and worked as a conservator for the National Museums of Kenya, the National Museum of Ethiopia and the Institute of Ethiopian Studies. She was chair of the ethnography section of the United Kingdom Institute for Conservation, ICON (2005-08). Between 2009 and 2012, her work focused on the conservation of the tangible and intangible heritage of the Kurdish Nomadic tribes at the Textile Museum of Erbil. Since September 2012, she has been honorary research associate at the Institute of Archaeology (University College London) and research associate at the department of history and archaeology of the University of Nairobi in Kenya. Her main field of interest is the research of ethical conservation practices in relation to social development and human rights. Dr Deisser is an active contributor to conservation debate and networks across related conservation disciplines and contexts such as heritage and nature conservation and philosophy. Since 2012, she has coordinated the Heritage Conservation and Human Rights (HCHR) network, based at the University of Nairobi.

Mugwima Njuguna is an architect and planner, and the founder director, Centre for Urban Studies, Jomo Kenyatta University of Agriculture and Technology. He has extensively researched on conservation of historic areas and buildings. He is a registered architect, corporate member and graduate member of the architects and town planning chapters of the Architectural Association of Kenya respectively. Dr Mugwima is also a member of ICOMOS, an affiliate of Forum UNESCO-University and Heritage Network (FUUH), and a signatory to the ICOMOS INTABAU Venice Declaration as well as a member of Nature Kenya and the Kenya Book Foundation. He has published several papers, and supported the publication of the seminal book, The Venice Charter 
Revisited, Modernism, Conservation and Tradition in the 21st Century. He co-authored Nairobi: An Architectural Jubilee 1963-2013 (Vol. 1). Dr Mugwima is a founder member of the Heritage Conservation and Human Rights network. Currently he is investigating the conservation of the railway heritage in Kenya.

Ochieng' Aggrey Adimo is lecturer in the faculty of agriculture of Jomo Kenyatta University of Agriculture and Technology. He received his PhD in landscape planning and conservation from Jomo Kenyatta University of Agriculture and Technology in 2013. He specializes in landscape assessment, landscape ecology and GIS and remote sensing.

Okello Benter is senior technician in the department of landscape architecture in Jomo Kenyatta University of Agriculture and Technology. She has served as a member of the research and innovation committee in the department since 2010, and is a member of the exhibition and landscape consultation committee in the department, where she serves as site manager for projects. Benter holds a bachelor's degree in horticulture from the University of Egerton and a master's degree in landscape planning and conservation from JKUAT.

Munala Gerryshom is senior lecturer at the Centre for Urban Studies, JKUAT. He is a corporate member, Architectural Association of Kenya (AAK) and a registered practising architect, lead environmental impact assessor and auditor, National Environmental and Management Authority (NEMA) as well as a member of European Water Resource Association. He is a member of ISO TC 224 and Nature Kenya. Dr Munala is actively involved in teaching, research, supervision and has participated in university related architectural and planning projects. Dr Munala has published several refereed journal papers and most recently co-authored Nairobi: An Architectural Jubilee 1963-2013 (Vol. 1).

Evaristus Irandu is associate professor in the department of geography and environmental studies of the University of Nairobi. He holds a PhD degree in economic geography, specializing in transport and tourism development. He joined the University of Nairobi in 1988 as an assistant lecturer and served as the chair of the department from September 1999 to August 2005. His current research interests include air transport development, international tourism, ecotourism and heritage tourism.

Felix Kiruthu is head of the public policy and administration department at Kenyatta University in Kenya. He is a historian specializing in the history of the African political economy and a board member of the Kenyatta University Centre for Refugee Studies and Empowerment (KU-CRSE). Since 1997, Kiruthu has taught in the department of 
history, archaeology and political studies at Kenyatta University. Besides his research interests in political economy, he has also researched the urban history of Africa with special focus on labour relations and informal enterprises. His other research interests include biographies of prominent individuals, pedagogical methods in the study of history, as well as peace and conflict studies.

Mwanzia Kyule is a lecturer of archaeology, heritage and tourism, University of Nairobi. He is trained as an archaeologist and paleoanthropologist and has work experience in information and computing technology (ICT), curriculum development, capacity building, e-learning and distance education. His topical interests are heritage impact assessment, cultural resources management, indigenous knowledge and systems, human behavioural evolution, sustainable tourism, environment and conservation, African art and crafts.

Freda M'Mbogori joined the National Museums of Kenya, having done a first degree in archaeology at the University of Nairobi. While at the museum, she took a postgraduate course in museum conservation at University College London and later pursued a master's degree in archaeology and a PhD from University of Bergen, Norway, and University of Paris X, France, respectively. Dr Nkirote has been involved in museum conservation projects, conducted by the Kenya museum conservation team where she took a leading role. She has co-edited the book Humans \& the Environment: New Archaeological Perspectives for the Twenty-First Century, as well as authored the monograph Populations and Ceramic Traditions: Revisiting the Tana Ware of Coastal Kenya (7th-14th Century AD).

John Bosco Mukundi is associate professor in the faculty of agriculture of Jomo Kenyatta University of Agriculture and Technology. He received his $\mathrm{PhD}$ in landscape sciences and ecology from Osaka Prefecture University in 2001. He specializes in landscape planning and conservation in urban and rural landscapes, rehabilitation ecology, planting design and environmental horticulture. His research includes the study of structural and distribution of vegetation in urban green spaces, assessment of ecological services of avifauna in agricultural landscapes and rehabilitation processes of disturbed landscapes. He is a member of IALE-Africa, the Ecological Society of East Africa, the International Society of Horticultural Science and the network of Urban Biodiversity and Design. He is a referee to the International Journal of Biodiversity and Conservation and the African Journal of Environmental Science and Technology. 
Anthony Njeru Murithi has, since 2012, practised landscape architecture in both Kenya and Japan. He obtained a first class honours bachelor's degree in landscape architecture from Jomo Kenyatta University of Agriculture and Technology in 2012 and later a master's degree from Chiba University in Japan. His research interests include rural heritage, environmental aesthetics, car-free cities and green infrastructure. Murithi is currently undertaking a $\mathrm{PhD}$ at Chiba University.

Lydia Muthuma is an art historian. She has over twenty years' teaching experience in the field of aesthetics. Her research interests revolve around urban dynamics and related visual art forms. She has carried out research, curated exhibitions and authored several academic publications. Among her works are Nairobi in Pictures: Political Icons, 18991999 and the exhibition 'NYROBI, from papyrus swamp to modern capital city'. She is investigating the African city as a product of modernism. Dr Muthuma is a member of the International Association for Aesthetics (IAA).

Susan Mwangi is lecturer at the department of history, archaeology and political studies, Kenyatta University, Nairobi. Her areas of research interests include memorialization, political studies and gender issues.

Francis Mwaura is senior lecturer in the department of geography and environmental studies, University of Nairobi. He is a PhD, MSc and BSc holder in tropical biogeography and has considerable experience in issues concerning the interface between society and natural heritage with emphasis on biodiversity and ecosystems in tropical areas especially Eastern Africa. Dr Mwaura is the thematic head for the biogeography and natural resources management sections at the department of geography and environmental studies. The author is a member of a number of associations including Africa Nature People for Nature (P4N), Heritage Conservation and Human Rights (HCHR) network, and Eastern Africa Population, Health and Environment (PHE) network. He was a fellow of the 2012 African Climate Change Fellowship Programme (ACCFP) of the Climate Change Adaptation in Africa (CCAA) and the Global Change System for Analysis, Research and Training (START).

Orinda Shadrack Okumu holds an undergraduate degree in anthropology and a master's degree in development anthropology from the University of Nairobi. He works with African Cultural Network as a program officer in charge of research, and has a passion for intangible cultural heritage (ICH). He has an interest in qualitative research, evaluation and development issues. 
Paul Opondo is senior lecturer at the department of history and political science, Moi University, Eldoret, Kenya. He has a PhD in history from University of South Africa (UNISA). His PhD thesis focused on fishers and fish traders of Lake Victoria, Kenya where he looked at the indigenous methods of fishing and conservation and how the Luo people of Lake Victoria coped with the colonial policies on fisheries.

Robert Rukwaro is associate professor, department of architecture and building science, University of Nairobi, Kenya. He is the dean, School of the Built Environment, University of Nairobi.

Parita Shah is a tutorial fellow in the department of geography and environmental studies of the University of Nairobi. She holds a BA (geography) from University of London and MA in environmental planning and management from the University of Nairobi. Her research interests include biodiversity conservation, contribution of biodiversity to livelihoods, environmental impact assessments and natural and cultural tourism.

Muhoro Teckla is lecturer in the department of construction management, JKUAT. She lectures in theory and design studio at the undergraduate level and is engaged with the Centre for Urban Studies based at JKUAT. Ms Muhoro holds a BArch (USA) and an MArch (Belgium). She has worked extensively with international organizations on issues of urban development, human settlements, best practices, local leadership and partnership building. In the private sector, she has engaged in urban and infrastructure development in Africa, focused on training, product development and project management. She co-authored Nairobi: An Architectural Jubilee 1963-2013 (Vol. 1).

Ephraim Wahome is associate professor in the department of history and archaeology in the department of history, University of Nairobi. He is also the associate dean, faculty of arts, University of Nairobi. His main areas of interest include heritage conservation, prehistory, cultural tourism and human rights.

Arnold Onyango Watako is lecturer in the department of environmental horticulture of Jaramogi Oginga University. He has been a lecturer for the last three decades in the university. He is also a consultant in interior plantscaping. 



\section{Introduction}

Conservation principles and practices evolve and adapt to the cultural, political, social and economic environments in which they take place. These environments have radically changed since Cesare Brandi's theory of conservation (2005), the research of Miriam Clavir in preserving what is valued (2002) and the contemporary theory of conservation (Muños Viñas 2005). Brandi, who in 1939 became the first director of the Central Institute for Restoration in Rome, Italy, published a landmark theoretical essay on restoration. His essay outlines a theoretical and practical framework to address some of the most complex problems faced by conservators and sums up the essence of works of art, including architecture. Although the key principles of conservation are widening and moving in the direction of the protection of the non-material environment, as developed by Miriam Clavir, Brandi's theory remains an internationally recognized paradigm in the development of conservation policy. Miriam Clavir has worked as a conservator since 1969. Her philosophical approach to conservation is also internationally recognized and focuses on the relationship between museums and preservation, particularly in relation to indigenous peoples' material culture and in response to aboriginal concerns. Her work has significantly influenced conservation practices as it concentrates on the underlying philosophical issues in museum conservation, such as the preservation of cultural significance. The philosophical attitudes of Brandi and Clavir underline how conservation as a profession has slowly shifted in approach from privileging scientific expertise towards more crossdisciplinary exchanges (Eastop 2006; Peters 2008). The rationale for this transformation resides partly in the emergence of a preventive approach to conservation prompted by economic factors encountered in public and private cultural institutions. As part of these philosophical and legal advancements, the thinking about heritage conservation has 
integrated within its practices concepts of politics and religious beliefs as well as social and economic development (De La Torre 2002; Deisser 2009). Thus, in many ways, cultural heritage defines what it means to be human.

The end of the Cold War, globalization, the opening of China and Africa to the international markets, the expansion of new technologies and the rise of regional conflicts are critical milestones that have also affected society as well as a society's relationship to its heritage, its value and its preservation (Appadurai 1986). In Kenya, cultural and natural heritage has a particular value as the country's pre-historic heritage not only tells the story of man's origin and evolution, but it has also contributed to the understanding of the earth's history. Fossils and artefacts spanning over 27 million years have been discovered and conserved by the National Museums of Kenya (NMK). This heritage inspires a sense of belonging and is a source of pride for Kenyans but also for all citizens of the world (Abungu 2005).

In the meantime, the subject of antiquities trafficking is gaining attention in international security discourse, as the high demand for cultural, ethnic and religious artefacts begins to attract not only the interest of art collectors but also terrorist groups. A prime example of this is the steady rise in the market value of African art. Since 2006, demand for African tribal art has surpassed that for antiquities of Roman, Byzantine and Egyptian origin (Tribble 2015). Indeed, the eager expansion of antiquities dealers into countries that lack legal protections or enforcement mechanisms raises concerns that African countries currently experiencing conflicts will attract looters, traffickers and criminal networks. Cultural and natural heritage artefacts have become a significant source of income for terrorist groups such as Islamic State of Iraq and the Levant (ISIL) and Al-Shabaab (Brodie 2011). Some of the oldest traces of highly cultured civilizations can be found in Kenya's neighbouring country, Somalia (Mire 2011). This includes Muslim sultanates, Bantu huntergatherer societies, and nomadic tribes such as the Somalis and Oromo (Tribble 2015). Al-Shabaab's involvement in the wildlife trafficking network is especially noteworthy when assessing its potential for involvement in the illicit antiquities trade. Since being forced out of its strategic centres in Mogadishu and Kismayo, Al-Shabaab has become reliant on the profits it reaps from illegal ivory and is reportedly seeking new interactions with a complex network of poachers, ex-soldiers, brokers and informants to buy ivory poached in Kenya (Kalron \& Crosta 2012).

In a socio-cultural context where heritage values fluctuate, it is essential to question the rationale for, and value of, active participation 
of individuals and communities in the field of conservation, and to debate the 'added value of cultural and natural heritage' to society (Taylor \& Lennon 2011). In order to respond to the Kenyan socio-cultural and political environment, it is critical to think, talk and act differently and to develop ethics and conservation practices that respond to the needs of the society. The Kenyan people and their heritage can benefit from new types of alliances to address contemporary societal conflicts.

This is what this book examines by bringing together essays by heritage experts from different scientific backgrounds, including conservation, heritage management, museum studies, archaeology, environment and social sciences, architecture and landscape, geography, philosophy and economy. The book is also directed to graduate students of the same disciplines who are interested in reading about heritage conservation from an international perspective.

This book is structured around three key themes: first, the relationship underlying ethics, practices and legal issues; second, the exploration of architectural and urban heritage of Nairobi. The third theme examines natural heritage, landscapes and sacred sites in relation to local communities and tourism. The contributors are experts in their respective fields and provide current insights into approaches and practices in natural and heritage conservation. While the subject is relevant and somewhat applicable to other countries and regions, the case studies are anchored in Kenya, which has a long-standing experience in both natural and cultural heritage conservation. The different chapters provide an historical perspective on conservation practices and explore the impact of conservation ethics and practices on socio-cultural, economic and ecological contexts. The key objectives of this book are, first, to provide an overview of conservation practices in Kenya from 2000 to 2015 and, second, to highlight the role of natural and cultural heritage as key factors of social-economic development and as potential instruments for conflict resolution. The book employs a cross-disciplinary approach in discussing conservation of natural and cultural heritage, gathering contributions from the fields of conservation, philosophy, history, archaeology, sociology, architecture, planning, landscape architecture, art, urban design, anthropology, environmental and wildlife organizations, human rights and public policy.

Conservation practices are intimately linked to codes of ethics dictated by local and/or international systems of values. In turn, these values are inscribed in legal frameworks or they comply with legal texts. The beginning of the twenty-first century has seen a developing trend in the destruction of diverse forms of heritage (archaeological 
sites, underwater artefacts, buildings and cultural landscapes) while anticipating efficient preservation through open legal access. At the same time, the importance of conserving natural and cultural heritage is increasingly acknowledged all around the world. Public access to the practice of conservation has gradually increased, in particular in the field of intangible heritage. However, the conservation of natural and cultural heritage must not conflict with human rights. In Kenya, the rights entrenched in the constitution have fostered debates on the relevance of natural and cultural heritage conservation instruments, their potential cross-relevance, and the inclusion of key stakeholders. For instance, Chapter 2 of the Kenya Constitution recognizes culture as the foundation of the nation and affirms that the state shall recognize and promote all forms of national and cultural expression, as well as the roles of indigenous technologies in the development of the nation (KLR 2009). In times of economic development or in times of political conflicts, the value of heritage receives renewed attention through trafficking or destruction on one hand or rescue and preservation on the other. As a result, the empowerment of communities in conflict through the practice of heritage conservation is a contentious and central issue which serves as an extension of human rights and democracy (Eastop 2002; Silverman \& Ruggles 2007; Deisser 2009).

Anne-Marie Deisser and Ephraim Wahome discuss how the principles of human rights in the framework of the African Union (AU) legal instruments, the Constitution of Kenya (2010) and the National Museums and Heritage Act (2006) apply in the areas of conservation of natural and cultural heritage. They also address the relationships and potential conflicts between these legal instruments and the UNESCO conventions. Heritage professionals working in the field of environmental conservation have addressed in depth the relationship between heritage conservation and human rights (Abdullahi 2002; Logan \& Craith 2010; Dorfman 2012). However, this linkage is not sufficiently researched, or properly understood, in the field of cultural heritage conservation, where emphasis is on the conservation of fabric with little attention paid to the fundamental rights of the custodians: access, interpretation of values and use of their heritage. Deisser and Wahome understand custodians as the people living in the vicinity of the heritage to be conserved. In some instances, access to heritage may be controlled by various heritage authorities, which are averse to the interests of the actual custodians (James 2007). In the opening chapter, Deisser and Wahome explore access to heritage conservation as an opportunity for dialogue and cross-disciplinary partnership in Kenya. The two authors 
probe the legal opportunities available for access to conservation as a human right. The global and local conflicts surrounding conservation practices are discussed through case studies. To this end, the chapter reviews the African Union and Kenya's legal standards that take cognizance of conservation as a human right.

Similarly, it is critical to highlight the necessity to reconsider Kenya's legal framework pertaining to cultural heritage resources, by briefly revisiting the circumstances that informed the enactment of the relevant laws. This is the concern of Mwanzia Kyule who argues, in Chapter 2, that the existing legislation is not adequate in meeting local and national interests, and that although some legal instruments have served the country's heritage conservation in the past, the legislation has turned cultural heritage management in Kenya into a framework of policy abstractions which is nearly irrelevant and unresponsive to changing local and international circumstances. While Kenya does have a formal cultural heritage policy, decisions on cultural heritage affairs are informed, in large measure, by the National Museums and Heritage Act (CAP 216) of 2006, which extends authority for the management of Kenya's cultural patrimony to the National Museums of Kenya (NMK). Kyule uncovers contradictions between and within these legal instruments and recommends the development of a cultural heritage policy that respects local ownership and compares with international standards. He examines the Cultural Heritage Resources Management (CHRM) framework and analyzes the rationale that guides the administration, study, protection, conservation and use of a nation's cultural heritage, and their sustainability for the benefit of present and future generations. Kenya's cultural heritage is described in the forms of archaeological resources, cultural sites and landscapes, monuments, ecofacts and artefacts, and oral traditions. Ethnic laws, customs and customary laws, indigenous knowledge, history and historical evidence as found in art, music, records, museum catalogues and academic studies are discussed within the framework of CHRM and their potential in the enactment of new legal instruments are discussed. Effective CHRM policy necessarily requires legal tools that are designed to overcome the challenges posed by the quest for Cultural Intellectual Property Rights (CIPR), the recognition of indigenous peoples' ownership and the just compensation for use of cultural heritage (Greaves 1996). These requirements underline the interrelationship between natural, tangible and intangible heritage when conservation is at stake (Bouchenaki 2003). While intangible heritage has been recently defined and codified by UNESCO (2003), its meaning and values for Kenyan heritage experts 
are still under discussion. In Kenya, cultural and natural heritage, as expressed through time and space, can either be tangible or intangible. Tangible aspects of cultural heritage include mainly artefacts; intangible cultural and natural heritage include human beings' intelligence and practices. Intangible cultural heritage appears in many forms, including oral traditions, languages, performing arts, social practices, traditional craftsmanship, rituals and festive events, knowledge and practices about nature and the 'universe'. Intangible heritage does not only represent inherited traditions from the past but also contemporary rural and urban practices in which diverse cultural groups take part and construct their social lives. Intangible heritage and its related practices, therefore, form part of the daily life of humans, including different belief systems and their interactions with the socio-cultural and natural environments.

In Chapter 3, Orinda Shadrack Okumu discusses the rationale for preserving tangible and intangible heritage to confront transformations such as decrease, disruption and sometimes extinction through intergenerational transfer. Okumu aims at relating elements of the UNESCO's Intangible Cultural Heritage (ICH)'s instruments to the specificities of the Kenyan intangible heritage. He underlines the role(s) these instruments can play for the wellbeing of the society, and their potential in safeguarding intangible heritage. He particularly focuses on digitization as a conservation practice. It is undeniable that the conservation of ICH impacts on issues of sustainable development, people's wellbeing and quality of life. The chapter presents case studies at national and local levels and describes the different forms intangible heritage takes in Kenya (cultural and natural), while underlining the critical significance of intangible heritage as part of early human history in the Rift Valley of Kenya.

In the second theme of this book, the questions of architectural and urban heritage are discussed by Lydia Muthuma. In Chapter 4, she argues that part of the answer to the question: 'what is it to be Kenyan?' can be found in the 'choreography of the urban public space of Nairobi'. She explains how the British colonial power, in place at the beginning of the twentieth century, proceeded to impart a specific identity to Kenya. The chosen public space for inscribing this identity was Nairobi's Central Business District (CBD). The CBD is a collective, contemporary and remembered experience for the majority of Kenyan citizens. The monuments of the CBD provide a foundation upon which a collective identity can develop and within which debates about the association between collective memory and identity take place. The author inventories the public monuments in Nairobi's CBD. She recounts the narratives 
of some monuments in order to provide a clear understanding of their nature and relevance to nation-building. For instance, the Nairobi City Square is described as the place where Kenya's political aesthetic is wrought, which belongs to the past, current and future generations as a 'heritage right'. She describes in detail the Carrier Corps monument and how it represents a collective rather than an individual history in Kenyan society. In demonstrating the association between collective identity and the sense of belonging, the chapter highlights the importance of heritage conservation. While raising questions of debate for the Kenyan public and civil society, Muthuma suggests some conservation approaches and practices in the framework of a national heritage at risk. Other questions raised in this chapter include: Do monuments generate any cognitive or affective responses? Are monuments of symbolic value, are they still public mementos? How do their meanings and significance change over time? Are there multiple political meanings attached to the same monument? Muthuma argues that withdrawing knowledge of public space by 'withdrawing' monuments of political and historical nature (colonial and contemporary) is to take away heritage from the public. Therefore, documenting this heritage, its significance and value(s) is critical to transfer this national heritage to future generations.

Architecture is an important carrier of the social, political and cultural history of a nation. In Chapter 5, Muhoro Teckla, Munala Gerryshom and Mugwima Njuguna share their views on the architectural morphology of Nairobi and the implications the history of the Kenyan nation has on the conservation of the built heritage. The development of architectural styles in Nairobi can be traced to the arrival of the Kenya Uganda Railway line on the vast plains through which flowed nrobi ('stream of cold water'). The present site of Nairobi was selected as a stores depot, shunting yard and camping ground for the thousands of Indian labourers and British colonials, who came to Kenya seeking work, employed by the British to work on the line. The railhead reached Nairobi in June 1899, in the same year that the administrative government was set up. This duality as a meeting and administrative point established Nairobi as a key town along the railway line. In 1907, Nairobi was made the capital of Kenya. Nairobi retains valuable architectural fabric that has cultural, artistic, and religious significance and is influenced by foreign interactions and exchanges. This results in an architectural vocabulary that reflects imported aspirations and values, as evidenced in the buildings. The buildings in Nairobi are heavily influenced by colonial features which are then modified to suit the local culture, climate, tradition, materials and technology. The three 
authors survey some conserved buildings and present tangible evidence of this morphology of urban architecture while identifying the factors that influenced and initiated their development. The authors' document the conservation approach used within the Kenya's legal framework to preserve these buildings, establish the different foreign influences in the typologies, and highlight the key features that make these buildings significant. They go on to discuss the architectural character of the historic buildings in their context and identify the values that make these buildings significant to the Kenyan people. In addition, they examine the reasons for the degradation of historic buildings, the criteria for gazetting buildings and monuments and the potential conservation management strategies.

Crafts represent an important part of Kenya's cultural heritage and an intimate link with the socio-cultural and sometimes economic life of rural Kenya. As part of this heritage, the bao game is rooted in the daily life of Kenyan citizens and has become an international reference as a game of strategy. In Chapter 6, Mwanzia Kyule provides an explicit, albeit simplified understanding of the history, nature, function and cultural significance of the African bao game. bao is the Bantu name for the Eastern Africa variant of the mankala group of games. The mankala are indigenous African mathematical strategy board games and perhaps the prototype of numerous board games including chess, pachisi and draughts. The chapter presents brief reviews of past research on topics related to the bao games. Archaeological evidence is presented to confirm the origins and continuous in situ evolution of the bao in Africa. For this purpose, Kyule makes the prehistoric sites and archaeological landscapes of the central and south Rift Valley of Kenya his case studies. A major example is the bao game boards heritage at the Hyrax Hill Pre-Historic Sites, Nakuru, Kenya where archaeological research spanning the past seventy years has led to the accumulation of critical data and documentation on the bao. Mwanzia further discusses the cultural aspects of the bao game in traditional African societies from prehistory to the advent of information and computing technologies (ICT) and the significant impact the Internet has had on the nature and functions of the bao. Over time, the bao has acquired a broad base of reference amongst different cultures within the African continent because of its wide distribution as well as its antiquity. It can be played for any number of reasons, such as entertainment, as an avenue to identify solutions in conflicts and disputes, and even as a ritual performance. The rationale for conserving the bao games, as well as the practices used for doing so, are discussed by the author with a focus on access, education and 
museum exhibitions. First, the method, style and rules of many traditional games, including the bao, have been preserved by oral traditions. Second, the potential of the bao as an educational tool for children has captured the interest of academic authorities, which see the educational value of the game in relation to the concepts of democracy and conflict resolution. Finally, the bao is raising interest in museums worldwide, with exhibitions, competitions and workshops organized on their premises.

The conservation of tangible and intangible cultural heritage in Kenya is largely dependent on the practitioners' willingness to embrace contemporary practices. To a large extent, adoption of new practices and the subsequent discarding of traditional ways reduce as one moves away from urban areas. Most rural areas have maintained and continue to perform some of their traditional cultural practices with little interference. However, with the introduction of formal education and Christianity, several cultural practices are being abandoned due to the perception that they are 'ungodly' and therefore transmission from the bearers to the next generation is unachievable. Some of the most affected cultural practices relate to traditional technologies. For instance, Kenyan traditional technologies do not only include the techniques of making the end product, but they also depend on supernatural powers for their success. The technological processes are governed by rules and regulations, as well as rituals and sacrifices which form an integral part of the overall production. In addition, remedial practices exist for anyone who might break the rules knowingly or unknowingly to appease the powers that may be. Given the inherent dynamic nature of technology, conservation of traditional technologies remains threatened due to their ability to become obsolete while lack of value-added to the end products demeans their market demand, making the practice unattractive to the practitioners. Conservation and subsequent revival of traditional technologies remains a big challenge to the conservator as both the techniques and the products are intertwined and therefore, attention must be paid to both the intangible (technological skill and supernatural beliefs) and tangible (the end product). Conservation is only achievable through safeguarding of the craft, thus ensuring the continuity of its production. In Chapter 7, Freda M'Mbogori focuses on traditional pottery making as one of the technologies that is specialized and has lost its appeal among several local societies due to cultural, economic and social factors. She further underscores the multiple benefits of conserving traditional technologies and suggests possible ways of transmitting and safeguarding them. The chapter offers examples from 
two Kenyan ethnolinguistic groups (Bantu and Cushitic speakers) in order to illustrate the rigorous technical skills that must be learnt, and some of the social/cultural values that are involved in pottery making (M'Mbogori 2015).

The third theme of this book explores the relation between local communities and tourism, natural heritage, landscapes and sacred sites. Wildlife, ownership, governance, use, access and management are the key words of this theme. In Chapter 8, Francis Mwaura takes the long view of wildlife heritage to discuss its use in Kenya in the past, present and in the future. Wildlife heritage is one of the key assets of Kenya's national identity and economy. Tourism has a long-standing tradition in Kenya, and in fact was more developed than in any other East African country before independence. After 1963, tourism was the fastest growing sector of the nation's economy. Wildlife heritage ownership in Kenya has gone through a number of important milestones based on the sociopolitical history of the country. Mwaura describes the wildlife heritage in Kenya through three historical stages: the pre-colonial phase before 1885, the colonial phase from 1885-1962 and the independence phase after 1963. The pre-colonial phase focuses on heritage ownership and practices of use and access, including customary wildlife governance. The second phase covers the colonization era when the wildlife heritage in Kenya became a major attraction for Europeans and Americans. The third stage considers wildlife heritage during and after the independence era, including the main challenges facing wildlife management and wildlife poaching. The final part of the chapter focuses on the future of wildlife heritage management in the twenty-first century and considers three key questions: How effective are the current wildlife policies? What is the place of local communities in the ownership and management of wildlife heritage? How should the benefits of wildlife heritage in Kenya be shared more equitably under the devolved government system? Despite the important role of wildlife heritage to the economy, this asset continues to experience significant challenges, particularly in terms of the alarming decline in wildlife populations. The author argues that there has not been sufficient effort to explore and document the relationship between wildlife heritage ownership and the quality of wildlife conservation in Kenya. The key question is to establish whether the survival of wildlife heritage rests on the ownership status based on the lessons of the past. Since independence, Kenya has relied very heavily on wildlife and beach resources as its main tourist attractions. Kenya, like many African countries, has increasingly relied on tourism as one of the top foreign exchange earners. While wildlife heritage has a long 
history and ties with tourism, the development of cultural heritage tourism in Kenya requires a strategy in the diversification of products proposed to national and international tourists. Cultural heritage tourism is a fast growing niche market, which is geared towards learning, experiencing and seeing local sites, cultures and traditions (Timothy and Boyd 2006). Kenya is richly endowed with diverse cultural heritage resources that can be developed.

Njeru Murithi evaluates how rural heritage can be conserved in relation to aesthetics and wellbeing in Chapter 9. Peoples' preferences for rural landscapes differ widely. Research on landscape aesthetics has consistently established that most people prefer wooded, savannah-like settings with open vistas, clumps of trees, topographic variation, lakes, streams or other water sources (McGranahan 2008). Natural areas and forests surrounding farmlands create an aesthetic view and maintain biodiversity by hosting wildlife. In addition, directed attention towards scenic landscapes has also been observed as a restorative process. Rural tourism is also largely dependent on the scenic quality of the environment. Murithi discusses the concepts and strategies required for rural heritage conservation in Kenya, with particular focus on natural landscape diversity, access and use. The chapter briefly describes how collecting data from landscape users can be applied to assess and classify the value of rural heritage to ensure that public interest is respected. Amongst the public interests, the author looks at safety issues, general welfare and psychological characteristics. The methodology used to assess people's perceptions towards the physical attributes of the rural landscapes is based on the analysis of the designers and policy makers' guidelines in relation to aesthetics and landscape conservation plans. This chapter is partly based on on-going research undertaken by the author who seeks to establish residents' attitudes drawn from the best practices in management of the Satoyama (traditional agricultural and forest landscape) in Japan. Satoyoma was created and maintained with the cooperation of the local population in farming and forestry. The author seeks to facilitate the development of similar strategies for the conservation of rural heritage in Kenya.

Offering greater access to heritage assets would increase Kenya's competitiveness as a top tourist destination in Africa. This is the focus of Evaristus Irandu and Parita Shah, who discuss the challenges faced in the development of heritage products in Chapter 10. The analysis is supported by case studies, secondary sources, visitor surveys and interviews with cultural heritage site managers, to illustrate heritage tourism potential. The chapter highlights the critical need to develop products 
adapted to cultural heritage and the potential relation these products may have on the conservation of cultural heritage. In order to make cultural heritage tourism sustainable and more appealing to domestic and international tourists, some strategies need to be adopted. Links between tourism and cultural heritage conservation have become increasingly stronger since the late 1990s. The authors discuss the International Cultural Tourism Chapter - Managing Tourism at Places of Heritage Significance, set up by the International Council on Monuments and Sites (ICOMOS 2013), as well as collaboration among stakeholders, promotion of cultural heritage tourism products and conservation of national cultural and historic resources. In addition to wildlife and cultural heritage, Kenya hosts various scenic rural landscapes whose conservation has been ignored. Many rural areas in Kenya have therefore lost their distinct character and ended up as homogenized landscapes. Extensive subdivision has over time degraded the traditional structures, defining the composition of land units in regard to the positioning, size and interdependence of dwellings, farmlands and adjacent natural areas. Such rural areas contain croplands, wetlands, bare hills and woodlands. Most rural landscapes in Kenya have been systematically altered to the extent that almost all spaces have had human influence.

Rural heritage landscapes have cultural values linked to cultural ecosystems, indigenous knowledge and geomorphological features. Much of African heritage is vested in spirits, songs, dances and narrations rather than tangible heritage. The natural and cultural features of the environment are often associated with the identity of an individual, a society or a community. Most cultural landscapes are in the custody of local communities in Kenya; understanding how the local communities perceive these landscapes are critical for their conservation.

The objective of Okello Benter et al. in Chapter 11 is to study and identify the symbolic meanings of ecological features and the cultural values of the community for Kit-Mikayi landscape interpretation and conservation. Cultural landscapes have been defined as cultural properties representing the combined works of nature and of man significant for nature conservation (UNESCO 2003). Cultural landscapes are vessels of cultural values and contribute to the identity of communities (Stephenson 2008). In addition, it can be argued that culture is not static and is an important driver to ecosystem change (Van Eetvelde \& Antrop 2009). Community protected landscapes play significant, but often imperceptible, role in providing cultural ecosystem services. Nature conservation practitioners have debated about the ways in which spiritual and religious values can be instrumental in promoting biodiversity 
conservation (Posey 1999; Sponsel 2001). Cultural knowledge is embedded in words, in stories, and in artefacts inherited from and shared with other humans (D'andrade 1996). Language expresses this cultural knowledge through expression of cultural ideas, beliefs, and values identified by humans. The Kit-Mikayi site serves as a sacred site for local communities and has great potential as a tourist destination in the Western Kenya tourist circuit. However, there is little information about the unique character of the site and the associated cultural values held by the community. The authors' observations are based on onsite observations and questionnaires directed to neighbouring residents. The research identifies songs, dances and narrations and categorizes them according to their meanings and values on site. The conclusion demonstrates that the process of decision-making and development of effective policy relies on the identification of ecologically based landscape features that are associated with particular cultural heritage values.

Community participation in the conservation of cultural and natural heritage has become a key element of good conservation practices. Robert Rukwaro presents an example of community participation to the preservation of an historical site: the Agikuyu shrine. The Agikuyu shrine is gazetted as a national monument by the National Museums of Kenya (NMK). It has symbolic, ritual and aesthetic values that fulfil the ceremonial functions and spiritual beliefs of the Kikuyu community. The community members believe that they should be recognized as the custodians of the shrine and be consulted in its conservation management, giving equal prominence to the physical, cultural, spiritual and economic aspects and values of the heritage site. Chapter 12 aims to establish how the community is involved in identification, planning and implementation of the conservation project and to analyze the steps being taken to strengthen the local community capacity in the formulation of cultural values associated with the Agikuyu shrine. The author argues that it is the loss of this heritage that prompted the stakeholders and local community to join hands with the aim of reviving it. The local community felt that the conservation programmes being carried out were not integrating well into their lives and that the physical aspects of the heritage site were being given more prominence than the cultural and economic aspects of their lives. Robert Rukwaro explains how and why the local community elders have not been consulted during the development of the heritage site since 1950. A description of the site development and related preservation/destruction is provided with a focus on the British colonial administration during the Mau Mau war of independence (1952-1960), tourist management during the 1980s and 
the rise of illegal land sales in the 1990s. The chapter discusses the practical problems faced by the local residents when they realized that there was a motive engineered by the former Kenya African National Union (KANU) regime to grab the shrine and how they sought assistance from the Green Belt Movement (GBM), which was, and still is, the mainstay in protection against land grabbing in the country.

Heritage landmarks in Kenya include mountains, forests, rivers, caves, beaches on the Indian Ocean, and Lake Victoria. Rural Kenyans are increasingly aware of the social value of conserving nature through good environmental management, education and appreciation of culture and involvement of the ordinary citizens in state conservation policies. However, there is a growing need to engage history with natural heritage and to relate culture with nature. In Chapter 13, Paul Opondo examines the indigenous methods used by the Luo fishermen to use, exploit and conserve fish. The Luo's social life is closely intertwined with their environment and economic systems. The objective of the chapter is to identify those traditional methods of fishing and conservation used by the fishers of Lake Victoria which may be integrated within government policies so as to ensure sustainability. The methodology used by the author includes the collection of oral information from fishing crew and fish traders along the beaches of Kisumu, with a focus on Dunga beach. The chapter also refers to secondary sources from Kenya Marine and Fisheries Research Institute and various Kenyan universities. The author uses concepts such as 'private access' versus 'common access' to fisheries together with conservation and management theories. This approach supports the analysis of the management and conservation practices of Luo fishermen and those of modern state policies. The chapter provides details on how the Luo fishermen and women established rules governing the use of nets, hooks, baits and canoes, which further ensured the sustainable use of the lake's fish resources. The author explains the conservation impact of the 'closed season' which coincides with the period of work in the farms. The chapter provides a comparison with the national and regional legal instruments. For instance, Opondo examines the relevance of the government rules, the significance of national and regional taxes, licenses on conservation issues and the importance of decrees on seasonal closures to support the Beach Management Units (BMU) of Lake Victoria. The author highlights the need to involve the local people, who are the main agents in overfishing, in the use, conservation and management of fisheries, to ensure sustainability in the exploitation of fishery resources and, therefore, conservation of indigenous practices of Luo's fishermen and women. 
The place of Mau Mau memory and culture in the history of Kenya is a significant and sensitive subject of research. Ephraim Wahome, Felix Kiruthu and Susan Mwangi trace this forgotten heritage in order to provide public access and at the same time ensure the preservation of memory. When Buijtenhuijs revisited the Mau Mau movement in the 1970s, it was argued that much about it had already been documented. However, the Mau Mau remains shrouded in 'mystery' as not much has been written about its tangible and intangible cultural heritage including the trenches, burial sites and monuments. Its legacy as a significant historical episode has been obscured by post-colonial political gimmicks of use and abuse, coupled with negative scholarly discourses, which have conspired to deny the freedom fighters their rightful place in history. In Chapter 14, the authors examine the memorization of the Mau Mau legacy, its politicization and the apparent socio-political rifts emerging from its poor management and seclusion by the political elite. The chapter looks into reasons for the suppression of the movement's memory by interrogating its significance in contemporary Kenya's history. The authors contend that successful reconstruction of the heritage is a necessary step in the much needed reconciliation process. The origins of the Mau Mau have been discussed by many scholars, including Kanogo (1987), Anderson (2005) and Elkins (2005) who generally agree that the Mau Mau war had something to do with British colonial oppression. In 1915, the colonial government enacted the Crown Lands Ordinance, which effectively relegated the Africans into a state of perpetual tenancy on their own land. Berman and Lonsdale (1992) concur that Mau Mau grievances date back to the Resident Native Labourers Ordinance of 1918, which systematically reduced indigenous landowners to squatters and sources of labour for the emergent settler economy. As a result of this transformation, the history of Kenyan communities was significantly altered, culminating in the declaration of a state of emergency in 1952. Unfortunately, the Mau Mau struggle against the British colonists in Kenya, which contributed to the country's independence in 1963, has not been given the attention it deserves. The authors argue that it is not only important for scholars to conduct studies on the movement, but also to document it for the benefit of memorization and posterity. The Mau Mau sites in Kenya are many and varied, including their complex communication networks, trenches, caves, gun factories, oaths sites, offices, detention camps and burial places. Many more sites remain to be discovered for the general public to truly appreciate the place of fighters in the history of Kenya. 
This book, we expect, will be an essential reference text for conservation, museum and heritage professionals, students and other persons interested in natural and cultural heritage theories and practices, including heritage management challenges. Contributions from the fields of conservation, philosophy, history, archaeology, sociology, architecture, planning, landscape architecture, art, urban design, anthropology, environmental and wildlife organizations, human rights and public policy and other related fields make it an invaluable resource. 


\section{. \\ Access to heritage conservation as a human right in Kenya}

Anne-Marie Deisser and Ephraim Wahome

\section{Introduction}

In times of economic development and political conflicts, the value of heritage receives renewed attention through trafficking or destruction on the one hand, or through rescue and preservation on the other. As a result, the empowerment of communities in conflict through the practice of heritage conservation is a contentious and central issue which serves as an extension of human rights and democracy (Eastop 2002; Silverman \& Ruggles 2007; Deisser 2009; Jokiletho 2012; Coombes, Hughes \& Muneme 2014). This chapter highlights the application of the principles of human rights in the framework of the African Union (AU) legal instruments, the Constitution of Kenya (2010) and the National Museums and Heritage Act (2006) in the areas of conservation of natural and cultural heritage. It also addresses the relationships and potential conflicts between these legal instruments and UNESCO conventions.

Heritage professionals working in the field of environmental conservation have addressed the relationship between heritage conservation and human rights in depth (Abdullahi 2002; Logan \& Craith 2010; Dorfman 2012; Makagon, Jonas \& Roe 2014). However, this linkage is not sufficiently researched, or properly understood, in the field of cultural heritage conservation, where emphasis is on the conservation of fabric with less attention being devoted to the fundamental rights of the custodians in terms of access, interpretation of values and use of their heritage (Eastop 2006; Peters 2008; Clavir 2009). By custodians we mean the people living in the vicinity of the heritage to be conserved. In some instances, access to heritage may be controlled by various heritage authorities which are averse to the interests of the actual custodians 
(James 2007, 1). In this regard, the issue of multiculturalism has been dealt within the Universal Declaration of Human Rights, as expressed by Ayton-Shenker (1995):

Universal human rights do not impose one cultural standard, rather one legal standard of minimum protection necessary for human dignity. As a legal standard, adopted through the United Nations, universal human rights represent the hard-won consensus of the international community, not the cultural imperialism of any particular region or set of traditions $(1995,2)$.

\section{Culture, heritage and human rights in Kenya}

The definition of culture has evolved and enlarged its scope of interpretation and applications from the definition of culture provided in the Convention for the Protection of Cultural Property in the Event of Armed Conflict (Hague Convention 1954; Thomas 1999). This has an impact on both heritage conservation and its relation to human rights (Paudel \& Ojha 2007). The Hague Convention regards culture as including mainly movable and immovable property, archaeological sites, scientific collections and written archives (UNESCO 1954, 8). In 2001, the Universal Declaration on Cultural Diversity noted that 'culture is at the heart of contemporary debates about identity, social cohesion, and the development of a knowledge-based economy' (UNESCO 2001, 2). In 2006, the definition of culture as provided in the Charter for African Cultural Renaissance affirms that:

Culture should be regarded as the set of distinctive linguistic, spiritual, material, intellectual and emotional features of the society or a social group, and that it encompasses, in addition to art and literature, lifestyles, ways of living together, value systems, traditions and beliefs; That all cultures emanate from the societies, communities, groups and individuals and that any African cultural policy should of necessity enable peoples to evolve for increased responsibility in its development (AU 2006, 2).

The Kenyan Constitution recognizes, but does not define, culture as the foundation of the nation and the cumulative civilization of the Kenyan people and nation, though it fails to define the term 'culture' (Laws of Kenya 2010, 16). The National Museums and Heritage Act 
of 2006 defines cultural heritage as monuments, architectural works, groups of separate or connected buildings, works of humanity or the combined works of nature and humanity, archaeological sites and objects of archaeological, palaeontogical and historical interest (KLR 2006, 5-6).

The definitions allow for cross-disciplinary and cross-cultural approaches to conservation. They not only emphasize the spiritual and emotional features of culture and nature but they also reveal the role that African cultural policies can play in increasing access to culture, its development and conservation.

\section{African Union and Kenyan legal standards}

The African Union has developed legal instruments that support and promote the protection of heritage. Amongst these instruments, this chapter examines the Charter for African Cultural Renaissance, the Banjul Charter, the Maputo Convention and the African Convention on the Conservation of Nature and Natural Resources (Mutua 2008). This is followed by an examination of United Nations (UN) instruments that complement and support the Kenyan and AU texts like the Declaration on the Rights of Indigenous Peoples (2008) and the Convention for the Safeguarding of the Intangible Cultural Heritage (2003).

From a philosophical perspective, the Charter for African Cultural Renaissance is an important document in articulating access to conservation as a human right. The charter, enacted in 2006, is not yet in force. However, Kenya has ratified the Cultural Charter for Africa, adopted in 1981, from which the Charter for African Cultural Renaissance takes inspiration. Some of its objectives and principles clearly beckon the notion of 'cultural heritage', 'human rights', 'preservation' and 'promotion of peace' in order 'to preserve and promote the African cultural heritage through preservation, restoration and rehabilitation' (AU 2006, 4). Its second objective provides for a link between culture and the promotion of peace (AU 2006, 5). A third objective, 'to develop all the dynamic values of the African cultural heritage that promote human rights, social cohesion and human development', highlights the dynamic values of African heritage in the promotion of human rights, among which access and preservation of cultural heritage are implicit (AU 2006, 5). However, the role of state parties in cultural development, especially in the protection of cultural heritage, is less clearly articulated in the charter. The recommendations for protection do not include the terms 
'human rights' and 'development', but exclusively consider issues of illicit traffic; return of stolen property and the ratification of UNESCOassociated conventions by state parties (AU 2006, 11). There is therefore a normative gap between the objectives-principles of the charter, which use the terms 'conservation', 'preservation', 'prevention' and the final provisions of the charter where these words are replaced by the generic term 'protection' (AU 2006, 10-11). This juridical choice of terms leaves little space for the conservation 'actors' to justify their actions in line with the charter's objectives.

Another fundamental legal text is the African Charter on Human and Peoples' Rights, also known as the Banjul Charter, adopted in 1981 and ratified by Kenya in 1992. This charter is the basis of Africa's continental human rights system, which recognizes universally accepted cultural, civil and political rights. The rationale behind the charter was to challenge Africa's own neglect of human rights abuses in the post-colonial period, and to urge members of the Organisation of African Unity (OAU), now the African Union (AU), to adopt a regional human rights instrument (Fanana 2002). The charter makes reference to cultural heritage preservation and development in terms of both rights and duties. For example, article 17 states that 'every individual may freely, take part in the cultural life of his community' (AU 1981, 2). Article 22 highlights the right for people to freely participate in their economic, social and cultural development (AU 1981, 1). Finally, article 29 states that 'the individual shall also have the duty: to preserve and strengthen positive African cultural values in his relations with other members of the society' (AU 1981, 7). One major challenge with cultural rights is their collective nature, which implies that practices that are sanctioned by the community, like female genital mutilation or gender disparity, may contravene justice to individuals as embodied in the human rights instruments, and are usually ignored and allowed to thrive. This implies that injustices may be perpetuated in the cover of collective rights (Hodder 2010).

The Maputo Convention (2003) is the Revised African Convention on the Conservation of Nature and Natural Resources, ratified by Kenya in 1969. The text is important because it integrates environmental conservation considerations with socio-economic concerns. For instance, it calls for the state parties to integrate developmental and environmental concerns by treating both as an integral part of national and/or local development plans. Furthermore, the Convention spells out that ecological, social, economic and cultural factors should be given full consideration in their development, with the overall objective of promoting sustainable development (IUCN 2006). 
The United Nations (UN) Declaration on the Rights of Indigenous Peoples (2008) offers a framework for 'heritage conservation and human rights' to develop in practice. Article 11 affirms that 'Indigenous peoples have the right to practice and revitalize their cultural traditions and customs. This includes the right to maintain, protect and develop the past, present and future manifestations of their cultures, such as archaeological and historical sites, artefacts, designs, ceremonies, technologies and visual and performing arts and literature' (UN 2008, 6).

The Convention for the Safeguarding of the Intangible Cultural Heritage (2003), ratified by Kenya in 2007, is a milestone in the interpretation of culture and its conservation. The Convention clearly requires state parties to adopt a general policy aimed at integrating the safeguarding of intangible heritage into planning programmes and to foster scientific, technical and artistic studies, with a view to effective safeguarding (UNESCO 2003, 6). In addition, the Convention requires state parties to adopt appropriate legal measures aimed at ensuring access to the intangible cultural heritage while respecting customary practices governing access to specific aspects of such heritage. Finally, article 15 acknowledges the right of communities, groups and individuals that create maintain and transmit heritage to participate in its management (UNESCO 2003, 7).

These international conventions and declarations demonstrate how individual and collective entitlement to culture should incorporate the custodians in the protection of heritage. Cultural rights are part of fundamental human rights to individuals and communities, which must be promoted and protected by the signatory states. To a large extent, cultural rights are poorly understood, mainly due to the vagueness and broadness of the meaning of the terms culture and nature and the general feeling that the rights are inferior and not attainable (Katz 1998; Symonids 1998; Donders 2008, 232).

\section{Threats to Kenyan cultural heritage: a case study of the Kenyan coast}

Kenyan cultural heritage has been exposed to various threats, ranging from simple negligence to deliberate destruction and illicit trade. This has led to a systematic demise that dates back to the earliest contacts with foreign cultures in the era of exploration. Cultural heritage was, from the beginning, treated with curiosity as an indicator of primitive development of human culture or lack of it (Tribble 2015). The 
Kenyan coast, with its rich and diverse heritage, has suffered significantly in the process, in particular the Mijikenda ('the Nine Tribes'). These nine Bantu ethnic groups inhabit the coast of Kenya, between the Sabaki and the Umba rivers, in an area stretching from the border with Tanzania in the south to near the border Somalia in the north. A welldocumented case cited by Udvardy, Giles and Mitsanze (2003) is the transatlantic trade in vigango, or memorial statues from the Mijikenda ethnic group, which were transported to various museums and universities worldwide as objects of curiosity. Unfortunately, the process of destruction and trade is in most cases facilitated by members of the community from which the objects originate. Their motives pit personal gains against the spirit of heritage conservation. The common practice of recycling ancient built heritage, widespread in Siyu historic town, off the coast of Lamu, is one amongst numerous cases that have been documented (Wahome 2013).

Case studies from the coastal region demonstrate a link between natural and cultural heritage and the need to protect both if the benefits of conservation are to be fully appreciated (Pannel 2006; Taylor \& Lennon 2011). Poor management of either one is likely to affect the other and deny custodians access to their heritage, thereby militating against their human rights and peaceful co-existence as stipulated in domestic and international instruments. Many examples of violation of the rights to access culture are manifest in Kenya in the form of deliberate destruction or neglect.

The most severely affected heritage is located in the coastal region, which has a rich array of tangible and intangible history. The ecology is also highly susceptible to anthropogenic agents of deterioration. The coastal town of Lamu, a UNESCO World Heritage site, is threatened by a virtual lack of proper management of heritage, neglect and political intrigues (Mabulla 2000). The town was listed due to its rich Swahili tangible and intangible heritage and its continued occupation through time. Its outstanding architecture and general artistic traditions also distinguish it from similar settlements along the East African coast. Massive investment in Lamu Archipelago through the construction of a port serving a substantial part of East Africa, including Southern Sudan, Ethiopia and Kenya, poses a threat to Lamu's heritage since modalities for its protection are not yet in place primarily due to lack of resources and apparent rush for land by potential investors. The emerging Lamu PortSouthern Sudan-Ethiopia Transport (LAPSSET) corridor is expected to be the home of a massive port with 32 berths, an oil refinery and three airports. It will also serve as a key terminus for a connecting railway 
line, pipeline and a highway network. A 981.5 megawatt coal power plant, worth Ksh 180 billion, is also under construction and threatening to displace 60,000 from the island Manda, part of the Archipelago, to the dismay of county administration (Wasuna 2015; Jenje 2015).

Population explosion has also impacted resources like water and sanitary services. The population of the coastal region have continued to increase since the 1990s when national census indicated faster inter-censual growth rates, compared to other urban areas in Kenya, including Nairobi (KNBS 1999, 52). As an example, the population of the coastal region grew from 3.7 to 4.2 percent in 1979-89 and 1989-99 inter-censual periods, while all the urban population growth rates were on the decline (Figure 1.1). This is supported by a sudden increase in population from 894,131 in the 1999 census to 3,325,307 in the 2009 census (Figure 1.2). Population growth accompanied by poor living conditions, increasing pollution and housing and agricultural activity has led to massive destruction of heritage in the Archipelago, particularly through the recycling of old buildings and disposal of movable heritage.

Encroachments on the dunes, the primary water reservoirs for the island, due to corrupt practices further endanger the sustainability of ecological and cultural resources. Under these conditions, heritage conservation and the right to access heritage is compromised. UNESCO (2015) contends that LAPSSET will definitely impact the inscribed Lamu Old Town as the massive infrastructural development destabilizes the fragile ecology and culture. It also cites feasibility studies which

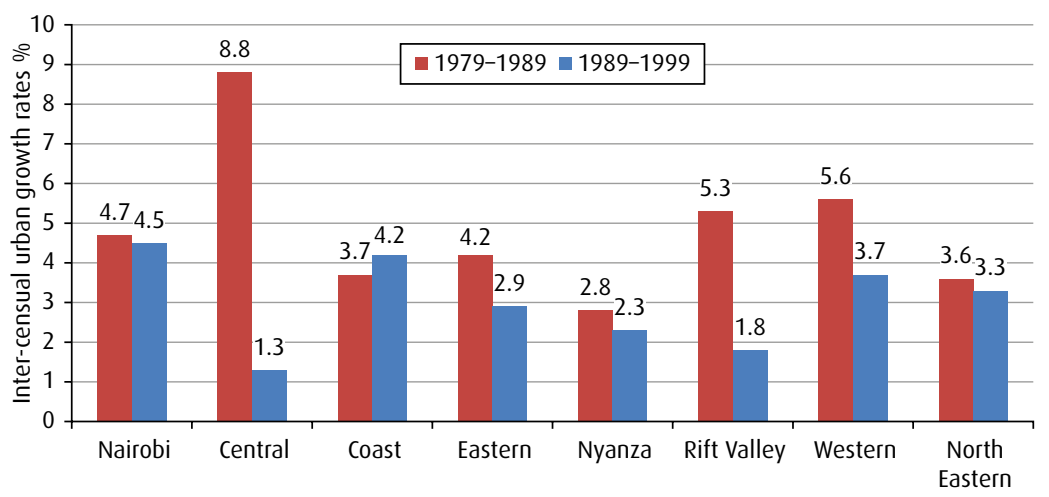

Figure 1.1 Kenyan inter-censual urban growth rates \% (adapted from KNBS 1999) 


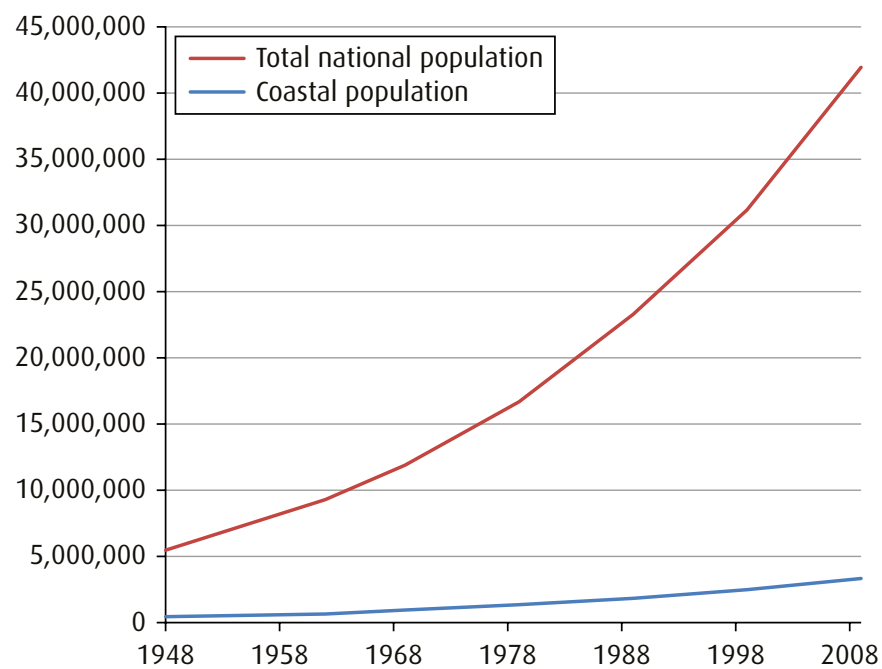

Figure 1.2 National and coastal population trends since 1948 (adapted from KNBS 2009)

foresee considerable social and environmental impact on the entire Archipelago's fragile ecosystem (UNESCO 2015). One feasibility study projected a population increase in the Archipelago from the current 101,000 to $1,250,000$, which increases the risk of further degradation (UNESCO 2015). Limited information and lack of community involvement in designing mitigation measures are considered as major limitations by UNESCO (2015). It contends that the World Heritage site and its surroundings are threatened by uncontrolled development, lack of clear buffer zones or management plans and the build-up of massive infrastructure. The ports, cities and resorts planned for the Archipelago will definitely impact on the outstanding universal value of the inscribed site. Such forms of destruction will negatively impact the right to heritage access for present and future stakeholders.

Access to heritage as a right is also threatened by insecurity, which has plagued the island. Terrorist menace makes cultural and natural heritage virtually inaccessible, particularly for non-residents. The situation is more complicated in the far-flung areas of Lamu Archipelago such as Siyu, Kiunga, Pate and Shanga that are rich in heritage but, unfortunately, neglected and vandalized repeatedly. Because most of the destruction of the heritage emanates from the community itself, the issue of human rights and the perceived value of heritage are therefore 
put into question. The problem also emanates from the conservation and heritage listing processes, which are largely based on scientific values rather than socio-cultural communal and individual values.

The heritage of the Mijikenda communities living along the coastal region of Kenya covers a wide area, which is listed as a World Heritage site. However, part of this heritage has been lost as the population expands and forests are increasingly hived off to create urban centres, residences and agricultural land. In fact humans' economic survival is a primary determinant of the survival of heritage in Kenya. The sites are threatened by a combination of anthropogenic and ecological factors (Gathito 2005). The Mijikenda ethnic group, historically made up of nine inter-linked groups, have distinct ceremonial sites known as the Kaya. The ceremonial sites exist in the form of 11 strips of forest inscribed by UNESCO on the list of tangible and intangible cultural heritage of Kenya (2008). The sites were listed on the basis of religious and spiritual life of the community, historical continuity, ecosystem sustainability for the forest strips, and the vulnerability of both tangible and intangible heritage. While the Kayas were in active use from the sixteenth century to 1940, they are currently revered among the Mijikenda people as the homes of the ancestors, indicating some form of cultural continuity (Spear 1978). Many challenges have conspired to threaten this heritage and its central position in the community. First, the progressive displacement of the Mijikenda from their prime coastal lands by the Arabs and later by the Europeans coupled with the introduction of new ways of life and modes of trading impacted the sites negatively (Karanja 2009, 914). This change fast-tracked the commodification of available resources and endangered the traditional leadership system based on gerontocracy. It also destabilized the social hierarchy as wealthy merchants slowly edged out the elders and occupied the apex of the social pyramid (Spear 1978). Secondly, economic development encouraged the encroachment of the Kaya sites by illegal loggers, and emergent urban centres led to continued destruction of heritage (Githitho 2005). The third threat emanates from direct theft and sale of grave markers known as vigango (Deisser 2007). This kind of destruction takes place in spite of the existence of Kenyan and UNESCO legal instruments as the perceived economic benefits expand with increasing populations along the coast. The National Museums and Heritage Act provides for unfettered protection of heritage though financial challenges seem to hamper its effectiveness. Parts VIII and IX of the Act protect heritage through stringent rules on antiquities dealers (KLR 2006, 50) as well as exploration and export permits (KLR 2006, 54). In spite of the listing, 


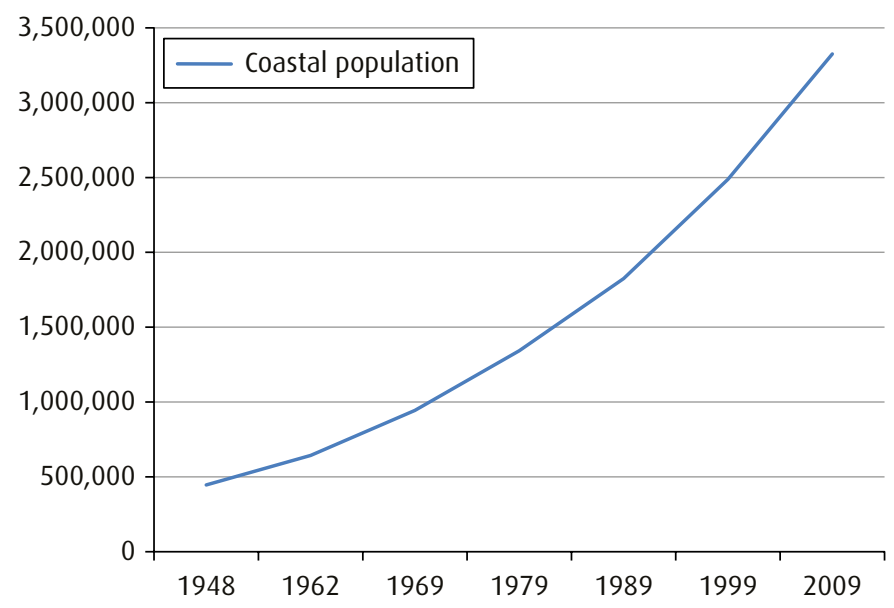

Figure 1.3 Coastal population trend since 1948 (adapted from KNBS 2009)

the unabating destruction of the heritage due to increasing population and agricultural needs poses a threat to the universal value defining the sites (Figure 1.3). This essentially becomes a threat to the rights of the community and other interested stakeholders. The provision of access in the constitution and other international human rights instruments are therefore violated.

Finally, the future of the Kayas is further threatened by the discovery of large mineral deposits within the sacred forests and adjoining areas, thereby exposing them to extraction and displacement of indigenous people (Business Daily 2005, 12). Under the prevailing conditions, the sacred forests and associated conservation issues have been heavily politicized and concurrent discourses have been tilted toward the value of human development at the expense of the environment. 'The outcome of politics on the Kaya is systematic weakening of the gerontocracy leadership structure through accusations and counter-accusations centred on amateurism, fraudulence, greed and disloyalty to their fellow Mijikenda' (McIntosh 2009, 35). Such political intrigues and greed have translated into continued shrinking of the size of the original Kaya sites as documented by Mwandoto (2014, 41) and Gitau (2011, 22).

From these examples, it is clear that access to heritage as a human right is impended by failure to apply existing international and domestic standards. Knowledge and practice(s) by stakeholders in conservation form part of the right to participate in cultural life and natural environment as defined in the Universal Declaration of Human Rights (1948). 
The concepts of 'human rights' and 'heritage' are inextricably intertwined in peace-building and social development (Lotte 2014). Access to heritage conservation as a human right can be developed following the same thematic areas of sustainability: social, economic and environmental (Sullivan 2004). National legal instruments provide the foundation to appreciate heritage values and recognize the physical and intellectual property rights within the broader legal framework provided by the Universal Declaration of Human Rights. This context sets the legal ground for academics, NGOs and local communities to develop shared conservation ethics and practices with the support of national and local authorities (Deisser 2008). However, from the analysis of African Union legal instruments and the Kenyan Constitution, it can be observed that a structured discourse on cultural heritage conservation policies is still in its infancy and the sector is yet to develop to the level of organization attained in the natural heritage conservation. The examples show that the 'local' best practices and legal tools are not implemented. There is a risk that an exclusively local approach to heritage conservation fosters political 'manipulation' and economic appropriation of the heritage by the private sector, driven by profit making. In that context, access to heritage conservation as a human right strengthens the need to fully appreciate the depth of spiritual, emotional and social links, which make up the approach to culture and its conservation that is critical to issues of socio-cultural and economic development. Development and conservation seem to collide due to divergent interests and unmet population needs. This complicates access to heritage as a human right.

The common patterns in the examples drawn from the Kenyan coast show a close link between nature and culture in the formulation and interpretation of the common local and international standards. The questions surrounding the 'nature of culture' and 'culture of nature' are inherent to every human society in scientific, philosophical and religious aspects. However, the meanings of the terms 'culture' and 'nature' are quite diverse. Is there culture in nature and is there nature in culture? This is a question that cannot be answered without looking at 'our' own place in nature, a place that is defined by our culture. Importantly, the existence of a culture means that knowledge and habits are acquired from other individuals. As culture involves, individuals learn from each other (Boyd \& Richerson 1995). Cultural forces affect our perception of what is natural (Wilson 1991). In this regard, heritage professionals can play a role in our perception and experience of the value we attribute to our 'natural' surroundings (Strathern, M. 1980). The dichotomy doesn't always exist for non-conservator experts; not all people make 
the distinction between nature and culture (Deisser 2015). For many communities and individuals, the boundary is ambiguous. In fact, conserving natural heritage may imply to conserve cultural heritage, and vice versa. This holistic approach is often applied in knowledge systems embedded in the cultural traditions of local communities, such as 'traditional knowledge (TK), indigenous knowledge (IK), traditional ecological knowledge (TEK) and the new and emerging technologies'. These knowledge classifications generally refer to the accumulated experience and know-how that people in a given community have developed over time.

The examples also show that an increase in population impacts cultural heritage and natural heritage in similar ways, especially in the case of the Kayas. The same can be said of the impact of LAPSSET on the fragile ecosystem and the equally susceptible indigenous Swahili cultures. Policymakers tend to see more direct benefits in the conservation of nature, where a higher level of activism is apparent than in cultural conservation. Even in cases where the two are inextricably linked, there are concerted attempts to separate them as distinct issues that should be handled differently, at the risk of breaching extant instruments, thus abusing human rights.

A case in point is the separation of two corruption cases on gazetted heritage presented to the Public Investment Committee (PIC 2012), which concluded that the gazetted Ojijo cultural property, which was threatened at the time, should be de-gazetted while the Karura Forest property retained its gazette status. It is also important to note that private ownership of title deeds of the individuals involved in Karura forest case were revoked while Ojijo cultural property owners retained their titles, though they had been acquired corruptly (PIC 2009, 2012). Ojijo cultural property remains a major political issue to date and to the dismay of conservators. This blatant breach of the sanctity of cultural properties emanated from a misconception among the top lawmakers in the nation that economic progress overrides all other forms of human ambitions. It is also informed by poor appreciation of cultural heritage in the community. This study highlights that the two forms of heritage need urgent protection through proper use of domestic and international instruments which the country is signatory to. The constitution is clear on the issue of culture and nature but the level of sensitization is low. Communities need to be sensitized on the access to culture as a human right and ultimately on the access to its conservation. 


\section{Conclusion}

This chapter has established the need constantly to involve the custodians of heritage and heritage managers in natural and cultural conservation programmes as a way of enhancing awareness of their rights in relation heritage. Such access aims to ensure that human rights are explicitly and implicitly observed and protected. Providing access to conservation decisions and practices to local communities and heritage 'owners' would promote the conservation of natural and cultural heritage (Amareswar 2009). Access to conservation practices also creates a sense of belonging and gives essence to the heritage, thereby enhancing sustainability. Barring these provisions, the opposite can also happen in the absence of proper policies, legal structures and monitoring systems. Given the instruments in operation in Kenya, the implementation of conservation measures is possible. However, the monitoring aspect is dogged by corruption, greed and politics. The national policy framework is short of proper measures on community involvement and punishment of offenders (Yim 2002). Heritage managers for sustainable conservation should emulate strong cultural conservation policies. This sustainability should also take cognisance of human rights of the indigenous communities and the users of the heritage as stipulated in the bill of rights within the constitution of Kenya. Observing human rights would simply mean that custodians, besides politically driven state parties, would enjoy protection through the legal instruments rather than fighting the instruments (Lynch 2012).

The relationship between cultural and natural heritage is rooted in the Kenyan socio-cultural history and their conservation should be treated equitably when a potential threat is envisaged. The tendency to ignore culture emanates from limited knowledge of its importance and lack of sensitization to its direct benefits to present and future generations. Lack of appreciation of the legal instruments and access to heritage also constitutes a key hindrance to cultural heritage conservation. Basic human rights to the access of heritage and its conservation cannot be attained without proper enforcement of the national and international legal instruments. Enforcing the basic principles of human rights makes the conservation of cultural and natural heritage accessible, feasible and 'user-friendly' to the Kenyan custodians. 


\section{2 \\ Assessment of legislation on cultural heritage resources in Kenya}

Mwanzia Kyule

\section{Introduction}

Cultural Heritage Resources Management (CHRM) can be described as the framework that guides the administration, study, protection, conservation and use of a people's cultural heritage and their sustainability for the benefit of present and future generations. Attributes of cultural heritage include archaeological resources (artefacts, ecofacts and features), cultural sites and landscapes, monuments, oral traditions, customs and customary law, indigenous knowledge, history and historical evidence as can be found in art, music and records, and traditional cultural expressions, among others (UNESCO 1972; Sanders 1999; UNESCO 2003; Von Lewinski 2004; Ndoro 2009). Effective CHRM policy necessarily requires legal tools that are designed to overcome the challenges posed by the quest for cultural intellectual property rights (Greaves 1996; Tremolada 2014), recognition of local ownership, and the just compensation for use of cultural heritage (Ndeti 1975; Greaves 1996; Mumma 2009; Adam 2012).

This chapter reviews and examines Kenya's CHRM legal framework, highlights contradictions between and within varied laws, and presents the argument that existing legislations are outdated and unresponsive, and are, as currently constituted, inadequate to attract and sustain beneficial interest in cultural heritage. The chapter provides suggestions for remedy geared toward the development of a reengineered cultural heritage policy with local ownership and universal compatibility. 


\section{Kenya's cultural heritage policy and legislation}

Despite the promulgation of the Constitution of Kenya (2010), the core of Kenya's cultural heritage legislations still maintains outmoded and vague, and contains contentious grey sections (e.g., Cap 216, Cap 8, Cap 14, Cap 19, Cap 12, Cap 300 and Cap 509) that do not reflect the aspirations, true picture and hue of Kenya's cultural heritage, and draw attention to inherent shortcomings in a dynamic world. The relevance, scope and structural competence of some of the national institutions involved in cultural heritage resources management in modern Kenya can be subjected to the following questions:

1. Are the various statutory bodies created to handle cultural heritage issues in Kenya legally equipped with the dynamism required to represent and articulate complex and evolving CHRM issues?

2. Do the institutions charged with the country's conservation planning and management have the capacity and legal constituency to carry out their mandate effectively?

3. Can these institutions effectively execute their mandates to encourage and actualize research and promote cultural heritage conservation?

4. Can they oversee the transformation of cultural heritage resources into viable and sustainable local heritage enterprises?

5. Can they effectively prosecute and, therefore, discourage offenders?

6. Are Kenyans aware of, and in charge of, their own cultural heritage, management and destiny?

\section{Kenya's cultural heritage policy framework}

Theoretically, the administration of Kenya's cultural heritage is informed by the Kenya National Policy on Culture and Heritage (NPCH) and by the provisions of articles 11, 40, and 69 of the Kenya Constitution (Republic of Kenya 2010). According to the NPCH (Republic of Kenya 2009), the onset of colonialism imposed foreign languages, values, beliefs, lifestyles and traditions, thereby suppressing indigenous elements of culture and heritage and alienating Kenyans from many of their cultural practices. Furthermore, the colonizers imposed various legislations and institutions with the objective of protecting their own cultural, political and economic interests (Karega 2014). Hence, one 
of the key objectives of the NPCH was to rectify that situation and restore national pride. In general, the NPCH is a collection of policy statements and definitions with little to offer in terms of CHRM practice. The policies promulgated therein lack legal backing, although the NPCH does expect parliament to facilitate implementation through the development of relevant laws to actualize the policy. Article 11 of the Fifth Schedule of the Kenya Constitution (Republic of Kenya 2010) requires parliament to enact legislations in respect to culture within the first five years from the date of promulgation (27 August 2010). Accordingly, enactment of such legislations should be no later than 27 August 2015. Towards this end, the Ministry of Sports, Culture and the Arts held a consultative workshop that brought together government and the private sector to discuss a Zero Draft of The National Culture Bill (2014) at the Kenya Institute of Curriculum Development (KICD) in Nairobi on 30th January 2015. Some of the highlights of the Draft Bill included a proposal for a National Council for Culture and the Arts, and a National Fund for Culture and the Arts. Others included provisions for communities to receive compensation or royalties for the use of their cultures and cultural heritage. Additionally, the Protection of Traditional Knowledge and Traditional Cultural Expressions Bill (2013) is intended to operationalize the National Policy on Traditional Knowledge, Genetic Resources and Traditional Cultural Expressions (2009b).

At the practical level, the National Museums and Heritage Act, Cap 216 (Republic of Kenya 2006a) and less importantly both the Environmental Management and Co-ordination Act, Cap 8 (Republic of Kenya 1999) and the Land Act (Republic of Kenya 2012a) operationalize the management of Kenya's cultural heritage. Others include Cap 19 (the Public Archives and Documentation Service Act of 1991) and Cap 509 (Kenya's Industrial Property Act of 2001). Cap 216 extends authority for the management of Kenya's cultural heritage only to the National Museums of Kenya (NMK). The Act repealed, but borrowed heavily from, the Antiquities and Monuments Act, Cap 215 (Republic of Kenya 1984a), and the National Museums Act, Cap 216 (Republic of Kenya 1984b). The structure and character of Cap 216, and other legislations that relate to Kenya's cultural heritage, derive from the English legal convention whose rubric of intellectual property does not necessarily provide for cultural resource rights of local people who own the heritage (Posey \& Dutfield 1996; Ndoro \& Kiriama 2009; Adam 2012).

Up to December 2009, several amendments were introduced to related laws so as to provide consistency and also remove pertinent 
redundancies and contradictions for purposes of operationalizing Cap 216. These amendments include: Section 23 of Cap 12 (the Copyright Act), Section 145 and 201 of Cap 265 (the Local Government Act), Section 7 of Cap 306 (the Mining Act), Section 17 of Cap 499 (the Registration of Business Names Act), Section 47 of Act No. 6 (the Physical Planning Act), Section 116 of Cap 280 (the Government Lands Act), Section 65 of Cap 281 (the Registration of Titles Act), Section 72 of Cap 282 (the Land Titles Act), and Section 136 of Cap 300 (the Registered Land Act).

Through Cap 8 (Republic of Kenya 1999), the National Environment Management Authority (NEMA) was established in 2002 with a mandate to coordinate lead agencies and stakeholders in the implementation of all government policies relating to the environment. According to the National Environment Policy (Republic of Kenya 2013) NEMA's priority area of focus is in environmental management that leads to a clean, healthy and sustainable environment. NEMA, therefore, lacks jurisdiction to intervene in cultural heritage matters unless they touch significantly on the overall natural environment. To this end, NEMA has occasionally included cultural/heritage impact assessment in their overall Environment Impact Assessments (EIAs) for planned development projects.

\section{Cultural heritage as a human right}

The International Council on Monuments and Sites (ICOMOS) convention in Stockholm in 1998 called for international cooperation in the legislation and other statutory measures in order to preserve and enrich the world's cultural diversity. The meeting emphasized the need to recognize, appreciate and maintain heritage-appropriate development strate-

gies, and an equitable partnership between societies, the private sector and individuals so as to harmonize varied interests affecting cultural heritage and to reconcile preservation with development. The meeting recognized the importance of specific conventions relating to cultural heritage and its preservation, and affirmed the right to cultural heritage as an integral part of human rights.

ICOMOS also affirmed the irreplaceable nature of archaeological material and the threat posed by a world in constant transformation. Other ideals propagated by ICOMOS include the right to have the authentic testimony of cultural heritage respected as an expression of one's cultural identity within the human family; the right to better understand one's heritage and that of others; the right to appropriate use 
of heritage; the right to participate in decisions affecting heritage and the cultural values it embodies; and the right to form associations for the promotion of cultural heritage.

Some of the tenets identified by ICOMOS (1998), as well as the Convention for the Safeguarding of the Intangible Cultural Heritage (UNESCO 2003), which Kenya signed in 2007, have been ratified by articles 11, 40, 69 and 260 of the Kenya Constitution (2010). Under article 11(1), the Constitution recognizes culture as the foundation of the nation and as the cumulative civilization of the Kenyan people and nation. It mandates the state to promote all forms of national and cultural expression through literature, the arts, traditional celebrations, science, communication, information, mass media, publications, libraries and other cultural heritage; recognizes the role of science and indigenous technologies in the development of the nation; and promotes the intellectual property rights of the people of Kenya (Republic of Kenya 2010).

The ICOMOS (1998) and UNESCO $(1972,2003)$ values are also addressed, albeit haphazardly, by various Kenyan laws, such as the National Museums and Heritage Act, the Environmental Management and Co-ordination Act and Kenya's Industrial Property Act.

\section{Heritage and intellectual property rights}

Intellectual property is a western concept that defines mostly corporate and sometimes private individual ownership and rights to ingenuity, inventions, innovations and their uses (Von Lewinski 2004; Farah \& Tremolada 2014). In its entirety, the concept does not cover what may appear to lack definite origin and ownership, as is the case with cultural heritage. Consequently, cultural property rights are not covered by Kenya's Industrial Property Act (CAP 509), which empowers the Director of Kenya Industrial Property Institute (KIPI) to grant industrial property rights and to register patents, utility models and industrial designs (Republic of Kenya 2001). However, there was an attempt to address the situation in the form of an amendment to Section 23 of the Copyright Act (Cap 12 of 2001) by adding a subsection immediately after Subsection 4, as follows:

Notwithstanding anything else contained in this Act, copyright in works eligible for copyright and vested in the National Museums Board of Directors or the National Museums is conferred in perpetuity on the National Museums. 
Article 40(5) of the Kenya Constitution (2010) obliges the state to support, promote and protect the intellectual property rights of the people of Kenya while article 69(1)(c) and (e) mandates the state to protect and enhance intellectual property and traditional knowledge. The Protection of Traditional Knowledge and Traditional Cultural Expressions Bill (2013) has already been formulated to actualize articles 260, 40(5), 69(1)(c) and (e) while drafting of the National Culture Bill (2014) is in progress to actualize article 11. Regionally, the East African Community (EAC) presented a first reading of the EAC Creative and Cultural Industries Bill (2015) on 27 January 2015 to the Committee of General Purpose during the Fourth Meeting of the 3rd Session of the 3rd Assembly plenary session held in Arusha, Tanzania.

The varied ethnic nature, history and spatial distribution of Kenya's cultural heritage makes the existing legislations ineffective in aspects of administration and viable management, and are certainly wanting the impetus for the development of sustainable heritage enterprises. Attempts to legislate traditional or cultural resources into modern society must, hence, first appreciate the circumstances of complexity of definition of traditional resources and rights that accrue from those resources due to the diversity of distinct cultural groups in Kenya (Ndeti 1975; Adam 2012). Secondly, such diverse cultural complexity is compounded by the fact that traditional resources are transitional, with a symbolic value that makes them right for that time and place, so long as they remain relevant to those who have use for, or are affected by the prevailing culture. Thirdly, the symbolic value of traditional or cultural resources cannot be restricted in a time capsule that declares certain cultural materials antique or otherwise, just because they existed before or after a certain date that has no significance on the existing cultural resource context. Kenya's law, Cap 216 for example, identifies an object of archaeological or palaeontological interest as 'an antiquity which was in existence before the year 1800', and an object of historical, cultural or scientific interest as 'an object which came into existence in or after the year 1800’ (Republic of Kenya 2006a).

\section{Bones of contention in Kenya's CHRM related legislations}

Cap 216 specifies the functions of the NMK and bestows the responsibility for researching and interpreting the country's cultural heritage to the public. The Act affirms the country's interest in locating, protecting and 
preserving palaeo-anthropological, archaeological and historic properties. These properties include sites, objects and buildings of historical, archaeological or architectural significance (Republic of Kenya 2006a). The Act places the responsibility of implementing the law on the minister (now known as cabinet secretary) responsible for the NMK, while it also places the custodianship of all material protected by law under the board of trustees of the NMK. The cabinet secretary is empowered by this Act to legally designate any publicly and privately owned property that may have national cultural significance as a monument.

Cap 216 appears to have been designed to especially apply to archaeology and palaeontological heritage, monuments and architectural works, tangible cultural sites predating 1800 and natural heritage, and is almost mute when it comes to other forms of cultural heritage. Except for a few paragraphs that provide heritage term definitions, the content of the act focuses almost entirely on the establishment of the National Museums of Kenya.

There are inconsistencies and contradictions between Cap 216 and other laws that variously affect the process of research, study, curation and storage, conservation and management of cultural heritage, especially archaeologically recovered material and antiquities. Some of the laws at variance with Cap 216 include the Records Disposal Act (Cap 14 of 1972), and the Public Archives and Documentation Service Act (Cap 19 of 1991). Further, the responsibilities of formulation, execution and implementation of policy is scattered between the ministries responsible for cultural heritage (currently the Ministry of Sports, Culture and the Arts), on the one hand and, on the other, the ministries responsible for lands, devolution and planning and, recently, education.

Cap 216 is non-committal, and/or silent on public and scholars' concerns about the sustainability of cultural heritage management beyond curation, especially the relevance of heritage such as archaeological or paleontological material, or the transformation of cultural heritage to sustainable income generating enterprises. It is not clear on the rights of community cultural heritage ownership, use and compensation of exploitation of the same. It further promotes western perceptions of indigenous cultures (Martinez-Cobo 1981; Sanders 1999), and negates communal public-orientated approaches toward cultural heritage resources management. Cap 216 is also ambiguous on the modalities of repatriating stolen or loaned cultural heritage material held in either private collections or public museums and universities in foreign countries. 
In accordance with Cap 216, archaeological sites may not be destroyed, excavated or altered without an exploration/excavation permit issued by the cabinet secretary or designate. At present, the Ministry of Education, Science and Technology through the Kenya National Council for Science and Technology, first issues a research license, while Section 27 grants discretion to the cabinet secretary responsible for the NMK to issue exploration/excavation permits on public and private land (Republic of Kenya 2006a). An archaeologist needs the two documents before undertaking any fieldwork. The research license does not guarantee a researcher entry on land to explore/excavate, and neither does it guarantee that a researcher will be permitted by the cabinet secretary to undertake explorations/excavations. It is also not clear who, between the NMK Board and the cabinet secretary, is liable under Section 27 , bearing in mind their respective advisory and policy-making capacities on the issue of licenses. Inherently, the Act leaves loopholes for abuse and corruption by irresponsible government officials, including the cabinet secretary, and does not outline the procedure to be followed in such circumstances. This diminishes licensed researchers to the goodwill of the landowners and the mercy of the cabinet secretary.

Notably, during the late 1990s, the NMK introduced a research and excavation permit by-law that requires individual research projects to assume responsibility of conservation of excavated material. In practice, this by-law is more often than not overlooked as researchers cite reasons of limited funding that do not cover conservation. Without an Act of Parliament to legally rationalize conservation, it is impractical to hold any researcher legally responsible for conservation and most projects do not consider their conservation duty to extend beyond providing wooden storage boxes and cartons for acquired material.

The same by-law requires researchers, especially those involved in international projects, to be accompanied by NMK staff whenever they go out for fieldwork research. The objective of this section of the by-law is to provide hands-on field training to NMK staff, as well as to monitor, on behalf of NMK, and ensure that researchers abide by the terms of their research permits. Often, this staff comprises technicians with inadequate formal education and training and, therefore, inherent inability to grasp the modalities of the researches they are expected to monitor. These circumstances provide opportunities for unscrupulous researchers to either break or not entirely abide by any guidelines that may be hindering their project interests in the field, as well as not recording and sometimes smuggling rare finds out of the country. 
To address these shortcomings, a single license could be granted with express permission to research and explore/excavate, subject to guidelines and other relevant provisions that prevent violations and protect the landowner's constitutional right to use of land. A preferred scenario would be to create a new regulatory agency such as the envisioned National Council for Culture in the draft National Culture Bill, under whose issuing responsibility exploration/excavation permits would fall. In this scenario, NMK would be required to apply for permits to the regulatory agency the same way other institutions and researchers would be doing.

While NMK is mandated by Cap 216 to ensure effective acquisition, conservation and management of the country's cultural heritage, the institution is not known to initiate its own research or conservation projects in the national interest. At present, NMK undertakes, when absolutely unavoidable, basic and minimal conservation measures on the country's cultural heritage, and in some cases, individual researchers would undertake some conservation on palaeo-anthropological material they have excavated and contemporary material culture they have collected from villagers. Any meaningful research activity undertaken under the aegis of NMK is largely by foreign scholars and institutions for purposes of addressing scientific and academic research gaps and questions raised elsewhere, or by entities such as oil exploration and mineral mining companies who sometimes undertake basic heritage surveys as part of NEMA's project environment impact assessment requirements, and also to comply with conservation laws in their countries of origin. The outcome of these researches and conservation programs rarely reflect or are identifiable with local aspirations and expected benefits, such as the development of business enterprises based on heritage resources.

Some of the reasons for this state of affairs may include the absence of research and conservation funding budgets at the NMK, which in itself is a reflection of a lack of enthusiasm and interest in heritage at the national level. This set of circumstances can be explained by a lack of awareness in the public domain about the benefits of cultural heritage, mainly because little attention is given to heritage content in the school curriculum, which is then reflected at the general public level where, for example, archaeological research is viewed as a pastime of foreigners, and therefore perceived to have no relevance or value to national development. 
Further inadequacies are illustrated by Section 2 of Cap 216, which defines antiquity as:

any movable object other than a book or document made in or imported into Kenya before the year 1895, or any human, faunal and floral remains of similar minimum age which may exist in Kenya.

This section flies in the face of definitions of African traditional resource rights which have symbolic value but cannot be defined by a time parameter that declares cultural materials to be antique or otherwise, just because they existed before or after a certain date that has no bearing on their cultural context, past or present. As it is, Cap 216 limits the practical application of the law in identifying cultural heritage that may have resulted after 1895 . It would appear that any antiquities in existence will remain the only legal cultural heritage materials, and that any objects, records and monuments made after 1895 can never really be legally recognized as antiquities under Cap 216, circumstances notwithstanding.

Additionally, a possible conflict area exists in terms of ownership mandate of such objects should they be the subject of litigation. This is because several areas of other legislations have the same custodianship mandate to act in the matter of the same objects. For example, while the Public Archives and Documentation Service Act, Cap 19, Sections 2 and 4 , provides for the preservation of public archives and public and historical records, it also duplicates and conflicts with the Cap 216 and with the National Parks Ordinance of 1945, which provides for 'the preservation of wildlife and flora and objects of aesthetic beauty, geological, prehistoric, archaeological or scientific interest'.

The Records Disposal Act (Cap 14) provides for the disposal of records in the custody of the High Court or the Registrar General without recourse to any other body. When taken in tandem with Cap 19, these acts clearly infringe on the rights of the general public and the NMK to access objects that may, despite the definition limitations of Cap 216, qualify as national cultural heritage. Harmonization of these sections to avoid duplication of roles and conflicts of ownership or custody is necessary. In order to forestall the destruction of heritage, Cap 14 and Cap 19 could be revised to remove infringement of rights of the public to identify what may be saved as National Cultural Heritage. 
Section 29 of Cap 216 recognizes failure to pay compensation for disturbance of the rights of the owner or occupier of private land or damage to the land, or property therein. But it is silent on disputes concerning foreign researchers. What, for example, would happen if the researcher refused to pay compensation for disturbance rights of the owner of the land under dispute, considering that the landowner has a six-month and two-year period to lodge his/her claim, possibly long after the researcher has finalized his/her project and left the country? To counter this, there is need for a provision for land use deposits and/or contractual licenses (licenses for value) to protect the interest of the landowner or occupier affected by archaeological projects, except where such land is acquired under the Land Acquisition Act (Cap 295).

Section 29 of Cap 216 further provides for the determination of the value of the compensation at the discretion of the district (now county) commissioner, with no clear guidelines as to the value of damage to the land, crops, buildings, stock or pasture placed on the land and disturbance to the landowner. In view of the limited jurisdiction of a county commissioner in matters of punishment and compensation, it would appear that a landowner is clearly at a disadvantage when it comes to compensation rights.

Cap 216 establishes the NMK Board to act as an authority and assist the government within the meaning and purposes of Cap 216 with two basic administrative functions. These are to manage the general development of heritage and to advise the National Museums. The NMK Board is bound to have a conflict of interest and cannot be expected to be fair in its mandate as a regulator in the face of competing interests. This was recently brought to light by the controversy involving the Community Museums of Kenya (CMK), a non-government organization, which involved the discovery of the fossil Ororin tugenensis in the Tugen area of Baringo in the year 2000. In this case, the NMK Board declared the CMK an illegal body which had flouted the law. In any event, the CMK went ahead and exported the controversial specimen to Paris, France, for analysis (with approval from a cabinet secretary whose purview did not include the NMK), and eventually opened its doors to the public in Nairobi soon after. This particular event has generated controversy as to whether the law in Kenya does or does not allow for the creation of private museums, as well as the status of privately held material that may qualify as national cultural heritage.

Sections 52 to 55 (Republic of Kenya 2006a) give authority to the cabinet secretary to issue export licenses for antiques or protected objects but does not specify an undertaking by the exporter, or the 
cabinet secretary, to bring the objects back to the country or point of origin. In order to ensure their return, a provision should be written into law, binding the exporter to bring back antiquities or protected objects at the exporter's own expense within a defined time frame. There should be a provision to also bind the cabinet secretary to ensure compliance by the exporter. However, a preferred option would be to remove this kind of responsibility from a cabinet secretary, who is essentially a political appointee without protected tenure in the ministerial portfolio, and to transfer the same to either the NMK or a regulatory agency in the lines proposed earlier.

\section{Cultural heritage management in Kenya: which direction?}

The institutions responsible for cultural heritage and the policies that inform legislation in any country should be unique as they are mooted in that country's history and traditions (Ndeti 1975). A cultural heritage policy framework is, therefore, expected to reflect that country's historical realities, present needs and future aspirations. Due to the nature of globalization in the twenty-first century, legislation relating to individual nations' CHRM and its application must conform to international norms of heritage conservation and management. It should also reflect an agreed definition of what constitutes cultural heritage resources between cultural custodians, governments and other stakeholders. Satisfactory legislation should also accommodate education and training, relevant research, cultural continuity, ownership and use, and business development.

Any effective cultural heritage policy and its strategy should, therefore, provide the means by which legislation in a country's cultural heritage is implemented. One of the available options is to entrench cultural property and traditional resource rights in law, while recognizing the need to seek partnership and co-operation from all stakeholders. Such considerations would enhance local acceptance of cultural heritage resources and by extension, sustainability, while ensuring conformity with internationally recognized recommendations, charters and conventions.

By and large, Cap 216 does not conform to modern cultural heritage resources management practice or the dynamics of globalization. It has contradictions and overlaps, and it is inconsistent with other national laws; it is colonial and it appears to favour foreign researchers 
at the expense of local professionals (Karega 2009; Harrison \& Hughes 2010; Karega 2014). It does not provide for the development of entrepreneurship or sustainable careers based on heritage resources. To address the shortcomings of Cap 216 as it is currently constituted, there is need to undertake a comprehensive review, and preferably a complete overhaul, so that the law can be compatible with the Kenya Constitution (2010), especially with regard to the recognition of culture rights and the establishment of devolved county governments, as well as contemporary economic and social-cultural aspirations. The ideals of cultural heritage management should be described in the form of a new legislative Act (for example, the National Culture Bill which is in the process of formulation) whose objective should include the undertaking of national responsibility to safeguard all forms and types of cultural heritage. Such heritage law should be separate from the law that establishes and guides the NMK.

The envisioned revisions or overhaul should seek to regulate the relations between the government on the one hand and, on the other, stakeholders including the NMK, private museums, universities, NGOs, Kenya Cultural Centre (Republic of Kenya 2012b), research institutions, researchers, cultural heritage enterprise, local authorities, ethnic groups, international organizations and landowners on whose property the cultural heritage exists. The National Council for Culture and the Arts proposed in the draft National Culture Bill should provide advisory and oversight with capacity to monitor and review the various cultural heritage practices and policies in the country to reflect changing circumstances, reviewing and bringing into harmony the various pieces of legislation that govern cultural heritage practice, facilitating professional practice in cultural heritage through a set of guidelines available to all, identifying, mapping and taking inventory of all cultural resources in a national register of important landscapes, sites and monuments.

The Act should empower the envisioned agency to make 'heritage inspection' or 'heritage investigation' mandatory, where in the agency's opinion the land may contain a cultural, historical and/or archaeological site which may be subject to subdivision and/or alienation from government ownership, or alteration by natural or human causes. Currently, the NMK has this responsibility but in a very limited way (as part of gazetting process), but it lacks the required empowerment to implement. The purpose of a heritage inspection should be to assess the cultural significance of land or other property, to determine the presence of cultural landscapes that warrant protection, or are already protected, and to undertake investigation in order to recover information 
which might otherwise be lost as a result of landscape alteration or destruction. Regulatory agencies following these aspirations exist in Norway (the Directorate for Cultural Heritage, under the Norwegian Ministry of the Environment), and in South Korea (the Cultural Heritage Administration of Korea).

\section{Conclusion}

This chapter has demonstrated that pieces of legislation relating to cultural heritage resources in Kenya are in need of review or complete overhaul. Legislation relating to cultural resources management and their application must have local ownership while conforming to global norms of heritage research, conservation and management. Legislation should reflect policy designed to perpetuate research in the national and local communities' interest, and the management of cultural heritage resources that are of obvious benefit to local owners in terms of posterity as well as economic and/or monetary gain. The absence of these goals in existing Kenyan legislation on cultural heritage represents inadequacies for sustainable cultural heritage research, conservation and management. These inadequacies may be explained by the fact that legislation on Kenya's cultural heritage originated under circumstances that emanated from colonial mindsets (Harrison \& Hughes 2010; Karega 2014), and were not particularly designed to serve national and/or local communities' interests.

Previous but futile attempts to correct the anomalies have included the repeal of both the Antiquities and Monuments Act (Republic of Kenya 1984a) and the National Museums Act (Republic of Kenya 1984b), the enactment of the National Museums and Heritage Act (Republic of Kenya 2006), and the development of the National Policy on Culture and Heritage (Republic of Kenya 2009). The most significant step, however, was the promulgation of the Kenya Constitution (Republic of Kenya 2010) on 27th August 2010. The Kenya Constitution (2010) represents a paradigm shift in the way Kenya views and engages with cultural heritage. Of particular note is the constitutionalization of culture and heritage rights, devolution of the mandate to legislate and manage cultural heritage (Fourth Schedule, Part 2), and the requirement to enact laws to ensure that communities receive compensation or royalties for the use of their cultures and cultural heritage. In compliance with the Fifth Schedule of the Kenya Constitution (2010), ministries responsible for various 
aspects of culture and heritage have either formulated or are in the process of formulating Draft Bills for presentation to parliament. They include the National Culture Bill (2014) and the Protection of Traditional Knowledge and Traditional Cultural Expressions Bill (2013), which were expected to have become law not later than 27 August 2015.

The legal implications of an effective cultural resources policy must be tenable at the local and regional level where such resources are found, according to the functions that identify and make them the culturally significant symbols deserving of conservation and preservation. Satisfactory legislation will therefore depend on genuine or perceived local ownership as well as acceptance internationally. The yardstick for evaluating the successes and failures of such legislation can then be measured by the extent to which the strategy does or does not succeed in helping fulfil the objectives of the policy framework. 


\section{3 \\ The concept of intangible cultural heritage in Kenya}

Orinda Shadrack Okumu

\section{Introduction}

Intangible cultural heritage (ICH) is the legacy of physical property and intangible attributes of a group or society that are inherited from past generations, maintained in the present and bestowed for the benefit of future generations (Singh 2011). UNESCO's 2003 Convention for the Safeguarding of the Intangible Cultural Heritage proposes five broad 'domains', such as oral traditions and expressions, including language as a vehicle of the intangible cultural heritage; performing arts; social practices, rituals and festive events; knowledge and practices concerning nature and the universe; and traditional craftsmanship. The scope of cultural heritage has, however, changed considerably in recent decades, as noted by UNESCO (2013). Cultural heritage, which traditionally was associated with monuments and collections of objects, now covers in its wider understanding the traditions and living expressions inherited from ancestors and passed on to descendants.

Kenya boasts of its rich and diverse cultures and has a National Heritage Policy that recognizes its diversity. The country is multi-lingual with over forty indigenous languages and numerous dialects (Republic of Kenya 2009). From the Kaya Kinondo sacred forest on the southeastern coast to Lake Turkana in the north, Kenya boasts a unique and varied tangible and intangible heritage.

The intangible side of Kenya, though not much recognized, includes the several dialects; foodways and cuisines, eating habits and times; traditional knowledge and belief systems; names and naming systems; lifetime ceremonies and celebrations, including death, births, weddings 
and initiations; dressing styles, and the knowledge base that adapts these intangible cultural elements to their immediate environments.

UNESCO (2003) argues that intangible cultural heritage has its basis in communities and the continuing activities of members who possess specific knowledge of traditions, skills and customs of these communities. As such, Kenya can be classified as rich in ICH and in order to safeguard such intangible wealth, there is need to identify and document the ICH elements in information formats such as photographs, journals, manuals, scripts, videos of interviews and performance demonstrations.

\section{The place of ICH in the conservation of Kenya's history and identity}

According to Madman (2005), identity is a construction, a consequence of a process of interaction between people, institutions and practices. This position embodies the ideas of change, flexibility, fluidity, and negotiation of identity in relation to social change and dominant cultural elements. As such, every reality generates its own ontology and, therefore, ontologically speaking, identities in Kenya are hybrid because of biological and cultural mixing over the years.

A critical review of Kenyans' identities would reveal that various agents have produced, engaged in, and are still embodied in the process of shaping Kenya as a nation over a period ranging from the precolonial, to the colonial and post-colonial eras (Asoka 2007). Various agents in Kenya richly describe the country through individuals, groups, institutions; the state and the socio-structural conditions within which they are produced. These forces have been instrumental in forging the identity of Kenya as a nation. In addition, the activities, affiliations, celebrations, emblems, names, idioms, institutions, memories, monuments, representations, statues, symbols and texts that embody and engender culture are critical in portraying Kenyans' identities.

UNESCO (2012) states that intangible cultural heritage makes people and communities distinguishable in term of their history, nationalities, languages, ideology and values. It is to be noted that heritage as a source of identity is a seal that sets people apart as nations and communities. The preservation of Tangible Cultural Heritage (TCH) and $\mathrm{ICH}$, including indigenous knowledge, helps to preserve the self-identification of people and can ensure the continuous existence of indigenous and traditional peoples. The discovery of the two-million-year-old fossilized 
skull of Homo habilis on the shores of Lake Turkana in 1972, for instance, cemented Kenya's identity as the original 'Cradle of Mankind' - the place where man first straightened his back and became a hunter on the plains of East Africa.

The past can best be understood by studying tangible and intangible heritage that has been preserved over the generations (Little 2006). Preservation and study of ICH in Kenya can therefore help Kenyans to have a better understanding of the forces and circumstances that brought them to their current situation, according to Little. Kenya's identity, which is traced from the past, is embodied in TCH such as monuments, statues, emblems and institutions or inscribed in ICH such as the songs (national anthem), mottos, symbols, memories, stories or literature. As such, the ICH embodied and inscribed in literature reflects a better understanding of ourselves in the present by drawing from the past.

The Kenyan national flag, for instance, is a source of identity and tells us much about the history of Kenya. The national anthem, monuments such as those of Dedan Kamahi (Leader of the Kenya Land and Freedom Army and the Mau Mau uprising), Tom Mboya (Kenyan trade unionist, Pan-Africanist, freedom fighter and one of the founding father of the republic of Kenya) on the streets of Nairobi; the street names, the clothing, etc., all give Kenya her identity and meaning in time and space. This creates a sense of belonging as it espouses the common experiences in Kenya. The natural heritage has also created a sense of identity: the Kaya forest along the coast and the Kakamega forest in western Kenya, for instance, have been used to identify and tell more about the Mijikenda ('the nine tribes', the Bantu ethnic groups inhabiting the coast of Kenya) and the Luhya (Luhya refers to both the people and their language from the Western province of Kenya), respectively, hence providing a reason for their conservation.

As part of identity, Rouard (2001) argues, there exists a link between intangible cultural heritage and farming societies in Kenya. He sees this link as made up of material and immaterial components which are related to a wide variety of fields, including history, architecture, arts, culture (languages, songs, stories, music, dance), techniques, food processing skills, the environment, the fauna and flora as well as natural and built landscape. He further notes that the erosion of such ICH is likely to have a direct negative impact, not only on people's history, culture and identity, but also on their food production means and methods, their culinary habits, as well as their environmental conservation methods. In Kenya, for instance, the traditional foodways of the 
Isukha farmers (Luhya tribe), their language, environment and ceremonies clearly brand them and distinguish them from the Maasai who are pastoralists. The erosion of ICH from either or both groups would contribute to culture and identity loss.

Kenyans have not fully appreciated and acknowledged intangible cultural heritage (Schwimmer 2001). It should be seen in its relationship to time, as a vector of memory, to space as a geographical identifier, and to a group or society as an indicator of belonging. It should be jealously guarded since its loss, erosion and/or destruction can result in serious negative impact.

Along the same lines, Asoka (2007) notes that cultural identity ought to be viewed as one of the critical ingredients for nation-building and attainment of national sovereignty. Epistemologically speaking, Asoka further argues that the identities of Kenyans are impure and unstable, and the demystification of the past through tangible and intangible cultural heritage must offer a basis for crafting a new national consciousness that belies the requisite identities. Such requisite identities, as he says, will create custodians of a new public morality in Kenya.

On the basis of identity, Koichiro (2001) points out that cultural heritage gives evidence of the roots of the cultural traditions of the people and/or history of the communities. It demonstrates its role as a means of affirming the cultural identity of the people and communities, their importance as a source of inspiration and intercultural exchange, and as an agent in bringing people or communities together in mutual appreciation and respect. It is therefore important that ICH is safeguarded in every way possible.

\section{Kenyan ICH in the age of globalization}

Globalization, according to Esikot (2012), is the ravaging force on the social, political, cultural and economic spheres of the world, whose effects, whether negative or positive, are universally undeniable. Globalization is reshaping how we have traditionally gone about studying the social world and human culture (Appelbaum \& Robinson 2005).

Koichiro (2001) perceives intangible cultural heritage as a melting pot for creative expressions, a vital factor in cultural identity, promotion and creativity, as well the carrier of cultural diversity across the global village. He notes that cultural heritage plays an essential role in national and international development, and in fostering tolerance and harmonious interaction between cultures in the era of globalization, 
when many forms of cultural heritage are in danger of disappearing. He further observes that cultural heritage is threatened by cultural standardization, conflict, tourism, industrialization, rural exodus migration and environmental deterioration, and that these lead to conflict arising from competition for the scarce resources available.

While some scholars view globalization as a modern form of westernization, this chapter uses Oduwole's (2012) idea, according to which the philosophy of globalization is one of universalization, a process that unifies the world. 'In this respect, rather than breed homogenization, globalization will breed heterogenization in which everybody and every culture will have one thing or the other to contribute in terms of meaning, identity, culture, politics and economy' (Oduwole 2012, 89). Based on this view, there is need to document and preserve the original (known) as we move to the hybrid (unknown) to avoid loss of ICH in the process of interactions and changes.

This is necessary since, as Esikot $(2012,133)$ notes, there has never been a static culture in history, pre- or post-globalization. Cultures are created according to the locations and environments in which people live and serve at any particular time and circumstance. In retrospect, it is evident that African nations, Kenya included, have to live with the consequences of this development and, as such, have reached a 'crossroads in the face of globalization' (Jaja 2012, 83). Globalization, therefore, offers the African continent not only the chance to make its contributions to the global village, but also the challenge to rethink itself and its cultural personality. It offers Kenya possibilities to distance herself from the habit of 'lamenting over our past predicament' (Oduwole 2012, 93) by taking action and shaping the global village with its unique distribution and diversity of culture.

\section{ICH, economic and socio-cultural development in Kenya}

As noted by Koichiro (2001), ICH plays an essential role in national and international development. It enhances tolerance and harmonious interactions between cultures in the era of globalization. As such, no society can flourish without ICH and no development can be sustainable without it (Gill \& Gilson 1994). ICH holds answers to many of the challenges that societies face today. Awareness of the connection between culture and development underscores the critical importance of intangible cultural heritage to the development process. The living practices, 
expressions and knowledge systems that provide meaning to communities, and explain their world view, are enshrined in ICH.

Kenya Vision 2030, the blueprint for development in Kenya, aims at making the country a globally competitive and prosperous nation through enhanced security, peace building, conflict management, participatory governance, legal reforms and inculcation of a culture of respect for sanctity of human life. This, however, does not take place in a vacuum but within a nation with its identity and cultural orientation. The development process must recognize Kenya's cultural diversity and rich heritage and use these as a tool for attaining Vision 2030. As such, the contribution of heritage, both tangible and intangible, to development in Kenya cannot be underestimated (Republic of Kenya 2009).

Though it is not very aggressive in using ICH for development, Kenya has used artistic heritage to promote tourism through oral literature such as songs, traditional dances, poems and even cuisines. Kenyan ICH has also been embodied in various artistic materials sold in small curio shops to tourists as souvenirs during their visits. Though such ventures are small scale, they have provided income and employment opportunities to Kenyans. Kenya has also had an increase in trade related to traditional cultural knowledge and expressions. These include tourism related to activities such as traditional songs and dance, cultural artefacts such as wood and soft stones, carvings and traditional baskets such as Kiondo. In addition, the marketing and economic earnings from artistic heritage in Kenya help communities to strengthen their cultural identity and to contribute to cultural diversity (UNCTAD 2008).

As part of indigenous knowledge (IK), traditional medicines, including products such as the Neem tree for treatment of various diseases, Prunus africana for treatment of prostate cancer, and Artemisia afra for treatment of malaria, have been used and sold across the globe. These, quantified into money value, run into millions of Kenyan shillings (Wekundah 2012).

The ICH manifestations and cultural events related to intangible heritage, especially festivals and other artistic events for the general public, have a positive impact on the local economic activity in all sectors. These cultural events are important sources of revenue for the local economies and need to be safeguarded. Examples of such festivals in Kenya include the Lake Turkana festival and the Lamu cultural festival, which involves a celebration of the unique Swahili heritage of the Lamu Archipelago as one of the World Heritage sites. Such cultural activities induce expenditures by participants and audience, and hence give a boost to the local economy (UNCTAD 2008). 
Similarly, cultural activities and the promotion of historic heritage sites can boost the revitalization and renaissance of cities or communities. For example, in Senegal, the listing of Saint-Louis City on the UNESCO World Heritage List has renewed the interest in this city which saw its number of visitors increase fivefold from 2000 to 2008 (UNESCO 2014). The same has been witnessed in Lamu, which is also listed as a World Heritage site. Kenya, therefore, needs to think not only about her many heritage sites, but also about how many of its cultural events and activities could be promoted to boost development around such areas.

\section{ICH and environmental conservation in Kenya}

Historically, traditional local communities in different parts of the world have continued to rely on IK to conserve the environment and deal with natural disasters. Communities, particularly those in drought- or floodprone areas, have generated a vast body of IK on disaster prevention and mitigation through early warning systems and preparedness (Roncoli et al. 2002).

IK on the domestication of plants and animals, which is part of $\mathrm{ICH}$, has evolved over the last 10,000 years and is critical in responding to risks related to climate change at the local level (Agrawal 2008). In Kenya, for example, the Maasai, Samburu, Rendille, Pokot, Pokomo and Borana people occupy large parts of the Arid and Semi-Arid Lands (ASAL). These pastoralist/agro-pastoralist communities own about $50 \%$ of the cattle and small ruminant herd and $100 \%$ of the camel population in Kenya. Over time, these communities have developed complex human (language, indigenous technical knowledge, culture), natural (uniquely adapted breeds), and social (networks) capital, which have undergirded adaptation to their environment.

This knowledge system, also known as traditional, local or indigenous, has been used by the communities as a bulwark for adaptation and mitigation against the effects of a changing and increasingly variable climate. The Pokot, for example, have a lively and informed understanding of their environment and the possibilities it provides for living. They have long created a workable livelihood within several different ecological zones to satisfy their economic needs. They have also established economic specialization and regional trade, particularly in grain and livestock between farming and herding sectors (Potter \& Sheppard 1998).

Indigenous knowledge systems manifest themselves through different dimensions. Among these are agriculture, medicine, security, 
botany, zoology, craft skills and linguistics. In Kenya, as in other African countries, indigenous knowledge systems (IKSs) were used to administer peace, harmony, and order amongst people and their physical environment (Mawere \& Kadenge 2010). The use of contemporary indigenous climate forecasts information for farm-level decision in Kenya is clearly described in Ngugi (1999). The knowledge, innovations and practices of indigenous people and local communities are a show of their cultures. Therefore, protection of peoples' cultures entails preserving the link between people and natural features, including plants and animals. Protection of indigenous traditional knowledge can, therefore, help to conserve the environment and promote sustainable agriculture and food security (Wekundah 2012). The preservation of the Kaya forests in Kenya is a good example. Kaya forests are rich in biodiversity and are believed to be home to some of the rarest flora with important medicinal value, courtesy of the Mijikenda IKSs. It is estimated that about $50 \%$ of Kenya's rare plant species are found within the coastal ecosystem, most of which lies in the Kaya forests, thus making these forests great repositories of plants species (Joliffe 2005). According to Joliffe (2005), the Kaya Waa forest, for example, faces a major threat as the most soughtafter development sites for 'eco-hotels', lodges and holiday cottages. Yet the forest has two unique and endangered plants: Ziziphus robertsoniana and an undescribed species only known in Kinondo. In addition, local mammals such as the Zanj elephant shrew (Rhynchocyon petersi) and primates, namely the colobus monkey, are endangered. Kinondo Kaya forest is also the place where the Digo community communicate with their ancestral spirits through worship and sacrificial offerings to have the ancestors intercede in their problems. They also conduct rituals and prayers for the sick and the troubled, for rain and good harvest, for wisdom and strength, as well as atonements for offences against nature. It is against this background that the National Museums of Kenya, World Wide Fund for Nature through the Coastal Forests Conservation Unit (CFCU) and Kaya elders themselves, have come together to conserve these forests using the local communities' IK. As the case of Kaya indicates, much more needs to be done to help preserve the other cultural and natural aspects threatened with extinction.

\section{Safeguarding and preservation of ICH in Kenya}

As noted by UNESCO (2003), ICH is fragile and its safeguarding is urgent. Safeguarding does not mean fixing or freezing intangible 
cultural heritage in some pure or primordial form. Safeguarding ICH is about the transfer of knowledge, skills and meaning. It is the transmission or communication of heritage from generation to generation rather than the production of concrete manifestations such as dances, songs, musical instruments or crafts (UNESCO 2003). It involves strengthening and reinforcing the diverse and varied $\mathrm{ICH}$ and TCH necessary for the continuous evolution and transmission to future generations.

In Kenya, attempts have been made to safeguard the wisdom in traditional knowledge and traditional cultural expressions. This is evidenced by various policies, such as the National Policy on Traditional Knowledge, Genetic Resources and Traditional Cultural Expressions, the National Policy on Culture and Heritage, the Policy on Traditional Medicine and Medicinal Plants and the Constitution of Kenya (2010), all of which recognize the centrality of culture and ICH in human development, and the need to preserve culture (Ndua 2013). In a bid to safeguard ICH, the National Museums and other bodies have digitized some of Kenya's ICH and TCH, including the Isukha foodways, the Kaya forests and other vital stories and monuments on Kenyan heritage.

There are, however, many elements of ICH that could die out or disappear if not safeguarded. This is evidenced by the large number of ICH, such as cultural practices, dance and languages threatened by extinction. Crystal (2000) mentions that although there are 6,000 languages in the world, half of them are likely to die in the next century. It has been projected that every two weeks or so, the last elderly man or woman with full command of a particular language dies. At that rate, as many as 2,500 native languages will have become extinct by the year 2100 (Moore 2006).

The scenario painted above indicates how clear and quick measures need to be taken in order to maintain the linguistic diversity of the world, and thereby preserve global cultural diversity. Of the world's 6,000 languages, one third of them $(2,000)$ are in Africa, a significant number of which are endangered. Notably, Kenya, whose linguistic diversity numbers several endangered languages, becomes a fertile ground for language preservation, specially endangered languages. Batibo (2005) observes that Kenya risks losing languages which are already rated as being highly endangered: Boni, Dahalo, Burji, Daasanach, Digo, Konkani, Malakote (Ilwana), Nubi, Sagalla, Sanye, Suba, Chifundi and Vumba.

Sommer (1992) recorded the plight of each of these languages in a survey on the dying-out of African languages. He opines that none of these Kenyan languages may resist extinction. Fifteen years on, and 
their situation has gotten worse. Among the factors leading to their attrition is bilingualism in the dominant language, assimilation into the larger languages surrounding the endangered ones, and reduced populations of the elderly and lack of, or few, speakers among the younger generation.

The Atlas of the World's Languages in Danger (2010) lists six Kenyan languages among those that are already extinct. These include the El Molo, Kore, Lorkoti, Sogoo (also called Okiek), Yaaku and Kinare. The same atlas speculates that some of these languages lost their last native speakers between 1990 and 1992. Moreover, a number of other languages are categorized as 'severely endangered', 'critically endangered', 'definitely endangered' and 'vulnerable'. The language endangerment situation in Kenya is summed up in Table 3.1 (Moseley 2010).

Table 3.1 Levels of vitality for endangered languages of Kenya (adapted from Moseley 2010)

\begin{tabular}{|c|c|c|c|c|c|}
\hline $\begin{array}{l}\text { Name of } \\
\text { language }\end{array}$ & $\begin{array}{l}\text { Alternate } \\
\text { name }\end{array}$ & Vitality & $\begin{array}{l}\text { No of } \\
\text { speakers }\end{array}$ & Year & Location \\
\hline Omotik & Laamoot & $\begin{array}{l}\text { Critically } \\
\text { endangered }\end{array}$ & 50 & 1992 & Rift Valley \\
\hline Elmolo & & Extinct & - & 1992 & Rift Valley \\
\hline Bong'om & & $\begin{array}{l}\text { Definitely } \\
\text { endangered }\end{array}$ & 1,000 & 2007 & $\begin{array}{l}\text { Somali Kenya } \\
\text { Border }\end{array}$ \\
\hline Boni & $\begin{array}{l}\text { Aweera, } \\
\text { Waata }\end{array}$ & $\begin{array}{l}\text { Definitely } \\
\text { endangered }\end{array}$ & 3,000 & 1990 & North Eastern \\
\hline Burji & & Vulnerable & 7,000 & 1994 & North Eastern \\
\hline Dahalo & & $\begin{array}{l}\text { Severely } \\
\text { endangered }\end{array}$ & 400 & 1992 & $\begin{array}{l}\text { Mouth of } \\
\text { R. Tana }\end{array}$ \\
\hline Kinare & & Extinct & - & 1992 & Makuyu region \\
\hline Kore & & Extinct & - & 1992 & Coastal region \\
\hline Lorkoti & & Extinct & - & 1992 & Eastern (Embu) \\
\hline Ongamo & $\begin{array}{l}\text { Ngasa/ } \\
\text { Nadza }\end{array}$ & $\begin{array}{l}\text { Critically } \\
\text { endangered }\end{array}$ & 200 & 1992 & $\begin{array}{l}\text { Kenya-TZ } \\
\text { Border- } \\
\text { Kilimanjaro }\end{array}$ \\
\hline Sogoo & & Extinct & - & 1992 & - \\
\hline Suba & & Vulnerable & 10,000 & 1992 & $\begin{array}{l}\text { Kenya/ } \\
\text { Tanzania }\end{array}$ \\
\hline Yaaku & & Extinct & - & 1990 & - \\
\hline
\end{tabular}


With such high rates of extinction, there is urgent need to digitize the languages and cultural aspects associated with the threatened ICH. This also calls for good policy and ethical frameworks. Kenya, therefore, should embrace and improve clarity on intellectual property ownership of the digital works. This could enrich and enhance ICH archival services and spur new mutually beneficial collaborations between institutions and communities, while promoting wider respect for cultural diversity, facilitating educational and scholarly opportunities, and stimulating creativity as well as community development.

Intellectual property ownership rights are a problem since the issue of patents has not been taken seriously across Africa. In Kenya, patents are issued by the Kenya Industrial Property Institute (KIPI) under the Industrial Property Act (2001). This, however, has not been done very effectively. Kenya's kiondo, for instance, was patented by the Japanese without any benefits accruing to Kenya, and this patent has not been revoked to date (Wekundah 2012).

Some changes in the trend have, however, been witnessed with repatriation from the West of crucial items of $\mathrm{ICH}$, for example, the vigango of the Giriama people of the coastal region. To prevent misappropriation of ICH or IK, Kenya should document IK with a view of establishing a digital library or safeguarding them in other formats. This will enable states to check the possible misuse; the requirement of proof of origin for material to be patented and prior informed consent (Wekundah 2012). In addition, there is need for serious commitment to preserving ICH by the various stakeholders.

\section{The roles of governments, NGOs and communities in safeguarding and protecting intangible cultural heritage}

Historically, 'cultural preservation' was one of the tasks of colonizers and others from the West who collected cultural artefacts and brought them back to be studied and exhibited in European museums. Western scientific studies of non-western cultures systematically displaced cultures from their original frameworks and led to interpretations of nonwestern cultures based on Western values (Kreps 2003).

This situation has, however, changed of late; according to article 11 of the Convention, each state party is required to take the necessary measures to ensure the safeguarding of the ICH present in its territory and to 
include communities, groups and relevant NGOs in the identification and definition of elements of that ICH. Though the state parties are given the mandate to safeguard their ICH, UNESCO (2003) recognizes the role of stakeholders in that it is the communities who create ICH and keep it alive. They, therefore, have a privileged place in safeguarding it. Communities with active ICH are better placed than anyone else to identify and safeguard it, and therefore they should therefore be involved when their ICH is to be identified through inventorying.

Community-based documentation, for instance, has been done in Kenya among the Mijikenda of the coastal region, the Isukha of Western Kenya and the people of West Pokot. These self-documentation processes have turned out to be successful ways to preserve orally transmitted botanical knowledge and to make it available for present and future generations, thus contributing to their viability. The challenge with preservation is that the local communities themselves, especially in Kenya, often do not see the importance of preserving their oral traditions, their IK and their languages. They consider their own cultural heritage as backward and as a hindrance to their ability to access 'modern society' and economic wealth. It is essential, therefore, not only to create a political environment that values and respects minority cultures, but also to encourage communities to become aware of their own cultural treasures and to help them find ways to preserve those treasures (Condominas 2001).

\section{Digitization of intangible cultural heritage in Kenya}

From the late 1970s onwards, paper archives started to be converted to digital formats: text files, databases, CAD files and so on (Richards 2002). Due to urbanization, industrialization, climate change, large-scale immigration, mass tourism and armed conflicts, this conservation approach is increasingly taken into consideration by heritage professionals and local authorities responsible for the conservation of national heritage.

In Kenya, digital media is still not the best since it has challenges, some of which include low community participation, low technical knowhow, inadequate policy about intellectual property rights and insufficient commitment from stakeholders. These and other limitations could slow down or impede the rate of digitization, but as of now, Kenya is fast moving towards digitization of its ICH. Though the Kenya National Archives has reported over 13 million digitized documents, it remains difficult to establish the number of digitized records across different fields and departments within the nation. 


\section{Ethical issues in preserving intangible cultural heritage}

While the aims of digitization are to preserve and disseminate intangible heritage, and to promote nation-building and appreciation of cultural diversity through an understanding of the history and culture of a particular group, there are a number of ethical pitfalls associated with such projects (Lor \& Britz 2004).

Because ICH is a communal property, the originating communities have a right to share in the benefits of their knowledge when this is made available to other parties. Exploitation can result from asymmetrical relationships, as recognized by Limb (2004). In this regard, Britz and Lor (2004) have argued, on the basis of the principle of distributive justice, that developing countries also have a moral responsibility to disseminate their heritage to other countries and share in the benefits of their knowledge.

The ethical codes of information professionals generally promote compliance with intellectual property laws and conventions. In such codes, it is held that users of digitized content should refrain from abuse of copyrighted materials. Digitizing and holding institutions have a responsibility to educate users and put in place measures to prevent abuse, without inhibiting legally permitted fair use. It has been argued in the library profession that 'digital is not different' (IFLA 2002). This implies that, at a minimum, fair use of digital resources should not be more restricted than the use of analogue resources. Furthermore, access by originating communities should be free of charge.

When engaged in digital preservation activities, information professionals have a responsibility to their institutions to ensure ethical decision-making on all aspects of digitization and preservation, for example, applying professional, non-arbitrary and nonbiased criteria to the selection of material to be digitized and preserved (Baker 2011).

\section{Conclusion}

ICH is the basis of any nation's or community's knowledge, identities, wealth and development. Its safeguarding and preservation lays a foundation for present and future identities, innovation and development. Though preservation comes with challenges and ethical issues, 
the fruits are more precious than the sweat; the benefits include good health, education, peaceful coexistence and sustained development. As a way forward, efforts should be directed by all stakeholders in the ICH sector towards creating interventions to protect and safeguard intangible cultural heritage in times of crisis, conflict, natural disaster or in the phase of development; supporting projects aiming at the research, documentation, conservation, restoration and promotion of heritage goods, both movable and immovable and intangible; promotion of projects aiming at the identification, the inventory and the study of intangible cultural heritage, focused on finding ways to use, promote and contribute economically, socially and culturally in a way that is both respectful for the heritage values and useful to the society. 


\section{4 \\ The conservation of public monuments as a tool for building collective identity in Nairobi}

Lydia Muthuma

\section{Introduction}

Because they are crafted from a common experience, monuments lend themselves easily to articulating collective identity. Those in Nairobi are no exception. They are here explored as a bridge between collective memory and national identity; as an answer to what it really means to be Kenyan. This chapter offers an insight into the choreography of public space in Nairobi's Central Business District (CBD). Since this site foregrounds the nation's monuments, it is a condensation of the national narrative and the place par excellence for political aesthetics: the politics of colonial power, indigenous protest and post-colonial wrangles.

To withdraw the knowledge of this space by withdrawing its monuments (colonial or post-colonial) is to deny future generations their rightful heritage. It is equivalent to offering a blank as historical data. The City Square, as the place where Kenya's political aesthetic is wrought, belongs to the past, current and future generations alike. Conservation hence assumes significant dimensions.

This chapter presents a description of the monuments, recounting the narratives of some to provide a clearer understanding of their nature and relevance to nation-building. It is followed by a closer inspection of the Carrier Corps, which represents a collective, rather than an individual's, role in the Kenyan society. The importance of heritage 
conservation is highlighted in demonstrating the association between collective identity and a sense of belonging. Potential questions, to be debated by the Kenyan public, together with suggestions toward conservation approaches, conclude the chapter.

\section{Public monuments: negotiating a collective identity}

A people's identity is showcased in their public monuments. These reflect who they are, that which defines and constitutes them, the 'common union' that binds them. Should a community's monuments be taken away, its identity or principle of union is also interfered with.

By administering a geographical boundary, the British colonial authority loosely bound together forty-three different ethnic communities, each with distinct social-linguistic traditions and a variety of material cultural artefacts. This was the British East Africa Protectorate that later became the Kenya Colony. It never really had a unified culture. The task of weaving these communities into a cultural commonality, rather than a loosely bound state, was left to the post-colonial government. And it involves conserving the distinct uniqueness of each community while creating a national heritage - a delicate balance between respecting diversity while striving for overall unity. Yet, achieving this balance is expedient; for the post-colonial state to preserve its existence, it must create a national identity, a 'credible' heritage.

Heritage relies heavily on culture and the arts. These are critical tools in answering the question 'who is (or is not) Kenyan?'. The centrality of the visual arts, specifically public monuments, in negotiating this identity cannot be gainsaid and it forms our point of interest.

Monuments, as manifestations of the collective, create a common actual and remembered experience. They knit individuals together while delineating their unique commonality. In the case of Kenya, they are intended to bring together the disparate pre-colonial and colonial ethnicities into one nation.

A certain representation of national identity can be found in the choreography of public space, in the commemorative memorials erected to persons and events that are deemed important; important for preservation as public property (public referring to all forty-three ethnic communities) and to mark out distinct characteristics that make this public 'Kenyan'. Kenya is a colonial construct. The British laboured to inscribe 
a specific identity, choosing Nairobi's CBD for this inscription. To better appreciate monuments of the post-colony, a consideration of preceding colonial memorials may be instructive.

The CBD developed organically, after the Uganda Railway selected this spot for its central administrative functions. Government followed suit and in 1905, Mombasa ceded the place of colonial capital to Nairobi. As Muthuma (2013) narrates, in the early 1900s, the CBD belonged exclusively to the railway authorities. But in 1902, the government was accorded the necessary land regardless of claims by the railways or others, because of the politicians' incessant complaints. Thereafter, the colonial government spent years, up to 1963, inscribing monuments in a bid to brand Nairobi with an unmistakable British identity.

The district's boundaries are the Uhuru Highway to the West, and Haile Selassie Avenue to the South (Figure 4.1). The eastern boundary is Moi Avenue, while University Way marks its northern limit. This district is the symbol of political power. In it are the material icons of governance, such as the Parliament, the Supreme Court and sculptures of various leaders.

Both colonial and post-colonial leaders have their statues erected here. They include Queen Victoria, Kings George V and VI, and Lord Delamere, a member of the British peerage. President Jomo Kenyatta, the Mau Mau freedom fighter Dedan Kimathi and national leader Tom Mboya are the contributions of the post-colony.

Table 4.1 Tabulation of monuments according to the subject depicted

\begin{tabular}{llll}
\hline Subject depicted & $\begin{array}{l}\text { Head of state or } \\
\text { monarch }\end{array}$ & $\begin{array}{l}\text { Other minor } \\
\text { politician }\end{array}$ & $\begin{array}{l}\text { Minority group } \\
\text { monument }\end{array}$ \\
\hline Era & & & \\
\hline Colonial era & $\begin{array}{l}\text { 1. Queen Victoria } \\
\text { 4. King George V* }\end{array}$ & 2. Lord Delamere* & 8. Carrier Corps \\
& $\begin{array}{l}\text { 5. King George VI* } \\
\text { Post-colonial era }\end{array}$ & $\begin{array}{l}\text { 4. Jomo Kenyatta } \\
\text { 6. Jomo Kenyatta }\end{array}$ & $\begin{array}{l}\text { 3. Dedan Kimathi } \\
\text { 7. Tom Mboya }\end{array}$ \\
\hline
\end{tabular}

(*) These statues were subsequently relocated or pulled down: Lord Delamere in 1963, and George V and George VI in 1964.

Number 4 corresponds to two different monuments that were erected on the same site at different times (Muthuma 2013). 


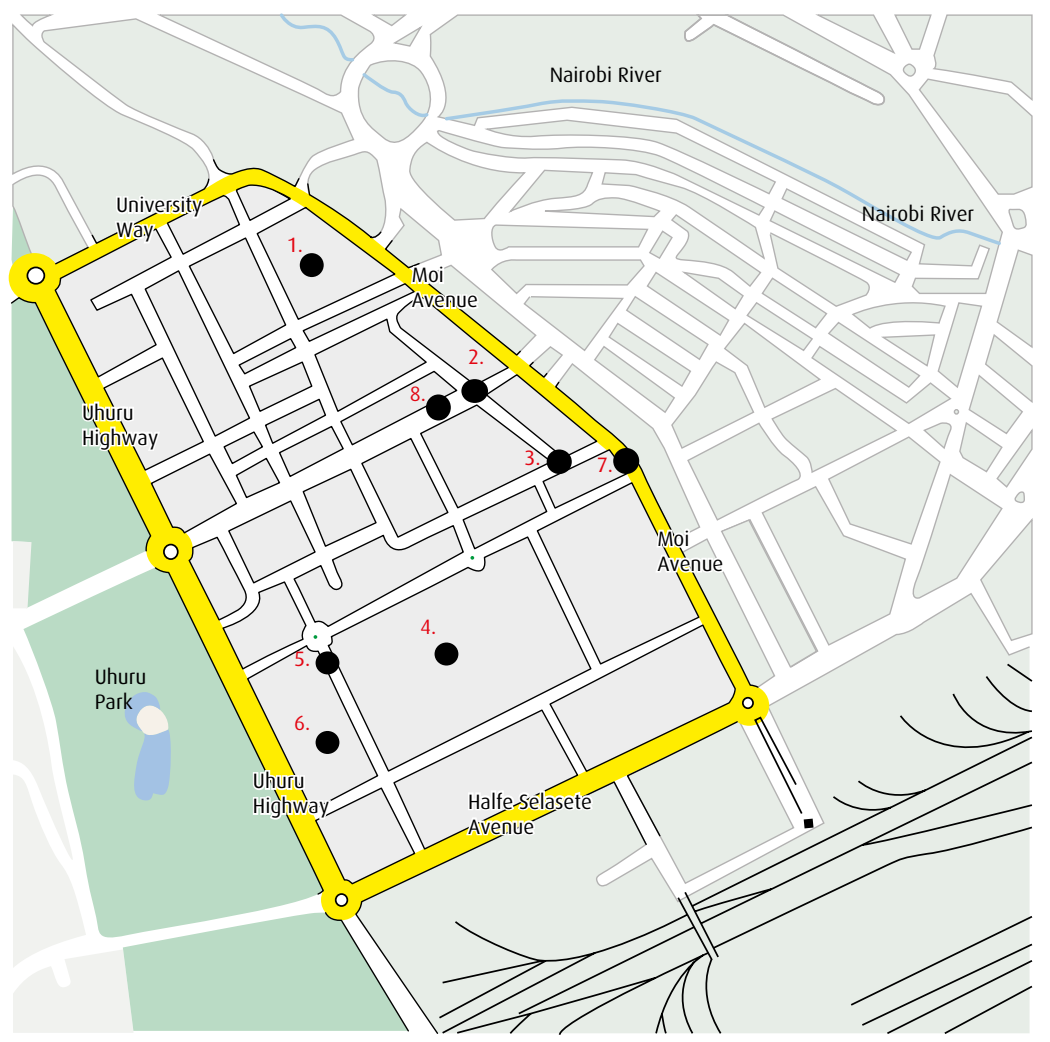

\section{Queen Victoria}

2. Lord Delamere (has been relocated)

3. Dedan Kimathi

4. King George V (has been pulled down)

4. Jomo Kenyatta (replaced King

George V, which was pulled down)
5. King George VI (has been pulled down)

6. Jomo Kenyatta's Mausoleum

7. Tom Mboya

8. Carrier Corps (African War Memorial)

Number 4 corresponds to two different monuments that were erected on the same site but at different times (Muthuma 2013)

Figure 4.1 Monuments described in this chapter and their locations (Muthuma 2014) 
Queen Victorio (1819-1901)

In chronological order, the first monument to be erected in Nairobi's CBD was the statue of Queen Victoria in Jeevanjee Gardens (Figure 4.1). Victoria, second longest-reigning British monarch and figurehead of a vast empire, was queen of the United Kingdom of Great Britain and Ireland. She was also the empress of India, Canada, Australia, New Zealand and large parts of Africa. Her son, the Duke of Connaught, unveiled her statue in Nairobi in 1906. The plaque on it reads: 'The statue of Her Late Majesty Queen Victoria, Empress of India. Presented to the Town of Nairobi by A.M. Jeevanjee. Unveiled by H.R.H. The Duke of Connaught'. Jeevanjee Gardens (once known as Victoria Gardens) comprise a park, donated by Alibhai Jeevanjee, an Indian merchant, politician and philanthropist. He started building these gardens in 1904 and in 1906 made them a gift to the people of Nairobi. In 1991, Jeevanjee Gardens featured in national news because political leaders wanted the site as a commercial venture. A multi-storeyed car park was one of the proposed developments for construction. The proposal did not go through as Patel (2002) narrates. Queen Victoria's statue is still extant, but has lately (August 2015) been pulled down after being vandalized.

\section{Lord Delamere (1870-1931)}

Hugh Cholmondeley, third Baron Delamere, was a member of the British peerage. He was one of the first and most influential British settlers in Kenya, where he arrived in 1901 and acquired vast land holdings. Delamere was the unofficial leader of the colony's European community. Nairobi's Sixth Avenue, the principal street, was named after him and a statue was erected at the street's head. With the attainment of independence in 1963, this statue was relocated to his Soysambu Estate in Elementaita, Kenya.

\section{Dedan Kimathi (1920-56)}

According to Hirst (2006), a sculpture of Dedan Kimathi, the foremost Mau Mau leader who died in 1956, was commissioned by the Kenyan Government to stand outside the State Law Office in Sheria House. The then Attorney General, Charles Mugane Njonjo, did not approve this choice and the statue of Kimathi was never installed. This was in the early 1970s (Figure 4.2).

The commissioning of a second statue of Kimathi became possible almost 30 years later; in September 2003. Many historians, among 


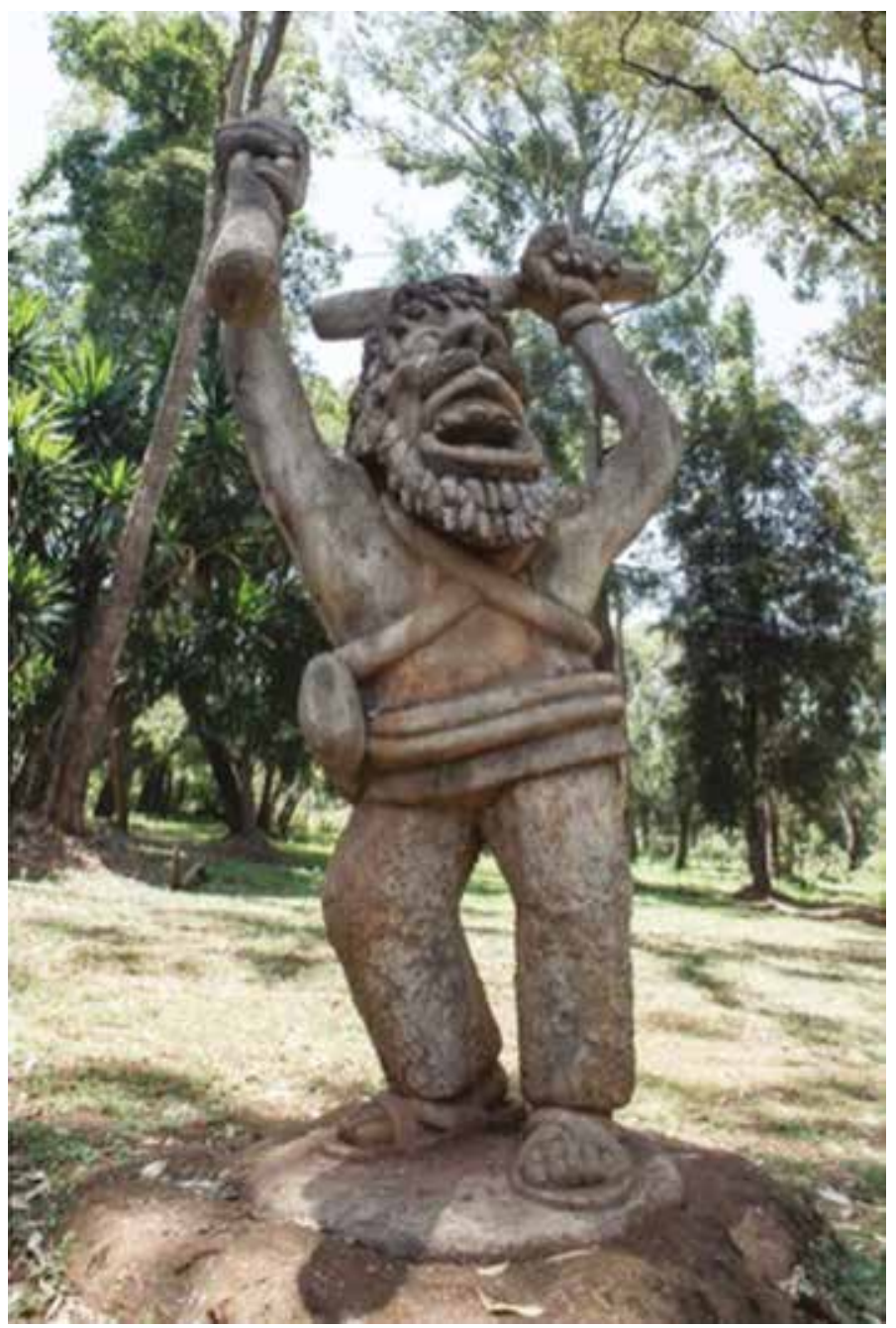

Figure 4.2 Dedan Kimathi wa Waciuri by Samuel Wanjau. This is the sculpture that was commissioned in the 1970s, but never installed. It lies in the garden of Paa-ya-Paa (Muthuma 2014)

them Coombes (2011) noted this development, commenting that while the Mau Mau movement is considered the major force responsible for Kenya's liberation from the clutches of British colonialism, it was not commemorated until 2006. Kenya's third president, Mwai Kibaki, commissioned a new sculpture of Kimathi. It was installed on Kimathi Street in 2006 . 


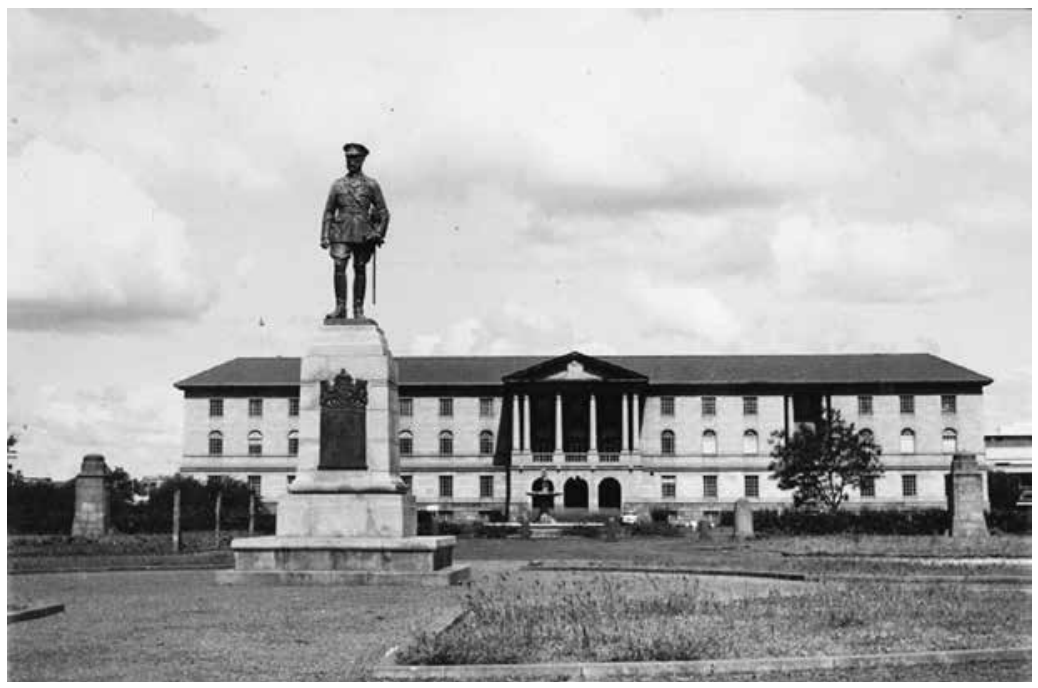

Figure 4.3 Statue of King George V in front of Nairobi High Court (Railway Museum, Nairobi 2014)

\section{King George V (1865-1936)}

King George V was king of the United Kingdom and the British Dominions and Emperor of India. He became king in 1910, gaining public respect during World War I. In 1935, he celebrated his silver jubilee, an occasion of great public rejoicing among the British. The High Court in Kenya Colony (today's Supreme Court) was completed that year. Later, a statue of George V graced the Town Square, the grounds on which the court stands and Nairobi's foremost public space. This statue was pulled down as independence (1963) drew near.

\section{Jomo Kenyotto (1889-1978)}

Jomo Kenyatta attended a local mission school and worked as a water meter reader and a store clerk. He later joined politics, visited the United Kingdom, wrote a thesis under the tutelage of Bronislav Malinowski, the renowned scholar at the prestigious London School of Economics. At the declaration of the State of Emergency in 1952, Kenyatta, along with other local leaders, was imprisoned by the colonial government for allegedly managing the Mau Mau. He was the first prime minister of a self-governing Kenya. A year later, in 1964, he became the first president of independent Kenya. During Kenyatta's tenure, the country enjoyed political stability and economic progress. He is acclaimed, from all 
quarters of the world, as a great statesman and visionary leader (MurrayBrown 1973). Delamere Avenue was renamed Kenyatta Avenue in 1964. A statue of the 'father of the nation' was erected outside the parliament, where he is depicted in his bush jacket and flywhisk, as he appeared to the world media shortly after his release from prison. Later, in 1973, to mark ten years of independence, another statue of Kenyatta was erected in City Square. It stands where the statue of King George V previously stood (Larsen 2013).

\section{King George VI (1895-1952)}

In 1936, George VI unexpectedly became king following the abdication of his brother Edward VIII. He was king of the United Kingdom and the Dominions of the British Commonwealth. Unlike his father, who oversaw a war that ended on a high note for the British Empire, World War II left the United Kingdom in a weak economic position. George VI was emotionally drained by the political and economic hardships of the postwar Empire. World War II marked the beginning of the end of the British Empire and it signaled the de-colonization of Africa. In 1952, Mau Mau activities forced the colonial government in Kenya to declare a state of emergency. The colony had started on the road to political independence. Amid the panic of the British settlers, the monarch's commemorative plaque, set within a fountain, was erected along Connaught Road (today's Parliament Road). As independence drew close, this plaque was pulled down, but its fountain left intact (Figure 4.4).

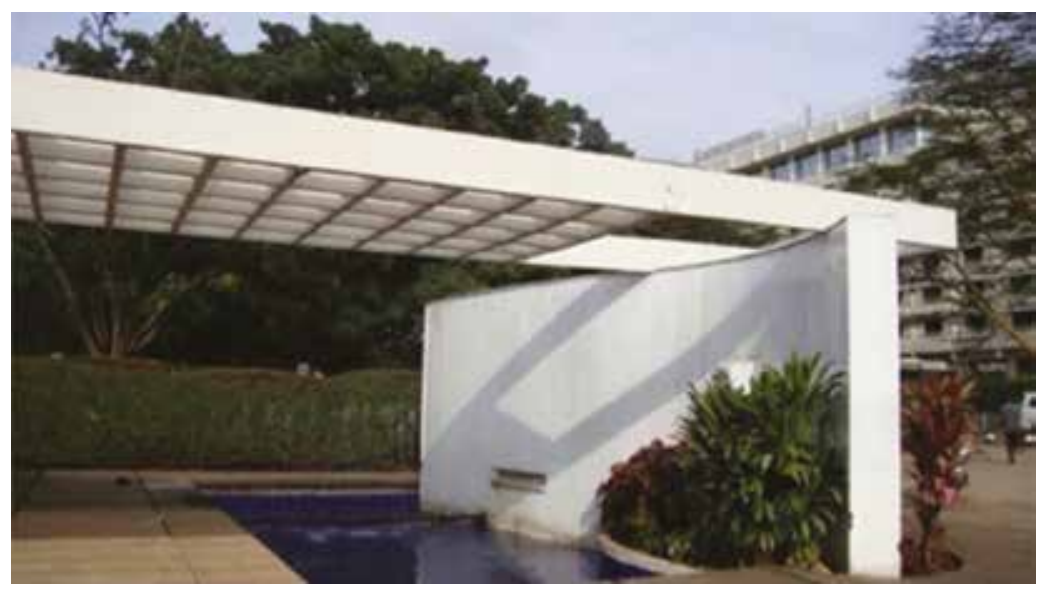

Figure 4.4 Fountain where a plaque of King George VI was mounted (Muthuma 2014) 


\section{Tom Mboyo (d. 1969)}

The only other statue of significance which does not depict a head of state, in addition to Kimathi's, is that of Tom Mboya. He was prominent in the politics of independence. Mboya was shot dead in Nairobi in 1969. As a national martyr, he is commemorated, not on the street that bears his name, but on Moi Avenue. This location is more prominent and befits Mboya's importance and place in history: it is the scene at which he was assassinated.

\section{The African War Memorial or Carrier Corps}

Chronologically, the Carrier Corps was the second monument in CBD. Created in Kenya during World War I, Carrier Corps was a military labour organization that recruited (and often conscripted) over 400,000 African men for porterage and logistical support. The organization was seen, by the British, as a remarkable feat of improvisation. It was run by a small number of colonial officials in response to the excessive demands of the British military for carriers and more and more native manpower. Having commemorated the European and Indian war victims elsewhere in the city, this sculpture at the city's centre was dedicated to the African carriers (Figure 4.5). It was erected in 1928 and stands on Delamere Avenue (today's Kenyatta Avenue).

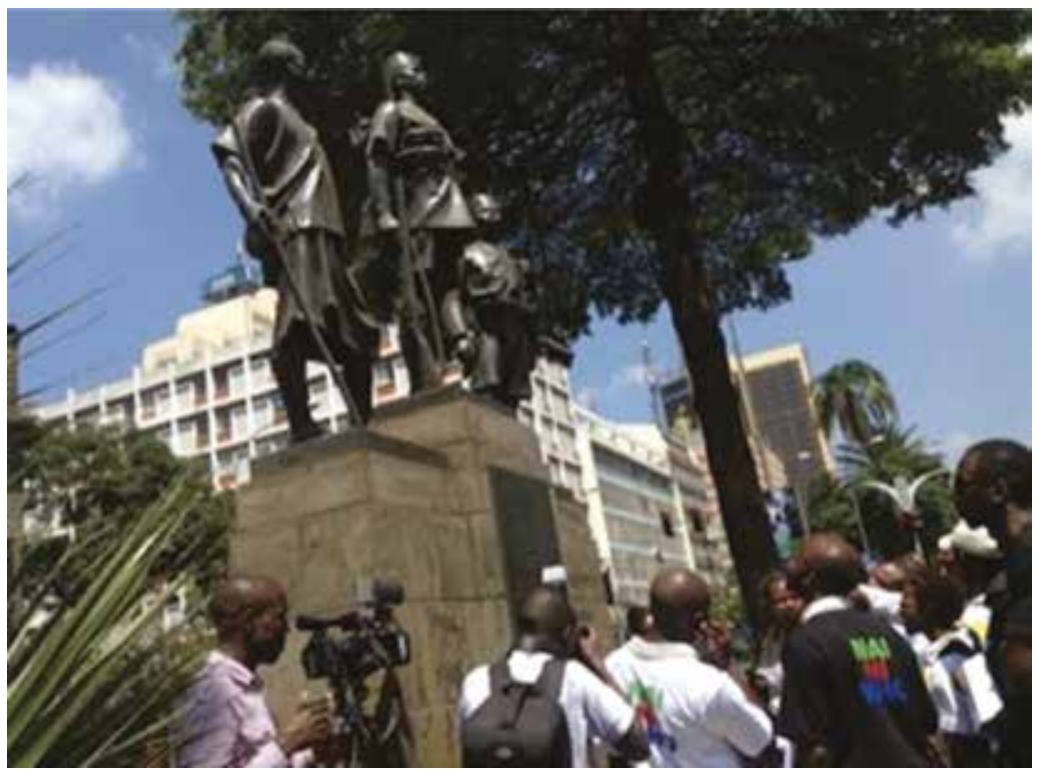

Figure 4.5 The Carrier Corps (African War Memorial) on Kenyatta Avenue (Muthuma 2014) 


\section{Monuments: a unified heritage for disparate peoples}

A city's monuments provide a foundation upon which a civic identity can develop. This identity is a significant ingredient in transforming a collection of disparate peoples into one unified culture, which is a challenge for many urban sites in East Africa today. Monuments inscribe the citizens' life into urban space. The life of the community, its history and achievements, its aspirations and goals are metaphorically captured in these monuments; the old ones preserve the memory of the people while the contemporary ones perpetuate the memory of great (and smaller) men and their great accomplishments. And this is precisely what makes monuments artifacts, vehicles of the citizens' culture and history, symbols of identity - and a consequent component of human rights.

Public monuments, seen as works of art, often contain a narrative that is told in image as stories are in words. Narratives, in turn, are accounts of events both true and imagined that shape us as individuals or as society. They are containers of ideas and of emotions; of memories and hopes; of aspirations or frustrations, beauty or lack of it. All of these inform our sensibilities, our appreciation, our understanding and consequent expression of who we really are (our authentic selves). This is why the aesthetics and politics of public monuments stand for the national script; they represent Nairobi as Kenya's capital city, once a bastion of colonial rule in East Africa and now the principle of nation-state building, the fulcrum of post-colonial politics.

\section{City Square as a monument}

Nairobi's City Square, embedded within the CBD, can be considered a monument in itself. It contained sculptures of colonial monarchs and now hosts those of Jomo Kenyatta (numbers 4, 5 and 6 in Figure 4.1). It is the place for political aesthetics, especially political identity. Designed by the colonial authority in the late 1940s and 50s, this kernel of political articulation held the choicest monuments: King George V and George VI. One stood in front of Nairobi's High Court -the most tangible expression of Britannia's 'law and order' - while the other was ensconced in a fountain at the west end of the square. The monuments appeared at a time when the settlers in Kenya needed an urgent reminder of 'feeling at home', surrounded as they were by the raging Mau Mau. It was during the state of emergency, starting in October 1952, when for the first time it dawned on the colonials that Britannia's rule may not be as long-lived 
as had previously been believed. Installing representations of the head of the Empire was perhaps a salve to frayed colonial nerves. The 1963 change in political power saw a corresponding change in City Square's monuments. As Larsen (2013) points out:

Colonial Nairobi's monumental landscape was inscribed by those who had the power to do so and they controlled what was written into the landscape. However, resistance by the colonised could be made apparent... As soon as the country achieved its independence on 12 December 1963, the once-colonised removed monuments erected by the former coloniser... the King George V statue and the bronze portrait plaque of the King George VI memorial were... removed.

The statue of George V gave way to a sculpture of Jomo Kenyatta, the founding father of independent Kenya. It is interesting to note that George V's statue was removed together with the plinth it stood on. George VI's plaque, however, was removed while its fountain (its setting) was left intact. Today it is a commemorative fountain that pays homage to no one in particular; a stage set without the hero in sight, leading the viewer to wonder what purpose is met by preserving an empty backdrop. We could hazard the following interpretation: in the absence of the fountain's main actor or message, in the absence of the generation it was addressed to, perhaps it seemed pointless to pull down this empty stage set, this otherwise beautiful piece of architecture. Could it have been preserved, more for its aesthetic value and less for its wanting hero? Maybe a certain amount of aesthetic appeal contributes to a monument's conservation. The fountain could have formed an appealing background for the statue of Jomo Kenyatta that now stands in front of the Parliament Buildings. Instead, this fountain has come to act as an introduction to his mausoleum, which unfortunately is inaccessible to the public.

There have been questions about the removal of the statues of George V and VI. The British did rule over Kenya as attested to by the monarchs' statues in City Square; these stood as part of the continuum that is Kenya's political datum. The pertinent concern is whether one can (or should) wipe out a 'representation' of actual historical happening. It could be further argued that the act of removing the statues is an attempt to negate history. However, the rules governing public space are not identical to those that apply in historical re-construction. Public space demands a constant 'now'. The act on show is always in the present 
tense. King George V was in the public space when British rule was current. Jomo Kenyatta is in the public space when indigenous rule is ongoing. Public space acts as the stage where 'live' political shows unfold. King George V is not on centre stage today, the spot light is not on him, therefore he is not 'showing' in public space.

On the other hand, an approach to conservation that sees culture as a 'living' unbroken continuum is laudable; a culture that preserves past and present monuments would contribute greatly to the right of future generations to know (and therefore own) their urban cultural heritage. Monuments of conspicuous figures in public space are likely to be removed with regime change (e.g. the statue of King George V in comparison to the Carrier Corps). Therefore, the community ought to figure out ways of conserving them. This is because they are part and parcel of the heritage that belongs to every citizen by right.

These monuments, regardless of one's political affiliation, are integral to Kenyan history. Whether or not they happen to occupy centre stage (the current public space) or have been relegated to some back stage (museum space, actual or virtual), they need to be conserved if we are going to hand over a complete and 'honest' heritage to future generations.

Heritage and national identity are current topics. Although colonial monuments form an actual part of the country's political heritage, national debate is silent about them. What import does this silence have for the present and future generations? How are they to remember colonial rule? How are they to memorialize or conceive of it? If indeed they ought to! City Square, both in colonial and post-colonial times, belongs to contemporary Kenyans as it did to their forefathers. Withdrawing knowledge of heritage by withdrawing its monuments is equivalent to offering incomplete information about its evolution and identity. A complete account of the monuments in Nairobi's public space ought to be reachable, if and when wisely conserved.

\section{Carrier Corps monument - made by who and for whom?}

Bordering on City Square, along Kenyatta Avenue, is a monument of three soldiers. It is slightly larger than life, featuring men equipped for war. One is in military uniform; the two in kanzu (Muslim dress worn by men). The monument depicts a soldier and carriers of World War I. They commemorate the involvement of the Kenyan (the African) in wars that were not of his making. Kenya was involved in both the world wars because it had 
been annexed by the British Empire. In World War I, locally drawn 'King's African Rifles' (KAR) formed part of the British battalion that fought the Germans in neighbouring Tanganyika. They served in the same capacity during World War II, but this time in Abyssinia and overseas in Burma. Africans were enlisted as carrier corps, 'the feet and hands of the fighting men'. Their recruitment ground was somewhere in the vicinity of Ngara, the place called Kariokor (a Swahili or Kikuyu corruption of Carrier Corps). Here they met, to be enlisted into the army; here theyleft the eventname, bequeathing a memory and a history to otherwise open space. There is a glaring anomaly however: the Carrier Corps sculpture is not on the grounds of Kariokor; it stands on Kenyatta Avenue near City Square. In 1928, when this monument was erected, Kariokor grounds would have been the obvious choice to site it. But it was not in the European part of segregated Nairobi, the city proper. It was in the town's periphery. The government of the day chose to bring in the re-presentation of the war carriers into the town's centre while denying the actual persons (represented in it) entry. 1928 Nairobi was segregated according to race. This monument was supposedly addressed to the indigenous Kenyan the surviving carrier and his relatives - but placed in an area that was out of bounds to him. Bennet (1963) reminds us that according to colonial law, the indigenous Kenyan needed a kipande (Kiswahili for a pass card) to account for his usually brief transit in Nairobi and its precincts. The contradiction is that this monument was in the vicinity of the European colonial, the part of the city that was inaccessible to the actual carrier and his milieu. The aesthetics of politics dictated the appropriate site for the monument. Its target audience, those who were to view it and be grateful to their government, were frequenters of Delamere Avenue (today's Kenyatta Avenue). Besides, parliament in colonial times conducted its debates in Memorial Hall, which as the name suggests, was put up in memory of British victory in World War I. That is why an obelisk was erected, in memory of the war dead, the European war dead. Across the street, the Carrier Corps was erected as a separate memorial for the African dead, and was, therefore, referred to as the African War Memorial, as Larsen (2013) explains. At the base of this African Memorial there is an inscription, in English, Kiswahili and Arabic, citing the (British) public gratitude in the elegant words of the author Rudyard Kipling:

This is to the memory of the native African troops who fought: to the carriers who were the feet and hands of the army: and to all other men who served and died for their king and country in 
Eastern Africa in the great war, 1914 - 1918. If you fight for your country even if you die, your sons will remember your name.

Ironically, the African Kenyan, depicted in the Carrier Corps monument, was not fighting for his country; Kenya had no adversaries in World War I. Consequently, today's Kenyan appears to have little connection with this monument. What purpose, then, does it serve - or any monument for that matter? One reason for creating a monument is to record an important event in its fullness, capturing even the accompanying emotion, for good artwork is a record of emotions. This sculpture, and it has good technical standards, does not embody the emotions of the indigenous Kenyans who do not even stop to look at it.

Did the British fail then in erecting it? And if they did, why does the post-colony conserve it? In erecting war monuments, the British Empire needed a smooth consistency of imperial culture. The War Council in London was not making decisions exclusively for Nairobi, but rather for all British subjects flung all over the vast empire. The Carrier Corps monument is therefore more than a display of Kenya's African politics, unless it is seen as a mere record of their passive political voice. The placement (physical location) of this monument had more to do with the colonizer than with the 'silent' carrier. How he felt about World War I: his pride, his shame or his frustration, is not the overriding emotion captured in this artwork; it is about the settler's view of the Carrier Corps; his representation of them; his memory of their role in his own wars. This makes the monument paternalistic. 'The African War Memorial' belongs to the ruling colonial and his political aesthetics. Perhaps its site is not a mistake after all: the European part of colonial Nairobi, on the street that carried Lord Delamere's name and therefore symbolized his colonizing gesture.

If the settler was happy (or otherwise provoked) by this sculpture, what about the African it purports to represent? How could he (and can he, today) identify with this monument? He is yet to elicit any responsepositive or negative - towards it. Total neglect is all that the monument receives from indigenous Kenyans. It is to be wondered then that the monument has been preserved, leading to the question, 'when the public changes, does the significance of a monument change as well?' Does the Carrier Corps monument generate any cognitive or affective response, in terms of history, the present or future aspirations? For a while the European colonial community still registers some response to it, as discovered during the historical walking tours conducted in Nairobi in 2013. The African crowd displays no response whatsoever. 
Its disconnection is total. Hence the seemingly idle question: is it still a public monument? This issue is yet to be resolved by the Kenyan public. Lack of African participation, and the wide social distance between the carrier corps class and the colonial political leadership, is evident in this monument; a plausible explanation of the total blindness that this wellexecuted artwork is met with, in spite of being at the geographical and symbolic centre of Nairobi's central space.

The 'narrative' contained in this sculpture elicits indifference, reducing it to a material landmark devoid of symbolism, cultural attachment or national pride. Yet at one time, the monument was hegemonic and it continues to be housed on a prime site. This raises more questions than it answers. Now that political power has shifted hands (from British colonial to indigenous post-colonial leaders) what happens to the monument? Is a monument still a public memento, bereft of its cultural symbolism? It would appear there are multiple political histories attached to specific monuments.

\section{Conservation of the Carrier Corps}

The Carrier Corps monument was a product of World War I; a consequence of quarrels in far-away Europe. The indigenous Kenyan was necessarily passive, and so too is his response to the monument. While it was possible to coerce his participation in the World Wars, it has proved impossible to coerce his emotional attachment to this sculpture, its technical perfection notwithstanding. Those who imbued the Carrier Corps monument with animating symbolism are now not in power. But, whereas other colonial monuments have been pulled down, such as both King George sculptures (1963), this one continues to occupy central space in the post-colony. A possible reason for its conservation is its subject matter: it depicts the African Carrier Corps, a marginal group during colonial rule. Now that the once marginalized are turned leaders, there would be little sense in tearing down their own image - even if it was erected by a past and hostile regime. Maybe the monument did not exit public space along with the colonial regime because of its inclusive gesture: addressing the marginalized African, thus bringing him into the space of performance of power. It brought in the colonized subject from the shadows of political nonperformance, dragging him into the CBD centre stage - albeit more in the physical sense than through meaningful positive action.

Inclusiveness and broad participation, even at the level of mere public gestures, appear to contribute decisively to the conservation of a monument. Perhaps we may conclude that a way of making 
monuments live beyond the lifetime of the regime that erects them is to be inclusive, to take into consideration the right of all to be represented in public space. Inclusive visual language, elements and references can be useful; not limiting oneself to the taste, issues and views of the majority but sensitively catering to the minority as well. Other ways of exercising broad-mindedness in putting up public monuments is to rise above the constraints of the debate of the moment, to be a visionary.

\section{Conclusion}

This chapter has discussed collective memory and representation through public monuments, which are intimately related to national identity. It has demonstrated the role of Nairobi's City Square as the key public space for the articulation of national identity. This is where the colonial government erected statues of its monarchs and where Jomo Kenyatta replaced them after independence in 1963.

Colonial monuments have not been preserved even in less public space such as the museum. Perhaps this is an oversight that needs remedying. The monument to the carrier corps of World War I, although not in City Square, is outstanding. It does not depict a specific person but rather a collective. Further, it represents a minority (in terms of political power) and has managed not to be pulled down with the change in regime and the reign of political power. It has been unwittingly conserved.

Suggestions and observations for constructive heritage conservation encompass monuments. Those that take into consideration the right of all to be represented in public space tend to be more easily conserved and outlive the regime that erects them. Aesthetic appeal also contributes to a monument's conservation. 


\section{5}

\section{Reflections on architectural morphology in Nairobi, Kenya: implications for conservation of the built heritage}

Muhoro Teckla, Munala Gerryshom and Mugwima Njuguna

\section{Introduction}

Architecture is the carrier of the social, political and cultural history of a nation. Reference to an architectural style or pattern requires a search into the history, culture and aspirations of a nation's people. As Kenya's first and capital city, Nairobi is centre place and has a multiplicity of distinctive building forms.

Nairobi has a valuable architectural fabric that is rich in cultural, artistic, architectural and religious significance enriched by foreign influences. The political patronage that accompanies these influences has resulted in an architectural vocabulary that expresses imported aspirations and values, as evidenced in the city's buildings. These buildings are heavily influenced by colonial features which are then modified by local culture, climate, tradition, materials and technology. This chapter discusses important historic buildings, presents tangible evidence of morphological interplay and identifies the factors that influenced their design and construction. To put today's conservation efforts into historical perspective, it is helpful to look back at the local and international situation, as it existed a hundred or more years ago, in order to understand the prevailing dynamics of the time.

The chapter also assesses select historic buildings from preindependence Kenya, establishes various foreign influences on building typologies and highlights the application of conservation principles 
within the Kenyan legal framework. It discusses the historic buildings' architectural character, key features in their context and values that make these buildings significant to the Kenyan people.

\section{Historical development}

The development of architectural styles in Nairobi can be traced to the arrival of the railway line on the vast plains through which flowed nrobi (stream of cold water), in the Maa language. The railway builders chose this area as an ideal resting destination while awaiting ascent of the steep Limuru escarpments (Hill 1976). According to Van Zwannenburg and King (1975), the choice of Nairobi was further enhanced through its functioning as a trading centre for Kikuyu and Maasai women prior to the coming of the railway. The present site of Nairobi was selected as a stores depot, shunting yard (place where trains are shifted from one track to another), and camping ground for the thousands of Indian labourers (also British colonials, who came to Kenya seeking work) employed by the British to work on the line. Arthur Church was commissioned, therefore, to prepare a town layout for the railway depot in 1898 (Hill 1976). This plan, the first official one for Nairobi, had two main streets, Victoria Street (today Tom Mboya Street) and Station Street. It also had ten avenues, staff quarters and an Indian commercial area (Hill 1976). The railhead reached Nairobi on 30th May 1899 (Smart 1950) and found a small depot active with trade and commerce. In the same year the administrative government was also set up (Pavitt 2008). This duality as a meeting and administrative point established Nairobi as a key town along the railway line. In 1899 Engineer Sir George Whitehouse remarked that 'Nairobi itself will in the course of the next two years become a large and flourishing place and already there are many applications for sites for hotels, shops and house' (cited in Tiwari 1981). In 1907, Nairobi was made the capital of Kenya.

In 1920, Nairobi's size was $25 \mathrm{~km}^{2}$, in 1927 it was $90 \mathrm{~km}^{2}$ and by 1995 the area had grown to $684 \mathrm{~km}^{2}$ (UN 1995). As Nairobi grew, so did its commercial and administrative status. As areas such as Bazaar Street (today Biashara Street) came into being, main business streets like Delamere Street (today Kenyatta Avenue) and Government Road (today Moi Avenue) also emerged as important shopping areas. Thus, a majority of the city's old buildings are found on these streets. According to Smart (1950), the early phase of Nairobi's development was largely characterized by the emergence of corrugated iron sheet structures 
which were to change from 1906 as dressed stone started appearing with the transformation of the Bank of India into the first stone building. As the settlers established themselves, eclectic Victorian-period buildings characterized by massive masonry and attractive façades started dotting the railway town in both folk and academic forms (Wahome et al. 2013).

The British colonialists brought along their culture and customs, which influenced the existing local cultures. Arguably, the most significant influences introduced by the colonialists were their system of government and their styles of architecture. The impact was felt in both public and private architecture in and around the town centre in form of institutional, commercial and residential buildings.

Undoubtedly, the European style influenced the architectural development of the city in multiple ways. It is, however, noteworthy that Nairobi is a multi-racial city comprising a predominantly African population with European and other racial groups. Consequently, its development has been influenced by these various cultures as well, and their legacies are visible in the rich and diverse architectural heritage that remains until today.

\section{Historic architectural morphology}

To appreciate the significance of historic buildings in Nairobi, an understanding of the influences on appearance, shape and form is important. Attributes that reflect a time period of history carry with them evidence of the thinking of the builders. Nairobi's historic buildings have borrowed from diverse influences and merged with local peculiarities to give rise to buildings that have homogenous characteristics.

\section{Building materials}

A survey of the historic buildings in Nairobi indicates that these buildings give the city an important, distinguishing character. As morphology is concerned with factors that govern and influence form, it is noteworthy that European settlers predominantly used locally available materials in their construction. Blue granite stone was easily available in and around Nairobi; it was durable and thus widely used in building. Most historic buildings still retain their rustic facades of blue granite stone, but some have suffered from haphazard application of paint and other renders. 
Another material of notable usage was Nairobi claystone. It was used for important buildings such as All Saints Cathedral. Although easy to dress, use of claystone was somewhat replaced by concrete blocks and ferro-concrete construction due to several factors including location of its thin outcrops on steep valley slopes (which made it uneconomical to quarry), its dull colour, and its difficulty to extract in large sound blocks. Claystone, however, remained popular in construction of residential buildings.

As of the late 1940s, sand was harvested in Athi River, Konza, Ulu, and Kajiado areas and shipped by rail to Nairobi. No lime was being produced in Nairobi, although limestone deposits in Athi River existed. Lime was obtained from Kenya Marble Quarries near Kajiado, Mombasa and Homa Bay.

Comparatively low quantities of bricks and tiles were made. This was due to their production being dependent on rainfall for water supply and difficulties in obtaining sufficient labour and fuel. Roofing tiles were produced locally, though tile production experienced similar challenges to brick production. Cement roofing tiles were also being manufactured in Nairobi as of the late 1940s.

Some materials were imported, however, such as Mangalore tiles (of hard, lateritic red clay originating in Mangalore, India) used for roofing. Overall, before the 1950s no cement was made from raw materials in Kenya (White et al. 1948). Doors and windows were framed from hardwood timber which was harvested from the indigenous forests. Grilles and other metallic motifs were curved from wrought iron.

\section{Foreign building styles and their attributes}

It is noteworthy that while some architectural styles are universally recognized, there is sometimes variation among scholars and historians on their categorization, naming of styles and periods of popularity. The historic buildings in Nairobi have borrowed a lot of their building character from foreign influences, mainly colonial-imported architecture. These influences are visible individually or in combinations in various buildings. Some of the architectural styles and their characteristics are described as follows:

\section{A) European influences}

(i) Classical revival style: Classical revival is based on the architecture of Ancient Greece and Rome (City of Chicago (COC) 1995). It was widespread in colonial Nairobi; it is expressed 


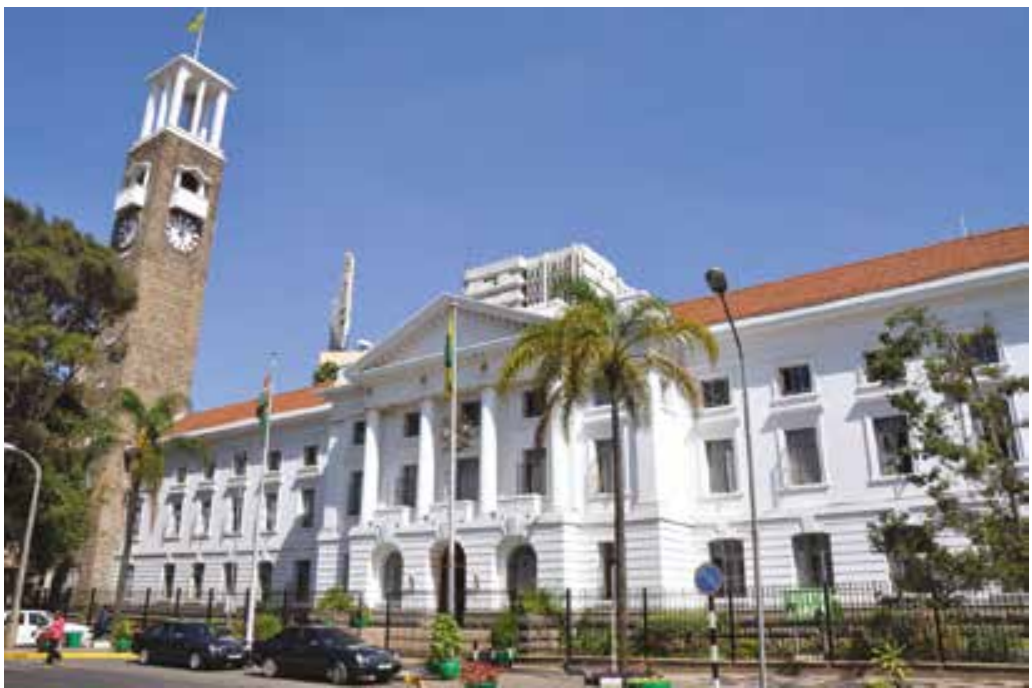

Figure 5.1 Colonnaded façades of City Hall (wikimedia.org, accessed 22 February 2016)

largely in public building architecture. It was meant to be a symbol of expression of imperial authority (Wahome et al. 2013) in the colony. Common characteristics include symmetrical façades, towers or other projecting building elements, classical ornaments including columns, cornices and triangular pediments, roofline balustrades, and use of a wide variety of materials, including bricks, stone, terra cotta and wood. Some important examples in Nairobi include Railway Headquarters, Law Courts and City Hall (Figure 5.1).

(ii) Renaissance revival style: The churches and palaces of Renaissance Italy were the inspiration for this revival style (COC 1995). It emphasized the rebirth and development of distinctive ancient Greek and Roman material culture. Common characteristics include symmetry, rustication, quoining, profusion of triangular and round-arched pediments, cornices and lintels, proportion, geometry and regularity of parts as was particular to classical Roman architecture and round-arched windows and arcades (that is, covered walkways or porches, formed by rows of arches rested on columns). In Nairobi, it manifested itself in buildings like the current Panafric House (Figure 5.2) and the Westminster buildings along Kenyatta Avenue, where clean dressed local stones adorn their facades. 


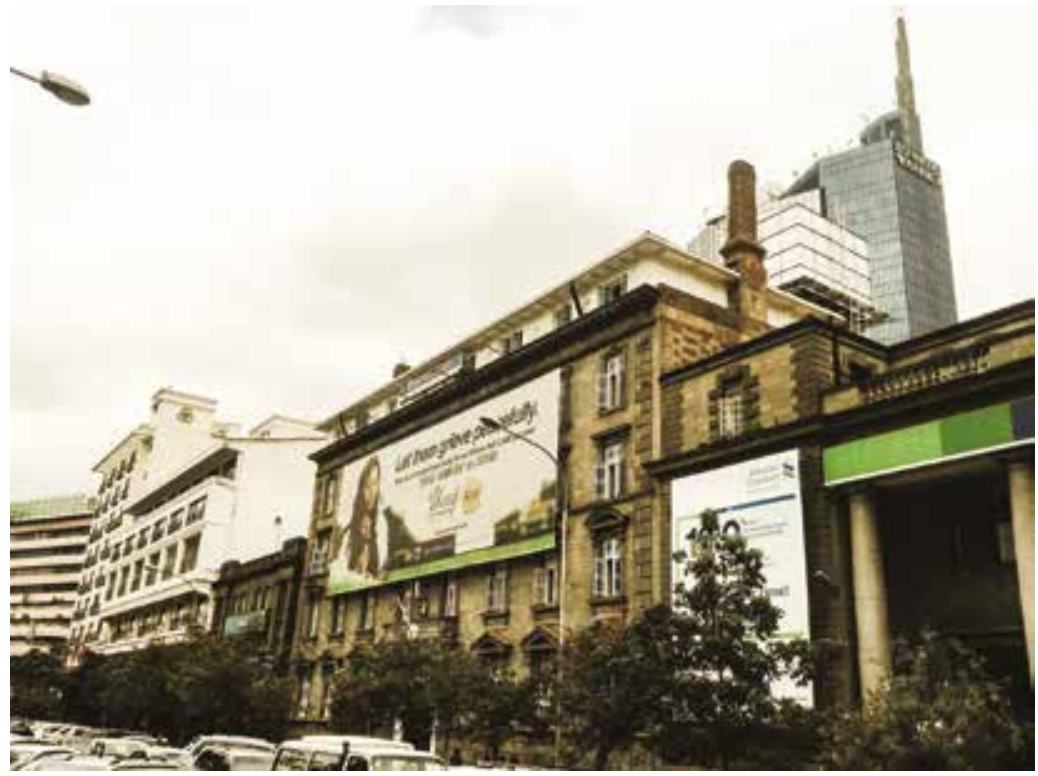

Figure 5.2 Symmetry, use of pediments, rustication, quoining and cornice on Panafric House (http://nairobians.net/, accessed February 2016)

(iii) English Gothic revival style: A rise of interest in the church architecture of medieval France, England, and Germany during the nineteenth century inspired the Gothic revival, a popular style until the 1930s (COC 1995). It was an attempt to break from the monotony of neo-classicism through eclectic form (Wahome et al. 2013). With Christianity, the British introduced church architecture inspired by the Gothic style. Common characteristics include masonry construction, vertical proportions, carved stone ornaments, prominent bell towers, tall pointed arches and windows, often filled with stained glass. The similarity in church architecture emphasized the intrinsic characteristics of this style. An example of English Gothic revival architecture is All Saints Cathedral (Figure 5.3).

(iv) Georgian architectural style: It is named after eighteenthand nineteenth-century British monarchs. Georgian designs usually lay within the classical orders of architecture and employed a decorative vocabulary derived from Ancient Rome or Greece (COC 1995). Late Georgian architecture's common characteristics include proportion 


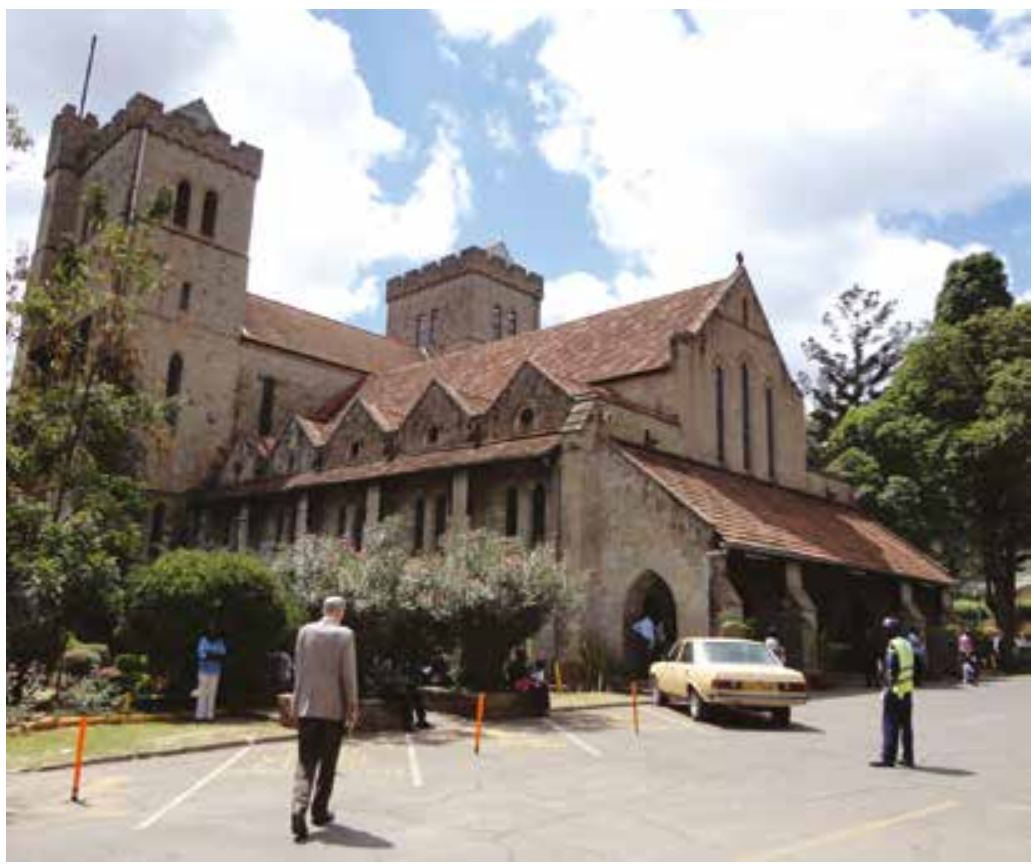

Figure 5.3 Masonry construction, vertical proportions and carved stone ornaments (https://gregorycrofford.com/, accessed 6 March 2016)

and balance, use of simple mathematical ratios, symmetrical facades often with side porches, use of brick, stone or wooden walls, entrances decorated with sidelights, transoms, ornamental columns and pediments. The Old Provincial Commissioner's Office building (Figure 5.4) and Kipande House along Kenyatta Avenue are good examples of this eclectic style.

(v) Tudor revival style: The Tudor style was an attempt to create architecture with a traditional, picturesque appearance. It is based on English domestic architecture from the 1500s and 1600s (COC 1995). Common characteristics include: steeply pitched roofs - often with front facing gable or multiple gables, decorative timbered wall surfaces, decorative front or side chimneys, diamond-shaped casement windows, use of stucco, masonry or masonry-veneered construction, often with ornamental stonework or brickwork and irregular massing. This architecture resonated mainly in residential buildings, although a few commercial buildings were constructed 


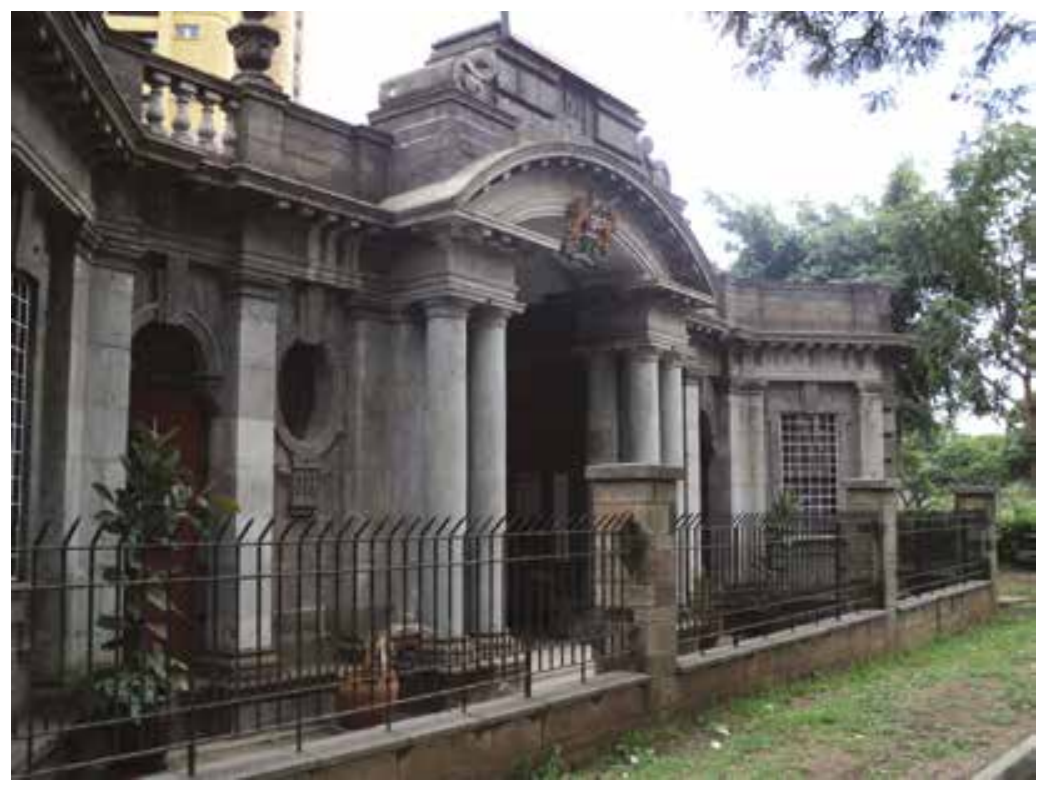

Figure 5.4 Old Provincial Commissioner's Office (http://theglobalgrid. org/, accessed 22 February 2016)

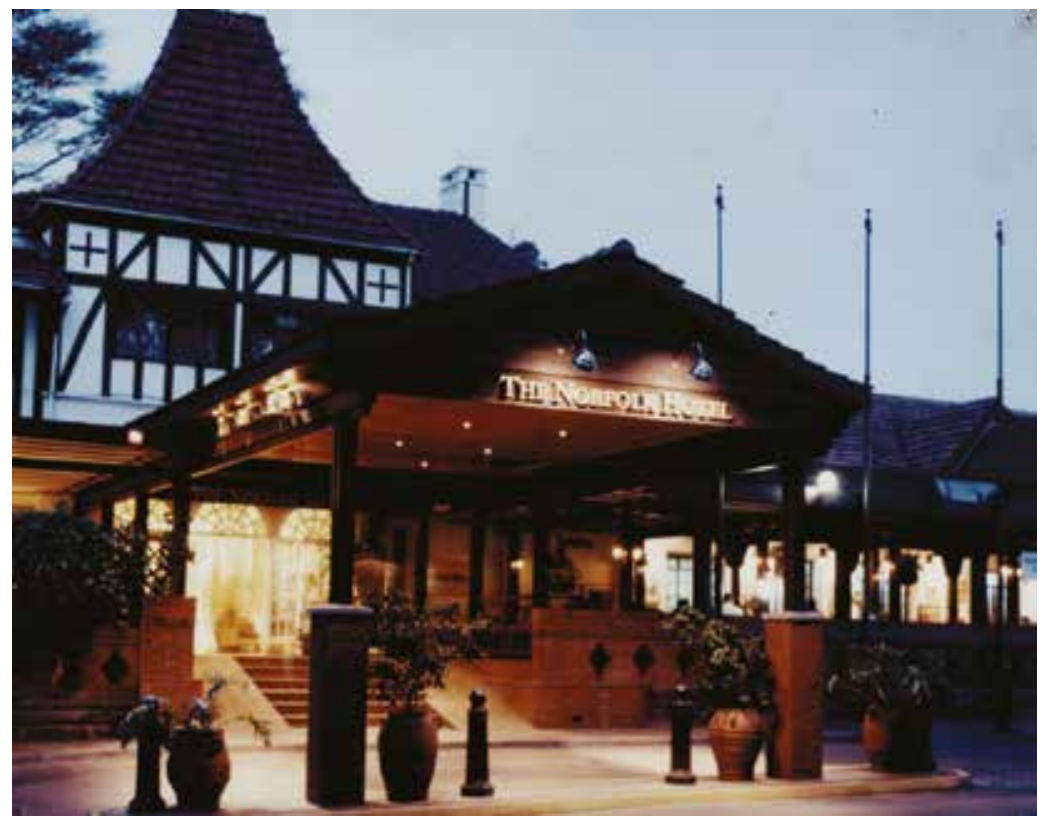

Figure 5.5 Norfolk Hotel (http://www.beglinwoods.com/, accessed 22 February 2016) 
using it, for instance Norfolk Hotel along Harry Thuku Road (Figure 5.5).

(vi) Art Deco: This style began in France and flourished between the interwar years (1918-45) when rapid industrialization was transforming culture and influencing construction (COC 1995). Motifs were borrowed from the machine age and technology imagery and materials were commonly used (Figure 5.6). Common characteristics include rich colours, bold geometric shapes, lavish ornamentation, horizontal or vertical orientation, rounded edges, corner windows and glass block walls. As an alternative to the more

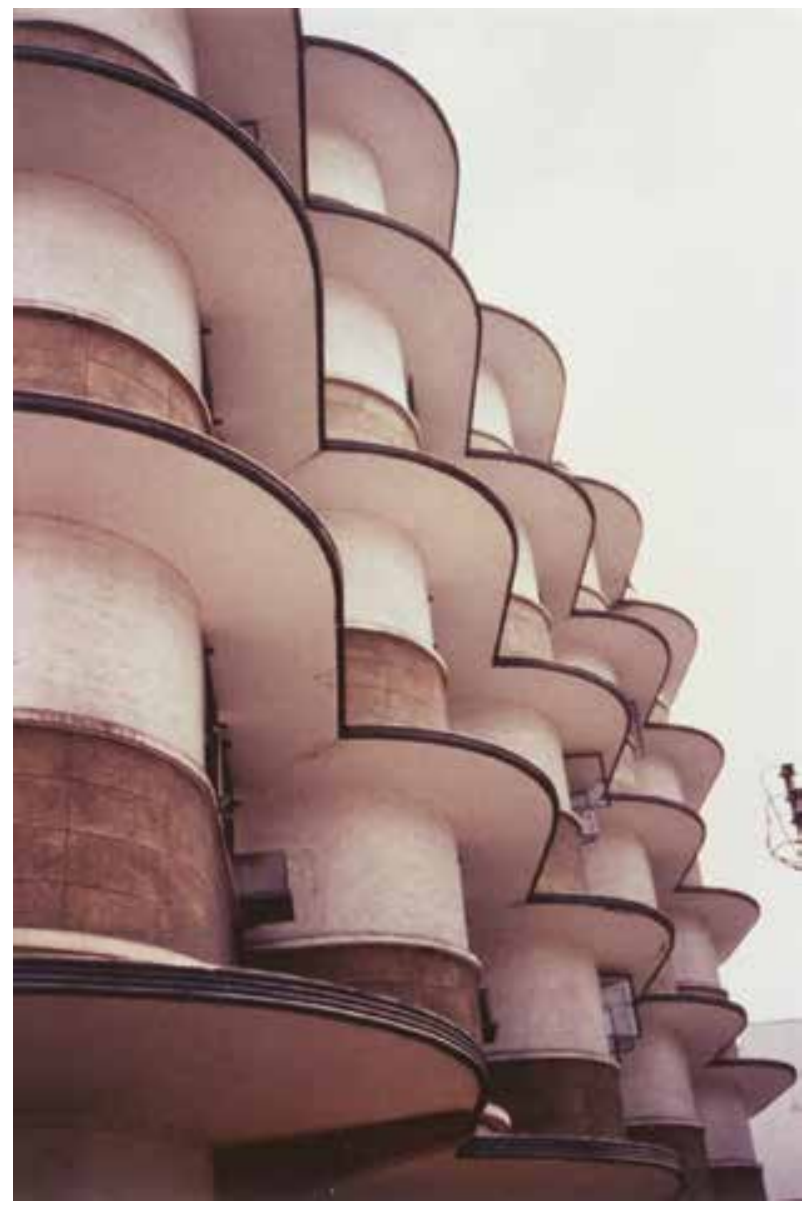

Figure 5.6 Kenwood House (http://4.bp.blogspot.com/, accessed 22 February 2016) 
classical styles, Art Deco was embraced in the transformation of the Indian bazaar and adjoining areas between mid-1930s and 1950 (Salvadori 1996). Its lack of a clear, definitive character and leaning on stylized and abstracted forms endeared itself to both the public and private property designers.

\section{B) Asian influences}

The character of Nairobi in the early years was a combination of two disparate elements: the railway area and the congested Indian Bazaar.

After World War I, European settlers gained more influence in colonial administration and one instrument they employed to propagate their presence was town planning, especially zoning. This meant that various locations were designated as European, Indian and African residential areas. The areas allocated to Indians included the Indian Bazaar, which combined residential and commercial activities in a building typology influenced by practicality and typologies found in India. This comprised commercial activities on the ground floor of the building with residential quarters on the upper floor or a commercial section towards the front of the building with a residential section towards the rear, often housing lodgers (White et al. 1948). Use of materials was also distinctive, with many structures being initially constructed from corrugated iron sheets (typically for roofing, but sometimes also for walling), either exclusively or in combination with other more permanent materials such as brick and stone. Away from the bazaar area, Indians were provided with bungalows in Pangani in 1927 that lacked basic functional elements like sitting rooms or courtyards (Salvadori 1996). Therefore, the Indian non-registered architects took advantage of these shortcomings to modify the buildings. Elsewhere, they also built religious buildings such as Singh Sabha Sikh Temple. The ease of execution and functionality of these Indian styles led to other architects borrowing and replicating them in other structures like Sheria House (Figure 5.7) and Parliament Buildings. Elsewhere, they also built religious buildings such as Singh Sabha Sikh Temple (Figure 5.8). 


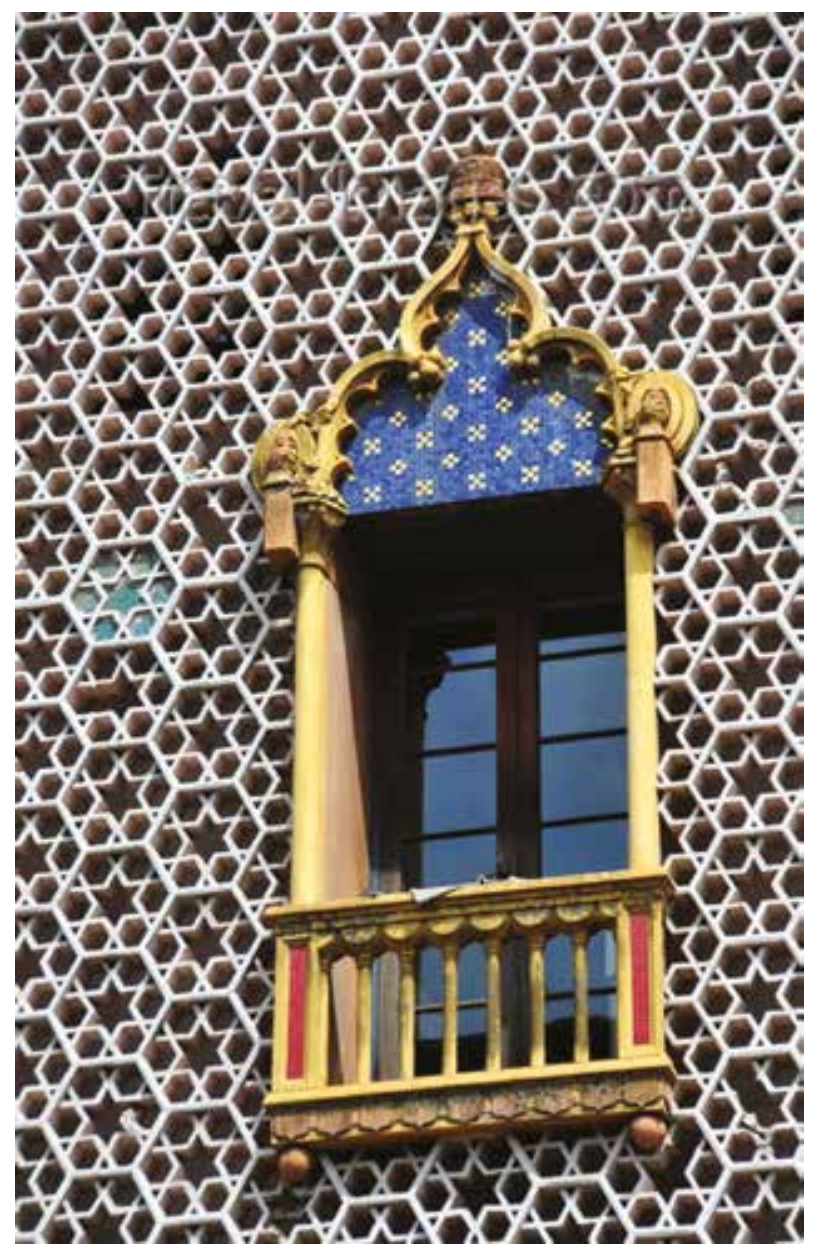

Figure 5.7 Sheria House (http://www.travel-images.com/, accessed 22 February 2016)

\section{Status of historic buildings}

Clearly, Nairobi's historic buildings have considerable architectural merit that warrants their maintenance. The walls of most buildings are generally in good condition; surface erosion has been moderate, carved ornamental details are still relatively crisp in most locations. However, there is noticeable vertical and diagonal cracks and discolouration in some buildings where neglect has crept in. Due to weather conditions and adverse human use, some buildings require extensive intervention to restore them to their original appearance, for instance, the IBEA building along Moi 


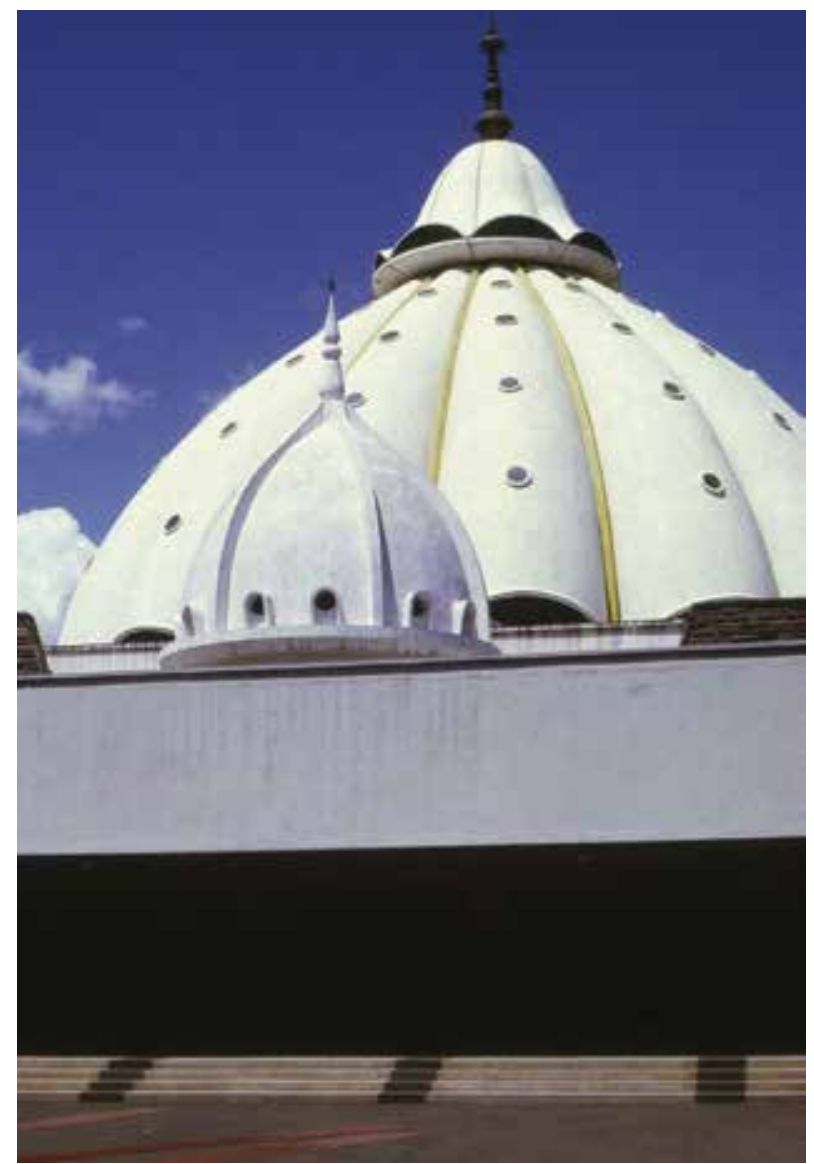

Figure 5.8 Singh Sabha Temple (http://i0.wp.com/, accessed 22 February 2016)

Avenue. Other buildings have been allowed to deteriorate to the 'point of no return' and their restoration would prove both technically difficult and costly, for instance, the '1918' building along Ronald Ngala Street. The preservation and significance of these buildings is being undermined by:

1. Lack of proper maintenance

2. Total destruction of historically and/or architecturally significant buildings

3. Change of buildings' character due to inappropriate additions and alterations

4. Pollution

The status of the selected buildings is shown in Table 5.1. 
Table 5.1 Status of selected historic buildings in Nairobi (adapted from National Museums of Kenya 2003)

\begin{tabular}{|c|c|c|c|c|c|}
\hline Building & $\begin{array}{l}\text { Present } \\
\text { use }\end{array}$ & $\begin{array}{l}\text { Original } \\
\text { use }\end{array}$ & Ownership & Condition & Notable architectural features \\
\hline $\begin{array}{l}\text { Darkhana Jamatkhana } \\
\text { (Khoja Mosque) (1920) }\end{array}$ & Mosque & Mosque & Community & Good & $\begin{array}{l}\text { Use of arches, fair-finished stone } \\
\text { facing, decorative motifs }\end{array}$ \\
\hline Elite House (1912) & $\begin{array}{l}\text { Commercial \& } \\
\text { hotel }\end{array}$ & Offices & Private & Good & $\begin{array}{l}\text { Pioneer office building in terms of scale } \\
\text { and interior and exterior finish }\end{array}$ \\
\hline $\begin{array}{l}\text { Old Provisional } \\
\text { Commissioner's Office } \\
\text { (1913) }\end{array}$ & Art gallery & Offices & $\begin{array}{l}\text { Public (National } \\
\text { Museums of Kenya) }\end{array}$ & $\begin{array}{l}\text { Stable, but } \\
\text { undergoing } \\
\text { change }\end{array}$ & $\begin{array}{l}\text { Intimate scale, typical British adminis- } \\
\text { trative building, decorative motifs }\end{array}$ \\
\hline $\begin{array}{l}\text { Standard Chartered } \\
\text { Building (1929) }\end{array}$ & Banking & Banking & $\begin{array}{l}\text { Standard Chartered } \\
\text { Bank }\end{array}$ & Good & $\begin{array}{l}\text { Prominent facade with rustication, } \\
\text { quoining and colonnade }\end{array}$ \\
\hline Panafric House (1928) & Offices & Offices & $\begin{array}{l}\text { Pan African Insurance } \\
\text { Holdings, Ltd. (Private) }\end{array}$ & Good & $\begin{array}{l}\text { Use of pediments, cornices, smooth } \\
\text { and rustic stones }\end{array}$ \\
\hline $\begin{array}{l}\text { Westminster House } \\
\text { (1928) }\end{array}$ & Offices & Lodging & $\begin{array}{l}\text { East African Building } \\
\text { Society }\end{array}$ & Good & $\begin{array}{l}\text { Distinctive entrance, polished stone } \\
\text { and roofline balustrade }\end{array}$ \\
\hline City Hall (1934) & Offices & Offices & $\begin{array}{l}\text { Public (Nairobi City } \\
\text { County) }\end{array}$ & Excellent & $\begin{array}{l}\text { Distinctive portals, classically colon- } \\
\text { naded main façade, clock tower }\end{array}$ \\
\hline $\begin{array}{l}\text { Chiromo Mansion } \\
\text { (1905) }\end{array}$ & $\begin{array}{l}\text { Office space } \\
\text { for university }\end{array}$ & Residential & University of Nairobi & Good & $\begin{array}{l}\text { Dutch gabled roof, elaborate wall } \\
\text { finish }\end{array}$ \\
\hline Jamia Mosque (1925) & Mosque & Mosque & Community & Good & Marble doomed roof \\
\hline
\end{tabular}


Table 5.1 (Continued)

\begin{tabular}{|c|c|c|c|c|c|}
\hline Building & $\begin{array}{l}\text { Present } \\
\text { use }\end{array}$ & $\begin{array}{l}\text { Original } \\
\text { use }\end{array}$ & Ownership & Condition & Notable architectural features \\
\hline $\begin{array}{l}\text { Imperial Chambers } \\
\text { (1914) }\end{array}$ & Commercial & Commercial & Private & Good & $\begin{array}{l}\text { Prominent well-proportioned and elegant } \\
\text { arch entrance, use of wrought iron }\end{array}$ \\
\hline $\begin{array}{l}\text { McMillan Memorial } \\
\text { Library (1928) }\end{array}$ & Library & Library & Trust owned & Good & $\begin{array}{l}\text { High quality craftsmanship, lion sculp- } \\
\text { tures at entrance, roofline balustrade }\end{array}$ \\
\hline $\begin{array}{l}\text { Surat District Association } \\
\text { Building (1943) }\end{array}$ & $\begin{array}{l}\text { Welfare } \\
\text { nursery in } \\
\text { one wing }\end{array}$ & Welfare & Community & $\begin{array}{l}\text { Good, but } \\
\text { evidence of } \\
\text { neglect }\end{array}$ & Well-detailed and polished finish \\
\hline $\begin{array}{l}\text { Ismail Rahimtulla Walji } \\
\text { Trust Library (1950) }\end{array}$ & Library & Library & Trust owned & $\begin{array}{l}\text { Good, though } \\
\text { undesirable } \\
\text { additions } \\
\text { emerging }\end{array}$ & $\begin{array}{l}\text { Prominent portal entrance with } \\
\text { distinctive pediment and Ionic columns }\end{array}$ \\
\hline $\begin{array}{l}\text { Karen Blixen Museum } \\
\text { (1912) }\end{array}$ & Museum & Residential & $\begin{array}{l}\text { Public (National } \\
\text { Museums of Kenya) }\end{array}$ & Good & $\begin{array}{l}\text { Second generation colonial residential } \\
\text { architecture constructed of stone }\end{array}$ \\
\hline Nairobi Club (1901) & Club & Club & Private & Good & $\begin{array}{l}\text { Complex of buildings that have } \\
\text { maintained character despite many } \\
\text { additions over time }\end{array}$ \\
\hline Kipande House (1913) & Bank & Warehouse & Private & Good & $\begin{array}{l}\text { Well-detailed, distinctive tower, use } \\
\text { of arches }\end{array}$ \\
\hline ‘1918’ building & Commercial & Residential & Private & $\begin{array}{l}\text { Stable interior } \\
\text { but adulter- } \\
\text { ated exterior }\end{array}$ & $\begin{array}{l}\text { Well-detailed and well-finished } \\
\text { exterior }\end{array}$ \\
\hline
\end{tabular}


Viewing the restoration and maintenance of old buildings as a form of heritage conservation rather than a commercial venture would greatly enhance preservation efforts spearheaded by public institutions such as the National Museums of Kenya (NMK). Some historic buildings have adapted new uses, yet continue to tell their stories of the past. These include Kipande House, which has been converted into a banking hall from a storage facility and the Old Provincial Commissioner's Office, which has been converted from an administrative building to an art gallery. These changes in use are a reflection of a shift in attitudes, hopes and aspirations of the various socio-economic groups that use and own these historic structures.

\section{Conservation management strategies}

For conservation to be effective, historic buildings must retain their integrity and play a stimulating role in their context while meeting the city's contemporary functions. It has been shown that conservation of the built heritage is more than a question of aesthetics since it touches on basic values, and pride in the past is the surest foundation for confidence in the future (Dobby 1978; Fitch 1990; Feilden 1994; Forsyth 2007; Rodwell 2007). Muños Viñas (2005) has emphasized that conservation is practised in order to cope with our 'own inability to invent the present'. This may be explained through the waning confidence in the 'present' and therefore an urge to revive the past. Less pessimistically, Constantine (1998), while citing Hockney, says that conservation is done for love, although he offers no explanation what that love is for (Muños Viñas 2005).

Historic buildings in Nairobi are threatened especially as the 'cult of the new' takes grip. In Nairobi, resolutions to conserve these buildings are often faced with uneasiness by property owners and tenants as the cost implications of such conservation are assessed. What many people forget is that these old buildings represent an irreplaceable heritage that is an important legacy from past generations, especially in terms of Nairobi's material and non-material cultures. Old buildings give a sense of cultural significance and allow the experience of architecture in a different way. They serve as memorials, providing continuity and linkage to earlier times.

A wealth of knowledge about a city can be derived from its built environment, and this can, among other benefits, facilitate increased civic pride and inter-generational dialogue regarding a nation's heritage. For instance, studying the history of the railway and the Norfolk Hotel in Nairobi tells the story of early life in the city as it developed 
around these two critical points. There is no accurate understanding of the history of Nairobi without grasping the history of the railway. In addition, documentation in its various forms, passing on of knowledge, and dialogue on urban heritage also contribute to the record-keeping and preservation of the city's past.

Nairobi has adopted various approaches in conservation of its significant buildings. These approaches are demonstrated in the different administrative actions taken by the authorities, building owners and property managers.

\section{Legal framework for conservation in Kenya}

The conservation of historic buildings in Kenya is governed by the National Museums and Heritage Act of 2006 (Cap 295). This is the successor of the Antiquities and Monuments Act (Cap 215), and the National Museums Act (Cap 216), both of 1984. The Antiquities and Monuments Act was enacted to provide for the preservation of antiquities and monuments in Kenya. The Act provided for comprehensive apparatus for the control of antiquities and monuments that existed under the Preservation of Objects of Archaeological and Palaeontological Interest Act (Cap 251), which was first enacted in 1934 and revised in 1962. The National Museums Act provided for the 'establishment, control, management and development of the national museums and any other connected purposes' (Republic of Kenya 1984).

The National Museums and Heritage Act of 2006 combines previous Acts and gives the 'authority' powers to protect and preserve monuments, of which historic buildings are a part. However, this body remains a limited 'watching brief' as it lacks effective management capacity and has limited financial strength.

\section{Listing}

The process of 'listing' is one of the most widely adopted measures for providing protection to buildings or sites of special interest, and is well established in practice and legislation. The NMK has a criterion that sets out broad terms of listing. The criterion is six-fold:

1. Architectural merit

Building style: Does the building exhibit any known architectural style? Can the building be associated with any architectural period or event? 
Streetscape elements: Does the building have any interesting or unique architectural elements - balcony, pediments, openings like arches?

2. Historical significance

Architectural style: Was the building put up during any historical known period?

History: Is the building associated with any significant national historical event/period?

3. Age of the building

4. Location

5. Condition of the building

6. Ownership: Is it a private or public or religious or social building?

Most listed buildings are privately owned and well cared for, bearing in mind the often disproportionate costs of repair and maintenance. The onus of keeping a listed building in good repair must rest in the first place (as with all property) with the owner, but there will be instances where an owner is not able to, or declines to, attend to repairs on the listed property with the consequence that the building's condition deteriorates. In such instances, the building's notable qualities are 'at risk' of being lost forever.

Whenever the conditions for listing are met, the government of Kenya's cabinet secretary, for the time being in charge of cultural affairs, on advice from the Director General of NMK, will gazette the building for listing. This process has not been smooth for many buildings as some owners have opposed it. Cases of 'mysterious fires and demolitions' have been witnessed while in other areas, houses in the Art Deco style in neighbourhoods such as Parklands, Ngara and Biashara Street are disappearing in favour of skyscrapers.

\section{Public porticipation efforts}

It has been emphasized that the most crucial factor in the conservation milieu is undoubtedly the attitude of the inhabitants of historic centres towards their protection and revival (Papageorgiou 1971). Policy can ultimately succeed only with sufficient support of the public. This, therefore, means that the success of conservation depends largely on the sympathetic understanding and the moral and practical support of the population. The public, however, should not be taken as a unified group and acknowledgement of its differences and plurality in terms of values, identities and interests should be made. Therefore, conservation should 
address diverse sets of views in an increasingly contested and pluralized urban context.

Public participation, in all its different guises, aims to involve the people who will be affected by commission or omission of action by the authority. Hence, a holistic process that inspires city residents and users, and that fosters a sense of civic pride and ownership must be evoked. This process must go beyond basic consultation to total involvement.

\section{Conclusion}

Architectural inspiration for the historic buildings in Nairobi may have had foreign influence but they still have significance. These buildings, in their various styles, paint Nairobi as a cross-cultural city where a range of world architecture has become acceptable. Historic buildings in Nairobi are under significant pressure from property and infrastructure development. There is conflict between urban change and heritage and this situation is physically obvious in towns and cities throughout Kenya today. The importance of historic buildings, however, cannot be overlooked. There is urgent need to develop new appropriate design linkages with the urban past that are at the same time relevant to the present and cognizant of the future.

Cities that have taken preservation seriously have provided incentives such as tax laws and financial benefits that favour owners of historical buildings. They also provide tax credits for the restoration of commercial buildings listed as monuments. Case studies from cities that have successfully preserved their old towns and buildings might be of use, if applied in Nairobi. This will help in ensuring that property owners do not feel short-changed or burdened when their buildings are listed as monuments.

The responsibility of conservation of buildings will need to go beyond simply preventing destruction, to actively caring for and maintaining buildings in good physical condition. Keeping historic buildings in constant and efficient use seems to be the best for their conservation. Sustainable, innovative conservation efforts involving all stakeholders need to be devised and implemented. Promotion of social inclusion by acknowledging the past and accepting present commercial and functional demands could see many of the buildings conserved for future generations. 


\section{6 \\ The bao: a board game in Africa's antiquity}

Mwanzia Kyule

\section{Introduction}

Bao is the Bantu name for the eastern African variant of the mankala group of games. The mankala are indigenous African mathematical strategy board games of skill and, perhaps, the prototype of other numerous board games including chess, pachisi and draughts. The word mankala itself is not used in reference to any particular game; rather, it is a blanket anthropological term that refers to a classification of board games of intelligence. The name derives from the Arabic verb naqala, which means 'to move something about'. The basic structure of mankala games involves sowing of counters in pits that are curved on a prepared flat surface.

In Kiswahili, the word bao is a generic term that can variously be used to mean 'wood' or 'board', in either case referring to the large flat wooden board punctuated with rows of shallow pits that are used to play the bao game. The word has also been used to refer to the aspect of scoring a goal in ball games like football and netball. Because of the widespread nature of the game as well as its antiquity in Africa, the bao has acquired a broad base of reference amongst different cultures within the continent.

In this chapter, brief reviews and evaluations of past research on topics related to the bao games are addressed. They include the nature, antiquity, origins, structure, history, function, game play variations and the significance of the bao in African cultural heritage. Archaeological evidence is presented to affirm origins and continuous in situ evolution of the bao in Africa. The chapter presents the argument that conservation of the bao will require identification of value and relevance of the 
game in modern lifestyles and the shift from dependency on oral traditions to documentation of all aspects of the games.

\section{Nature of the bao board game}

Mankala board games are the most widely distributed games in the world and are, or have been, commonly played in the Middle East, Central and Southeast Asia, as well as throughout Africa. In the Americas, mankala are played in the United States, originally in African-American and Syrian communities, in many Caribbean islands; Guyana, Surinam and in Brazil. Origins of the mankala group of games can be traced to Africa, where different variants are known to have existed for millennia before they were learned and incorporated in cultures elsewhere. In the Americas, board games such as Chuba, Pitfall, Kahla and Oh-Wah-Ree, derive their basic structure in outlook and philosophy from the mankala.

Many academic studies concerning the mankala group of games have been largely general and, to some extent, descriptive of the method and rules of play (Murray 1952; Bell 1979). Other studies have approached the subject from art-historical, psychological, pedagogical and anthropological perspectives. Prominent studies include three doctoral theses (Townshend 1986; Walker 1990; de Voogt 1995) and other extensive studies (Retschitzki 1990; Silva 1995; Russ 1984). De Voogt (1995) has studied the bao masters of East Africa, who play this challenging game in tournaments at a very high level. Bell (1979) describes seven variations of mankala games from Africa, India and South America.

Bao can be played for any number of reasons: entertainment, as an avenue to identify solutions in conflicts and disputes, and even as a ritual performance. The game is played by two persons, and depending on the set of rules used (which vary with different places and peoples), it could be played by more opponents (Driedger 1972; Boyd 1977).

The bao board comprises even rows of cup-like depressions, known as play pits. Some boards have large pits on the ends that are used for holding the play counters. The boards are usually wood (Figure 6.1), but temporary pits scraped on the ground are not uncommon (Figure 6.2). Some boards are cut into natural rock formations (Figure 6.3). Many prehistoric bao boards have been found curved on natural rock formations in or near archaeological sites (Figures 6.3, 6.4, 6.5 and 6.6). In the present time, bao boards may be fashioned from clay as well as plastics, fibre glass and metals. Playing pieces comprise counters in the form of seeds, stones, small sea shells and such other similar material that are placed in 


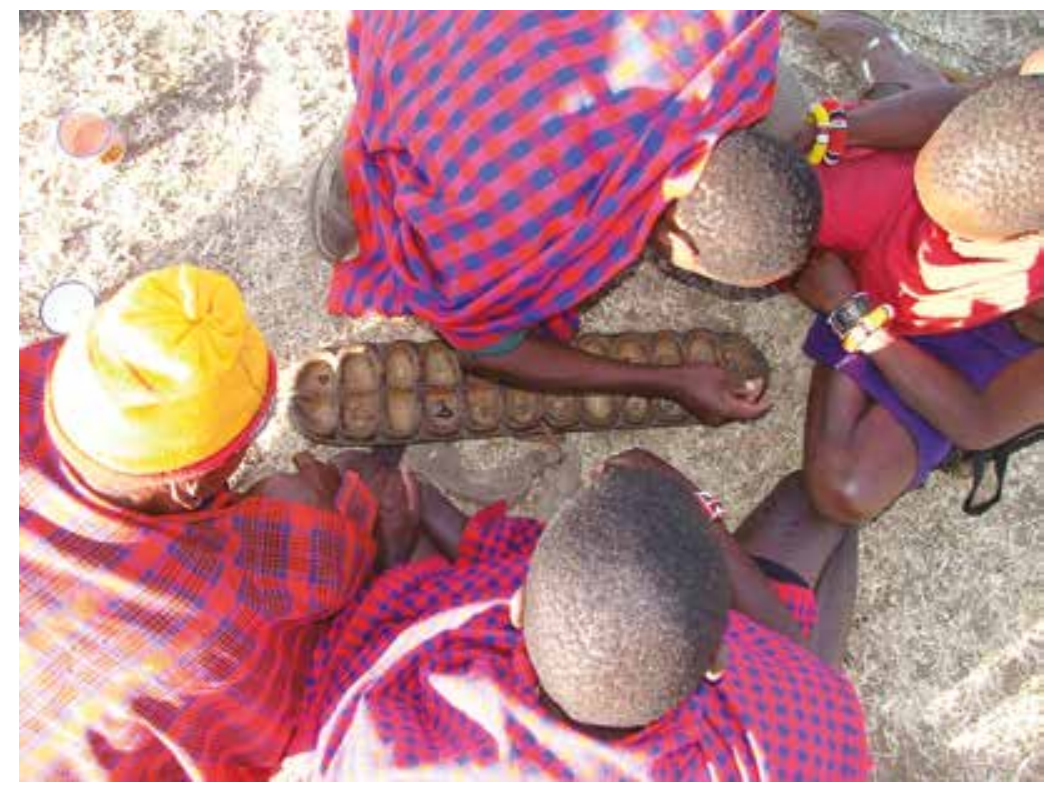

Figure 6.1 Maasai men playing bao on a wooden board at Olenkuluo near Ntuka, Narok County, Kenya (Kyule, M. 2004)

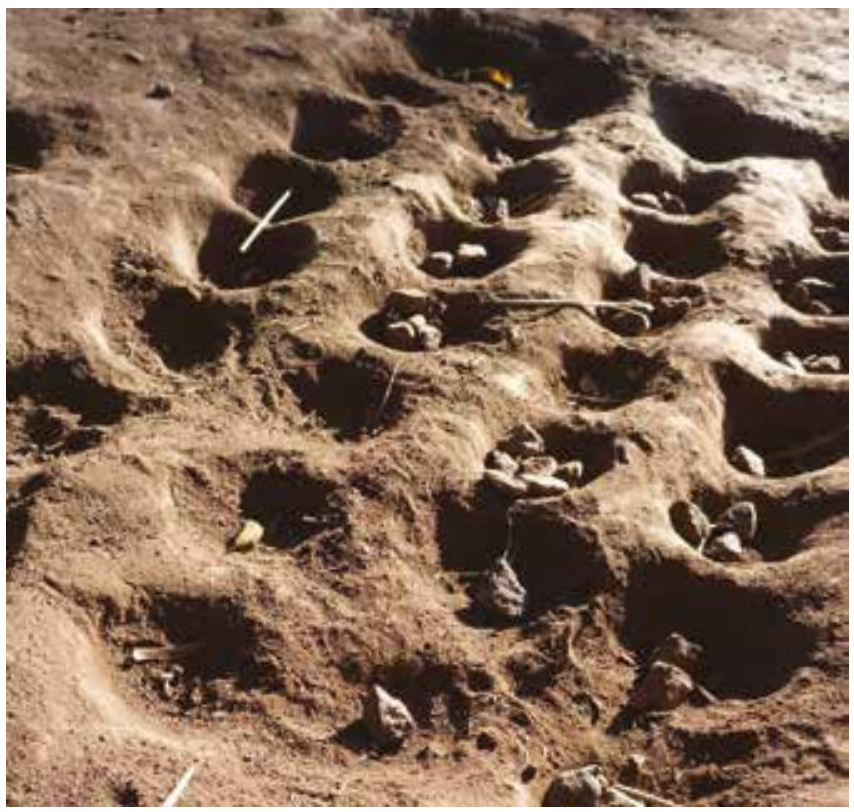

Figure 6.2 Temporary pits scraped by Akamba herd-boys on the ground to make a four-row, 32-pit bao game board platform at Kwethelu Village, Emali, Kenya (Kyule, C. 2013) 


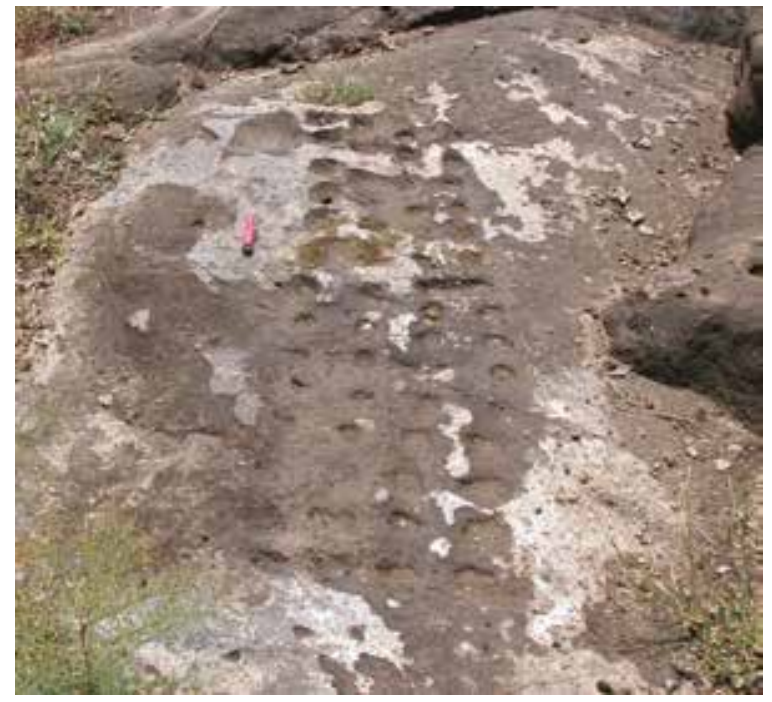

Figure 6.3 A four-row, 60-pit bao board complex on exposed rock surface near Leshota, Narok County, Kenya (Ambrose, S. 2005)

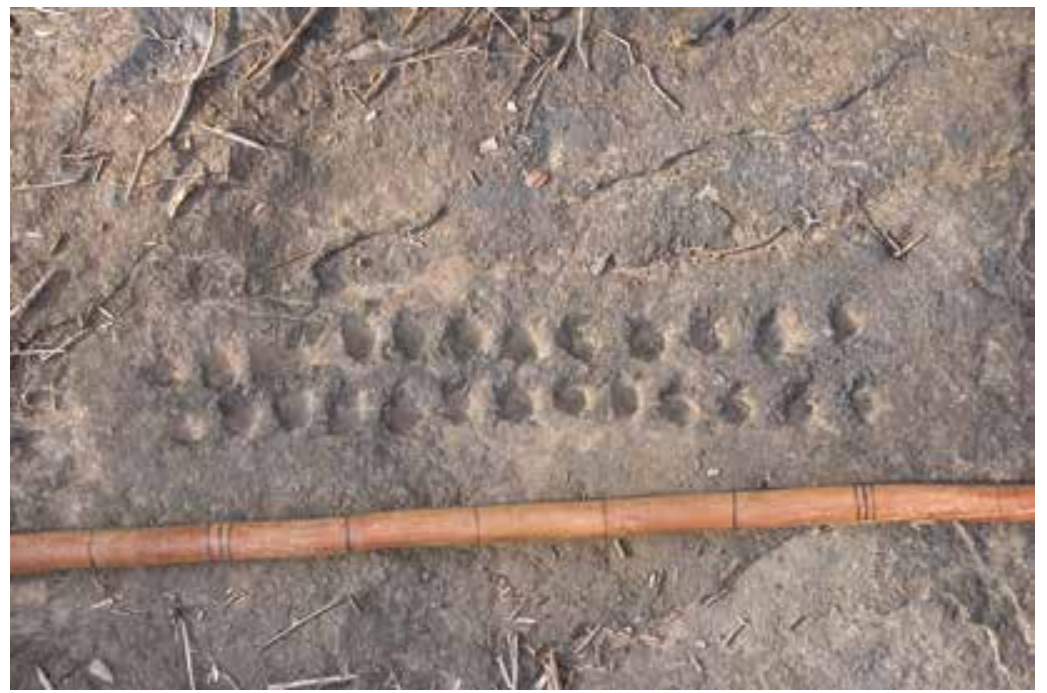

Figure 6.4 A two-row, 26-pit bao board cut into natural rock formations at archaeological site GvJh115, Narok County, Kenya (Ambrose, S. 2005) 


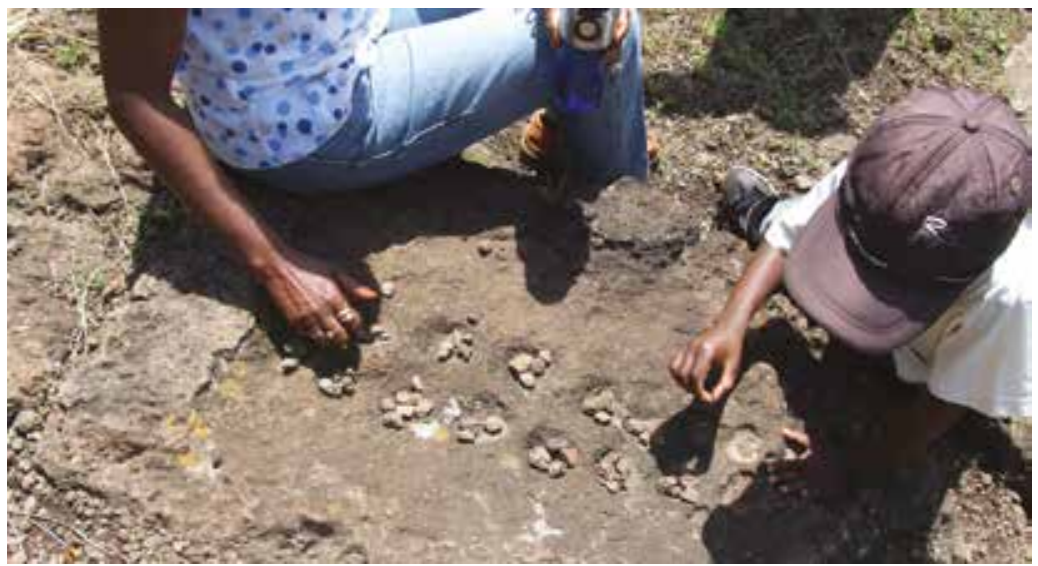

Figure 6.5 A prehistoric bao board curved on natural rock formation at Hyrax Hill archaeological landscapes, Nakuru, Kenya (Kyule, M. 2012)

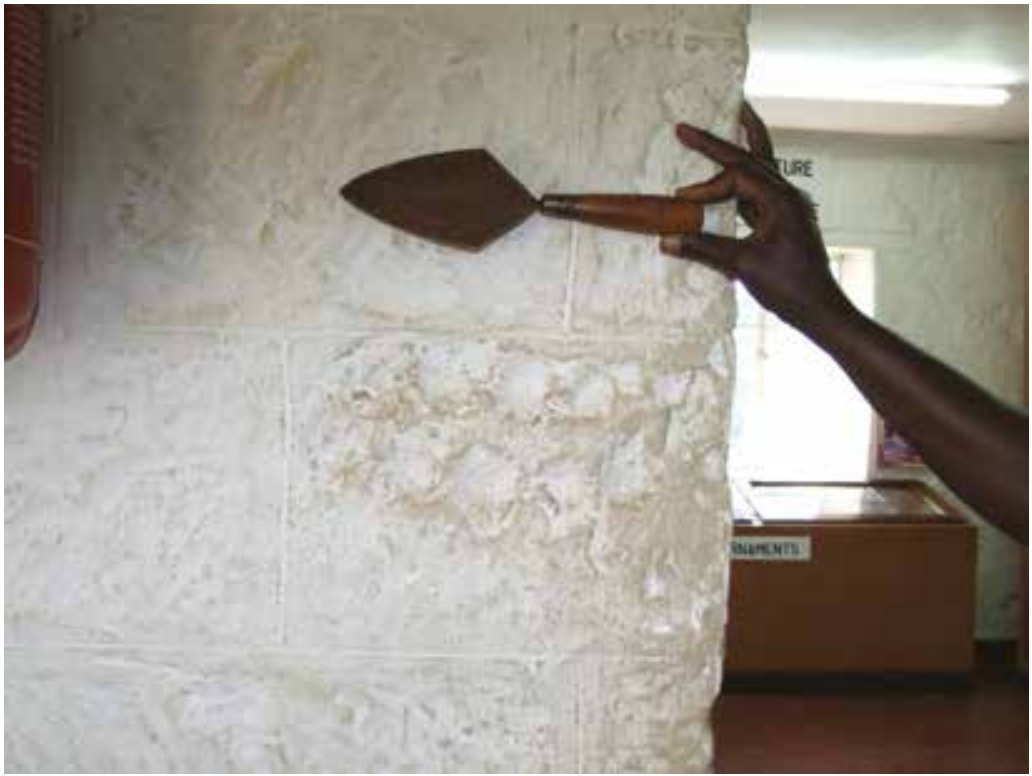

Figure 6.6 Remains of a bao board on one of the blocks used to build the Hyrax Hill site museum on the left side of the door leading to the building's west wing (Kyule, M. 1992) 
and transferred about the pits of the board during play. The pieces should be round and smooth so they are easy to pick up and drop quickly. They should also be nearly identical.

Traditionally, a game is named after the seeds, stones or any other kind of counters that may be found locally. During play, the counters are given other identities, for example, 'men' or 'wives', 'children' or 'cattle'. The pits into which counters fall may be referred to as 'houses', 'villages', the days of the week or the months of the year. The game board itself may symbolize the universe, the village, or a cattle kraal, representing a people's ideas about the cosmos, society or nature.

\section{Playing the bao}

The method, style and rules of many traditional games, including the bao, have been preserved by oral tradition. It is therefore not unusual that there are many ways and rules of playing bao, each dependent on regions and ethnic groups. Nevertheless, playing bao is a competitive, intense, absorbing and enlightening experience. While the rules vary, they all have in common deep strategy and tactical opportunities. The main objective in the game is to capture all the counters from the opponent's rows. This can be achieved by application of complicated moves that end in an empty pit opposite the seeds you want to capture. Upon visiting Zanzibar, and based on the teachings of Zanzibari bao masters, Alex de Voogt compiled a set of rules of the Zanzibari variant of the bao game sometime between 1991 and 1995 (de Voogt 1995). These rules are widely publicized on the Internet.

$B a o$ is not a game of chance and victory is never a function of luck; rather, foresight is the key to winning the bao. It requires considerable calculative strategy and is completely dependent on one's ability to reason and analyze. According to de Voogt (1995), the speed of the game means advanced players must make complicated and highly strategic moves in quick succession, and bao masters are renowned for being able to think tactically up to seven moves ahead. Some winning strategies include cheering fans that distract and rush their player's opponents by shouting at them and telling them to hurry up. A player can also cleverly and within the rules create a collection of pieces that, if used carefully, can make multiple captures at once. Other strategies include anticipation of the opponent's moves.

The orchestration of complicated captures and the capacity to calculate several and multiple elaborate moves ahead are central to the art 
of bao gaming. The development of such skills requires time, patience and the kind of dedication and talent characteristic of chess maestros. This abstract strategy aspect of the bao game may be compared, sometimes, to other row games that have been played in many parts of the world since ancient times. There are existing examples from ancient Egypt, India, Crete, Greece and Rome. In France and Italy such games have been known as linea or tabula, while in Germanic languages they are called mühle, and in England they are called mill games or morris games. 'Mill' or 'morris' may be a linguistic adaptation of the word 'Moor', the name of the Arabic people from North Africa who introduced many of these games into Europe in the middle ages.

Many variations of the bao game exist and, depending on the reasons for any particular game, rules may be adjusted upon agreement amongst the opponents to either shorten or lengthen the game. In one variant played on a two-row by six-row pit board, an opponent plays from the six pits along the bottom of the board and scores stones played into the larger home pit at the right edge of the board. The other opponent plays from the six small pits along the top of the board and scores stones played into the larger home pit at the left edge of the board. In one popular variation among the Maasai of Kenya (Hamilton 1962), play involves scooping the counters from one's pits and then sowing them one per pit around the board. Captures are made in a variety of ways. Since the pieces are common to both players, and constantly rotate around the board alternating both players' positions, it becomes a challenging strategy game. In other variations, the game is commonly played with a predetermined number of identical counters in the form of seeds, stones, cowry shells, small nuts, dung balls and such like. Opponents are required to rotate turns in picking and removing the entire contents of a play pit and sowing the same, one at a time, into successive play pits from their side of the board. Sowing is done counter clockwise, initially into play pits on one's side of the board, then one's own home pit and, finally the opponent's play pits. A player stops when the last piece falls into an empty pit. If the last piece is dispensed off on one's side of the board, the player acquires all counters in the opponent's opposite play pit by moving them across the board into one's own play pit. If the last counter played in a turn lands in one's home pit, then the player gets to play again. Games can take anywhere from 10 to 45 minutes, depending on the players' skills. The game ends when a player is left without counters in his inner row, or when he cannot take a turn. In both cases, this player loses the game. Since the game's goal is to capture the majority of the pieces, the player with the most counters at the end wins. 


\section{A brief history of the study of the bao board games}

Although bao is believed to be the oldest game in the world, scholars still debate its extraordinary antiquity, origins, and distribution throughout the world. Largely based on ignorance of the unique African attributes of the bao and related board games, some scholars (Flacourt 1661; Murray 1952) have erroneously asserted that the game originated in the Middle East and spread from there to Africa before it spread to the rest of Asia with Arab traders. There is, however, sufficient evidence, especially archaeological, to disapprove any notion of origins anywhere other than Africa. By the sixteenth century, the bao had been introduced in the Americas by Africans who were moved there as slaves during the slave trade (Bowdich 1819; Russ 1984).

Strong evidence of the game's antiquity is available in the form of blocks found amongst those used to build Egyptian pyramids and into which pits had been carved to provide playing boards (Sanderman 2002). A limestone board that was discovered in Memphis, Egypt, by the archaeologist Sir Flinders Petrie, is probably the oldest extant example of a bao game board (Petrie 1927). It has three rows of 14 pits and is estimated to be 3,500 years old. Rock cut game boards with two rows dating from around the second to ninth centuries AD have been found in Egypt, Turkey, Ethiopia and Sri Lanka. Four-row boards cut into rocks at various sites in Uganda, Kenya, Tanzania, Namibia and Angola remain undated. Certainly, boards dating back to the sixth century have been found in Zaire, Angola and Ghana. However, it is not certain that all ancient rock cut boards were actually used for playing bao. Some may have been used in fertility or divination rituals, for counting, or even for playing games other than bao.

The earliest written reference to bao is found in the tenth century Arabic text Kitab al Aghani, or 'book of songs', by Abu'l Faraj. Beginning in the sixteenth century, accounts of European visitors to Africa provide numerous allusions as well as accurate descriptions of bao games that attest to its wide geographical distribution. For example, Father Francesco Alvares, a chaplain of the Portuguese Embassy in Abyssinia in the 1520s, mentions a game board he found at the court of Emperor Lebna Dengel, who reigned from 1503 to 1540. In another narrative, Voyages, written by a French explorer, Jean de Thevenot, there is a description of bao being played on a two-row, 12-pit board in the Levant in the 1650s (Thevenot 1976). Thomas Hyde (1694) provides detailed descriptions of bao games played in Mesopotamia and Jerusalem. 
Traces of game boards dating to the fifteenth century have been found during archaeological excavations in Zimbabwe. Numerous bao game boards (Figures 6.3, 6.4 and 6.5) carved on rock surfaces have also been observed and partially studied at or near archaeological sites and landscapes in the central and south Rift Valley regions of Kenya (Kyule 1992, 1997; Kyule et al. 1997; Ambrose 1984a; Ambrose et al. 2007). Some of the earliest accounts of bao in sub-Saharan Africa include those by Richard Jobson (1623) where he reports observing two individuals playing a game on a piece of wood with pits in it and using 30 pebble stones. Etienne de Flacourt (1661) describes bao (fifangha in the local language) in Madagascar in the 1640s, a game that was played on a four-row wooden board containing 32 pits. Eighteenth-century English and French narratives mention bao played by the Wolof, Fulani and Mandinga peoples in the Sahel, as well as by coastal peoples in Ghana (then Gold Coast). Winterbottom (1803) describes k'yungee-bel (game of palm nuts) being played on a 12-pit, boat-shaped board in Sierra Leone, while Bowdich (1819) observed that the game was played among the Ashanti people whose king, Sai Tootuo Quamina, reputedly owned a game board made of gold.

The bao poem 'bao Naligwa' was written in the 1820 s by the Swahili poet Muyaka bin Haji in Mombasa, Kenya. The oldest known surviving wooden bao game board was made in 1896 in Malawi and is kept in the British Museum in London. By the end of the nineteenth century, mention of board games in Africa was common in accounts of European ethnologists and other visitors. The first worldwide perspectives of bao were published in the 1894 Annual Report of the US National Museum, now the Smithsonian Institution.

\section{Boo game boards in East Africa's prehistoric times}

Bao boards carved on rock outcrops have been found in indeterminate associations within or around archaeological sites and landscapes that yield pottery of the Lanet ware (Wandibba 1977; Bower et al. 1977; Bower and Nelson 1978; Ambrose 1984a). Pottery from the Hyrax Hill Sirikwa sites (Leakey 1945; Sutton 1987a; Kyule 1993) and surrounding sites at Deloraine (Sutton 1987b) and Lanet (Posnansky 1967) has been characterized by Sutton (1987a) as forming a central rift regional type, the Sirikwa ware, that falls within a broad range of the spatially extensive and chronologically divergent Lanet ware. Sirikwa ware appears in the archaeological record around the seventh century AD (Bower 
\& Nelson 1978). Related pottery excavated from sites in the Western highlands (Sutton 1973) and at Kabyoyon (Chapman 1966) would, in this order, and by virtue of their later place in chronological terms, form a separate variant of the Lanet ware which is closely allied to the central rift regional type. Other variants of Lanet ware are reported to have been excavated at the sites of Salasun, Nderit Drift, Akira and Seronera (Ambrose 1984a), and the Deloraine Iron Age pre-Sirikwa site (Cohen 1970; Ambrose 1984b).

Matson (1962) reported examples of these Lanet ware allied bao boards from districts that are presently occupied by the Sebei in the Mt. Elgon area and by the Keiyo, Tugen, Nyang'ori and Nandi in the western highlands (Sutton 1973; Jacobs 1969). Hamilton (1962) reports examples that are found beside the Nzoia River near Mumias town, and again at the Nderit region near Lanet in Nakuru. The remains of at least 25 bao board pairs have been exposed below the ground surface at Lanet archaeological site itself (Posnansky 1967) and in contexts which suggest that people of the Sirikwa culture may have made the boards. Sirikwa heritage bao game boards in the Nakuru region also occur at Hyrax Hill while comparable boards are known from the site of Salasun near Mt. Suswa, and the Nasera rock shelter site near Ngorongoro in Tanzania (Ambrose 1984a). Similar boards are reportedly known to exist in large numbers from sites in Uganda (Wayland 1936).

\section{Boo game boards heritage at the Hyrax Hill prehistoric sites in Nakuru, Kenya}

Hyrax Hill measures some 500 metres in a north to south alignment, and rises to a height of about 50 metres from the surrounding grasslands at roughly five kilometres to the north of Lake Nakuru, Kenya. Archaeological research interests at Hyrax Hill spanning the past 70 years have seen work undertaken on some of the sites, which has led to the accumulation of data and documentation of the results (Leakey 1945; Onyango-Abuje 1977; Sutton 1987a; Kyule 1992; Kyule 1997). During the 1937-8 excavations, M.D. Leakey assigned letters (A, B, C, etc.) to the Sirikwa features that she excavated at Hyrax Hill (Leakey 1945). The system has been followed ever since, and excavated hollows and mounds have, over the years, acquired the letters A to K.

Owing to its prehistoric importance, Hyrax Hill is a gazetted national monument with several excavated sites on public display and 
a site museum exhibiting material from Hyrax Hill itself and other sites in the central Rift Valley (Merrick 1983; Kyule 1993). Neolithic, Iron Age Sirikwa culture sites, a 'fort' and at least six bao game boards of unknown antiquity are found on different parts of the hill (Figures 6.5 and 6.6). They can be described as rock pecked, cup-like pits in two rows and are found on the lower portions of the hill. One other board can be seen on the east of a foot path that leads from the Hyrax Hill Museum building toward the Kenya Industrial Training Institute (about 750 metres from Hyrax Hill).

The bao boards, like the 'Hill Fort', have been associated indeterminately with either the Sirikwa culture phase or the Site I Iron Age culture phase on the Hill (Merrick 1983; Sutton 1987a). The occurrence of culturally modified prehistoric cattle ribs and the presence of bao game boards on rocks within and/or around the Hyrax Hill site may be an additional characteristic of Sirikwa heritage.

All the bao boards so far found on Hyrax Hill have been on the surface and all seem to be located in very strategic positions which command good views of the surrounding region. The bao boards differ in many structural aspects and seem to share only the characteristic of having two rows. Variations are present in the number and size of the pits in each row while some row alignments may sometimes be straight as others are curved or bent. One of the boards has been exposed for public exhibition on the north eastern part of the hill, a few metres from the site museum (Figure 6.5). One other bao board can be seen in one of the blocks used to build the site museum on the left side of the door leading to the building's west wing (Figure 6.6). Two other sites were shown to this author in 1991 by the then site curator, Mr Muli Mulwa, while the author located two more during the 1991 archaeological surface surveys on the hill. Comparable bao boards were reported below ground surface by Merrick and Posnansky during their excavations at the nearby late Iron Age site of Lanet (Posnansky 1967), and in association with Sirikwa culture archaeological material.

\section{Cultural aspects of the bao game in traditional African societies}

The bao game is ordinarily an outdoor, daytime entertainment activity to be enjoyed after the day's work is done. However, nocturnal games are played for other purposes; for example during funerary rites, bao is played more to placate the departed rather than amuse the living. 
According to Maasai elders in the Enaramatishoreki area along the Uaso Nyiro River in Narok County of Kenya, bao was traditionally a game for adult males, particularly elders (interview with this author, July 2004). Men played in public, but never with or before women or children. However, women and children were often allowed to play a simplified version of the game. This is believed to have been so as to preserve masculine authority. Conversely, both men and women among the Ashanti in Ghana are known to have played owari together, while Yoruba women have been observed to watch as men play ayo. It is also common to find various art objects depicting owari on ceremonial tools belonging to chiefs and on staffs carried by agents of the royalty.

In some societies, bao was historically used in the political sphere, especially for the purpose of selecting a new ruler. In Ivory Coast, for example, awele was played upon the death of an Alladin chief by rival potential successors all night and the winner would be announced as the new chief the following morning. This nocturnal playing has also been interpreted to imply that humans play only during the day while divinities, ancestors, and future rulers who are part of the supernatural world play throughout the night. Kingship rituals of the baGanda and the baKuba required a newly enthroned king to play mweso and lyeel respectively. The finesse of a new ruler's game and winnings was believed to reflect his intelligence, maturity and character, and confirmed whether he enjoyed divine approval.

Among the Lega (North Eastern Democratic Republic of Congo (DRC) Zaire) a miniature luzolo game board was shown to male initiates while proverbs associated with the game admonished them to respect their elders and honour the values of their people. Girls among the Fon of Benin play adji in coming of age rituals. The playing of a man's game by these women is symbolic of their new adult status.

\section{The boo in contemporary society}

Today, bao board games are played by children in rural African villages on temporary scraped pits on the ground (Figure 6.2) in the midst of activities and chores such as herding, collecting fire wood and fetching water in rivers. bao games are also played by young adults in tea kiosks and beer dens in rural areas and urban slums. It is also common to find bao boards placed in the sitting rooms of middle class homes in urban centers across sub-Saharan Africa. In Kenya, authentic bao game sets, mostly carved out of rare indigenous woods and Kisii soapstone, can be found in tourist and safari shops. These are largely designed with the 
foreign tourist customer in mind and usually make very good souvenir purchases.

In Tanzania, the Chama cha Michezo ya Jadi cha Dar es Salaam (CHAMIJADA), an association whose primary objective is to revive traditional and indigenous sports, played a major role in rekindling interest in bao as a tournament game. In 1966, the Chama cha Bao (Bao Society) was formed in Tanzania to promote the game of bao, and in 2010, their secretary Monday Likwepa formed Shirikisho la Mchezo wa bao Tanzania (SHIMBATA) to organize international bao tournaments. In the recent past, there have been annual official bao tournaments held in Lamu, Zanzibar, mainland Tanzania and Malawi, overseen by the Chama cha Bao. Indeed, bao tournaments are now an integral part of the Maulidi, the annual Lamu Cultural Festival (personal observation). Regular championships are held in other towns and cities in East Africa. Ghana is also expected to begin annual tournaments in the near future.

The advent of Information and Computing Technologies (ICT), and especially the Internet Revolution of the 1990s, has had significant impacts on the nature and functions of the bao game. Different versions and styles of the bao game have been programmed into computer applications and software and are available from the Internet. These can be downloaded to personal computers while other types can be played online with opponents from across the globe. Many smartphones are now sold with variants of the bao game as part of the package added advantage.

The potential of the bao as an educational tool for children has captured the interest of academic authorities and educationists have not been oblivious of the educational value of the game. This realization has roused calls for education strategists to utilize the bao in schools as well as its incorporation while developing school curriculum. It is also encouraging that global museums are increasingly exhibiting bao in addition to organizing awareness, competitions and workshops on their premises. Parents who are aware of the benefits of the bao in helping children to practise counting and arithmetic are keen to invest in budget bao game sets that are now readily available in toy and game shops, especially in Europe, Korea, Japan, China, India and America.

$B a o$ has also gained tremendous ground and acceptance globally, especially in Europe where it was first promoted by the British ethnologist, Philip Townshend in the 1970s (Townshend 1986), then by the Dutch psychologist Alexander Johan de Voogt who attempted, in his $\mathrm{PhD}$ dissertation (de Voogt 1995), to characterize bao mastership. Nino Vessella, an Italian Esperantist, started Klubo Internacia de 
bao-Amantoj (KIBA) in 2007 to promote bao in Europe. The Netherlands Baogenootschap (NBG) was started in 2009 for the same purpose. There are annual international tournaments in Europe, culminating into the European Championship. A National Schools Tournament is held every year in the United Kingdom. The last decade has also witnessed tournaments organized in the Caribbean (Antigua), in England (Cambridge), Italy (Rome, Senigallia, Turin) and the Netherlands (Berg en Dal, The Hague, Leiden, Nijmegen, Wageningen). Strong players also live in Switzerland. An international tournament was held in La Tour de Peilz in November 2012.

\section{Sustainability and conservation}

While oral traditions have played a significant role in the preservation of the method, style and rules of many traditional games, there is now an urgent need to complement oral traditions with concerted research efforts to document all aspects of the bao before society loses the custodial function of oral traditions to the dynamics of modern living. These dynamics require the identification of value of the bao, as well as its continued relevance in people's modern economics, politics, culture and society. In this respect, there are viable opportunities in the incorporation of bao in school curriculum as a teaching tool in early childhood development and education. And just like chess or football, there is need to recognize the sporting value of the bao in skills development, social cohesion, competitive spirit, as well as mundane functions such as the game's role in conflict resolution, and as a past time and a leisure activity. These opportunities are now possible with not only the traditional board, but also with the use of modern technology such as computers and smartphones.

Additional prospects are available in the development of new approaches that incorporate bao board games in mainstream community development planning, policies and programmes. The initiatives started by organizations such as the Chama cha Michezo ya Jadi cha Dar es Salaam and the Chama cha Bao, among others, are here viewed as supplementary and alternative approaches to the historical function of oral traditions in the preservation, development and conservation of the bao. As part of corporate responsibility, businesses can be encouraged to sponsor bao board game national tournaments and scheduled events such as the Maulidi. These tournaments and scheduled events can be mainstreamed into the national calendar of sporting events. 


\section{Conclusion}

There is no contention that the bao, together with its sister variants in the family of mankala board games, represents some of the earliest African manifestations of strategy gaming. The bao game is, without a doubt, at the upper limit of complexity that humans can master. The games are known by different names in different areas and regions and are played by literally hundreds of ethnic groups throughout Africa. The bao game is a wholly mathematical game that symbolizes multidisciplinary brainpower and real-world know-how. It requires great mental dexterity, concentration, counting, anticipation and planning. Bao, despite its primitive origins, is a contemplative game of strategy like chess, but played with great speed, while at the same time demanding both mental and physical agility. The game is based on counting and calculation and therefore involves no element of chance.

From vague beginnings as an ancient African pastime, the timeless traditional bao has managed to evolve to modern times and is definitely one among many of the significant African contributions to global culture. The establishment and confirmation of the game's African origins and antiquity, and eventual evolution through time to the present, reveals undeniable early and continuing African active and fascinating participation, in situ, creative global cultural origins and flows.

The emerging trends in museum exhibitions, as well as the positive momentum of popularity of the bao board games across Africa, Europe and the rest of the world, is good for the conservation of the bao. 


\section{Traditional technologies: a conservation challenge}

Freda M'Mbogori

\section{Introduction}

Conservation of tangible and intangible cultural heritage in Kenya is largely dependent on the practitioner's willingness to embrace incoming practices. To a large extent, adoption of new practices and the subsequent discarding of traditional ways lessen the further one moves away from urban areas. Most rural areas have maintained and continued to perform some of their traditional cultural practices with minimum interference. However, with the introduction of formal education and Christianity, several cultural practices are being abandoned due to the perception that they are 'ungodly' or transmission from the bearers to the next generation is unachievable for various other reasons. Some of the most affected cultural practices are traditional technologies. Traditional technologies do not only include the techniques of making an end product, but they also depend on supernatural powers for their success. The technological processes are governed by rules and regulations, as well as rituals and sacrifices which form an integral part of the overall production. In addition, remedial practices exist, to appease the powers that may be, for anyone who might break the rules knowingly or unknowingly. Also, given the inherently dynamic nature of technology, conservation of traditional technologies remains threatened because they tend to become obsolete. Traditional technologies also have a perceived lack of value-added for the end products; depressing market demand, hence making the practice unattractive to the practitioners. Conservation and subsequent revival of traditional technologies remain a big challenge to the conservator as both the techniques and the products are intertwined 
and, therefore, attention must be paid to both the intangible (technological skill and supernatural beliefs) and the tangible (the end product).

Conservation is only achievable through safeguarding of the craft and ensuring the continuity of its production. This chapter concerns itself with traditional pottery making as one of the technologies that are quite specialized yet have lost their appeal among several traditional societies due to cultural, economic and social factors. It further underscores the multiple benefits of conserving traditional technologies and suggests possible ways of transmitting and safeguarding them for posterity. The chapter uses examples from two ethnolinguistic groups (Bantu and Cushitic speakers) in Kenya to illustrate the rigorous technical skills that must be learnt, and some of the sociocultural values that are involved in pottery making.

\section{Traditional technologies in Kenya and their current state of conservation}

Traditional technologies in Kenya include pottery making, iron smelting, carving, leather working, bead working, weaving and traditional architecture. These practices existed before the colonial period and some have continued to evolve, while others are on the verge of extinction in some of the traditional societies. Among the technologies that have become extinct one counts iron smelting and traditional leather working, while pottery making and traditional architecture are quickly being replaced by exotic technologies.

Although traditional knowledge is essential for the above-mentioned technologies, artisans can manipulate their traditional skills to cope with modern demands and to remain relevant. This is possible where the technology is not socially embedded and the production processes are not considered delicate and hazardous since they do not involve transformation of the raw material from one state to another through firing. These would include carving, bead working, weaving and traditional architecture. These technologies do not require craft specialization and the knowledge is not passed through kinship. Any interested member of a traditional society can learn the skills and practise them as they wish. Therefore, several traditional products that rely on skill which is not specific to individuals or particular communities are still in production, though not in their pure traditional forms and with a high degree of modifications to suit the changing market demands and cultural dynamics. 
On the other hand, transformation of clay and iron ore into end products is a dangerous endeavour that is full of risks and could fail at any point since these processes require a high degree of specialization and several years of practice. As such, these processes always demand that the artisan invokes the intervention of supernatural powers through rituals and sacrifices as forms of prayer in order to have a successful production. Besides the dangers involved in the sourcing of the raw materials and in the eventual production processes, the skills are inherited and passed on from generation to generation through kinship. In the case of pottery making, learning begins at the age of about seven years, and the artisans can sell their first pots as teenagers. As such, due to the rigorous training and repetitive nature of production stages, the processes become motor skills which are not easily replaceable. Artisan trainees must belong to particular families whose economic occupation has always been pottery making or iron smelting, as the case may be. These families are feared or revered in some societies, while in others they are feared and reviled, as shown later in this chapter.

Therefore, to conserve traditional pottery making and iron smelting technologies, one must deal with both intangible (technical skills and supernatural requirements) and tangible (end product) aspects. As such, conservation of these two technologies is made difficult by the hectic nature of the processes involved and the modern disregard of traditional beliefs due to Christianization and formal education. Currently, in many Kenyan societies, traditional pottery making has completely stopped and clay objects have been replaced by plastic and metal. Similarly, the rituals and sacrifices to the supernatural are no longer relevant and anybody in the society can engage in the craft. It is, therefore, apparent that this part of the intangible heritage has already disappeared and that the traditional skills and technical processes may soon be totally replaced by incoming exotic technologies.

\section{Effects of Christianity and Western education on traditional technologies}

Loss of interest and subsequent demise of traditional technologies is attributable to several factors among which Christianity and Western education have played a major role. These factors include labour intensiveness, low market prices, poor marketing strategies, competition from metal and plastic products, and rapid shift from traditional cultural values to embracement of Western values. The latter has seen eligible youth 
apprentices move to urban areas in search of jobs and tutors abandon their crafts.

The success of traditional industries, as seen in the preceding section, is not only a function of technical skills but is also dependent on the good moods of the beings in the immaterial world. Mazama (2002) points out that, in the African context, people did not conceive of themselves as separated from the cosmos, but as beings completely integrated into a universe that is much larger than any of them and yet centred around them. The African people therefore believed in the continuity of life and the inter-connectivity between the unborn, the living and the dead (Donohungh 1935; Mbiti 1990). As such, it was mandatory that the ancestral spirits are appeased through rituals and sacrifices during each stage of traditional crafts which were considered delicate and dangerous, lest breakages or poor yield occur. Sindima (1990) notes that this mythical life of the African world, which provided for the existence of spirits and practice of sacrifices, was what liberal Christianity rejected as merely superstitious; the very thing that rationalism had struggled with in the sixteenth century and after. These values of African spirituality were thus demonized and Malinowski (1943) observes that the level of African life could be raised up to that of a European gentleman by exorcisms and exhortations. He further explains that the exorcisms which were meant to 'free' the African from his fear of sorcery and supernatural terrors were directed against witchcraft, polygamy, tribal warfare, cannibalism and going around naked, among other 'evils'.

In essence, the doctrine of Christianity was used as a vehicle through which the African world view of the supernatural could be changed. The missionaries taught Africans not to believe in their ancestors, but instead believe in the Trinity and in the Gospels. Moreover, the missionaries not only introduced the Christian doctrine, but also Western education. The word 'missionary' just like 'preacher' (today) was the same as that of teacher.

After the suppression of the traditional industries, the educated took the roles of clerks and teachers and thus, the Africans reinterpreted schools and Christianity to mean non-manual employment, modernity and progress (Coe 2002; Obiakor 2004). While the learners were the willing recipients, the chiefs only welcomed acquisition of skills without the Western religion. However, Ruther (2004) argues that contrary to the chiefs' desires, the missionaries defined literacy as a subordinate instrument employable only for the attainment of religious goals. This led to rapid acquisition of literacy and Christian values in societies since missionaries were seen as agents or bearers of civilization. Consequently, in 
place of industry and dignity of labour, young people were taught to look down on traditional industries or manual labour, and more value was given to white-collar jobs (Sindima, 1990). This paradigm shift resulted in profound negative effects on African spirituality and organization of labour.

In order to achieve the above results, the structure of Western education involved introduction of a school curriculum which was taught in a classroom setting and was formulated, fashioned and relished with western cultural ideals and values. Very little reference was made to indigenous African social and physical ecology or to African cultural values and ideals (Onwauch 1966). Contrary to the Western mode of education, the African societies educated their children through ongoing processes of life. Through certain religious rituals and practices, communal attainment of spiritual ideas was established. This way, children acquired the techniques of communication, making a living as well as acquiring the means of creative expressions within the culture (Onwauch, 1966). Likewise, teaching was carried on informally by family, by the play group, through initiation ceremonies and by apprenticeship, which was given by any professional group into which the individual was adopted (Malinowski 1943; Omolewa 2007). For example, in the case of pottery making, several recent studies have shown that, where the craft is still in practice, the learning is done at home and it occurs during childhood, and the learner acquires the skills through theory and practice (Arnold 1989; Crown 2000; Roux 2007). Due to consistent repetition of the steps involved over several years, the craft becomes a motor skill, and should the learner make any inventions during apprenticeship, it would only involve operations like decoration of vessels rather than invention of new forming skills (Roux 2011, citing Herbich 1997).

Currently, due to the classroom format of Western education, which has become totally entrenched in every African society, children are no longer available for apprenticeship. For instance in Kenya, a child's day begins at five in the morning when they must prepare and get ready to be in school by seven, they go through the classroom curriculum with two short breaks (a morning tea break and a lunch break, each lasting between half-an-hour and one hour) and go home after four in the afternoon. When they leave school, they bring with them school assignments which they must complete and present to the teachers the following day. This kind of curriculum does not leave any room for children to learn from their parents, hence making it impossible for older people to pass on their skills. Besides the adoption of Christian values 
and the tedious demands and competitive nature of Western education, the subjects that are taught in schools are not in favour of traditional values. African spiritual values, which are not provable by modern science in a laboratory, are trivialized and treated as ignorance and stupidity. Even today, most Christian churches frown upon African cultural expressions, as was observed by Tillotson (2010). As such, the African child is socialized to be ashamed of these values and to reject them. As a result, the traditional technologies such as pottery making, which depend on the supernatural, are now left in the hands of the elderly. Consequently, master potters have no one to pass the skills to, leaving the craft without successors (M'Mbogori 2006).

\section{Traditional technology: a case study of pottery making}

Unlike many other traditional technologies, pottery making remains the most accurate record of a community's identity both in the historical and archaeological record. Gosselain (2000) points out that pottery making technique is characterized by a greater stability through time and space, and hence has a tendency to reflect those most deeply rooted and enduring facets of identity. Until recently, the intangible value of pottery technology was poorly understood by scholars and, therefore, no concerted efforts have been directed towards conserving it. Without proper understanding of its cultural dynamics, conservation efforts would be futile, as indicated by efforts of the governmental and non-governmental organizations in Kenya who tried without success to improve pottery making processes by providing potters' wheels (Langenkamp 2000). The potters rejected the wheel although it is more efficient, less tedious and timesaving, because the traditional pottery making skills form a big part of a society's identity and hence they are difficult to replace (Arnold 1989; Stark 1998; Gosselain 2000; Livingstone-Smith 2000).

Further, technological studies have shown that each stage of the manufacturing process varies according to social groups. Depending on the level of interactions between communities, different ethnic groups may share pottery-making attributes. For example, Gosselain (2000) suggests that interactions may occur where clay sources are frequented by different potters and visible attributes on finished products such as pottery forms and decorations may be shared by unbounded individuals. He further observes that distinct communities in Africa may fire their pots in similar ways because this is done in the open and people can 
learn from watching. However, forming techniques can only be shared by bounded individuals (Gosselain 1998, 2000; Roux 2011) hence pottery can be used to inform on inter-community history of interactions and relationships.

Similarly, the social aspects of a community are also reflected in pottery making processes and tools. Pottery making aspects are dynamic and flexible, as seen in the adaptability of certain tools, postures, pottery styles, and other social factors, because the craft does not exist independent of other practices and value systems. Potters may adapt tools which are used for other purposes or even make pottery forms based on market demand (Dietler \& Herbich 1998; Gosselain 2010; Wynne-Jones \& Mapunda 2008).

To put the conservation issues into perspective and to demonstrate the intangible and tangible attributes of pottery making technology, the section below discusses the social and technical aspects of the craft using case studies from the Cushitic and Bantu speakers. The choice of varied ethnolinguistic groups is to validate that the pottery making issues are similar despite the differences in ethnic background. The Cushitic speakers are represented by the Somali of Garissa County and the Bantu speakers are represented by the Coastal potters from Kwale, Kilifi and Mombasa counties, respectively. The data presented below was collected by the author between 2009 and 2010 .

\section{Pottery making technology of the Cushitic speakers}

Ethnographic pottery making technology was observed and recorded from the Jareer, a Cushitic-speaking community of Garissa County in the North Eastern part of Kenya about 380 kilometres away from Nairobi (Figure 7.1).

The Jareer potters live in villages within Garissa town, among pastoral Somali clans, whose major economic activity is rearing of domestic animals. For the Jareer, pottery making is a major economic activity since they do not own domestic animals and the area is too dry to practise meaningful farming activities.

Besides, they do not own land because they are refugees or descendants of refugees who first migrated to Mandera (Somali/Kenya border) and later to Garissa, where they have lived since the 1980s. Some, however, own a minimum number of goats and sheep and farm on a very small scale on the floodplains of the Tana River. 


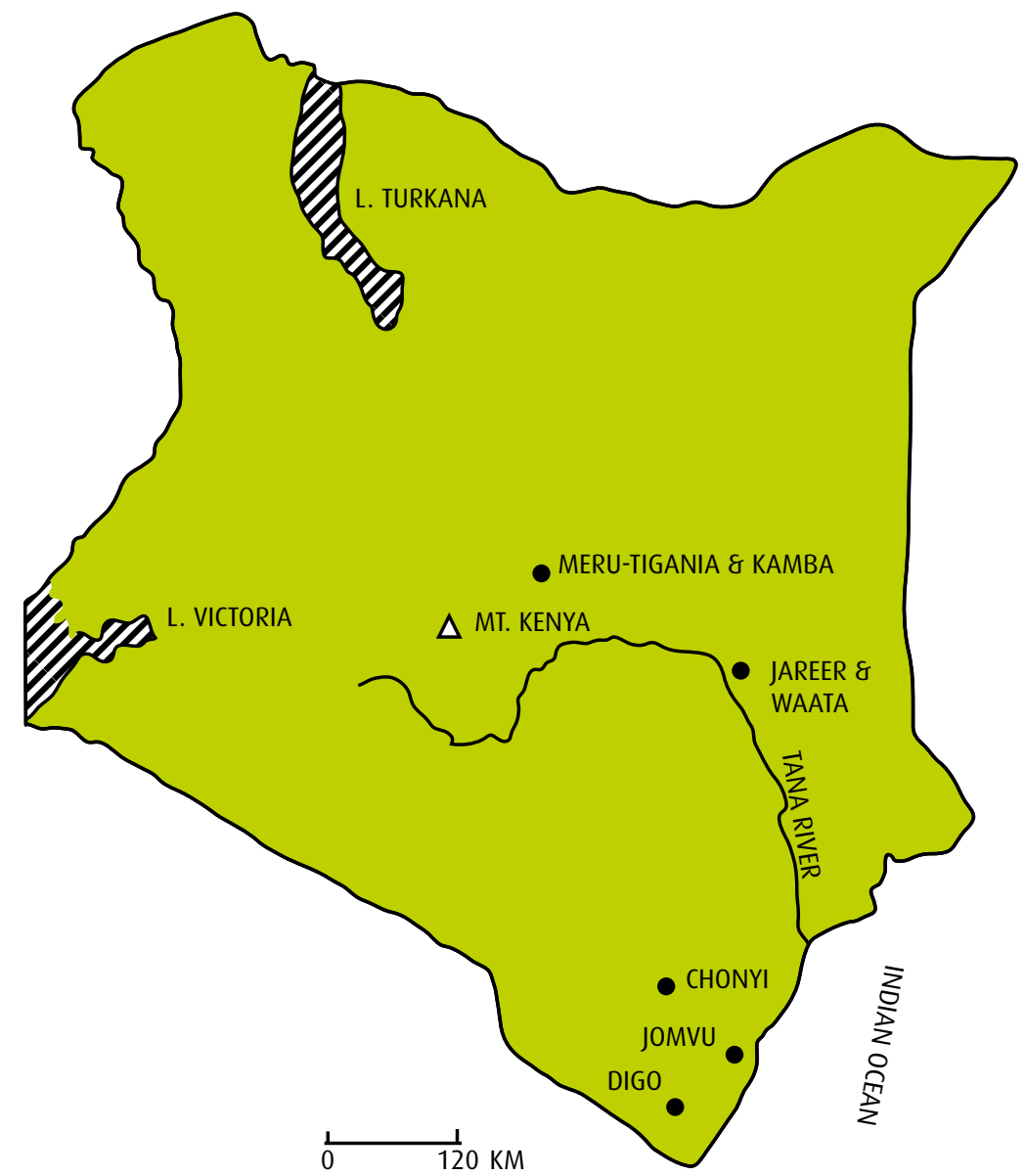

Figure 7.1 Locations of the interviewed potters (M'Mbogori 2015)

Acquisition of pottery making skills is by choice and male members of the Jareer families can choose to be or not to be potters. The interviewed potters within Garissa were males of between 30 and 60 years old. Two were brothers living a kilometre apart while the others did not claim any relationship. They asserted that potting is a very specialized job, which can only be practiced by men. Some of the reasons given why women cannot make pots were that they do not have the ability to sit the way men do when potting or that they are not trainable (no explanation was given as to why they are not trainable). They also pointed out that women do not need to acquire the skills of pottery making since the man is the sole breadwinner and in the unfortunate event of his death, the woman would remarry. 
All the potters, except one, maintained that they were taught the craft by their fathers. They asserted that their grandfathers taught their fathers and that the craft has been practised in the family through generations. However, one of the potters pointed out that he learnt from a potter who used to practise some 11 kilometres away from his home. He was curious about the craft and this made him want to learn, which he did by visiting his tutor every day after school.

The potters started to learn the craft at around age seven, when they watched and imitated their tutors. They practised by playing with clay and trying to reproduce what their tutors were making. During these times, they were instructed on posture, how to fix the coils and shape the pots. Meanwhile, they assisted their tutors with fetching of water, clay collection, kneading and firing, which gave them first-hand experience of the practices. On average, it took them up to age 15 or 18 to sell their first pots after rigorously engaging in all the technical processes, and first producing small vessels before being able to make large ones. Among the Somali clans, only the Jareer make pots. Pottery making is despised and the practitioners are looked down upon.

The Jareer potters make a variety of pottery with different forms and sizes depending on the function. The commonly made pots are water pots, cooking pots and incense burners (Figure 7.2).

To make a pot of any kind, a Jareer potter follows the sequence of steps shown in Figure 7.3, without any modifications or omissions.

In addition to following the technical steps, pottery-making among the Cushitic speakers is associated with supernatural forces. The success of the craft is dependent upon the good mood of the beings in the immaterial world. These spirits (devils, demons or ancestors, as different

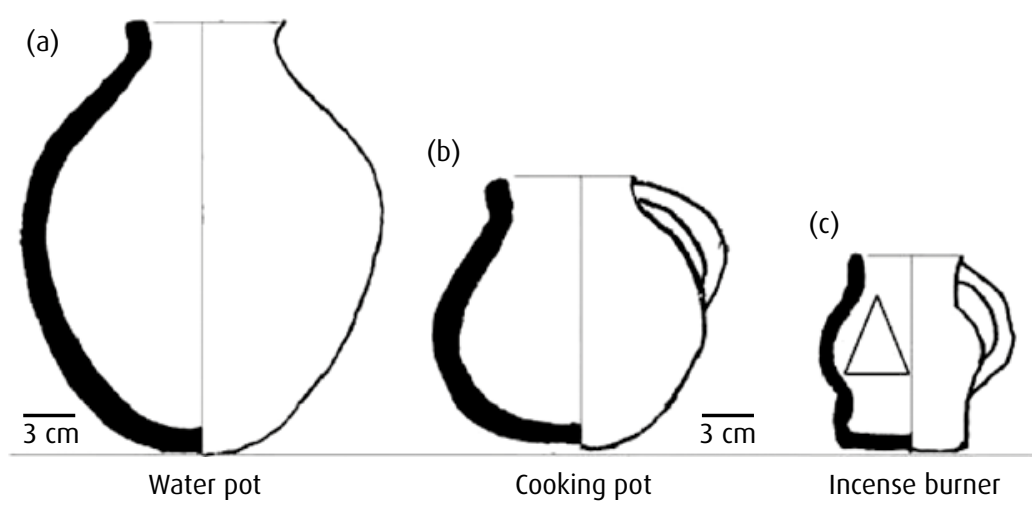

Figure 7.2 Pottery forms of Jareer (M'Mbogori 2015) 


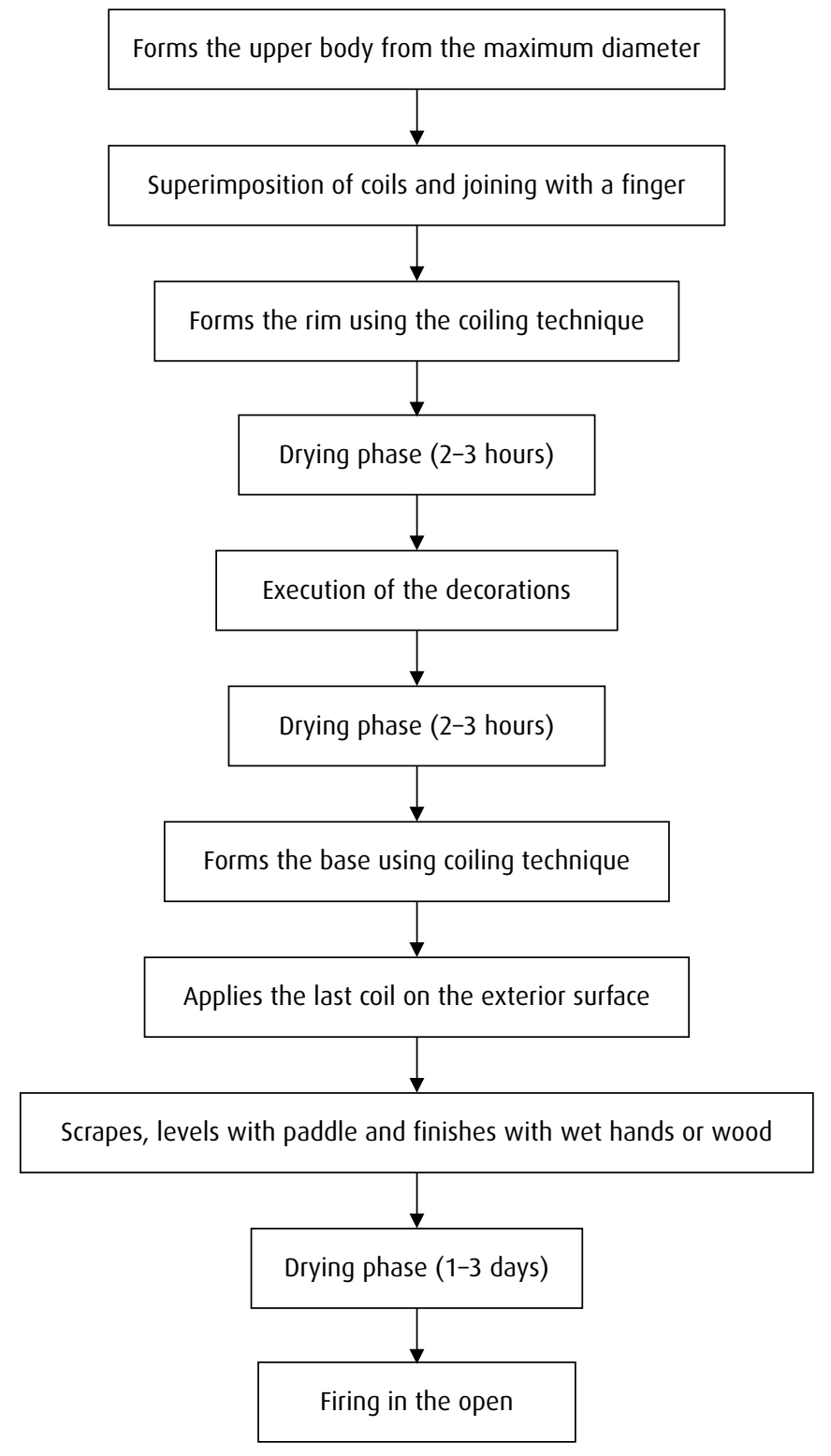

Figure 7.3 Pottery making chaîne opératoire of the Cushitic speakers (M’Mbogori 2015) 
artisans would refer to them) must be appeased during different stages of the chaîne opératoire (Table 7.1). Among the Jareer, the Eleye clan elders perform the initial ceremonies. They sacrifice a goat and perform special prayers to the spirits on behalf of the artisan. One of the Jareer potters pointed out that before he went for these prayers he was not able to make more than two pots in a day but after, he was able to make more than ten each day.

Table 7.1 Forbidden acts in Cushitic pottery making (M'Mbogori 2015)

\begin{tabular}{|c|c|c|}
\hline Forbidden acts & Consequences & Remedy \\
\hline $\begin{array}{l}\text { Stepping on the clay in } \\
\text { the potting area. }\end{array}$ & $\begin{array}{l}\text { This would cause the } \\
\text { clay not to produce pots, } \\
\text { such that they break } \\
\text { during firing. }\end{array}$ & $\begin{array}{l}\text { The artisan must } \\
\text { gather other artisans } \\
\text { and elders, slaughter } \\
\text { a goat and pour the } \\
\text { blood on the clay } \\
\text { source to appease the } \\
\text { offended spirits. }\end{array}$ \\
\hline $\begin{array}{l}\text { Potting while unclean. } \\
\text { No one is allowed to do } \\
\text { potting if he has had } \\
\text { intercourse and has not } \\
\text { bathed. }\end{array}$ & $\begin{array}{l}\text { This would provoke the } \\
\text { wrath of the spirits and } \\
\text { cause pots to break. }\end{array}$ & Goat sacrifice. \\
\hline $\begin{array}{l}\text { Looking inside the pot } \\
\text { during the forming of } \\
\text { the pot; apart from the } \\
\text { potter no other individ- } \\
\text { ual is allowed to look } \\
\text { inside the pot until it is } \\
\text { completed. }\end{array}$ & $\begin{array}{l}\text { The pot cracks during the } \\
\text { forming stage. }\end{array}$ & $\begin{array}{l}\text { Not known (potter did } \\
\text { not explain). }\end{array}$ \\
\hline $\begin{array}{l}\text { Potting when there is a } \\
\text { death in the family. }\end{array}$ & $\begin{array}{l}\text { Spirits will not allow the } \\
\text { potter to pot. Pots will } \\
\text { keep collapsing as a way } \\
\text { of communicating with } \\
\text { him. }\end{array}$ & $\begin{array}{l}\text { Potting must stop for } \\
\text { one month. }\end{array}$ \\
\hline $\begin{array}{l}\text { Other spiritually related } \\
\text { failures. Selling prob- } \\
\text { lems. Breaking pots. }\end{array}$ & $\begin{array}{l}\text { If the pots take a long } \\
\text { time to sell, then the } \\
\text { artisan realizes that the } \\
\text { spirits are not happy. } \\
\text { If the pots keep break- } \\
\text { ing during the forming } \\
\text { process or firing, it is a } \\
\text { sign of unhappy spirits. }\end{array}$ & $\begin{array}{l}\text { The potter takes } \\
\text { one pot by the rim } \\
\text { and smashes it as a } \\
\text { form of sacrifice. The } \\
\text { potter must sacrifice } \\
\text { a chicken at the clay } \\
\text { source. }\end{array}$ \\
\hline
\end{tabular}


A narrative is given of how the pots of the pioneer artisans kept breaking and they had to sacrifice a girl by the name Rahma. The soil from which her blood poured was always sprinkled on the pots during firing and her name chanted; this is the only way the firing could succeed (M'Mbogori 2011).

\section{Pottery making among the Coastal Bantu speakers}

The Coastal potters comprised two from Digo, four from Chonyi and two from Jomvu ethnic groups. The Digo live in Kwale County, the Chonyi in Kilifi County and the Jomvu in Mombasa (Figure 7.1).

The Digo do not make pots actively any more. They make them only occasionally for domestic use, such that we had to be directed to one elderly woman of about 80 years of age, who staged the craft for us. She is a well-respected potter who has passed the skills to her youngest daughter who was about 50 years of age at the time of the interview. We interviewed and recorded pottery making procedures from both the mother and daughter.

According to the elderly potter, she had stopped making pots in 2006 (three years before the interview) due to her age and not because the pots were not fetching enough money. On the other hand, her daughter, who is an elementary school teacher, has never engaged in full-time pottery making, but she has always potted as a part-time job. She stated that pots do not fetch much and, therefore, she would rather engage in other activities like horticultural farming.

In this community, although pottery making is regarded as a job for the poor, the potters are not treated as having low status: they can participate in community activities to the same level that the farmers, fishers and everyone else does. Any woman can choose to learn and practise pottery making. The craft is traditionally passed through kinship and the elderly potter pointed out that she had learnt from her mother, who had learnt from her grandmother. She pointed out that she learnt while helping her mother with lesser technical jobs like fetching of clay, water and firewood. She gradually worked up to assisting with firing, and later made small pots for sale before she started selling pots of all sizes after she got married and had her first child.

The four Chonyi potters interviewed were women of 48, 55, 58 and 75 years. These potters live in different villages, among other members of their community. They still make pots on a part-time basis, but only on request since demand is low as a result of the availability 
of factory-made aluminium, plastic and porcelain products. They mostly make pots in the evening after spending the day in their farms where they grow cashew nuts and coconut as cash crops and cereals for food.

Among the Chonyi, just like the Digo, pottery making is viewed as an occupation of the poor in the society, but potters are not treated differently from non-potters. The craft is practised only by women and any woman is allowed to learn if she so wishes, although most of the potters learn the skills from their relatives. They maintained that the skills are passed through kinship but it is not mandatory for anyone to learn. Two of the women pointed out that they started learning the craft from their mothers at about age seven, but sold their first pots during their teenage years. One learnt from her grandmother as a young girl (she could not recall the age), but she emphasized that although she learnt from her grandmother, and had the opportunity to start potting, she did not begin until she got married into her current village where the clay source is close by and abundant. She stated that it was the proximity of the clay source to the village that attracted her to the activity. The second Chonyi potter pointed out that her mother was a potter, but she too did not start practising until she got married. As a young girl she helped her mother with non-technical jobs, like fetching water, fetching clay (which she disliked) and firing, but she did not take any interest in learning how to pot. She was later taught by her sister as both sisters moved closer to the clay source when they got married. Just like the older Chonyi potter, she stresses that she could not pot in the place where she was born because the clay source was too far and she disliked walking the long distance to fetch it. However, since she had watched her mother during her childhood, she took a short period (duration not specified) to learn as an adult from her sister. The third and fourth potters live in a different village about five kilometres away from the first two. They learnt the craft from their mothers, who had been taught by their own mothers. These grandmothers did not only pass the skills to their mothers but to all their daughters. However, these potters claimed not to have passed the skills to their children since they were not interested and, besides, it was a dying craft.

The third Coastal Bantu group was the Jomvu, where two sisters aged 70 and 52 were interviewed. They made pots on a full-time basis and sold them in Mombasa town where they had permanently secured a market section for themselves. Unlike the Digo and Chonyi 
who live in rural areas, the Jomvu potters live in what can be described as a township among other members of their ethnic group. While pottery making is the most important occupation for the potters, they also engage in small businesses of selling vegetables next to the potting areas so that both activities can take place simultaneously. They purchase vegetables from Mombasa town using the profits from the pots, and then resell them to their neighbours at a profit.

The Jomvu potters are all women and they learnt the craft through kinship. In particular, the interviewed potters learned from their mother as small girls between the ages of seven and fifteen. However, they did not start making pots for sale until they got married. Before then, they assisted their mothers with the potting activities and they also made pots to be used by the family. They have not taught any of their children since the children have not shown interest. The craft is despised and this has contributed to their children's lack of interest, and also because it is not mandatory for potters' children to become potters. Despite the low status of the craft, the potters are treated the same way as the other members of the community and any woman who may be interested in learning the craft is allowed to do so.

The pottery repertoire of the coastal Bantu speakers consists of bowls, jars and incense burners. Bowls come in various sizes and are the most commonly produced items. Some are shallow with pronounced shoulders, whilst others are deeper. They have slightly everted rims and rounded bases. These are used for cooking. Likewise, jars come in various sizes; they are necked vessels with everted rims and round bases and are used for storage.

Table 7.2 gives a summary of the Coastal Bantu potters' tools and forming techniques which artisans follow as sequenced.

(a)

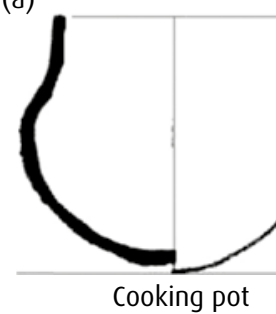

(b)

Figure 7.4 Pottery forms of Coastal Bantu speakers (M'Mbogori 2015) 
Table 7.2 Potters' tools, techniques and tutors of the Coastal Bantu speakers (M’Mbogori 2015)

\begin{tabular}{|c|c|c|c|}
\hline \multicolumn{4}{|c|}{ Costal Bantu potters' tools, techniques and tutors } \\
\hline $\begin{array}{l}\text { Potters' place of } \\
\text { residence }\end{array}$ & Digo & Chonyi & Jomvu \\
\hline Working tools & $\begin{array}{l}\text { Shell, wood, } \\
\text { stone, cloth }\end{array}$ & $\begin{array}{l}\text { Shell, wood, } \\
\text { stone, cloth, leaf }\end{array}$ & $\begin{array}{l}\text { Shell, wood, } \\
\text { stone, cloth, } \\
\text { shallow basin }\end{array}$ \\
\hline Tutor & Mother & $\begin{array}{l}\text { Mother, grand- } \\
\text { mother, sister }\end{array}$ & Mother \\
\hline Starting point & Base & Base & Base \\
\hline $\begin{array}{l}\text { Technique } \\
\text { (body/base) }\end{array}$ & $\begin{array}{l}\text { Drawing of } \\
\text { a lump }\end{array}$ & $\begin{array}{l}\text { Drawing of } \\
\text { a lump }\end{array}$ & $\begin{array}{l}\text { Drawing of } \\
\text { a lump }\end{array}$ \\
\hline Lump placement & Hole & Leaves & Shallow basin \\
\hline Fashioning & $\begin{array}{l}\text { Scraping } \\
\text { interior wall } \\
\text { with shell and } \\
\text { exterior wall } \\
\text { with wood }\end{array}$ & $\begin{array}{l}\text { Scraping interior } \\
\text { wall with shell } \\
\text { and exterior wall } \\
\text { with wood }\end{array}$ & $\begin{array}{l}\text { Scraping interior } \\
\text { wall with shell } \\
\text { and exterior wall } \\
\text { with wood }\end{array}$ \\
\hline Making the rim & Drawing & Coils/drawing & Coils \\
\hline Finishing & $\begin{array}{l}\text { Wet hands } \\
\text { and cloth }\end{array}$ & $\begin{array}{l}\text { Wet hands } \\
\text { and cloth }\end{array}$ & $\begin{array}{l}\text { Wet hands } \\
\text { and cloth }\end{array}$ \\
\hline Drying phase & 3 hours & 3 hours & 3 hours \\
\hline Decorations & $\begin{array}{l}\text { Ridge and } \\
\text { finger } \\
\text { impressions }\end{array}$ & $\begin{array}{l}\text { Dotted impres- } \\
\text { sions, crosses, } \\
\text { boxes and } \\
\text { breast }\end{array}$ & $\begin{array}{l}\text { Ridge, finger } \\
\text { impressions } \\
\text { and shell } \\
\text { impressions }\end{array}$ \\
\hline Drying phase & $3-5$ days & 3-5 days & $3-5$ days \\
\hline Firing & $\begin{array}{l}\text { Grass and } \\
\text { coconut } \\
\text { branches }\end{array}$ & $\begin{array}{l}\text { Grass and } \\
\text { coconut } \\
\text { branches }\end{array}$ & $\begin{array}{l}\text { Grass and } \\
\text { coconut shells }\end{array}$ \\
\hline Distribution & $\begin{array}{l}\text { Village and } \\
\text { market }\end{array}$ & Village & Market \\
\hline
\end{tabular}


Besides following the technical steps keenly, the potters must also observe several rules to ensure success during clay mining and pottery making. Some of the rules are as follows:

i. One is not allowed to go to the clay source when pregnant because digging of clay is likened with digging a grave.

ii. One is not allowed to go to the clay source with an infant who has not yet developed teeth.

iii. One must not make pots during one's menses.

iv. One should not collect clay or make pots after sexual intercourse.

\section{Summary and conclusions}

Except for the Jareer and the Jomvu, the rest of the Kenyan traditional societies do not make pots as a full time occupation. In recent years, the craft has declined substantially due to its labour intensiveness, the drop in skill transmission and low market prices. A recent survey (M'Mbogori, in press) has shown that while the traditional pots are in great demand, production has remained low due to the potters' inability to offer competitive prices, poor mobility and poor marketing strategies. Potters sell their pots only in their local markets and to middlemen who resell at exorbitant prices in other markets. This has impacted negatively on the craft and it is on the verge of disappearing completely if quick drastic measures are not put in place. Promotion and safeguarding of traditional pottery making in Kenya has the potential of not only helping in the conservation of traditional knowledge, but also offer employment to the youth and women, hence contributing to poverty eradication and overall economic stability for the potters and their families.

Conservation of the pottery making techniques which form a community's identity will ensure the craft's continuity and further inspire a sense of pride among the practicing societies. As seen in the opening paragraphs of this chapter, and demonstrated throughout, the conservation challenge lies in the entanglement of tangible and intangible aspects of the pottery making technology. Therefore, safeguarding requires concerted efforts from conservators, the research community, the government, community leaders and various other stakeholders, to do the following: 


\section{a) Research and documentation}

To map out pottery making activities in the regions, it is necessary to record all the tangible and intangible aspects on video and print. This exercise should include different professionals such as anthropologists, archaeologists and historians. This would help to understand the mechanisms and dynamics of the art and document its tangible and intangible aspects for posterity.

b) Potters' communitycapacity-building activities andimprovement of local marketing strategies

As demonstrated in the examples of the Cushitic and Bantu speakers, potters work as individuals and are not able to organize themselves and to find ways of countering emerging challenges. It would therefore be necessary to organize potters into groups where they have leaders, create proper records and keep books of accounts. They will put their resources together, which will enhance their working environment and increase their ability to penetrate the market and to negotiate with local authorities as a team. This will ensure continuity of production and, therefore, the conservation of the technology and practice.

\section{c) Enhancement of transmission methods}

Pottery making skills, rules and regulations are passed to family apprentices during production. This limits opportunities for other members of the society to learn. This strategy also extends the learning period over years. Therefore, as a conservation strategy, pottery making could be introduced as an extra-curricular activity in schools, where teachers could invite practitioners to talk to students and to offer practical lessons on the technology during school club days.

In sum, the stability of pottery making techniques through time and space can only be maintained through concerted conservation efforts. Such conservation efforts should not only be the museum conservators' headache, but a responsibility of community leaders and scholars since pottery making techniques attest to a community's deep-rooted identity. For the states that are struggling with multicultural challenges and ethnic issues of land ownership, pottery technology can be used to show unity in diversity though providing evidence of past interactions. 
8

\section{Wildlife heritage ownership and utilization in Kenya - the past, present and future}

Francis Mwaura

\section{Introduction}

Kenya ranks high in terms of biodiversity. It is considered one of the world's megadiverse countries with a valued wildlife heritage similar to that of Brazil, Indonesia, Congo, Madagascar, Tanzania and South Africa. Kenya's wildlife heritage includes approximately 21,575 insects, 1,133 birds, 314 mammals, 191 reptiles, 180 freshwater fish, 692 marine and brackish fish and 88 amphibian species (NEMA 2005). The government of Kenya in collaboration with the citizenry have made significant efforts towards the conservation of this rich wildlife heritage through the establishment of a network of conservation areas which include twenty-three terrestrial national parks, twenty-eight terrestrial national reserves, four marine national parks, six marine national reserves, and four national sanctuaries. In addition, there are over a hundred private and community conservancies which are commonly considered as 'parks outside parks' in different parts of the country. Recent estimates indicate that these conservation areas collectively account for about $12.6 \%$ of the country's total area. This is substantial when compared to other countries such as South Africa (6.1\%), Mauritius (3.3\%), Egypt (5.6\%), South Korea (3.6\%) and India (5.3\%) but inferior when compared with Tanzania (42.4\%), Uganda (32.6\%), Botswana (30.9\%) and Malaysia (30.7\%) (NCAPD 2010).

Kenya's wildlife heritage is a key asset for the tourism sector which accounts for about $10 \%$ of gross domestic product (GDP), making it the 
third largest contributor after agriculture and manufacturing. Wildlife tourism is occasionally the leading foreign exchange earner in Kenya, generating up to Ksh 75.2 billion (about US \$1 billion) per year. The tourism sector accounts for about $9 \%$ of total formal employment in the country (Wanyonyi 2012). Studies have previously established that approximately $70 \%$ of gross tourism earnings in Kenya and $5 \%$ of its GDP can be attributed to the spectacular wildlife heritage in the country (Emerton, Ndugire \& Bokea 1997). Consequently, one of the key goals of Kenya Vision 2030 is to ensure that the wildlife heritage is protected and the annual revenue from the tourism sector is increased to about Ksh 180 billion.

Despite the important role of wildlife heritage to the economy through tourism, this asset continues to experience significant challenges, especially in terms of continued decline in wildlife populations. Recent wildlife counts in the rangelands of Kenya, where most wildlife are concentrated, are dropping by over $50 \%$ for some species. The nonmigratory wildlife in Mara National Reserve, for example, declined by 58\% between 1977 and 1997 while wildlife populations in the Tsavo and Meru regions rangelands declined by $63 \%$ and $78 \%$, respectively, between 1977 and 2000 (Wakhungu et al. 2010). The rapid loss of wildlife can also be attributed to the fact that up to $70 \%$ of the wildlife in Kenya is found outside the protected areas, where it is at the mercy of private or communal landowners whose individual interests they consider more important than the national mission of protecting wildlife heritage as a valuable national asset (Western et al. 2006). Landowners are expected to allow wildlife within their property boundaries and tolerate the loss of land exploitation income (due to losses) that can be attributed to the presence of wildlife. This is mitigated by the tourism benefits accruing from ecotourism, which are shared throughout the country as state revenue which support education, health, security, among others. This calls for a lot of tolerance because not everyone is incurring the losses associated with sharing land with wildlife. Consequently, land use changes in many wildlife areas of Kenya have led to fierce competition between wildlife conservation, pastoralism and agricultural expansion (Serneels \& Lambin 2001).

The declining wildlife numbers in Kenya cannot be attributed to a single wildlife heritage governance regime because the history of wildlife management in Kenya stretches across a wide temporal spectrum since the pre-colonial times. Through the years this valued heritage has been managed by one government or another, starting with the pre-colonial chiefdoms. One of the most important issues is wildlife 
ownership, a question which is a key determinant of the quality of wildlife heritage management and protection. In the past, in Kenya as in other parts of the world, there have not been sufficient efforts to explore and document the relationship between wildlife heritage ownership and the quality of wildlife management and protection, hence the focus of this chapter. The key question is to establish whether the survival of wildlife heritage rests on its ownership status based on the management lessons of the past. In order to answer this question, this chapter explores the history of wildlife heritage ownership and management in Kenya as a key to the future of such heritage.

\section{Wildlife heritage ownership}

Ownership is probably one of the most critical attributes for any asset because it has a strong implication on many critical issues concerning access, utilization, sharing and protection. Like many other resources, wildlife heritage can be associated with four property rights dimensions, namely capital rights, use and economic rights, management rights and transfer rights, each of which controls a number of important issues (Table 8.1).

Wildlife heritage ownership is defined according to the distribution, sharing, holding and control of four bundles of property rights among the individuals and parties associated with the heritage. In most parts

Table 8.1 Wildlife heritage property rights and functions (Mwaura 2015)

\begin{tabular}{ll}
\hline Type of property right & Functions \\
\hline Capital rights & $\begin{array}{l}\text { Controlling heritage consumption - e.g. game meat } \\
\text { Controlling heritage destruction - e.g. wildlife } \\
\text { killing } \\
\text { Controlling heritage transformation - e.g. wildlife } \\
\text { taming or domestication or relocation }\end{array}$ \\
& Controlling use and derivation of benefits including \\
& income - e.g. through tourism \\
Use and economic & Controlling the population and typology of users \\
rights & Setting the terms and conditions for heritage use, \\
Management rights & including where to use, when to use and how to use \\
& Controlling a wide range of issues including \\
& heritage sale, mortgaging, leasing, renting, giving \\
& away, bequeathing or reserve for future use
\end{tabular}


of the world, the four bundles of property rights are rarely controlled by a single individual or entity but are shared by different stakeholders. The distribution and sharing of control and power through the property rights usually gives rise to four categories of wildlife heritage ownership regimes, namely: a) private ownership, b) state ownership, c) communal ownership and d) open access or free-for-all wildlife heritage.

The private ownership regime is associated with the wildlife heritage for which most of the property rights are vested in a single owner who can either be an individual, institution or company. The private ownership of wildlife heritage is common for certain types of wildlife in many parts of the world, such as the Asian elephant. A large number of wild elephants have been captured and entered into domesticity for at least 4,000 years. Records indicate that over 100,000 wild elephants were captured in the last century and perhaps two to four million in the entire history of elephant domestication (Sukumar 1992). Currently, it is estimated that approximately 12,000 of these Asian elephants are largely ignored by governments and remain private property. India, for example, harbours over $20 \%$ of the captive elephant population in Asia.

Such elephants are the property of the owners who, through training the animals, can use them in many different ways including carrying heavy objects such as timber. Domesticated elephants have been used in war, in ceremonies and as draft animals. They have also been used for their ability to travel over difficult terrain. In Africa, attempts at elephant domestication were made in the former Zaire by Leopold II, the King of Belgium, who set up an elephant training school in Congo in the late 1800 s where over 500 elephants were trained over 60 years until 1963 (Douglas-Hamilton 1992).

The Asian water buffalo has also been domesticated by humans for between 4,500 to 5,000 years in areas like India, Thailand, Vietnam, Sri Lanka and Cambodia, where they are privately used as draft, meat, and dairy animals. Water buffalo are especially suitable for tilling rice fields and buffalo milk is considered to be richer in fat and protein than that of dairy cows (Lau et al. 1998). It is estimated that there are at least 130 million domestic water buffalo, and more human beings depend on them than on any other domestic animal. Private property ownership of wildlife heritage is also associated with wildlife in captivity within private zoos around the world. The San Diego Zoo in the USA, which is one of the largest in the world at 107 acres, includes more than 4,000 animals of 950 different species (Fraser 1983). In 1983, it was estimated that there were over 70 zoos in North America alone that kept elephants either from Africa or Asia. 
In some countries, private ownership of wildlife heritage has gone beyond domesticated or captive species to the ownership of all the wildlife in private areas. In 1967, one year after the United Nations demanded that South Africa leave Namibia, the ruling South African apartheid government gave ownership of the local fauna predominantly to the white landowners. Consequently, the question of who owns the wildlife in Namibia has continued to be fraught with difficulties. State ownership of wildlife heritage is associated with the vesting of all wildlife property rights by the state. Such heritage is usually characterized by public ownership and state custodianship because although it is largely under the custodianship of governments, it actually belongs to the citizens and the government is only holding it in trust on their behalf. State property wildlife heritage can therefore be accurately considered as public heritage in which the citizens should have a major say, especially terms of its governance, utilization and even conservation and protection. In Kenya, most wildlife heritage is associated with this kind of ownership even within private land.

Communal ownership is associated with wildlife heritage whose property rights are vested in a defined group of owners such as an extended family, clan, tribe or village. This regime is nowadays associated with policies that strengthen the rights of local users to participate in management of wildlife heritage in order to strengthen stewardship and conservation outcomes (Wamicha \& Mwanje 2000; Sunderlin et al. 2008; Nelson 2010). However, in the past most wildlife heritage in many parts of the world including Africa, North America and Australia was totally in the hands of local communities through various forms of traditional use and customary stewardship. In Australia, for example, the bond between the indigenous Aborigines and wildlife was so close that until 1967 the government, due to outright racism, maliciously governed and managed both under the same portfolio defined by the 'Flora and Fauna Act'. In population censuses, Aboriginal people were counted and lumped together with wildlife heritage until the 1967 referendum, which extended Australian citizenship to the Aborigines.

The open access wildlife heritage ownership regime is associated with shared free-for-all wildlife resources, especially in the open sea beyond territorial waters. A good example of this is the oceanic wildlife which is commonly associated with the unregulated deep sea open access fishery. This involves a wide range of species such as tuna, whale and sharks that have been overexploited due to their high economic value. The open access wildlife heritage includes a wide range of birdlife in the oceans of the world. 


\section{Wildlife heritage ownership history in Kenya}

The history of wildlife heritage ownership in Kenya can be tracked along three distinct phases in relation to the country's history, namely a) the pre-colonial phase before 1885 , b) the colonial phase 1885-1962, and c) the independence phase after 1963. During this historical journey, the custodianship of wildlife heritage has changed hands several times in terms of governance, utilization and protection. This has had major implications on wildlife heritage and there are many important lessons to be learnt from this history in order to improve future management.

\section{The pre-colonial phase}

During the pre-colonial phase before 1885, wildlife heritage ownership in Kenya was predominantly communal, whereby utilization varied according to the needs and cultural practices of different ethnic groups. Records show that at this time, most of the country was characterized by lots of wildlife. According to Miller (1971) the Athi-Kapiti plains at the south of Nairobi National Park, in the vicinity of the proposed site for the Konza Technocity, a project marketed by the Kenyan government known as the African silicon savannah, was at that time stocked with an amazing variety of wildlife. It almost seemed like an ocean of many different animals such as zebra, giraffe, impala, Thomson's gazelle, Grant's gazelle, hartebeest, wildebeest and oryx in their hundreds upon endless hundreds as far as the eye could see. Similar sights have also been recorded in many other parts of the country.

Despite the easy access to this wildlife wealth, only a few ethnic communities were known to use wild game either as a source of food, clothing, ornaments or currency. According to Waithaka (2012), wild animals during this period were regarded as alternative livestock in some pastoral communities and were not hunted for food except during periods of extreme drought when livestock was scarce. In those days, wildlife featured prominently in most cultural activities, ceremonies and folklore. In most communities, folklore based on various aspects of wildlife was an important mode of imparting cultural and social norms and morals to the youth (Waithaka 2012). Some animals were recognized as community totems and were protected from any form of destruction. Different cultural practices forbade the hunting, killing or interfering with certain animals as well as their habitats. Others despised the use of 
wildlife resources and looked down upon the communities that did use them (Waithaka 2012).

However, some ethnic groups were known to use their wildlife heritage in different ways. For example, John Boyles, the self-proclaimed King of the Kikuyu, entered Kikuyu country from Naivasha in the 1890s. Many of the young armed warriors who initially confronted his entourage on the southern slopes of the Aberdares wore wonderful headdresses made of colobus monkey (Colobus angolensis) skin (Bulpett 2001). Thereafter, Boyles met with chief Karuri wa Gakure who ruled among the Agikuyu people at the time. He was also hosted by the famous chief Wangombe wa Ihura in Nyeri in the foot slopes of Mount Kenya. At that time, Chief Wangombe and his people were already engaging in ivory trade following their interaction with the Arab ivory traders (Bulpett 2001). According to Bulpett, Boyles was buying ivory of up to forty kilograms a piece from Chief Wangombe at the rate of two or three tusks a day at a cost of eight to ten shillings per tusk. When he ventured inside Mount Kenya forest, Boyles encountered the Ndorobo, who were great hunters and lived entirely on game meat and wild honey. Records indicate that Boyles spent time with the Ndorobo and joined their hunting missions in the sprawling Laikipia plains next to Naromoru which is said to have been like a huge natural zoo full of every kind of African game, including herds of zebra, giraffes, elephants, lions, hartebeest, eland, waterbuck and buffalo (Bulpett 2001). The large stock of wildlife heritage at the time can be attributed to the low human population density in many parts of Kenya as well as the limited impact the heritage owners had through direct consumption use. At the same time, vast areas of the country were available for wildlife whose destiny was largely in the hands of nature.

With the coming of the early explorers from Europe and the Middle East, the previously unknown wildlife heritage in Africa was quickly revealed to the rest of the world, where such heritage either did not exist or had already been ruthlessly exterminated, as was the case in Europe and North America. The spectacular wildlife in Africa thereafter became instrumental in connecting the continent to the world economy initially through the forceful robbery of resources by the more powerful societies at the time.

The Eastern coast of Africa is known to have attracted international maritime trade as far back as 3,500 years ago, with ivory playing an instrumental role of drawing East Africa into the world economy through long-distance trade (Waithaka 2012). Although East African ivory had long been exported to China and India, demand by European 
middle classes for luxury items such as billiard balls, piano keys and cutlery handles later created new markets for it. Ivory or 'white gold' was by far the most significant by-product of Africa's elephants (Kunkel 1982; Luxmoore 1991; Alpers 1992; Meredith 2001). The softer African ivory was preferred to the Asian type because it was better for cutting, sawing, painting, staining, slicing and carving.

Some of the Kenyan tribes which were known to openly and significantly engage in the ivory trade were the Kambas. The Kamba ivory traders were instrumental in opening a trade route between their region and Mombasa, which they used together with Arabs. One of the prominent figures was Chief Kivoi of Kitui. According to local history, the name of Voi town on the way to Mombasa comes from Chief Kivoi who settled near the Voi River. There the village grew to become a trading centre for the local Taita people with other Kenyan tribes and Arabs. Having dominated the regional trading network in the eighteenth century, the Kambas moved into the international trading network, and by the 1840s Kamba caravans were sending about five tonnes of ivory to the coast every week. In the interior, their trading parties were visiting not only their Kikuyu neighbors, but also places as far away as Mau, Gusii, Lake Baringo, and Samburu country. The East African ivory trade was probably a major driving force in the scramble for African resources which eventually contributed significantly in the justification for the colonization of African societies. The need for porters to carry ivory from inland areas to the coast contributed to the genesis of slave trade in East Africa with many trade caravans cutting through the region. Only a few communities such as the Kambas were supporting the Arabs in the illicit trade, with Chief Kivoi of Kitui featuring prominently in that business (Miller 1971). At the same time, some ethnic communities in the country, such as the Maasai and Kikuyu, were very hostile to the slave traders. When John Boyles met Chief Wangombe wa Ihura, for example, he had accumulated an arsenal of some one hundred rifles which he had stolen from Arab traders when they attempted to cross through his territory (Bulpett 2001).

\section{The colonial phase}

The rich wildlife heritage in Kenya can be considered as one of the contributory factors which attracted colonialism in the country and region. The events leading to the establishment of Kenya Colony date back to 1885 when the Berlin Conference was held in the official residence 
of Chancellor Otto von Bismarck, in Germany. The conference was attended by 16 diplomats from the most powerful nations in Europe, which included Britain, France, Germany, Belgium and Italy. The main agenda for the conference was the partitioning of Africa following the discovery of its vast resources, including wildlife. The conference was followed by six months of negotiation after which Kenya, among other countries, was declared a part of the British Protectorate. Britain's rule lasted nearly seventy years, from 1895 to 1963 (Waithaka 2012). One of the key developments at this time was the construction of the $£ 5$ million Kenya-Uganda railway, which commenced in 1996 and reached Kisumu in 1901, thereby completely transforming the future of Kenya, including its wildlife heritage.

With the railway line in operation, wildlife hunting became a bigtime business in Kenya, the repercussions of which are still felt now. The prospects of huge commercial profits from Africa's wildlife, which was almost free, eventually lured many professional hunters, mainly from Europe and America with the so-called 'Big Five' (buffalo, elephant, leopard, lion and rhino) as the main attraction (Waithaka 2012). During that time, wildlife trophies were skinned, salted and cured on the spot by expert African skinners, then transported by porters to Nairobi for loading onto the train and thereafter shipped onward to London for mounting by companies such as Rowland Ward of Piccadilly. This business eventually culminated in the infamous 'Big Hunt' involving many famous personalities who came to Kenya on hunting expeditions during the colonial phase. In 1907, Winston Churchill, the under secretary of state for the colonies of Great Britain in London, visited Kenya on a major hunting expedition (Wahome \& Gathungu 2013). During his trip, he was hosted at Lake Elementaita by Lord Delamere, the owner of the then Equator Ranch and present day Soysambu Ranch, with a huge population of game. He was later to narrate how he thoroughly enjoyed himself shooting warthogs, Grant's and Thomson gazelles, and elands (Churchill 1908). Two years later, former US President Theodore Roosevelt sailed to Mombasa to take part in one of the most elaborate hunting safaris that Kenya had ever seen (Miller 1971). With a large contingent of professional hunters, taxidermists, and over 500 porters to carry his loads of trophies, Roosevelt embarked on a safari that lasted the better part of the year, shooting game to the extent of attracting controversy on account of the sheer number of animals killed. According to Miller (1971), Roosevelt shot no fewer than 296 animals including nine lions, eight elephants, thirteen rhino (including nine white rhinos), six buffaloes and two bongo antelopes. The 'Big Hunt' is associated with 
a large number of other white people such as Edgar Beecher Bronson, an American rancher, Baden Powell, a hero of the infamous Boer war in Matabeleland and the world's chief of the Scout movement (which, ironically, champions animal rights), Ernest Hemingway, Geoffrey W. Griffin, who later founded and led the Starehe Boys School in Nairobi, and many others.

In the latter years of the colonial era, some of the big professional hunters such as Donald Ker and Sid Downey changed their ways and became experts and champions of wildlife tourism and heritage conservation, after causing huge damage to this valued heritage. In the spirit of racial integration and co-existence advocated by Jomo Kenyatta, some of the former colonialists who had engaged in sport and luxury hunting remained in Kenya after independence. A large number of these people voluntarily transformed themselves from top hunters to leading tourism investors and wildlife conservationists, using their vast networks around the world. However, some of them continued to engage in secret wildlife culling within their vast estates.

Overall, many colonialists took to wildlife hunting in Kenya between 1895 and early 1900. They transferred hundreds of wildlife trophies from the country to their homes or national museums and zoos in Europe and North America. This period can therefore be considered as one which culminated in a huge loss of Kenya's wildlife heritage without any compensation. During this time, private ownership of wildlife was not uncommon in Kenya. In the early 1900s, Rosendo Ribeiro, a Portuguese private doctor in Nairobi and a founder member of the Goan Institute, used to do his medical rounds on a zebra (Figure 8.1). Dr Ribeiro eventually sold the animal to a Bombay Zoo for a total of 800 rupees. He died in 1951, but is still remembered for his major role in taming a major bubonic plague outbreak which affected the city in 1902 and 1946, killing 500 people.

The origin of modern wildlife heritage conservation in Kenya can also be associated with the colonial period and is traced wayback to 1898 , when a law controlling wildlife hunting was first enacted. Thereafter, in 1907, the Game Department was established and charged with the responsibility of enforcing game laws and protecting the reserves. By the mid-1930s, thousands of wildlife had been eliminated by white farmers and government officers as a result of crop predation and invasion into human settlements. In Makueni area, for example, 996 rhinos were killed between 1944 and 1946 to open up an area of 200 square kilometres for settlement (Hunter 1952). Alarmed by the widespread cultivation and the huge numbers of animals killed to protect crops, a 


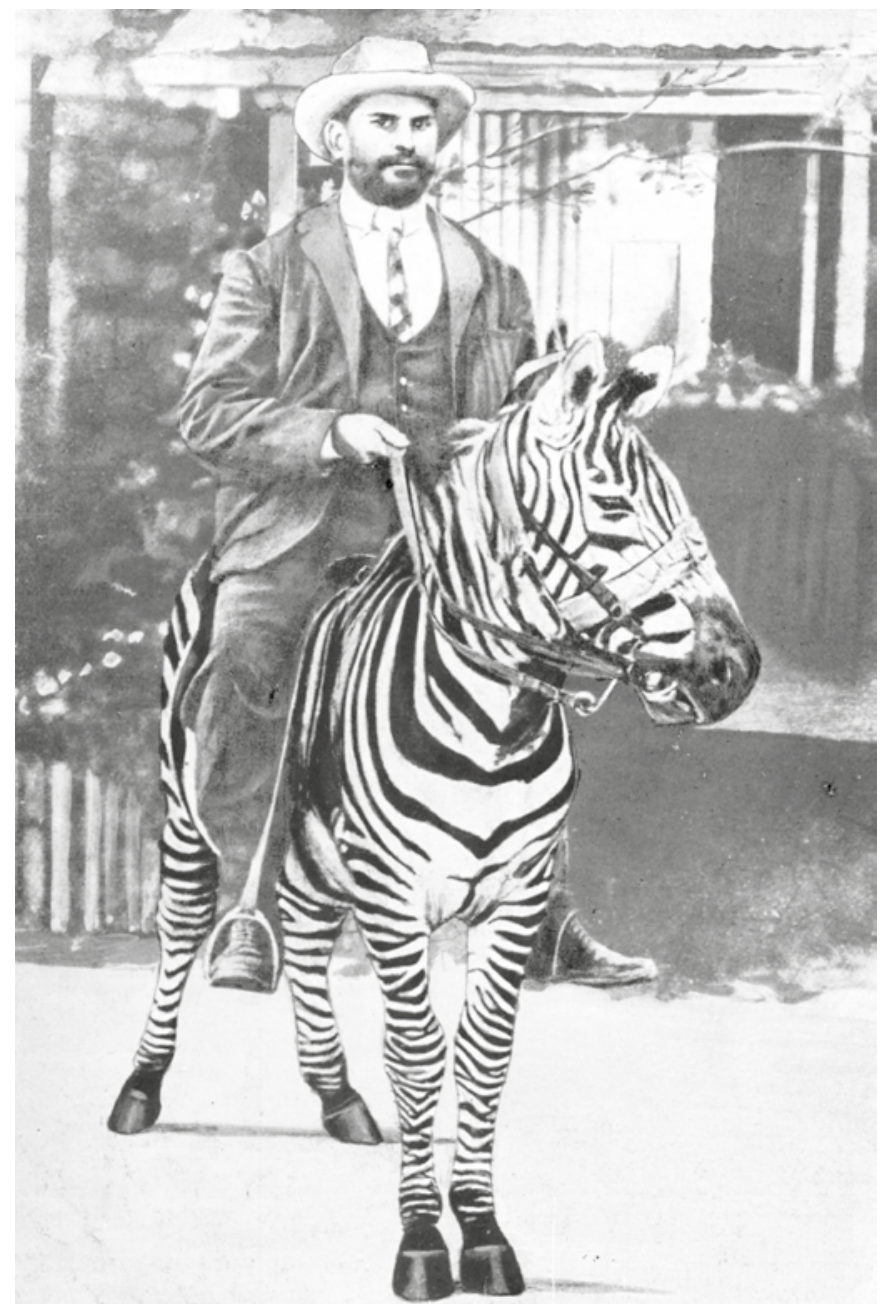

Figure 8.1 Dr Rosendo Ribeiro on a zebra ride in Nairobi (Smart 1950)

committee established by the British government in 1932 called for the establishment of 'national parks and reserves where hunting, killing or capturing of fauna, and the collection or destruction of flora would be limited or prohibited' (Waithaka 2012). The British also wanted such protected areas so that they could continue their big-game hunting safaris and offer exclusive recreation to the settlers, while the locals mostly served as spectators or guides, porters, and servants (Chongwa 2012). Consequently, the National Parks Ordinance of 1945 was adopted, thereby providing a good momentum for the establishment of initial 
protected areas in the country which started off with the establishment of Nairobi National Park in 1946, followed by Tsavo National Parks and Amboseli National Park in 1948. Thereafter, Aberdare Royal Park and Mount Kenya Royal Park were established in 1949 and 1950, respectively. Princess Elizabeth became Queen while on a visit to Aberdare National Park in 1952.

The establishment of wildlife heritage conservation areas marked a major departure from communal or customary ownership of wildlife heritage to the state property regime. During this transition, the land traditionally belonging to the Africans became the target for the establishment of national parks and forest reserves (Waithaka 2012). This marked the beginning of wildlife heritage nationalization in Kenya, as well as the alienation of Africans from the utilization, governance and conservation of a heritage they had nurtured and utilized for several hundred years.

According to Waithaka (2012) the 70-year colonial legacy in Kenya was marked by the alienation of people from the wildlife and other resources they had traditionally associated with and relied on. The wholesale forcible removal of entire populations from their native lands was carried out without any form of consultation or compensation. The tough legislation in favour of wildlife protection created conflicts that persist until now (Waithaka 2012). The new hunting laws essentially outlawed traditional subsistence hunting because the majority of indigenous people could not afford licenses. Subsequent game laws also banned traditional hunting techniques on the grounds that these techniques were cruel to animals, effectively declaring subsistence hunting illegal. The introduction of sport hunting was strongly resented by the native people who could not understand the basis for killing helpless animals for personal entertainment and self-gratification while they were denied their traditional means of subsistence and cultural practices (Waithaka 2012). Eventually, it became almost impossible for the Africans to co-exist with wildlife heritage without breaking the law. Many adult males were punished and imprisoned for petty offenses which largely solidified the negative attitudes towards wildlife and colonial rule. Wildlife heritage conservation areas were soon surrounded by hostile people who had no sympathy for the wildlife. By the 1950s, the desire to reclaim control of their natural heritage reached its zenith, and the struggle for political liberation became inevitable (Waithaka 2012). This led to the struggle for independence in the 1950s and 1960s.

During the struggle for independence in 1950-1962, wildlife heritage played a major role in supporting the lives of the freedom fighters 
around Central Kenya. When the freedom fighters ran short of food, they would normally set traps and catch wild game, especially antelopes (Kahiga 1990). One of the celebrated Mau Mau female survivors, the famous 'Field Marshall' Muthoni wa Kirima, is known for playing a major role in the trapping wildlife in the forest to feed the freedom fighters. The fighters used wildlife sounds to communicate with one another. They also used wildlife hides and skins for their clothing and beddings while in the forest. When Field Marshal Dedan Kimathi, the lead freedom fighter, was captured in 1956 with the help of loyalists, he was wearing a leopard skin.

\section{The independence phase}

Wildlife heritage ownership, utilization and governance after independence heavily adopted its frameworks from the colonial approach in policy, legal and institutional terms. Since independence in 1963, the governments of the day have continued to stress the need for people to live in harmony with the wildlife heritage. There has been considerable political will to conserve national wildlife heritage, as attested to by the government's commitment to fulfil the provisions of relevant conventions, treaties and protocols which Kenya is party to, such as the Convention on International Trade in Endangered Species of Wild Fauna and Flora (CITES), the Convention on Migratory Species (CMS) and UNESCO's World Heritage Convention (Juma \& Ojwang 1996; Manek 2001; Kameri-Mbote 2005).

According to Kameri-Mbote (2005), the first attempt at a comprehensive policy on wildlife management in Kenya is embodied in the Sessional Paper No. 3 of 1975, entitled A Statement on Future Wildlife Management Policy in Kenya. This policy was a radical departure from the preservationist policies preceding it, especially with regard to the recognition of the value of wildlife both within and outside the wildlife conservation areas. The policy recognized that wildlife needed space outside the protected areas if it were to flourish and envisioned the need to find ways through which such additional space for wildlife conservation could be secured from the landowners willing to accommodate wildlife. In 2013, the wildlife policy in Kenya was reviewed in order to provide a framework for conserving, in perpetuity, Kenya's rich diversity of species, habitats and ecosystems for the wellbeing of its people and the global community. The revised policy embraced the spirit of promoting wildlife conservation and management outside the protected 
areas by supporting landowners and communities to set aside wildlife conservation areas and sanctuaries within the framework of approved land use planning.

In the years since independence, beginning with Jomo Kenyatta (1962-78), the main task of implementing and enforcing wildlife policy and legal frameworks has changed through several governments and heads of state. Although the number of protected areas increased tremendously during the tenure of Jomo Kenyatta, from fewer than ten national parks and game reserves during the colonial period to over forty, the country suffered major losses in wildlife heritage through illegal poaching. During the independence period the population of elephants and rhinos in Kenya declined by over 60\%. Between 1970 and 1977, the country lost at least half of her elephants. In 1973, the country had an estimated population of 130,000 elephants, down from more than 140,000 the previous year. Today, the population is fewer than 50,000 .

In 1977, one year before his death, Jomo Kenyatta announced a ban on sport hunting throughout the country. However, this ban did not work due to poor enforcement, including widespread corruption at institutional level. The loss of wildlife heritage continued during the administration of Daniel Arap Moi (1978-2002). In 1988, for example, the total elephant count for the Tsavo Conservation Area (TCA), including the Galana Ranch and Mkomazi National Park in Tanzania, resulted in a minimum of 5,363 elephants, which was a 79\% decline compared to the 1970s. The establishment of Kenya Wildlife Services (KWS) in 1989 with the review of the Wildlife Act appeared to stem the loss of wildlife heritage in the country, although declining numbers in wildlife heritage continued to be a major challenge both during the governments of Mwai Kibaki (2002-13) and his successor, Uhuru Kenyatta. Their tenures have been associated with greater economic collaboration with China, with many Chinese companies securing contracts in the country. This has increased the problem of elephant and rhino poaching because China is a key market for ivory in the world (Gao \& Clark 2014).

\section{Return to community and wildlife heritage stewardship}

The revised wildlife policy in Kenya has strengthened participatory wildlife heritage management and appeared to restore the spirit of community engagement in the management of wildlife heritage in Kenya. 
This approach is desirable because over $70 \%$ of the wildlife heritage in Kenya is scattered outside the network of state protected areas within private or communal land in the country. For many years, a lot of communal land in Kenya, especially within the Maasai areas, has existed in the form of group ranches with common title deeds. In recent years, the subdivision of such land has started, thereby transforming the ownership of natural resources from common property to private property. This change in property rights regime is expected to have far-reaching negative impacts on wildlife heritage due to loss of valued habitats as a result of the unwillingness of private landowners to host wildlife in their properties, which has various costs including disease transmission, livestock predation and pasture sharing.

Many people believe that the only way out of this dilemma is through policy reforms, which will support the emerging interest in establishment of private and community conservancies as avenues for tapping into the tourism market. Communal conservancies comprise a single or more than one group ranches or communal land which is jointly owned by a tribe, a clan, a family or any other group of persons under customary law where the members of the group have agreed to put it under joint management as a single entity for more effective and sustainable utilization and management of natural resources. The establishment of conservancies has become popular in many parts of the country in the recent decade, with the Rift Valley region leading with the highest number of conservancies.

The community wildlife conservancy model is expected to boost government efforts in wildlife conservation and management in the country during the twenty-first century. The model has good opportunities for restoring the role of the citizenry in the governance of wildlife heritage within their local areas which was withdrawn in the colonial period. The value of community conservancies in boosting and improving wildlife heritage conservation and management is well demonstrated in the Greater Amboseli Region $\left(6,000 \mathrm{~km}^{2}\right)$ which had over twenty active community conservancies by 2013. The role of governance is largely in the hands of KWS, which is based at the Amboseli National Park. KWS has a network of eight outposts in the region which has over 80 different species of charismatic wildlife, including elephants (Loxodonta africana), black rhinos (Diceros bicornis Gray), cape buffalos (Syncerus caffer), gazelles (Gazella thomsonii, and Gazella granti), zebras (Equus burchelli), hippos (Hippopotamus amphibious), lions (Panthera leo), leopards (Panthera pardus), and spotted hyenas (Crocuta crocuta). Traditionally, over $80 \%$ of wildlife 
leave the national park during the wet season, eventually interacting with other ecosystems in areas such as the Tsavo, Mount Kilimanjaro and the Chyulu Hills. Apart from protecting the wildlife in the park, the KWS team of about 80 rangers is also expected to demonstrate government presence in the entire Kenyan ecosystem, which translates to approximately $120 \mathrm{~km}^{2}$ per ranger; an impossible task by most standards.

Through a public-private partnership, the community conservancies in the area, with the support of African Wildlife Foundation (AWF) and a charitable organization, Big Life Foundation, have established a Community Game Scout Program to enhance wildlife heritage conservation through regular patrols. The program has approximately 300 game scouts who work closely with KWS and over 30 scout outposts in the country as well as Tanzania. The program has 15 antipoaching vehicles (Land Cruisers, Land Rovers), monitoring aircrafts, latest technology night-vision equipment, GPSs and other necessary equipment for the scouts, and tracker dogs. The game scouts have so far helped to secure the arrest of 627 poachers and confiscated 1,630 weapons, which is a huge boost to the government efforts through KWS and other state security machinery.

The community conservancy model is a good alternative for ensuring a more equitable distribution and sharing of the tourism revenue with the grassroots communities who sacrifice a lot of their natural capital opportunities by hosting wildlife in their local areas. The state wildlife management model has failed with regard to effective compensation for such losses, thereby heightening the tension between people and wildlife. The existing conservancies in Kenya have played a significant role in wealth creation and distribution among pastoral communities around the country. In 2009, for example, the revenue from Kalama Conservancy in Samburu County totalled more than $\$ 70,000$, from which $60 \%$ was used to fund community projects such as school bursaries and water projects, $40 \%$ was used to fund annual operating costs of the conservancy. In 2000, the revenue generated in Namunyak Conservancy in the same county totalled more than $\$ 90,600$. Elsewhere, the Mara conservancies are generating US $\$ 1.8$ million annually for about 1,511 members. In Mara Naboisho Conservancy, the landowners receive a monthly income of roughly US $\$ 100$ as direct income for the land they have leased to the conservancy. Nationally the various conservancies generate an income of approximately US $\$ 5,000$ per month (US $\$ 60,000$ per annum) as direct benefits for 500 landowners. 


\section{Conclusion}

Wildlife heritage in Kenya has crossed a number of major milestones in the last one hundred years, particularly in terms of ownership, utilization, management and conservation. Many lessons can be learned from the key achievements and mistakes of the past. It is important to take stock of this history and use it to inform the future of wildlife heritage management in the country, which will be full of challenges due to the fierce competition between heritage conservation and development. However, the biggest challenge will be for all the generations of the day to ensure that the wildlife heritage of their time is passed on to the generations coming after them as envisaged in the national constitution.

Looking back at the history of wildlife heritage in Kenya, it is clear that the pre-colonial period was the most impressive in terms of harmonious co-existence between people and wildlife. During that period there was a high sense of respect and regard for wildlife welfare, probably due to the close integration of wildlife in culture through peoples' beliefs and practices, including taboos and fears. At that time, there was a low sense of individual selfishness and materialism because wildlife heritage was considered as a communal asset. The nationalization of wildlife heritage during the colonial and postcolonial phases can be blamed for creating tension and generating conflict between people and wildlife heritage through the hijacking of resources from the people, transferring them first to the colonialists and later to the government. The colonialists, after undertaking a catastrophic extermination of wildlife in Europe and North America, came to Kenya with their guns and wiped out a large part of the country's wildlife heritage, for which no compensation has ever been paid. It is ironic that some of the notorious wildlife hunters are now on the frontline as the most hard-line conservationists in the country, sometimes even opposing important government development projects with the help of the international conservation and funding agencies in Europe and the USA.

The direct engagement by subsequent governments of independent Kenya of the policies and legal frameworks of colonial times has continued to strain the relations between people and wildlife, thereby leading to major heritage losses. If the past wildlife heritage history is anything to go by, then the need to engage policies and a different governance approach which can restore the interest, respect and public confidence between people and their wildlife resources is urgent. This 
confidence prevailed during the pre-colonial times of communal wildlife heritage. It is certainly impossible to revive the wildlife heritage practices of the time due to the major transformations in natural capital ownership practices as well as widespread problem of cultural erosion. However, the community wildlife conservation model can play a beneficial role in restoring the lost confidence in wildlife governance.

The community conservancy model is a suitable vehicle which can bring a wide range of wildlife heritage benefits to the local people, including the following:

(a) Devolved governance of wildlife heritage in line with the Constitution of Kenya (2010)

(b) Empowerment mechanisms through the participation of local communities in wildlife heritage conservation and tourism benefit sharing

(c) Enhancement of community development through wealth creation

(d) Strengthened management skills and capacity for wildlife heritage management.

The major impediment for the success of this model, however, is ensuring a proper communal governance framework which will win the confidence of all the wildlife heritage property owners in different parts of the country. 


\section{9}

\section{Evaluating rural heritage conservation in Kenya: the case of Karue Hill, Embu County}

Anthony Njeru Murithi

\section{Introduction}

Kenya is host to a myriad of rural visual resources: a product of an intricate mix of geological processes, soil characteristics, climatic conditions and human activities. These rural landscapes comprise 'natural' elements such as wetlands, bare hills and woodlands, as well as those produced by human activities, including croplands. However, most rural landscapes in Kenya have been continually altered to the extent that so far, almost all spaces have had human influence. There is continued destruction of visual resources in rural areas for more intensive economic activities. The upsurge in conversion of agricultural land into palatial homes for sale in Kenya is a clear indication of the way land is viewed as a source of direct income: a capital base with little significance to aesthetics. Effective categorization, quantification and citizen participation in developing regional master plans and site-specific designs will greatly enhance the conservation of rural heritage in Kenya.

\section{Asserting the heritage value of rural visual resources}

Regional categorization of rural landscapes, according to Bruun (1988), should consider, among other things, natural conditions (landform, climate, soil and vegetation) and land use and infrastructure, cultural elements (archaeological monuments, vernacular 
architecture, as well as space characteristics and scale like openness and restriction). Natural areas, forests and surrounding farmlands are essential components that create aesthetic views as well as maintain biodiversity by hosting wildlife. Isolated idiosyncratic features on the rural landscape present epicentres around which animal life, plant life, agricultural and tourism activities revolve (Ryszkowski 1988). The Karue Hill in Embu County is an example: a visual resource whose preservation is critical for the sustainability of the rural heritage of the hill and its environs.

Conservation of rural heritage competes with other aspects of human life in and around these spaces, for instance cultural and economic activities. Without adequately catering for the interrelationships between rural visual resources and activities in and around these spaces, it is difficult to make meaningful progress in conservation. Takeuchi et al. (2003) posit the need to broaden the scope of conservation from mere preservation of natural areas to looking at ways to enhance co-existence between man and nature. Biodiversity is a key contributor to rural heritage in the form of unique and/or rare plants and animals. These plants and animals are at the centre of sustainability of the ecosystem and human life as well as tourism. They also play a great role in social activities and art, such as in the creation of poem motifs, songs, and so on, by indigenous peoples (UNEP 1999). This biodiversity is rarely limited to 'natural' areas but also includes humanmanaged landscapes like farmlands (Hiromi \& Kobori 2003) whose conservation encounters challenges due to existing land ownership structures and politics.

Human beings generally prefer natural environments to urban ones (Herzog 1988). Although rural environments may never provide a replacement to life in the city, they uplift the spirit with many people looking to nature for meaning and order, peace and tranquillity, introspection and stimulus (Mcharg 1969). The scenic character of these rural landscapes largely contributes to heritage value and subsequent conservation, especially in spaces that have retained their old character. The visual character of rural areas has been widely recognized as an important resource to human wellbeing and these areas should be viewed as not only productive but also scenic spaces. Nassauer (1989) notes that in the USA the motivation behind driving to the countryside is pegged as much on the experience of being in the country as it is on the need for vegetables. Attention directed towards scenic landscapes has also been observed as a restorative process against fatigue and stress since it avoids distractions (Kaplan 1995). In addition, the aesthetic quality of 
an environment affects the immediate experience and the sense of wellbeing in those surroundings (Nasar 1988). Rural tourism is also largely dependent on the scenic quality of the environment. Degrading the scenic qualities of the environment therefore reduces the national income that Kenya generates through tourism.

Increasing poverty in many rural parts of Kenya has led to destruction of vegetation cover and uncontrolled quarrying, stripping off the scenic quality of rural landscapes. Many policymakers have the common view of rural areas as either wilderness or purely functional landscapes suitable for agriculture and quarrying, where the dweller has no sense of aesthetics towards the surroundings. Uncontextual developments have produced identity disarray, thereby eroding the visual character of rural landscapes. Development of dwellings on previously unsettled land as populations rise is crucial to local populations, although this can be carried out in a way to ensure a balance of economic, environmental and heritage aspects of the rural landscape. The context, size of dwellings, architectural styles and visibility from main roads also affect the scenic character of a rural landscape and must be considered in formulating guidelines meant to promote rural heritage. Issues affecting both man and nature must be considered in rural heritage conservation (Takeuchi 2003), especially the simultaneous benefit for both humans and nature from natural resources, minimizing disruption of local processes as humans move to formally unsettled lands and retaining and/or creating 'nature' in managed landscapes.

\section{Quantifying rural heritage; developing positive theory}

Ignorance in regard to the aesthetic attributes of rural surroundings can be partially attributed to the economic approach to environmental resources, where resources are valued on the basis of their monetary worth. The lack of an alternative value measurement of these resources has led to destruction of the environment (UNEP 1999), hence a need to quantify elements of rural heritage. In order to develop design cues, planning guidelines and prioritize areas for conservation, it is critical to explain why some objects' features might be more attractive than others (McGranahan 2008). For landscape architects and policymakers to make appropriate conservation plans, designs and aesthetic guidelines relating to rural areas, they need to assess the variables that determine the aesthetic value that contributes positively to public perceptions. 
Ulrich (2006) posits three reasons for people's preference for certain objects. Firstly, users will prefer a beautiful artefact to an ugly artefact; secondly, the aesthetic response to an artefact is usually the first response to the artefact; and finally, beauty may serve as a signal for unobservable attributes of quality in an object. Over $90 \%$ of our perception of reality is visual perception (Wolski 1988), therefore, examining people's visual perception towards various environments can provide essential cues to the value they place on various attributes of the physical environment. Carlson (1977) advocates for the consideration of visual resources as equal to other land resources. This chapter proposes a method for assessing the aesthetic value of rural landscapes held by lay respondents, and the data interpreted on the basis of expert assessment of constituent variables, in order to draw a relationship between the physical attributes of the rural environment and people's perceptions.

Cues derived from perception assessments can be used in creating guidelines and master plans. Nasar (1988) presupposes that the ultimate goal of research into environmental aesthetics is the understanding of environmental influences on affects and translating that understanding into environmental design that is judged favourably by the public. According to Lang (1987), there are two broad approaches to the study of aesthetics. The first involves the study of the processes of perception, attitude formation and cognition; it is psychological in character and is concerned with positive theory (Figure 9.1). The second involves the study of aesthetic philosophies and the creative processes, and is largely metaphysical and psychoanalytical. It is concerned with normative theories of designers and artists (Figure 9.2). This chapter concentrates on the development of positive theory by using perceptions to develop design cues and policy guidelines.

To better plan, design and manage settings to fit people's preferences and activities for an improved quality of life, the knowledge of the relationships between properties of the visual environment and human

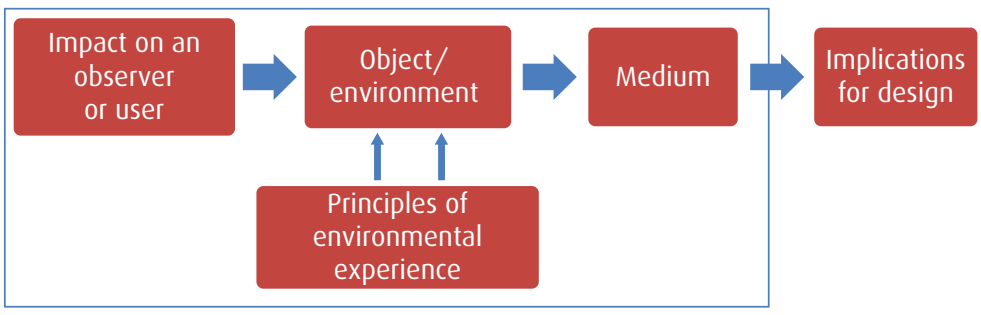

Figure 9.1 Developing positive theory (adapted from Lang 1987) 


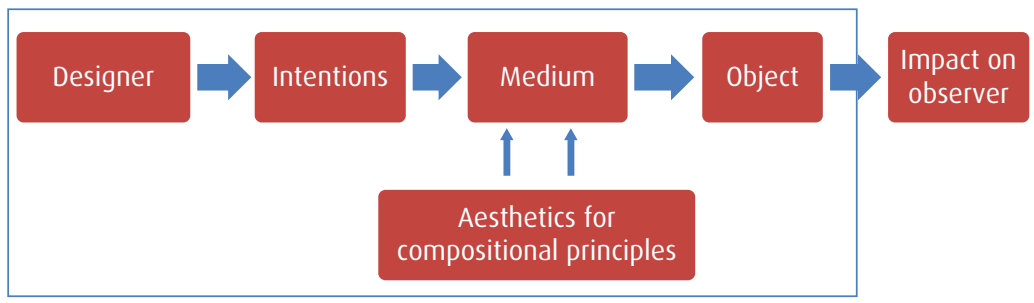

Figure 9.2 Developing normative theory (adapted from Lang 1987)

affect is critical (Nasar 1988). In addition, in order to obtain an accurate measure of likability of a rural heritage on the population, a keen selection of scenes for measurement is crucial. Herzog (1988) advocates for a broad sampling of scenes that reveal several categories of natural sceneries that are differentially preferred with specific identifiable variables that partially account for reactions to the natural environments. The analysis, description and manipulation of these variables should undoubtedly formulate a successful heritage conservation design based on public opinion.

\section{Citizen participation in rural landscape conservation}

Rural landscapes are components of grand aesthetic and cultural value. In most cases, the planning of these areas has been relegated to professionals who follow normative theories and individual tastes, creating psychological alienation. This approach eschews public participation. Scenic landscapes are thus homogenized due to loss of variety and complexity. Moreover, the planning process adopted in the conservation of rural areas has failed to incorporate social process, and emphasis has been on the technical aspects of master planning.

Some of the changes that have been prevalent in rural landscapes include indiscriminate quarrying, deforestation, new farming systems and incoherent architecture discordant with the surroundings (Coen 1987). Most of these processes take place on private land whose owners are more keen on direct benefits (Galzer 1988), hence the complexity in convincing them to adapt conservation measures. The conservation of rural heritage must involve citizens living in and/or owning land in these rural areas. The inter-linkage between settlements, farmlands, surrounding forests and water bodies must also be maintained for the visual landform to retain its aesthetic meaning (Takeuchi 2003). Heritage conservation must therefore be done in a way to stimulate the 
rural economy, for instance through tourism, without increasing the living costs of rural areas.

Efforts aimed at rural heritage conservation can involve the local populace at various levels, such as thinning existing trees in forests and planting new trees. Co-ownership of projects among the local communities, private developers and government agencies through shareholding also increases community attachment to a project. The involvement of volunteers and university researchers, designing certain areas for citizen parks or reserved areas and voluntary activities that renew citizens' identification with the traditional farmland surroundings also contributes greatly to successful rural heritage conservation (Takeuchi 2003). Pertinent rural conservation issues that citizens should be involved in include regulations in architecture and infrastructural development, such as maximum floor areas, that should not necessitate approval by government agencies, and earthwork (filling/excavation) projects. Spirn (1998) gives a vivid description of how land is shaped by human activities through time.

Natural processes establish the base rhythm that is expressed in the initial form of the land, to which culture, in turn, responds with new and changing themes that weave an intricate pattern, punctuated here and there by high points of nature and art. Landscape symphonies evolve continually in time, in predictable and unpredictable ways responding and process and to human purpose, and in landscape symphonies, all dwellers are composers and players (Spirn 1998, 22).

\section{Karue Hill, Embu County, Kenya}

Landmark features on the rural landscapes present a visual pause to a viewer before the meandering eye proceeds to experience the rest of the landscape. Karue Hill is such a landmark, located in Embu County off the Embu-Meru Road. It is a moderate hill that particularly draws its popularity from its vantage position, the unique rock formations (Figures 9.3 and 9.4) and the cultural significance it presents to the Aembu people. The dazzling view of the hill from the Embu-Meru highway is a distant attraction to a rural landscape comprising homesteads, farmlands and 'natural' areas. The hill, therefore, serves as a scenic attraction to travellers as well as an epicentre for the culture, farming activities and human life in the surrounding areas. It is undoubtedly an address unifying the local population to each other and to the rest of the world. 


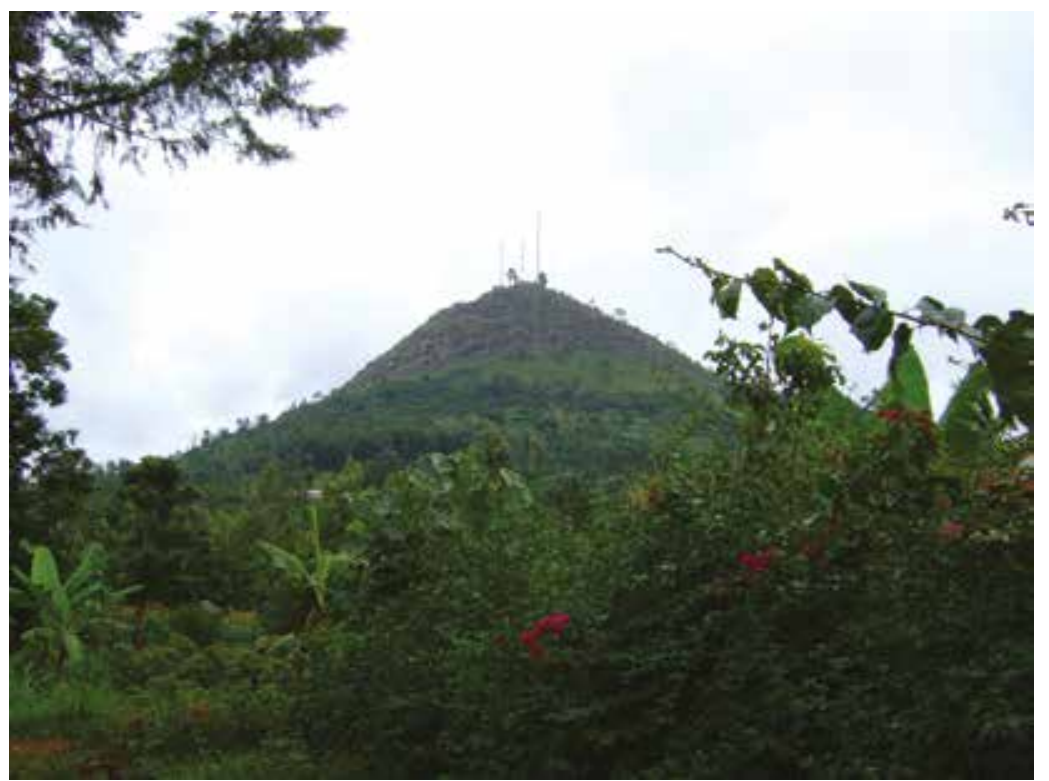

Figure 9.3 A view of Karue Hill (Murithi 2011)

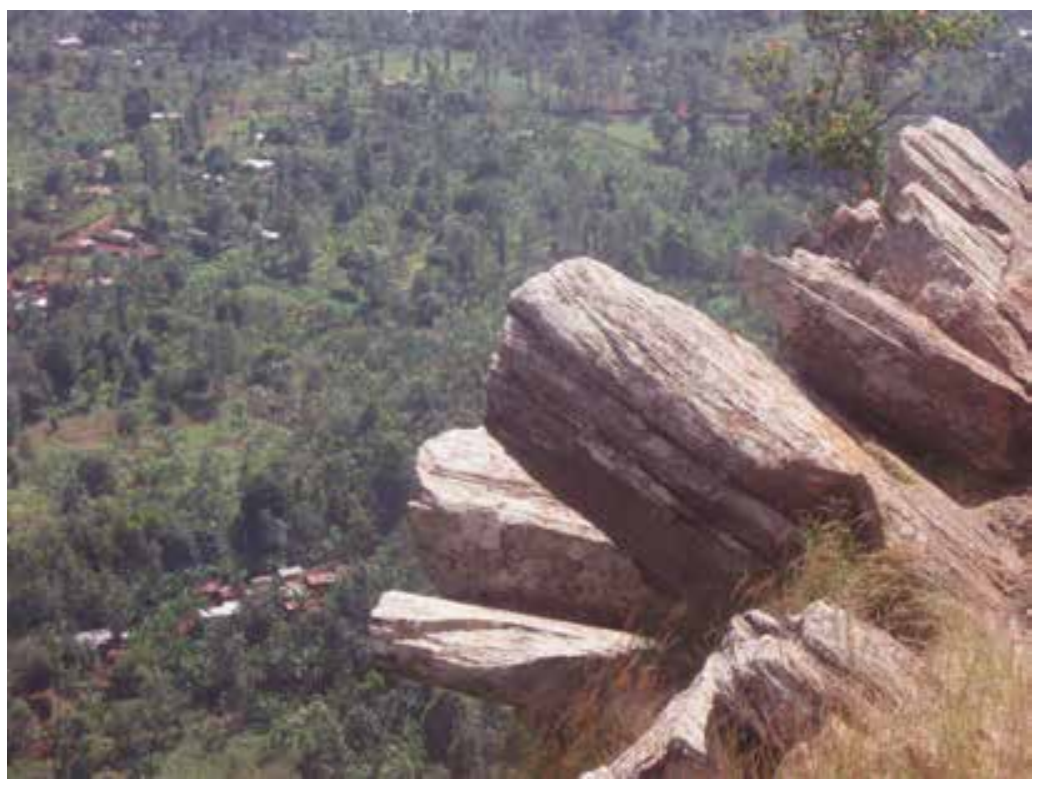

Figure 9.4 Unique rock formations on Karue Hill (Murithi 2011) 
Oral lore indicates that the hill was a host to spirits that worked at night and rendered any visits to the hill impossible. Missionaries are believed to have driven them to the Maranga Hill through loud prayers. The pouring of libations also took place at the hill. These included millet and beans by women collecting grinding stones. Today the hill is popular for romantic picnics, due to its serenity, but it is also used for prayers by different religious groups. The access to the hill is not well defined, making it less inviting to vistors. The place lacks appropriate trails up the steep slope; the elderly and physically challenged also find it difficult to climb to the peak, and this challenge effectively reduces the number of visitors.

Karue Hill is one of the visual resources whose potential for tourism has been undermined by the surrounding communities due to their concentration on direct economic benefits of quarrying and farming. The cultural significance of the hill has been reduced by changing lifestyles and poor preservation of local knowledge. Quarrying of rocks for construction materials by the residents and installation of telecommunication masts at the peak has also tampered with the interesting rock formations on the hill (Figures 9.5 and 9.6).

The establishment of unique visual experiences and rich cultural content on Karue Hill would be consistent with the government of

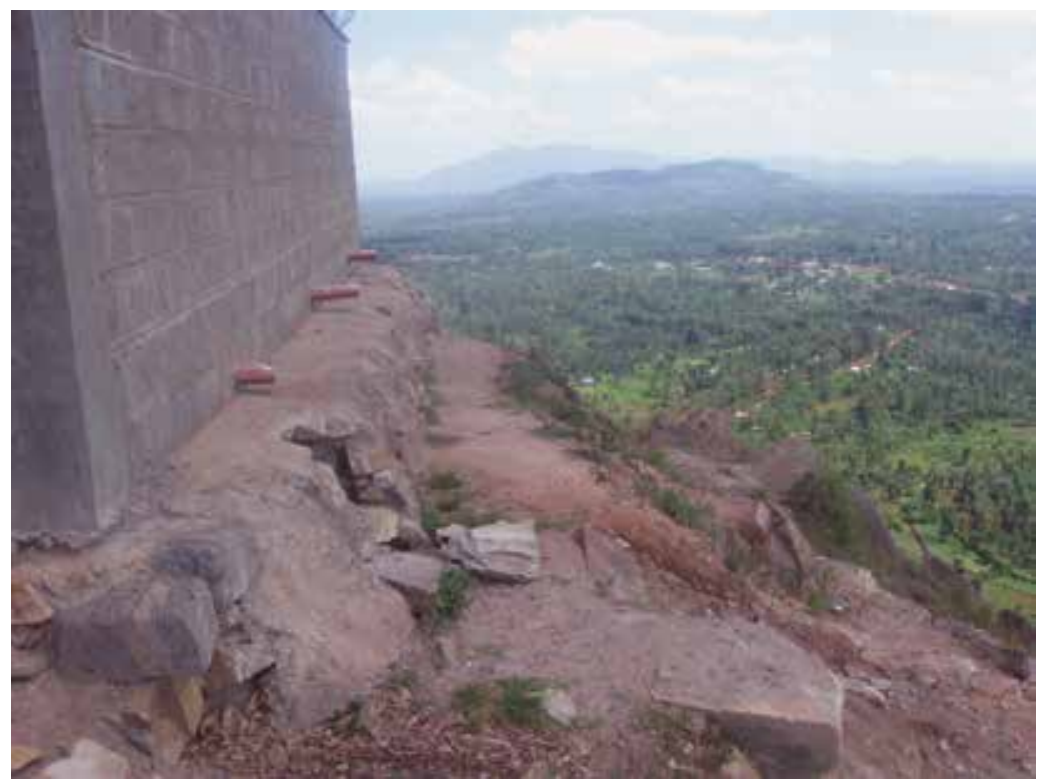

Figure 9.5 Discordant constructions at the peak (Murithi 2011) 


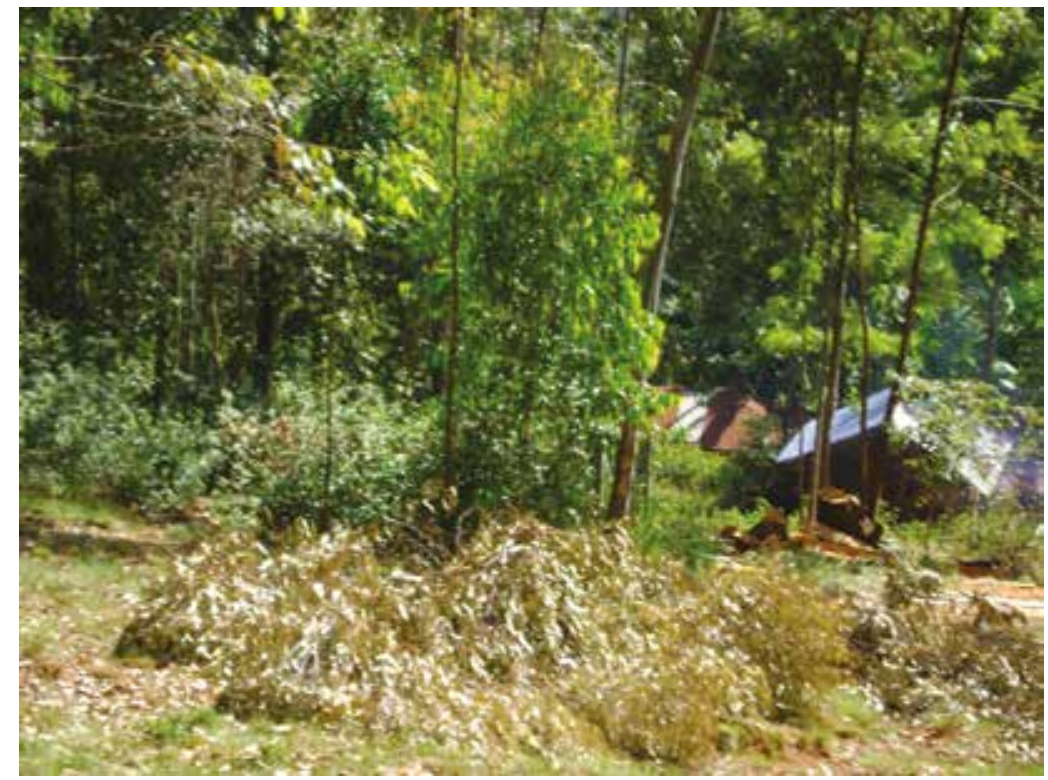

Figure 9.6 Deforestation on Karue Hill (Murithi 2011)

Kenya's aim of promoting all manners of national and cultural expressions through literature, the arts, traditional celebrations and other cultural heritage (Republic of Kenya 2010). Most people in Embu County depend on small-scale farming. This is currently on a downward trend. There is poorly developed tourism partly due to erosion of the indigenous culture and environmental degradation apparent in the deforestation and quarrying.

The research for this chapter was carried out as a survey using structured interviews. One hundred coloured photographs (from various places including the Karue Hill) in an album were sequentially exposed to respondents for at most five seconds, after which they stated their likability of the scenes in the photographs on a semantic differential scale. Four judges assessed the photographs on the basis of specific variables (coherence, spaciousness and complexity).

\section{Reassessing development and conservation in rural landscapes}

Rural areas should be conserved to retain their distinct character, a process that should involve slowing and possibly reversing the processes of change in areas which have not been completely destroyed. This should 
be done in a way to revitalize the rural economy rather than undermining development. County governments in Kenya should take part in formulating landscape planning policies and guidelines for rural areas that are specific to their regions. Additional site-specific guidelines should be formulated in management of rural recreation sites to ensure a balanced development process where development measures do not conflict with existing physical patterns and environmental processes.

This case study established the need to involve the local populace in planning and design for rural heritage conservation. Very little documentation exists concerning the visual and tourism aspects of these resources, which is a great indicator of how little attention it is given when compared to other aspects of the landscape, such as farming. Rural heritage as a resource can be a key attraction to pull development and economic growth to rural areas. As the monetary benefits of farming decline, tourism forms a major boost to the economies of rural areas in Kenya. Other facilities not designed for tourism can also be used to pull tourists into rural areas. Farmers and managers of processing factories can open up their places of work to encourage tourism. Some structures intended for housing, buying centres and others may be converted into tourist lounges. Walking trails in tea farms and rice paddies across Kenya with viewing decks and boardwalks can add to the excitement of experiencing a rural area.

The design in scenic rural areas should encourage learning and research activities, especially through a well-guided structure in naming of relevant spaces, plant species and artefacts. Visually appealing rural landscapes offer good outdoor spaces for learning about the natural environment processes which is also a representation of invisible processes that have shaped the landscape to its current state. Some spaces host unique flora and fauna rarely found elsewhere.

\section{Conclusion}

This chapter has established the need to involve residents of a rural area in generating ideas and formulating broad guidelines in rural heritage conservation and site-specific guidelines to uplift the number of rural tourists. It has also established likability for open spaces with a significant level of coherence, spaciousness, 'identifiability' and mystery. The degree of order or structure present in the immediate environment, such as coherence, and the extent to which the larger setting is well structured in depth - spaciousness - are components that aid in 
the process of 'making sense' of the environment. 'Identifiability', that is the ease of space users to understand a space, contributes highly to the space's likability. Rural recreation spaces should therefore be very legible to ensure their likability. The use of artefacts relevant to communities in focus enhances the familiarity of users to specific spaces. Mystery in experiencing spaces should be well articulated to satisfy the innate curiosity and urge to explore. This can be achieved by having spaces that encourage strolling and exploration; a user of a certain space should anticipate episodic views to be encountered through continued movement on site.

The use of photographs to obtain respondents' perceptions proved to be an effective and fast method in data collection. Coloured photographs drawn from the area and other places greatly engaged respondents in determining the visual quality which contributes vastly to the heritage value of rural areas. The residents of Karue Hill's vicinity should play the biggest role in the management of visual resources in the area. This would ensure that they use their own social structures and any available resources to accomplish community goals that are decided primarily by community representatives and are generally consistent with local attitudes and values. Conservation efforts in Karue Hill should be geared towards a shift from merely halting destruction of the environment resources to harvesting visual resources through tourism. 


\section{Development of cultural heritage tourism in Kenya: a strategy for diversification of tourism products}

Evaristus Irandu and Parita Shah

\section{Introduction}

Kenya is richly endowed with diverse cultural resources that can be developed for cultural heritage tourism. The exploitation of her heritage assets would increase Kenya's competitiveness as a top tourist destination in Africa. Today, the country is facing stiff competition from countries such as Seychelles, Mauritius, Namibia and Botswana which have diversified their tourism products. Since independence in 1963, Kenya has relied heavily on wildlife and beach resources as her main tourist attractions. Like many other countries in Africa, Kenya has come to rely increasingly on tourism as one of the top foreign exchange earners, so much so that her traditional tourism products based on wildlife and coastal beaches face the risk of losing their uniqueness and appeal.

There are a number of strategies to deal with this problem without jeopardizing the necessary foreign exchange earnings tourism brings to the country. In the case of Kenya, perhaps, the two most important ones are (a) dispersion of tourists to underdeveloped areas, and (b) diversification of products to include cultural heritage tourism and other forms of special-interest tourism. This chapter focuses on the latter strategy. The challenges faced in the development of cultural heritage assets as tourism products are also discussed. The chapter uses strengths, weaknesses, opportunities and threats (SWOT) analysis to establish the potential of cultural heritage tourism in Nairobi as a case study. It also uses secondary sources, visitor surveys and in-depth interviews 
with heritage site managers to illustrate the huge potential that exists in the country for cultural heritage tourism.

\section{Defining and conceptualizing cultural heritage tourism}

Today, tourism products are becoming very dynamic. As Nyaupane et al. (2006) and Sethi (2005) have observed, there is a shift from the normal tourism trends that centred on nature towards cultural heritage tourism. As this demand increases, countries begin to shift towards the supply side. Kenya should identify the means of developing her cultural heritage into attractive tourist attractions. This can be done by taking advantage of the country's unique culture, history and heritage by creating local, national and international awareness.

Culture is defined in different ways. For instance, Leiper (1995) defines culture as the intangible asset of heritage represented by a system of shared beliefs, customs, language and behaviours that members of society use to cope with their community and with one another, and that are transmitted from generation to generation through learning. According to UNESCO (1982), culture refers to the whole complex of distinctive spiritual, material, intellectual and emotional features that characterize a society or social group. It includes the fundamental human rights, value systems and traditions.

Thus, according to Leiper (1995) and UNESCO (1982), culture is the way of life of a group of people, the behaviours, beliefs, values and symbols that they accept, generally without thinking and that are passed along by communication and imitation from one generation to the next. It would appear that culture is the sum total of the learned behaviour of a group of people that is generally considered to be the tradition of that people. It can be observed that in any given society, material culture is viewed as a visual expression of identity and the use of material culture is thus seen as one of the most obvious manifestations of identity communication.

From the available literature, it can be deduced that culture has at least three different, but intertwined, meanings. The first meaning considers culture from the arts perspective and involves performances in theatres, dance or music halls and displays of fine art, and other artistic expressions. The second meaning refers to the unique natural features in the local landscape and built environment. The third meaning refers to the social and psychological practices upon which a people or society understand and interpret the world around them. In this chapter, 
the UNESCO (1982) definition is adopted because of its emphasis on the intangible aspects of culture.

Ivanovic $(2008,58)$ defines cultural heritage tourism as 'travelling to experience the places and activities that authentically represent the stories and people of the past and the present'. It can be argued that cultural heritage tourism includes historic buildings and monuments, the sites of important past events like battlefields, traditional landscapes and indigenous wildlife, language, literature, music and art, traditional events and folklore practices, traditional lifestyles including foodways and drink, and sports. According to the World Heritage Convention, cultural heritage includes both tangible and intangible assets, such as monuments (archaeological works, works of monumental sculpture and painting, elements or structures of an archaeological nature, inscriptions, cave dwellings and combinations of historic, artistic or scientific features), groups of buildings, sites, music, dance, drama and memory (UNESCO 2007).

Intangible cultural heritage is defined by $\operatorname{UNESCO}(2003,1)$ as 'the practices, representations, expressions, knowledge, skills - as well as the instruments, objects, artefacts and cultural spaces associated therewith - that communities, groups and, in some cases, individuals, recognize as part of their cultural heritage'. Intangible cultural heritage is transmitted from generation to generation and is constantly recreated by groups in response to their environment, their interactions with nature and their history, providing them with a sense of identity and continuity. In this chapter, prime consideration is given to those examples of intangible cultural heritage which promote mutual respect among communities, groups and individuals, as well as the principles of responsible and sustainable development.

According to the available literature, cultural heritage tourism is the hottest trend in the tourism industry (Cass \& Jahrig 1998). As Johnson (2002) observes, cultural heritage sites do not only have intrinsic beauty and value, they are among the key assets of tourism. Cultural heritage and tourism enjoy a special symbiotic relationship with each enriching the other. Dickinson (1996) opines that this is because tourists want to experience unique places, traditions and history, and learn about the cultural sites in their country.

\section{Typology of cultural heritage tourism}

In Kenya, the tourism industry has transformed from mass tourism to cultural tourism so as to reduce the large scale negative impacts 
generated from mass tourism, such as environmental pollution and overcrowding. Therefore, the role of culture is becoming increasingly important in the development of the tourism industry. The industry acts as a new platform to promote local cultures and international cultural exchange.

Cultural heritage tourism is a form of special-interest tourism that has been growing rapidly in the last few years and currently is ranked as one of the major growth areas in global tourism demand. Cultural endowments such as traditional architecture, unique streetscapes and historic sites are increasingly recognized as important tourist resources in both developed and developing countries. Cities are often important focal points for development based on these resources because they provide concentrations of heritage assets, infrastructure services, private sector activity and human resources. Improving the conservation and management of urban heritage is not only important for preserving its historic significance, but also for its potential to increase income-earning opportunities, city livability and competitiveness.

According to Smith (2003), the following list suggests a comprehensive typology of cultural tourism products that can be developed:

- Heritage sites, such as archaeological sites, whole towns, monuments, museums;

- Performing arts venues, including theatres, concert halls, cultural centres;

- Visual arts such as galleries, sculpture parks, photography exhibits, architecture;

- Festivals and special events, including music festivals, sporting events, carnivals;

- Religious sites, including cathedrals, temples, pilgrimage destinations, spiritual retreats;

- Rural destinations, such as villages, farms, national parks, ecomuseums;

- Indigenous communities and traditions, for example ethnic groups and minority cultures;

- Arts and crafts, such as textiles, pottery or painting;

- Language acquisition and practice;

- Gastronomy - wine tasting, food sampling, cookery courses;

- Industry and commerce like factory visits, mines, breweries and distilleries; 
- Modern popular culture expressions, e.g. pop music, shopping, fashion, media, design, technology;

- Special interest activities, such as painting, weaving or photography.

Many of the cultural tourism products outlined by Smith (2003) can be developed in Kenya to help diversify beyond beach and wildlife tourism. Moreover, there are numerous early and late Stone Age archaeological sites in Kenya, such as Olorgesaillie (Kajiado County), Kariandusi and Hyrax Hill (Nakuru County) that can be developed as cultural heritage sites. Music festivals, carnivals and sporting events can also be developed into cultural heritage attractions for domestic and international tourism.

\section{Cultural heritage and sustainability}

The quality and attractiveness of Kenya as a destination results from many centuries of development. This development has been shaped by the prevailing physical (natural landscape) and socio-economic factors. To sustain the attractiveness and competitiveness of the destination requires recognition and development of the very factors that have shaped it - the key to the development of cultural heritage, the real raw material for tourism.

Sustainable tourism has become a popular but ambiguous term. It is used to mean many things, from recycling, waste and energy reduction to limiting human impact on the natural and cultural resources. Countries and regions where the economy is driven by the tourism industry have become increasingly concerned with the environmental impact of, as well as the socio-cultural problems associated with, unsustainable tourism. As a result, there is now increasing agreement on the need to promote sustainable tourism development to minimize its environmental impact and to maximize its overall socio-economic benefits at tourist destinations. The concept of sustainable tourism, as developed by the UN World Tourism Organization (UNWTO) in the context of the United Nations sustainable development process, refers to tourist activities 'leading to management of all resources in such a way that economic, social and aesthetic needs can be fulfilled while maintaining cultural integrity, essential ecological processes, biological diversity and life 
support systems' (UN 2001). This chapter adopts this definition because it is flexible and allows a variety of approaches and interpretations of the concept. For example, cultural heritage tourism is considered as a form of sustainable tourism.

\section{Authenticity and commoditization}

According to Greenwood (1977), tourism tends to lead to commoditization of local culture. For example, colourful local costumes and customs, rituals and feasts, and folk and ethnic arts become touristic services or commodities as they come to be performed or produced for touristic consumption. The issue here is that commoditization is likely to change the meaning of cultural products, making them meaningless: worldwide experience shows that local culture is altered and often destroyed by the treatment of it as a touristic attraction (Greenwood 1977, 131). Besides, since local culture can be commoditized by anyone without the consent of the participants, it can be expropriated, and the local people exploited. Commoditization tends to destroy the authenticity of local cultural products leading to staged authenticity (MacCannell 1973). The problem of authenticity is of concern to Kenya as some people connive to sell inauthentic cultural products such as spears and shields to tourists.

\section{Theoretical framework}

Many studies on cultural heritage tourism have used social identity theory as the theoretical framework (Tajfel \& Turner 1978, 1986; Maghenda \& Mwanza 2014). Social identity theory postulates that when an in-group identity is made, people often wish to emphasize characteristics of their group that they value (Tajfel \& Turner 1986). The theory suggests that by expressing its distinctive characteristics, people can thereby assume unqualified pride in their membership in this group. Moreover, the theory suggests that public identification with the group translates into a greater sense of personal worth. This theory is relevant to the Kenyan situation. According to the theory, Kenyans can classify themselves as members of the same in-group, with their cultural heritage being the unifying factor. 


\section{Cultural heritage tourism in Kenya}

As Pattullo (2005), Potter et al. (2004) and Strachan (2002) have observed, many developing countries, including Kenya, have not developed their tourism industry much beyond the three Ss (sun, sand and sea). For example, Kenya has done little to attract cultural heritage tourists. It should be borne in mind that in society today, many people are travelling more than ever before, for many different reasons. Some travel for business, relaxation or adventure. Others travel to learn and experience the cultural heritage of other societies (Erickson 2001).

The development of cultural heritage tourism in Kenya can be rationalized on the grounds that it:

1. Increases diversity of tourist experiences;

2. Improves sustainability for cultural heritage sites through higher public profile and educational awareness;

3. Allows more Kenyans and tourists to share the rewarding and enormously varied opportunities for exploring the individual stories, communities, places and ideas that have shaped the country's social and physical environment.

Kenya has made a big contribution to the development of tourism both regionally and globally. For example, as early as AD 1331, what is presentday Kenya was already welcoming visitors (Were \& Wilson 1968). Prior to this period, trade between Asia and East Africa was thriving through Mombasa and other coastal towns. Kenya has many actual and potential products for cultural heritage tourism. For instance, the coastal city of Mombasa and the town of Lamu have unique architecture. Lamu has retained its original architectural style. The old Islamic town has no modern roads and donkeys are the only means of transport. Lamu has already been declared a UNESCO World Heritage site (Figure 10.1). Mombasa was founded in the twelfth century as an export centre for ivory and slaves. By AD 1490, it even overtook Kilwa in terms of settlement and development. Mombasa soon became the hub of Swahili culture (Were \& Wilson 1968). Other important cultural heritage sites in the country include:

1. Krapf Memorial Museum at Rabai in Kilifi County, which is considered as the first Church in Kenya, built by Luidwig Krapf in 1846. This church is associated with the arrival of Christianity (in Kenya) and modern formal education in Kenya (Maghenda \& Mwanza 2014). 


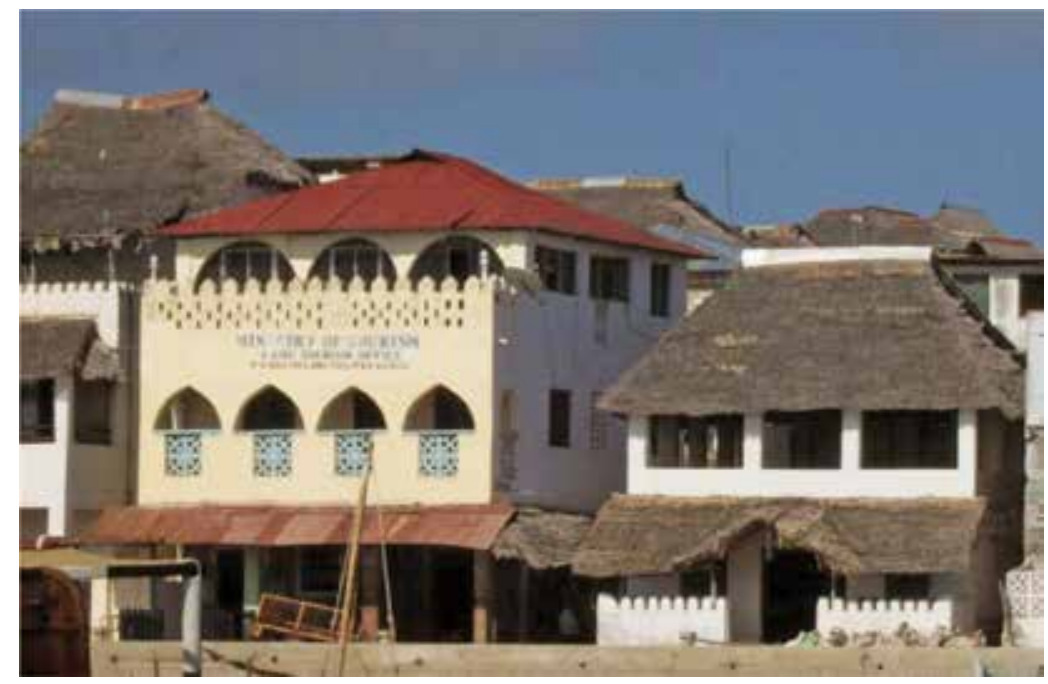

Figure 10.1 Lamu (Shah 2014)

2. Kaya Kinondo, also known as Kaya Ngalaani, is gazetted as National Monument under the National Museums Act. It is located on Kenya's south coast in Msambweni, Kwale County. It is owned communally by the local Digo community and is managed through a set of traditional rules and regulations (taboos) enforced by a council of elders, as it used to be since time immemorial. The forest is found close to the famous Diani beach, one of the most intensively developed tourist resorts on the Kenyan coast (Maghenda \& Mwanza 2014).

3. Kenyatta International Conference Centre (KICC). When local and foreign delegates come for conferences and meetings in Kenya, they usually meet at the KICC (Figure 10.2) which is the largest convention facility in East Africa.

4. Swaminarayan Temple on Forest Road, Nairobi (Figure 10.3). It can be said that wherever in the world the Indian diaspora reached, it carried with it a slice of India. That is, its cuisine and customs, culture and spirituality. This process enables the people of Indian origin to remain connected with the land of their ancestors. In Kenya where the pioneers among Indian settlers arrived over one hundred years ago, a new thirst for linkage with India is clearly noticeable. One of its best manifestations is the Swaminarayan Temple on the Forest Road in Nairobi. This magnificent temple was inaugurated on 29 August 1999 and its architecture is an attraction in itself. 
Its uniqueness stems from the innovative mix of religious and spiritual aspects with social, cultural and educational dimensions, all rooted in the soil of India and presented to the world under the inspiration of an outstanding sage of the modern times. (His Divine Holiness Pramukh Swami Maharaj 2002)

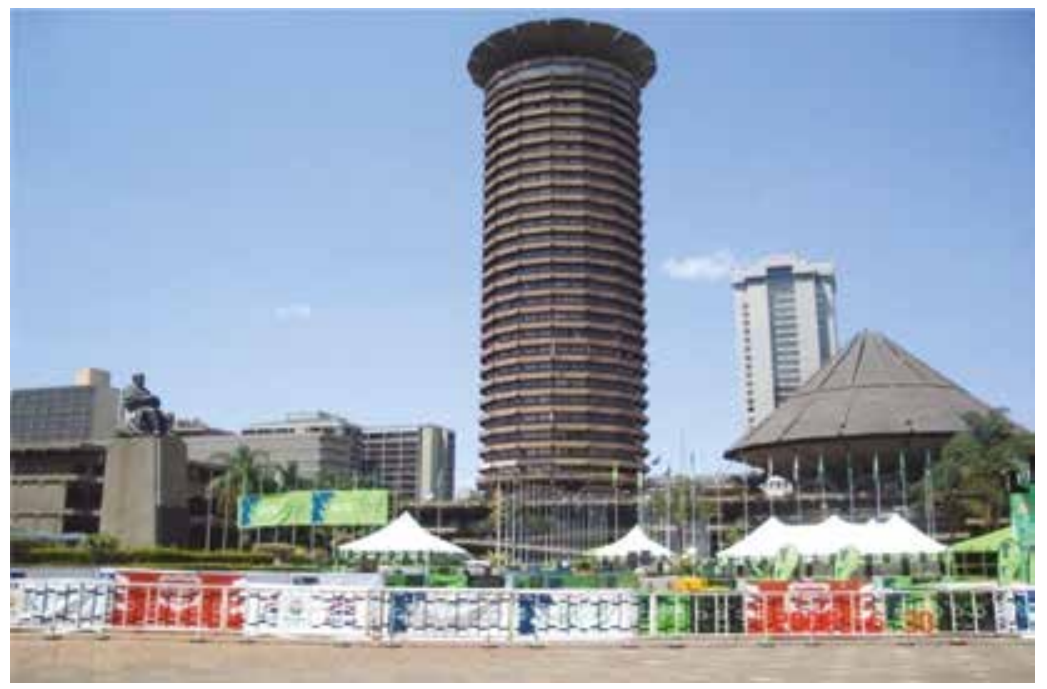

Figure 10.2 The Kenyatta International Conference Centre (worldpress.com 2016)

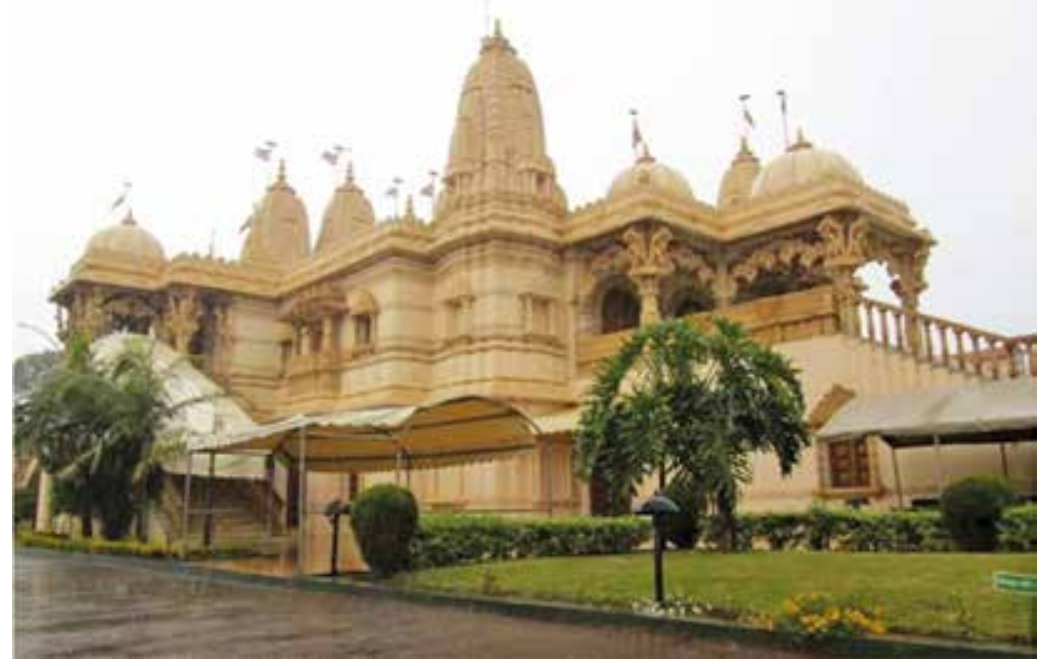

Figure 10.3 Swaminarayan Temple on Forest Road, Nairobi (Shah 2014) 
Kenya has several other beautiful Indian temples such as the Jain temple in Mombasa, the SSD temple in Nairobi and the Lakshminarayan temple in Kisumu. But the Swaminarayan temple complex is one of the newest and largest temples in Kenya.

Kenya has about 42 ethnic communities, each with its own unique culture and language developed over many years. These communities have their own artefacts consisting of implements, containers and dresses, among other types. These resources are continuously being preserved as well as conserved by the National Museums of Kenya (NMK).

\section{Cultural heritage tourism in Nairobi}

As indicated earlier in the chapter, a case study was developed for Nairobi as it was not possible to carry out a meaningful SWOT analysis for the whole country. Nairobi was chosen since it is cosmopolitan and the capital city. It is home to different Kenyan, African, European and Asian communities with their own unique cultures which are part and parcel of the country's national heritage.

Nairobi comes from the Maasai phrase enkare nairobi meaning 'a place of cool water'. This implies that the Maasai community used to graze their livestock in Nairobi before the arrival of the railway. When the Kenya-Uganda Railway (KUR) reached Nairobi in 1899, the railway contractors chose it as an ideal resting place before proceeding with the construction of the railway. It then grew as the British East Africa's commercial centre, and in 1907 became Kenya's capital (Mitullah 2003; Rakodi 1997). The city's size is $58,300 \mathrm{~km}^{2}$. Nairobi's population is over 3 million (KNBS 2009). The major rivers are the Nairobi, the Ngong and the Mathare, with the largest tract of an indigenous forest, the Karura Forest, lying to the north of the latter. Nairobi has a variety of known cultural heritage products which are offered to the tourists and others which have tourism potential. They are categorized into meeting places, remarkable architecture, public spaces, palaces, temples, sacred hills, forests and memory places. This is shown in Table 10.1.

Primary data was collected through questionnaires administered to tourists who visited the National Museums of Kenya (NMK), Nairobi National Park (NNP) and Karura Forest. The tourists were selected using simple random sampling. The three sites were selected because they all possess cultural heritage features. Therefore, it was important 
Table 10.1 Existing and potential cultural heritage products of Nairobi (Irandu \& Shah 2014)

\begin{tabular}{|c|c|c|c|c|c|c|c|c|c|}
\hline & $\begin{array}{l}\text { Marketing } \\
\text { place }\end{array}$ & $\begin{array}{l}\text { Remarkable } \\
\text { architecture }\end{array}$ & $\begin{array}{l}\text { Public spaces } \\
\text { for festivities }\end{array}$ & Palaces & Temples & $\begin{array}{l}\text { Scared } \\
\text { mountains }\end{array}$ & $\begin{array}{l}\text { Forest/ } \\
\text { caves }\end{array}$ & $\begin{array}{l}\text { Memory } \\
\text { places }\end{array}$ & $\begin{array}{l}\text { Cultural } \\
\text { sites }\end{array}$ \\
\hline $\begin{array}{l}\text { Current } \\
\text { products }\end{array}$ & $\begin{array}{l}\text { KICC } \\
\text { Hotels } \\
\text { Uhuru Park }\end{array}$ & $\begin{array}{l}\text { Donovan House } \\
\text { Don Bosco } \\
\text { Church, Upper } \\
\text { Hill }\end{array}$ & $\begin{array}{l}\text { Uhuru Park } \\
\text { Nyayo Stadium }\end{array}$ & & $\begin{array}{l}\text { Gurudwara } \\
\text { (Bazaar) of } \\
\text { 1940s }\end{array}$ & Ngong Hills & Karura & Karura & $\begin{array}{l}\text { Bomas } \\
\text { of Kenya } \\
\text { (Cultural } \\
\text { Centre) }\end{array}$ \\
\hline $\begin{array}{l}\text { Potential } \\
\text { products }\end{array}$ & & & Uhuru Gardens & $\begin{array}{l}\text { State } \\
\text { House }\end{array}$ & New temples & & & $\begin{array}{l}\text { Jomo } \\
\text { Kenyatta } \\
\text { Mausoleum }\end{array}$ & \\
\hline
\end{tabular}


to establish whether these sites were effectively marketed in order to develop tourists' interest in cultural heritage. In-depth interviews were held with site managers of the National Museums of Kenya (NMK), Nairobi National Park (NNP) and Karura Forest who were selected using purposive sampling. The aim of these interviews was to obtain information on the potential and possible exploitation of cultural heritage tourism products in Kenya.

\section{Discussion}

\section{Results from tourists}

In all three sites, the age distribution of tourists was similar. The age group 31-40 years was the most frequent, followed by $21-30$ and 11-20; 40-50; over 50 and 1-10 years. This is shown in Figure 10.4.

Research carried out by Poria et al. (2004) in the worship sites of the Wailing Wall in Jerusalem and the Massada in Israel showed that the 20-29 age group was the highest, followed by the 31-40 age group, while the others were consistent with Figure 10.1. This shows some variation in the findings. This could possibly be due to differences in levels of tourists' awareness of the cultural heritage products available at the sites.

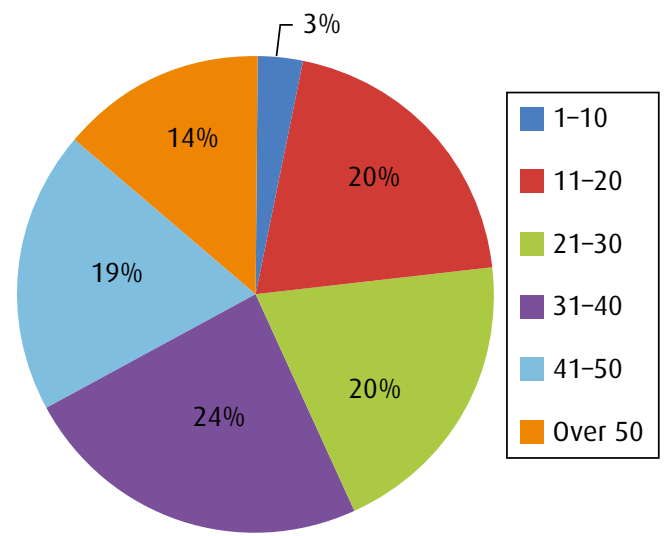

Figure 10.4 Age of tourists at the respective sites (Irandu \& Shah 2014) 


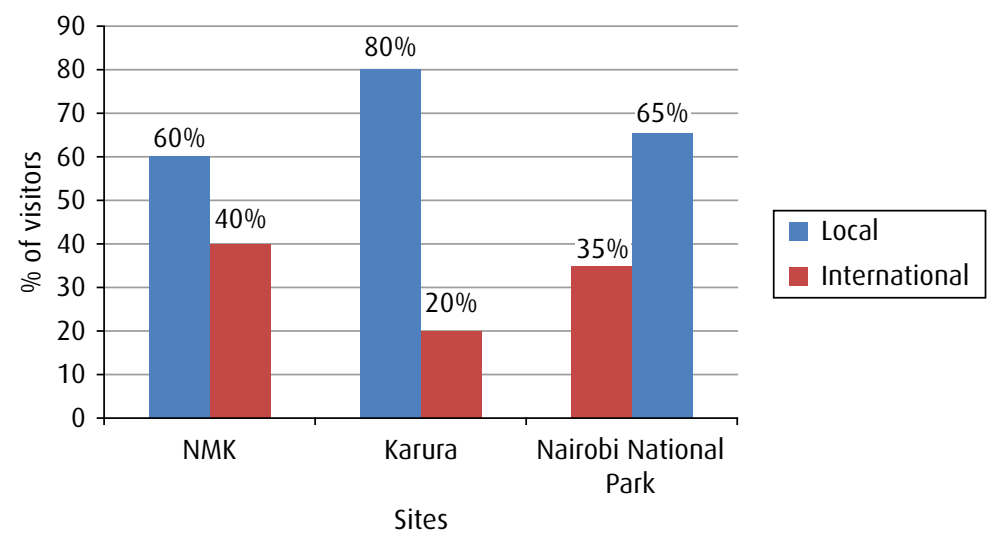

Figure 10.5 Types of visitors (Irandu \& Shah 2014)

\section{Types of tourists}

The number of domestic and international tourists varies from site to site as shown in Figure 10.5. The NMK and Karura Forest have the highest number of domestic tourists while the NNP has the highest number of international visitors. This is because in both NMK and Karura Forest, local visitors looked for places near their home which were reasonably affordable and sites offering education facilities. NNP mainly had international tourists because the site was expensive and beyond the reach of most local people.

\section{Preferred type of tourism}

The tourists were asked to indicate their favourite type of tourism. The results indicate that a majority selected both natural and cultural heritage, followed by cultural heritage and then natural heritage. This indicates that the preference for cultural heritage in the city is increasing (Figure 10.6).

\section{Reasons for visiting}

Respondents were also asked to state their reasons for visiting particular sites. They were given nine choices, which included education, branded product, relaxation, entertainment, cheap entrance, heritage value, sports, worship and biodiversity. Relaxation and biodiversity were rated the highest at 90\% while worship was rated the least at 3\% (Figure 10.7).

Worship was the least preferred reason for visiting the sites. This is because information obtained from tourists indicated that there was very little literature offered as well as very little marketing done on many 


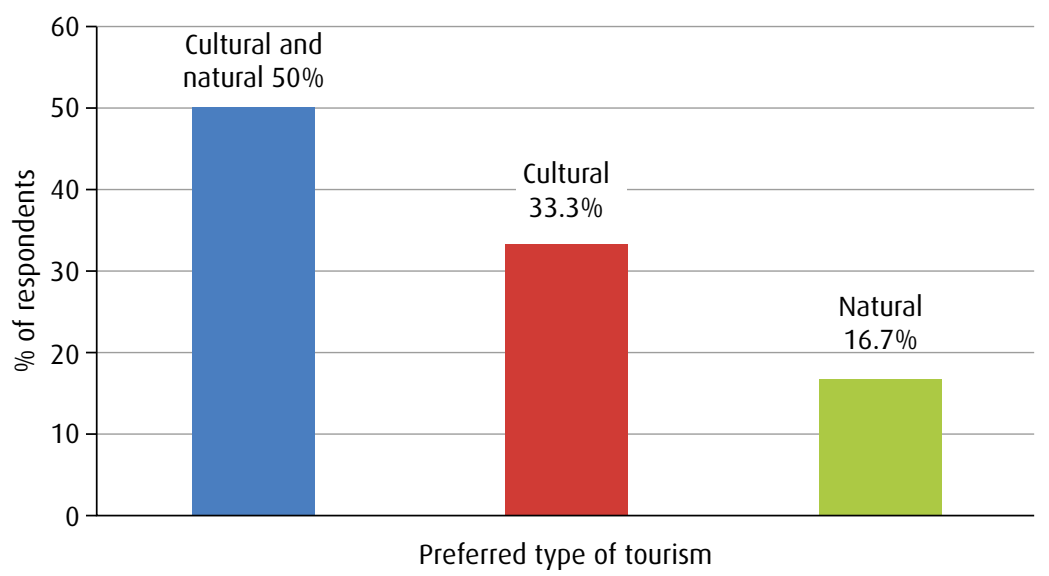

Figure 10.6 Preferred type of tourism (Irandu \& Shah 2014)

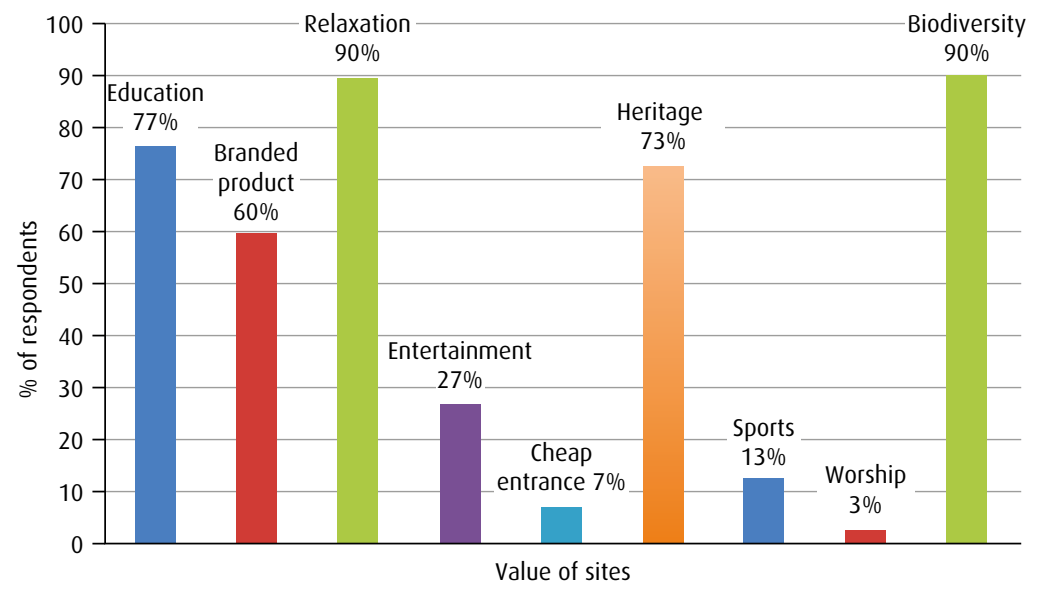

Figure 10.7 Perceived value of respective sites to tourists (Irandu \& Shah 2014)

worship sites. Similar sentiments are shared by the Getty Conservation Institute (2002), which states that places of worship are neglected when it comes to marketing them as sites of tourist interest. However in many other parts of the world, places of worship are very popular tourist sites, especially in Nepal (Nyaupane 2009).

One question was put exclusively to the tourists at Nairobi National Park (NNP). This question was based on whether they were aware that there was a heritage site inside the NNP (the elephant ivory burning site). Only $10 \%$ of respondents were aware of this site, indicating that the KWS had not concentrated on the heritage aspect of it. 


\section{Results from site managers}

\section{Site information}

All the three sites were open to the public. While the NNP and NMK were managed by government institutions, Karura Forest was managed privately. NNP and Karura Forest had cultural heritage and natural sites while the NMK had cultural heritage sites only. At Karura Forest, the cultural heritage included the Mau Mau Caves and the forest being a worship place for some indigenous Kikuyus. At the NNP, the cultural heritage was the ivory burning site while at the NMK the entire museum offered cultural heritage of Kenya.

According to the site officials, the tourists were looking for relaxation, education, shopping facility, sporting facility, indigenous knowledge, entertainment, peace, artefacts and biodiversity. The site officials ranked the priority as shown in Table 10.2.

Table 10.2 shows that in all three sites' education, relaxation, interest and peace were rated highly. In the historical sites (NMK and NNP), education, artefacts and indigenous knowledge were also rated very highly. This is very similar to the research done by Poria et al. (2003) in which tourists stated that the three main reasons for their visiting the sites were heritage experience, learning experience and recreational experience.

\section{Potential sites}

The three site managers suggested new sites with potential for tourism. They all suggested monuments and old buildings. They also suggested measures in order to safeguard the potential sites through fencing and

Table 10.2 Ranking of priorities by tourists (Irandu \& Shah 2014)

\begin{tabular}{lccc}
\hline Priority & NMK & Karura & NNP \\
\hline Relaxation/holiday & 3 & 2 & 2 \\
Education & 1 & 1 & 2 \\
Shopping facility & 4 & & 3 \\
Sports facility & 5 & 3 & \\
Indigenous knowledge/fame & 2 & 2 & 3 \\
Entertainment & 4 & & \\
Peace & 3 & 2 & 3 \\
Artefacts & 1 & 2 & 3 \\
Biodiversity & & & 1 \\
Interest & 1 & 1 & 1 \\
\hline
\end{tabular}


having guards who would be collecting revenue from visitors. This would give economic value to the buildings and monuments and raise funds to finance their conservation.

The SWOT analysis technique was used to show the strengths, weaknesses, opportunities and threats of cultural heritage in the city. This is shown in Table 10.3.

Table 10.3 SWOT analysis of the potential of Nairobi as a cultural heritage centre (Irandu \& Shah 2014)

\begin{tabular}{|c|c|}
\hline Strengths & Weaknesses \\
\hline $\begin{array}{l}\text { - Capital city status and main } \\
\text { cultural centre } \\
\text { - Presence of many institutions } \\
\text { of higher learning for training, } \\
\text { research and consultancy } \\
\text { - Location of NMK for conservation } \\
\text { of national heritage } \\
\text { - Karura Forest for conservation } \\
\text { of culture within city borders } \\
\text { - Location of National Theatre } \\
\text { - International conference } \\
\text { facilities, e.g. KICC } \\
\text { - Shopping malls } \\
\text { - Cosmopolitan and } \\
\text { multicultural city } \\
\text { - Industrial and cultural hub } \\
\text { - Sporting facilities } \\
\text { - Many temples, mosques, cathe- } \\
\text { drals and churches for religious } \\
\text { worship }\end{array}$ & $\begin{array}{l}\text { - Worship places not developed as poten- } \\
\text { tial tourist sites } \\
\text { - No flagship event linked to the city } \\
\text { - Little awareness of old buildings } \\
\text { - Insufficient nightlife } \\
\text { - Lack of funds } \\
\text { - Weak link between heritage conserva- } \\
\text { tion stakeholders, e.g. between NMK } \\
\text { and others } \\
\text { - Limited space for conservation } \\
\text { - Lack of intellectual property rights } \\
\text { - Lack of marketing initiatives for cul- } \\
\text { tural products } \\
\text { - Lack of international accreditations } \\
\text { - Poor dissemination of research results } \\
\text { - Lack of internships and exchange } \\
\text { programmes } \\
\text { - Low involvement of private stakeholders } \\
\text { - Slow response to market needs and } \\
\text { dearth of client-orientated programmes } \\
\text { - Obvious lack of management plans } \\
\text { - Lack of streamlining with cross- } \\
\text { sectors, e.g. culture and ICT, gender }\end{array}$ \\
\hline Opportunities & Threats \\
\hline $\begin{array}{l}\text { - Renovation of infrastructure } \\
\text { - Promotion and marketing of } \\
\text { heritage products } \\
\text { - Commercialization of cultural } \\
\text { activities } \\
\text { - Potential for more partnerships } \\
\text { - Increasing domestic tourism } \\
\text { - Volunteering staff } \\
\text { - Supportive government policies }\end{array}$ & $\begin{array}{l}\text { - Climate change } \\
\text { - Loss of intellectual property } \\
\text { - Theft and vandalism } \\
\text { - Insecurity } \\
\text { - HIV/AIDS leading to loss of culture } \\
\text { - Competition for land } \\
\text { - Poor infrastructure } \\
\text { - Illicit trafficking } \\
\text { - Loss of cultural heritage }\end{array}$ \\
\hline
\end{tabular}


From this SWOT analysis (Table 10.3), it is apparent that the city of Nairobi has many strengths and that there are opportunities that can be used for developing it further as a cultural heritage tourism hub in the country. The city already is the main cultural centre of the country as it houses the National Museum, the National Theatre and many places of worship. Opportunities to develop cultural heritage tourism also exist such as promotion and marketing of tourism products.

\section{Challenges of cultural heritage tourism}

Today, cultural heritage conservation in Kenya, like elsewhere in the developing world, faces many challenges. The site managers interviewed also cited challenges facing their sites. All three sites had similar problems. Funding was the major challenge, followed by poor implementation of policies and lack of enough trained personnel to help in the management of the sites. In order to overcome these challenges, various strategies have been developed, for example ecotourism activities that involve communities around the sites so as to improve their livelihood, and generating income through other means such as fund-raising and corporate sponsorships and architectural competitions. All the site managers indicated that the Ministry of Sports, Culture and Heritage and the Kenya Tourism Board must work together with all the cultural sites in the country so as to help market their products to a wider domestic and international tourist market.

Lack of funds is another important problem that results in lack of protection, interpretation and adequate visitor management. Cultural heritage conservation puts demands on infrastructure such as roads, airports, water supplies and public services like police and firefighting forces. This has been found to be a common problem throughout the world, but it is more serious in developing countries where public funds are scarce. Rapid urbanization in the developing world, including Kenya, also tends to push historic properties down the priority list. In other words, governments in developing countries tend to support urban development rather than conservation of cultural and historical resources. The crippling poverty of the majority of the population in the developing world makes them more interested in basic survival than conservation of cultural heritage. 


\section{Conclusions and policy recommendations}

In order to make cultural heritage tourism in Kenya sustainable and more appealing to domestic and international tourists, some strategies need to be adopted. These include collaboration among stakeholders, the promotion of attractive cultural heritage tourism products and the conservation of national cultural and historic resources. Due to its very nature, cultural heritage tourism requires effective partnerships. Therefore, there is need for local communities, NGOs, Kenya's government and development partners to work closely together in order to develop robust and sustainable cultural heritage tourism that can make a community a better place to live as well as an attractive tourist destination.

A deliberate effort should be made by all stakeholders to make tourist experiences as exciting, engaging and interactive as possible. This is particularly so given that today's cultural heritage tourist is more sophisticated and expects a high level of quality and an authentic experience. Many of the country's cultural and historic resources are irreplaceable. There is an urgent need to take good care of them for once they are lost, we will never get them back. 


\section{1}

\section{Significance of traditional oral information and natural artefacts for heritage conservation at the Kit-Mikayi cultural site}

Okello Benter, John Bosco Mukundi, Arnold Onyango

Watako and Ochieng' Aggrey Adimo

\section{Introduction}

Besides buildings and other tangible monuments, African heritage is vested in spiritual beliefs, songs, dances and narrations. These include tangible and intangible heritage as diverse as the way people utilize nature for fuelwood, medicine, fruits, craft and building materials. Community conservation efforts aimed at protecting and conserving cultural heritage are not widely documented, often due to poverty and inappropriate conservation policies. This chapter, apart from documenting sacredness and cultural value, assesses the aesthetic value of the Kit-Mikayi heritage site, and other important habitat management attributes.

Strategies in conserving cultural landscape have historically failed to show that these values are of outstanding global significance (Layton 1989). Events in history such as colonization, imperialism and now globalization have shaped culture significantly (Akande 2002). In Africa, the young generations have little knowledge about their own culture due to the strong influence of Western cultures, thus undermining their cultural heritage.

Natural features of the environment are often associated with the identity of an individual, society or community. They provide experiences shared across generations, as well as settings for communal 
interactions that are important to cultural ties. Cultural landscapes have been defined as cultural properties representing the combined works of nature and of man significant for nature conservation (UNESCO 2003). Cultural landscapes are vessels of cultural values and contribute to the identity of communities (Stephenson 2008). Culture is not static and often it is an important driver to ecosystem change (Antrop 2009; Van Eetvelde 2009).

From the sixteenth century onwards, many European artists painted landscapes. The whole of the world's surface, land uses, ecologies, interactions, practices, beliefs, concepts and traditions of people living within cultural landscapes promotes cultural heritage conservation. Nature conservation practitioners have debated about ways in which spiritual and religious values can be instrumental in promoting biodiversity conservation (Posey 1999; Sponsel 2001). Cultural knowledge is embedded in words, in stories, and in artefacts learned from and shared with other humans (D'Andrade 1996). Language shapes this cultural knowledge through the expression of cultural ideas, beliefs and values identified. Language is among the most powerful ways cultures map meanings, through which the world is made more intelligible (Spierenburg 2004). For instance, the variety of names for a single site points to shared histories in an increasing multicultural world (Stiebel 2000; Moore 2005). According to Keith (1990), language is a vehicle for accomplishing social interaction, an indispensable means of knowing the world and performing deeds within. In developing countries, the rapid increase in population has put pressure on natural resources, which has led to environmental degradation. High unemployment rates and poverty have not made things any better. Better management of a cultural landscape is the best option as it reduces pressure on natural resources, creates employment, improves the living standards of the rural community and conserves the environment (Aloo \& Ngugi 2005). For effective policy and decision making, it is important to identify specific ecologically based landscape features that are associated with the particular cultural heritage values of stakeholders in given cultural contexts, and assess how changes within a given time will affect these values (Chan 2009). Whereas cultural and heritage attractions are well planned, developed and marketed in other parts of the world, particularly in Europe, North America and Asia, most African countries, including Kenya, are yet to exploit the continent's heritage (Akama 2002). In Kenya, studies to quantify and define cultural heritage values are rare. The objective of this chapter is to determine residents' knowledge on cultural value of components within the Kit-Mikayi site in Kisumu, Kenya. 


\section{Description of the Kit-Mikayi site}

The study site was undertaken in 2013 in Kisumu County, about 30 km to the East of Kisumu City, and $1 \mathrm{~km}$ off Kisumu-Bondo road between Kaila, Lower Kadongo and Koker Kajuju sublocations. It lies between $34^{\circ} 32^{\prime} 27^{\prime \prime} E$ longitude and $0^{\circ} 07^{\prime} 03^{\prime \prime S}$ latitude, at an elevation of 2,101 m above sea level. The site is characterized by a landscape dotted with rocks that appear as huge columns piled together and seem to defy gravity with rock formations towering to a height of $21.3-24.4 \mathrm{~m}$. The cultural site covers an area of about $4.2 \mathrm{~km}^{2}$.

The mean annual temperature in this area ranges between $20^{\circ} \mathrm{C}$ and $30^{\circ} \mathrm{C}$ while the mean annual rainfall ranges between $1,000 \mathrm{~mm}$ and $1,800 \mathrm{~mm}$. Rainfall is biomodal with long rains in March to June and short rains from October to December. During the rainy seasons, morning humidity levels are between $80 \%$ and $90 \%$, with evening humidity percentage levels dropping to between $40 \%$ and $50 \%$. The dry weather allows for increased game and bird-watching (Republic of Kenya 2005).

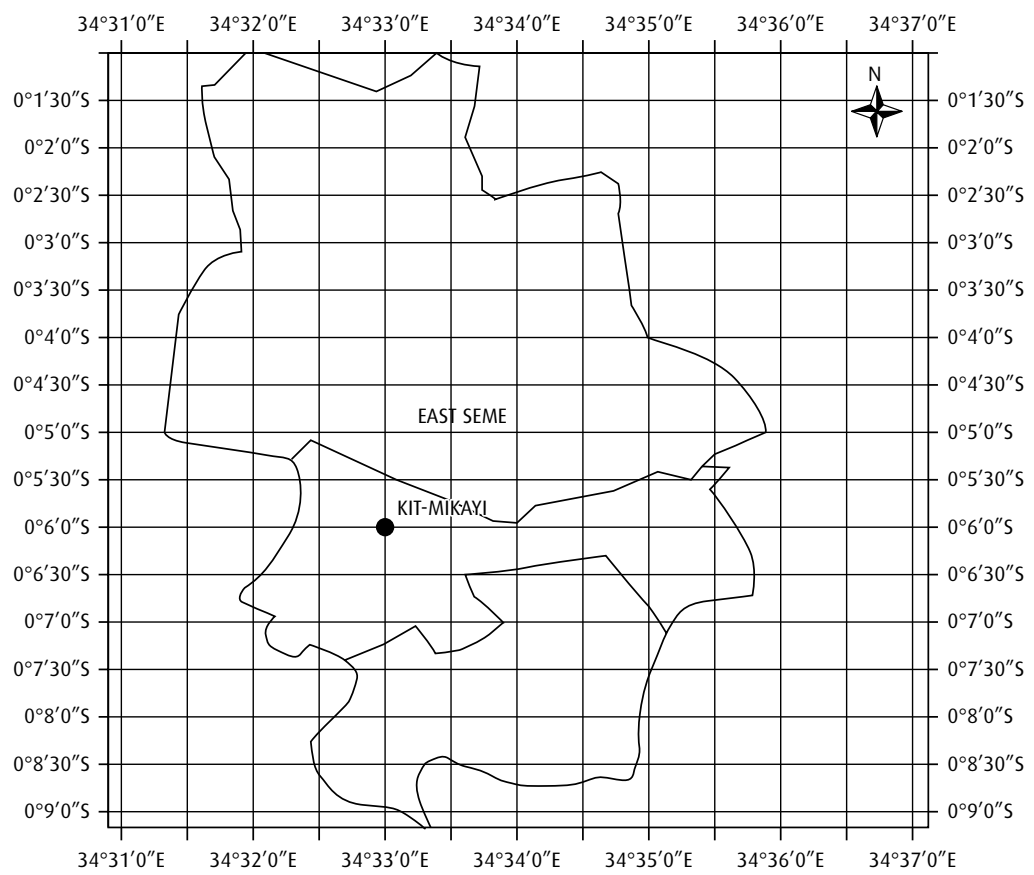

Figure 11.1 Map showing location of study site of Kit-Mikayi (Benter 2013) 


\section{Research design}

Data collection involved the use of questionnaires, video recording, narration and photography. The research was conducted through a survey of the local population. In preparation for data collection, a written consent from Jomo Kenyatta University of Agriculture and Technology was prepared informing the local administration of the researcher's presence and the intended activities in Kit-Mikayi sublocation in Kisumu County. The local administration, which included the chief of the area, assisted in accessing households when administering the questionnaires. Enumerators accompanied by the researcher conducted the interviews and photo ranking exercise. The target population for the study was the local communities residing within the area, government representatives including chiefs and village elders, and the visitors who came to the site. A sample size of 364 respondents was drawn. Later, households were selected from each stratum to obtain a systematic random sampling within the given village. Purposive sampling was used to collect information from government representatives like the chief and village elders representing the management of the cultural site.

The questionnaires contained both closed and open-ended questions. The first section of the questionnaire asked information on socioeconomic characteristics of the respondents. The second section recorded the cultural value of the site, including the respondents' knowledge and understanding of the site. The questionnaire further included a five point Likert scale: 4 = Very important, 3 = Important, 2 = Moderately important, $1=$ Less important and $0=$ Not important, for measuring the respondents' perception of the cultural site. Interviews were organized through the government structures within the sublocations and the villages headed by the chiefs and the village elders, respectively. Major landmarks were used in mapping and selecting the villages, then the households, where the questionnaires would be administered. A pre-test was conducted to test the reliability of the instruments and the validity of the study. Secondary data was collected through the desk reviews of the available theoretical and empirical literature on the associative cultural values.

\section{Survey results and discussion}

\section{Respondents' perceptions and cultural interpretation of the site}

Out of 364 respondents, 349 managed to complete and return the questionnaire. On the socio-economic characteristics of the respondents, 
the results showed that more males (76\%) were engaged in the cultural activities than females (24\%). Household chores were carried out by women. These women lacked access to physical and capital resources, decision-making and leadership, training and formal education. The age distribution of the respondents indicated that $91 \%$ were 41 years old or older. More than $80 \%$ were married. Results also showed that $94 \%$ of the respondents had less than tertiary level of education and $60 \%$ had primary education or below, which indicated that the overall respondents' level of education was low. Farming was the main economic activity practised by over $50 \%$ of the respondents. However, to supplement farming, they also practised basket weaving and the sale of herbal medicine. A highly educated community has always demonstrated better levels of utilization, management and conservation for the benefit of the community. Although most respondents were farmers, they preferred the site to be an ecotourism centre.

\section{Respondents' cultural linkages and knowledge on Kit-Mikayi}

Data on the cultural landscape were derived from five knowledge sources: folklores, songs, dances, special events and narrations. From the results, the dominant folklore characteristics of the site were those related to traditional belief. From the respondents' perception, $66 \%$ of those with an undergraduate level of education classified most folklore types as associated with traditional beliefs. Gender classification distinguished two main folklore types; those related to nature and those relating to traditional beliefs. Fifty-three percent of female respondents, a higher number than men, related the folklore to nature. Age group classification brought out the aspect of religion more strongly than other classifications. The 61 or older category showed strong associations with traditional beliefs.

\section{Identity and significance of folklores, songs and dances}

There were different types and names of folklores associated with the cultural site. These were categorized into four main groups: marriage, traditional beliefs, religion and nature. There were 12 types of songs mentioned by the respondents. Four songs were associated with marriage, namely bodi, dudu, mikayi and otenga. The praise songs of nyatiti, kambanane and kwanina were of the religious category. Nature as a folklore was associated with songs like ramogi in praise of a royal leader from the community. Orutu was sung to appease the spirits during 
sacrifice. Songs such as ohangla, siro and diewo were sung during the send-off ceremony for the deceased. Dance was accompanied by songs such as bodi for marriage and $d u d u$, performed during bountiful harvest in the land. The ramogi type of dance was performed during special events at the cultural site. The most frequently observed types of songs were ramogi, at $34 \%$ and $d u d u$, at $17 \%$.

\section{Types of services derived from the site}

In this category, meditation rated highest as a cultural service compared to the other cultural services, although at a low rate of $12 \%$. Most of the cultural and natural services such as nature, meditation, research and education were mostly rated as moderate, between $30 \%$ and $42 \%$. Activities such as relaxation and picnicking were mostly rated as less or not important. It means that visitors do not yet frequent the site for recreation purposes.

About $95 \%$ of the respondents had knowledge on the existence of the cultural site, but only $5 \%$ of respondents with genealogical roots to the study area were able to narrate the historical background of Kit-Mikayi. Respondents recognized the site as a place used to perform sacrificial rituals, mainly during morning hours. These were performed as a result of a calamity such as drought, or divorce and separation cases amongst the community.

The rock on-site has special significance in marriage ceremonies. While passing under the rock, the bridegroom sang a song and the bride ululated. It was supposed that this would lead to a long lasting marriage. Men believed that the rock sustains their marriages. Unlike the modern setting where marriage vows are performed in the law courts and evidenced by certificates of marriage issued by judges and magistrates, the rock acted as a sanction to enhanced marriage security. From the respondents' understanding and knowledge, after the sacrifices, heavy rainfall would follow immediately, which was interpreted as a sign to cement the marriage vows.

\section{Spiritual and religious significance of the site}

Out of the 349 respondents, three people narrated stories about Kit-Mikayi. The narrations were recorded in video and audio. The most common special event performed at the site was prayer (58\%). Religious people jam the shrine during the months of May and July when the rock releases water. Historically the rock had a healing 
power. Notably, the Legio Maria sect considered the shrine as the place of its founder, the late Melkiah Ondetto. There was a place in the shrine reserved specifically for Ondetto and Mary, the mother of Jesus Christ. This was in keeping with the sect's tenets. The place was considered sacred and this gave the local residents the right to fully participate in those activities. The link between religion and sacredness has considerably promoted environmental stewardship of the site. Such links have been recognized for enhancing environmental conservation (Dudley 2005; Wild 2008).

During times of catastrophe like hunger and famine, the elders would conduct sacrifices here and rain and bountiful harvests would follow. The rock was presumed to send visions to people as far as Alego Usonga in Siaya on the need to conduct sacrifices to avert calamities. These people would meet at Kit-Mikayi in their night dreams. The ritual entailed flinging a chicken on the rock before slaughtering it. It would then be roasted in full view of the elders. Prayers to God and the Sun would follow, before the elders partook of the meal. A cow would then be slaughtered by an aboriginal of the Seme clan of the Luo community. Prior to being sacrificed, the cow would be slapped several times until it urinated. If it did not urinate, it meant the gods were unhappy. The carcass would then be divided into three just like the rock was subdivided into three. The man slaughtering the cow had to be blameless. If he did not satisfy the criteria, the spirits would spurn the sacrifice and it would not be successful. A successful sacrifice resulted in rain and a bountiful harvest. The elders all dressed in Luo traditional regalia, brought their knives with them and consumed some of the meat raw. They would then go home to sow, and a bountiful harvest would be expected. This attachment of the community to the rock motivated them to conserve the site and protect it.

\section{Preference for socio-economic cultural practices}

Among the preferred socio-economic activities, ecotourism had the highest percentage. The results showed that a majority of respondents in all age categories, above $60 \%$, preferred ecotourism as the most viable socio-economic activity. The results also indicated that butterfly keeping was not preferred in the area, possibly due to lack of knowledge on its utilization for ecotourism and livelihood. The majority of the respondents who preferred the site to be used for ecotourism had attained an undergraduate level of education. Above $29 \%$ of them rated the activity 
as very important. About $21 \%$ of the 19 - to 40 -year-olds rated the site as very important for ecotourism, compared to over $29 \%$ of those under 18 years of age.

There is rapid expansion of agriculture adjacent to the cultural site and throughout the rocky areas leading to a decrease in ecological connectivity. Decreases in the abundance and compositional change of wildlife and plants were evident throughout the area, with local communities attributing this primarily to illegal hunting and harvesting.

\section{Conclusion}

The Kit-Mikayi cultural landscape is a multi-purpose landscape area. It is composed of multi-faceted interpretations, demonstrating the need for both tangible and intangible cultural data. It entails thematic folklore types that attest to the cultural richness of the community. Ramogi and $d u d u$ dances dominated the language expression of the cultural site, largely recognized by the age group above 61 years. A majority of respondents reported visiting the site frequently for nature experience and meditation while relaxation was rated less important by $53 \%$ of the respondents. The rock formation played a significant cultural role in making vows, prayer and offering sacrifices. More than $60 \%$ of respondents in all age categories preferred ecotourism as most sustainable socio-economic activity.

Recording of narrations in audio and video is an important venture that can be used by the community to re-live the history of the site and market the cultural site for enhanced ecotourism and heritage conservation. The link between religion and the Kit-Mikayi sacred site can promote environmental stewardship. Cultural services like sacrifices have played an important role in motivating public support for the protection of the ecosystem (Dudley 2005). Well-managed cultural landscape can lead the way to sustainable development in Kenya. 


\section{2}

\section{Community participation in conservation of gazetted cultural heritage sites: a case study of the Agikuyu shrine at Mukurwe wa Nyagathanga}

Robert Rukwaro

\section{Introduction}

The Agikuyu shrine is at times referred to in different expressions as the Agikuyu shrine, mythical site, and origin or heritage site. Thompson (1990) defines a shrine as a place associated with or containing memorabilia, or a casket containing a sacred relic, or a niche containing holy statues. In the context of this study, the shrine is the Mukurwe wa Nyagathaga site, a relic for the Agikuyu cradle since it serves as memorabilia of Gikuyu and Mumbi and the Agikuyu cultural life that governs surviving customs and beliefs from a past age. The Mukurwe or Mugumo tree at the site was viewed as an immemorial object of worship while Nyagathaga is a type of bird that used to build its nest and lived on the top of the sacred Mukurwe tree.

The Agikuyu shrine is located at Mukurwe wa Nyagathanga in Gakuyu Village, Gaturi location, Kiharu Division, Murang'a County, Kenya (Figures 12.1 and 12.2). It is the cradle of the Agikuyu civilization and has symbolic, ritualistic and aesthetic values that fulfilled the ceremonial functions and spiritual beliefs of the community. The Agikuyu ancestral parents, Gikuyu and Mumbi, were believed to have resided at Mukurwe wa Nyagathanga with their nine daughters, creating the origin of the clan system among the Agikuyu people. The daughters 
were: Wanjiru, Wanjiku, Wambui, Warigia, Waithera, Wacera, Wangui, Wairimu and Wangari (Kenyatta 1938).

The Mukurwe wa Nyagathanga shrine is a very significant landmark to the Agikuyu because of its ancestral, spiritual and cultural heritage. From time immemorial the shrine was considered sacred to the Agikuyu people. It was a place of offering sacrifices to Mwene-Nyaga (God), which was mostly done when the Agikuyu community was faced with calamities such as famine, epidemics, drought, internal conflict and waging wars against local or foreign invaders. Sacrifices were also offered as a thanksgiving to Mwene-Nyaga for his bounties. Overall, the shrine was the soul as well as the spiritual centre of Agikuyu life.

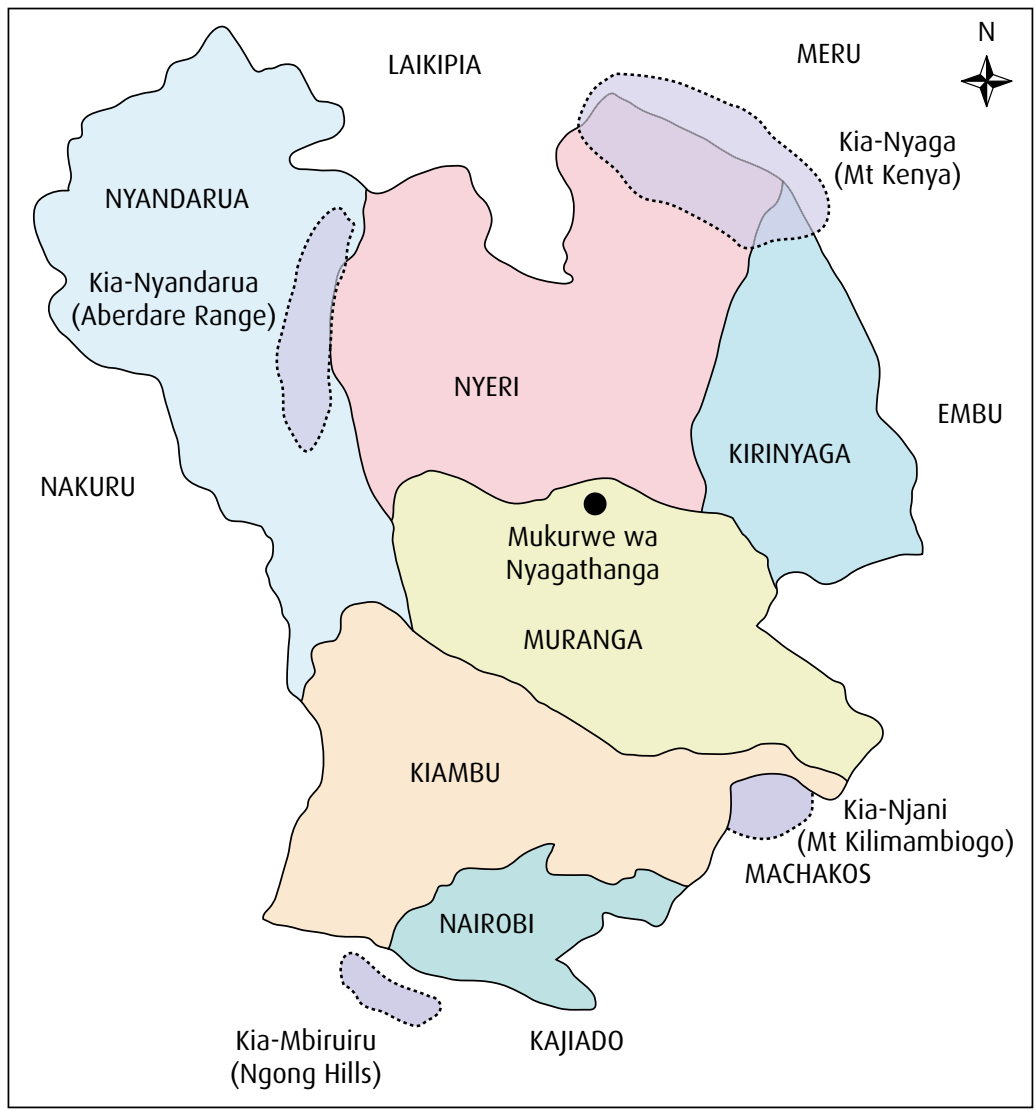

Figure 12.1 Map of Central Region showing the Kikuyu Holy Mountains and Mukurwe wa Nyagathanga site (adapted from George Phillip Ltd 1991) 


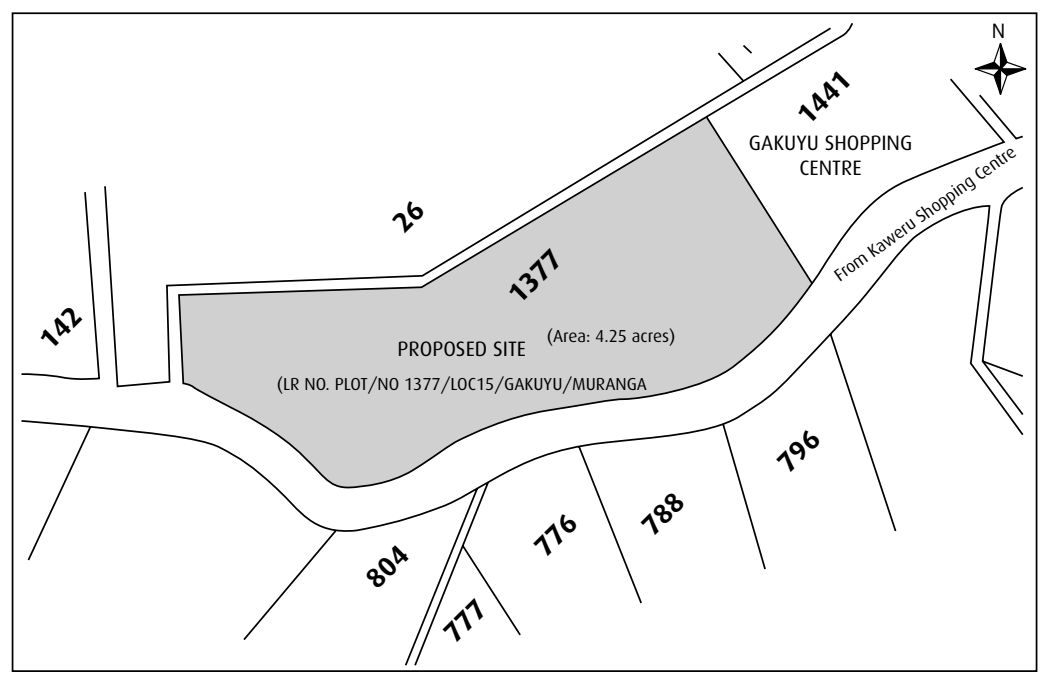

Figure 12.2 Location of Mukurwe wa Nyagathanga site (Survey of Kenya 1968)

The destruction of the shrine was planned and executed by British colonial rule in the hope to weaken the spiritual strength of the Agikuyu community. After the country gained independence, there was euphoria of land grabbing and the sacred site was no exception. The local community, with the help of Green Belt Movement, resisted any attempt to grab the shrine site. This was the beginning of an initiative to conserve the site. Several issues made the local community agitate for involvement in conservation programmes: conservation efforts lacked integration and coordination; the physical aspects of the heritage site were being given more prominence than the cultural and economic aspects of relevance to the local community and they were left out of both the planning and implementing stages of the conservation programmes. The local community felt that their participation would be an opportunity to air their views on the programmes. The locals viewed themselves as the immediate beneficiaries of conservation efforts implemented at the heritage site, as well as the makers of the heritage being conserved, and thus deserving to be involved in the conservation effort.

The objectives of this chapter, therefore, are to establish the purposes of restoration of the shrine site and its history and status, examine what activities the Agikuyu community are interested in carrying out at the site, establish the interests of different stakeholders involved in 
restoration of the site, and identify how local community and stakeholders can effectively participate in the conservation of the Agikuyu shrine and the challenges faced in restoration of the site.

\section{The concept of participation in conservation programmes}

Local involvement in heritage conservation ensures ecological and socio-economic sustainability (Rees 1989). Thus, successful implementation of conservation projects requires integrated planning, social processes; political viability and full support of the people it affects. Implementation is achieved through their government's social institutions and private entrepreneurship. Waziri and Swazuri (2012) posit that local involvement shapes the peoples' own destiny, ensures traditions and lifestyles are respected; and creates local employment, hence reviving the local economy. Further, they advocate that local involvement should extend beyond economic survival, environmental conservation and socio-cultural integrity to allowing the affected community to appropriate its own heritage resources.

In this sense, the concept of participation in conservation projects means that people are closely involved in the economic, social, cultural and political processes that affect their lives. Participation is therefore an important element of human development. Appleyard (1979) emphasizes that any conservation policy should take into account the economic, social and physical heritage of the settlement under conservation. People should have constant access to decision-making and power. This is the only surest way to contribute to economic growth and overall development.

Kiamba (1995) has emphasized that the cultural conservation of historical settlement sites should be seen as integral agenda in development of the community's livelihood. It is in this light that the Council of Europe (1979) agreed that the future of physical heritage depended upon its integration into the context of the lives of the people. The views of the local people should fit positively in the conserved projects and they should accept it.

Larkham (1996) sees the value of conservation as potential gained in tourism and enhanced economic activities within conserved areas. For these values to be innate to the community for whom conservation is intended, then, they must be part and parcel of the conservation agenda advanced by the government and non-government 
organizations. Larkham (1996) observes that the main problem with the way that conservation programmes are being carried out by government and non-government organizations is that they do not consider the socio-cultural systems that participated in the creation of the conserved monuments. Thus some members of the communities, whose identities they purport to conserve, are not taken into account and their cultures are given least attention. Further, the conserved heritage misses its real owners in restoring their past. This happens because of new emerging economic forces cast on the revenue brought in by tourism (Larkham 1996).

Further, Ben-Ali (1998) posits that the only way to achieve the identity and character of the monuments is by reviving traditional creation processes. For the Agikuyu shrine, these traditional creation processes are vital in the evolution of cultural heritage as it offers the only way of ensuring that cultural identity is maintained and sustained.

The above-mentioned authors of conservation programmes have discerned that economic, physical heritage and cultural identity as the mainstay for the settlement which has the conservation project. This means the policymakers and planners, among other stakeholders of conservation projects, should balance the physical development of historical sites and the mainstay aspects of the local community. Conservation development should accrue benefits to local community. Disregarding the local community in both the planning and implementation stages of the conservation project would lead to hostility, resentment and noncooperation in participating in stakeholders' owned and independently led projects.

\section{Regulatory and institutional framework for conserving heritage sites}

Kenya has a detailed legal and institutional framework to safeguard all its monuments, places and structures of historical importance. According to the Antiquities and Monuments Act (Cap 215) of 1984, a heritage site is a place of historical interest (Republic of Kenya 1984). The National Museum Act (Cap 216) of 1983 provides for establishment, control, management and development of national museums (Republic of Kenya 1983). The Antiquities and Monuments Act empowers the owners of the monument to continue with the same estate, right, title and interest in the monument. This echoes Larkham's (1996) position: where the owners of the monuments are seen as their curators, they should be 
at the forefront in conserving it. In this case, the Agikuyu community of Kenya are the guardian of the Agikuyu shrine. The Act also allows the guardians of a monument to maintain it, to restrict doing acts on or near the site of the monument, not to sell or lease or dispose the land on which the monument stands. The National Museums and Heritage Act of 2006 consolidated the law relating to national museums and heritage. The Act recognizes the role of the local community in participating fully in the planning and implementing the conservation of the heritage sites. Further, the Act allows the National Museums of Kenya to possess the monument if the guardian contravenes the authorities conferred to them by the Act. It also identifies the local authorities where the monument is situated as the institution that should carry out the daily management of the monuments.

The counties use Public Health Act (Cap 242) (Republic of Kenya 1986), Building Code (Republic of Kenya 1987), Physical Planning Act (Cap 286) (Republic of Kenya 1996), the Urban Areas and Cities Act (Acts No. 13) (Republic of Kenya 2011), to plan, control and maintain the monuments. They enforce any applicable by-laws or Acts during the conservation period of the monument. Construction at the site, of any kind, must be approved by the respective county and the National Museums of Kenya.

From this review of participation of local community and the regulatory and institutional framework, it is clear that participation of local community should be viewed as processes that empower the individuals and communities to achieve a more holistic conservation effort. It is discerned that the local community is the curator of what is being conserved and hence their full involvement in the conservation effort. Finally, this review of literature discerns that the continuity and identity of the people's heritage should be the basis of any conservation effort. This means that tourism and other economic opportunities arising from the conserved monuments should be viewed as secondary to the core of what is being conserved. This chapter establishes how the local community can effectively participate in the Agikuyu shrine conservation in a way that they view themselves as the curator of what is being conserved and the whole conservation effort is for their good.

\section{Data collection methods}

The Agikuyu shrine was studied using the case study design to plan a data collection method and analysis of the conservation programmes. 
The purpose of this approach was to create awareness of the participation process and to establish the perceptions of local community members and stakeholders in restoration of the site. The methods of data collection used include key informants, interview and questionnaires and site observations. Thirty-two questionnaires were administered to different stakeholders to collect data on the role the heritage site plays on the cultural and economic development of the local community. Other information sought through the questionnaires included participation of the local community on conservation effort, the roles of stakeholders and the objectives of their participation. The questionnaires further collected information on whether there were conservation committees and if local community members served on such committees as well as what they had achieved. Their needs and aspirations were also captured through interviews. The National Museums of Kenya and the Murang'a county government provided data on conservation programmes and how county government manages the site.

Focus group discussions and interviews were organized to gain insight on the views of the conservation programmes, participation of local residents and the history of the site in terms of people who have been involved in its conservation and restoration. Respondents for interviews and focus group discussions were selected from the Murang'a county government, local community at Gakuyu Market Centre and officials from the Green Belt Movement offices. Secondary data was sourced via Internet search and library researches at University of Nairobi and National Museums of Kenya. This author has been following the shrine's activities since 1999 and has observed the developments at the site and participation of the various stakeholders over this period.

Observations were made on features at the site that related to the conservation programmes being undertaken and recorded through photography and drawings. Data was analyzed using descriptive statistics and tabular presentations. Photographs presented the situation of different phenomena as observed in the field.

\section{Discussion of results}

\section{The purposes of restoration and conservation}

The purpose of restoration of Mukurwe wa Nyagathanga was to create unity and provide education about Agikuyu people, to symbolize the beginning of unity and the bonding of the Agikuyu ethnic group, 
to promote a sense of leadership, to return sacredness to Mukurwe wa Nyagathanga, and to showcase authentic cultural artefacts and architecture as practised by the ancestors.

\section{Brief history of the site and its status}

In a discussion with local elders, they narrated the events that led to the current physical and sacred status of the Agikuyu shrine. Before colonization by the British, the shrine was revered and was a central place of worship facing Mount Kenya, which the Agikuyu believed was God's abode. It was also from this place that God directed Gikuyu, Agikuyu ancestral man, to settle at Mukurwe wa Nyagathanga, where he met his wife Mumbi.

During the colonial rule, especially from the 1950s, the Agikuyu were restricted in using the shrine for praying, hence the beginning of its destruction. The British colonial administration destroyed the shrine during the Mau Mau war of national independence and erected an antiMau Mau military base. It was 1954 when the brutal villagization policy was enforced in Central Kenya in an attempt to weaken the Mau Mau guerrilla army. The community around the shrine was forced to clear the shrine, to cut down the sacred trees, which included the medicinal trees, to destroy the cultural material which bonded the Agikuyu people. Those who refused to participate in the destruction of the shrine were arrested, imprisoned and even tortured, while others were murdered. The British occupiers closed down the military base and evacuated the shrine in 1958 after it burnt down when lightning set fire to the buildings.

During the land demarcation and consolidation in 1959, the surrounding community (Clan of Acera) preserved the shrine on a sacred site which occupied 4.25 acres. They planted indigenous trees and fenced the holy place. The shrine land had no title deed and no owner, therefore no individual or community could claim its ownership. It collectively belonged to the Agikuyu people who are also referred to it as Nyumba ya Mumbi (House of Mumbi). However, today the shrine lies dilapidated as if it had been abandoned and long forgotten. Through conversion to Christianity, the majority of Agikuyu people seem to have forgotten their ancestors, their gods, their religion, history, heritage and culture.

The defunct Murang'a County Council (MCC) had, in the mid1980s, proposed a museum and a tourist hotel complex on the site (MCC 1985). This project accommodated various facilities: a museum and its 
attendant areas, the cultural centre, a tourist hotel with a swimming pool and its support facilities (Figures 12.3, 12.4 and 12.5), all on-site civil works, including the landscaping, and off-site works like an access road, electricity and water supply. The designs of the complex were implemented in the beginning of 1985, without consultation with the local community. The project stalled in 1990. The Council employed security guards to guard the property. It also happened that one of the old sacred fig trees (mugumo) at the site was cut by the Council guards without permission from the local elders. Nevertheless, the community around the shrine opposed the Council's actions.

Further, the euphoria of land grabbing in Kenya in the 1990s provided the impetus for protecting of the heritage site. The local community mobilized when it saw that the land belonging to the shrine was being grabbed, the fence was being removed, land was being subdivided and plots allocated to individuals by the former Kenya African National Union (KANU) regime in collusion with the defunct MCC. The local community sought assistance from the Green Belt Movement (GBM), which was the mainstay in protection against land grabbing in the country. The Green Belt Movement, under the courageous leadership of the Nobel Laureate Wangari Maathai, came to the rescue of the shrine and planted more indigenous trees.

To avoid land grabbing in the future, the shrine was officially gazetted on 6 October 1998 and confirmed the same year through a gazette notice numbered 167 as a national monument and a cultural heritage site in the Ministry of Culture and Heritage under National Museums of Kenya. Murang'a county government is the trustee of the national heritage while National Museums of Kenya is its custodian (Kenya Government 1998).

By 1998, the historic gazetted site was unkempt and in a derelict state. Other problems on the site included the dilapidated, incomplete tourist hotel structures, six kilometres of inaccessible road (during the rainy season) off the Murang'a-Iriaini road at the Kaweru shopping centre, and unfinished stone walling around the shrine. The stalled tourist hotel was a very insensitive response to a site charged with symbolic meaning. The site has electricity but no piped water. The Agikuyu culture is disappearing quickly; hence the site has had little or no representation of Agikuyu culture, which would demonstrate the significance of the shrine. It has lost the symbolic expression of important cultural heritage, thus prompting the stakeholders and local community to join hands in wanting to restore and conserve it. 


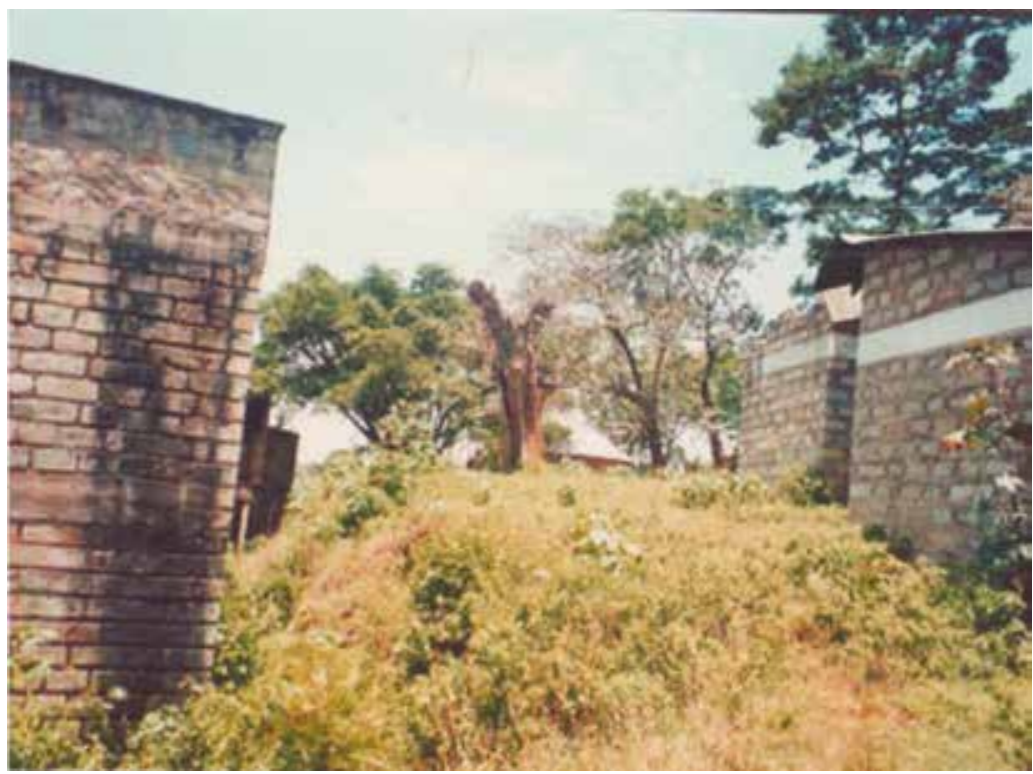

Figure 12.3 Mukurwe wa Nyagathanga: the place where God directed Gikuyu, the founder of the Agikuyu Nation, to settle (Rukwaro 2015)

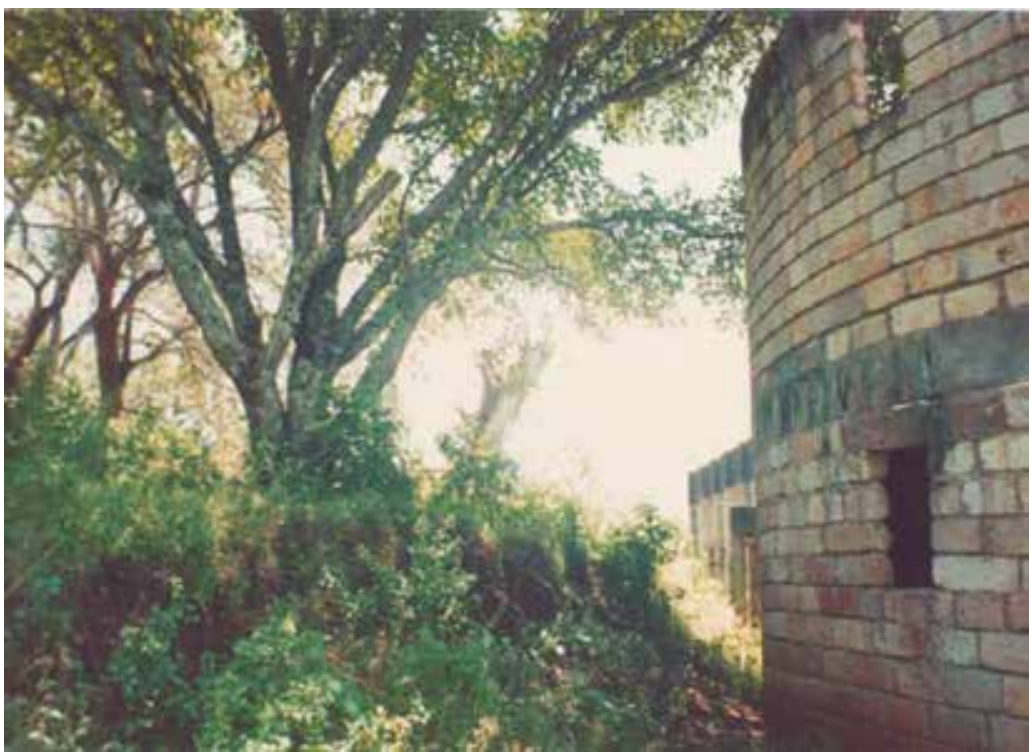

Figure 12.4 Mukurwe wa Nyagathanga: the stalled tourist hotel (Rukwaro 2015) 


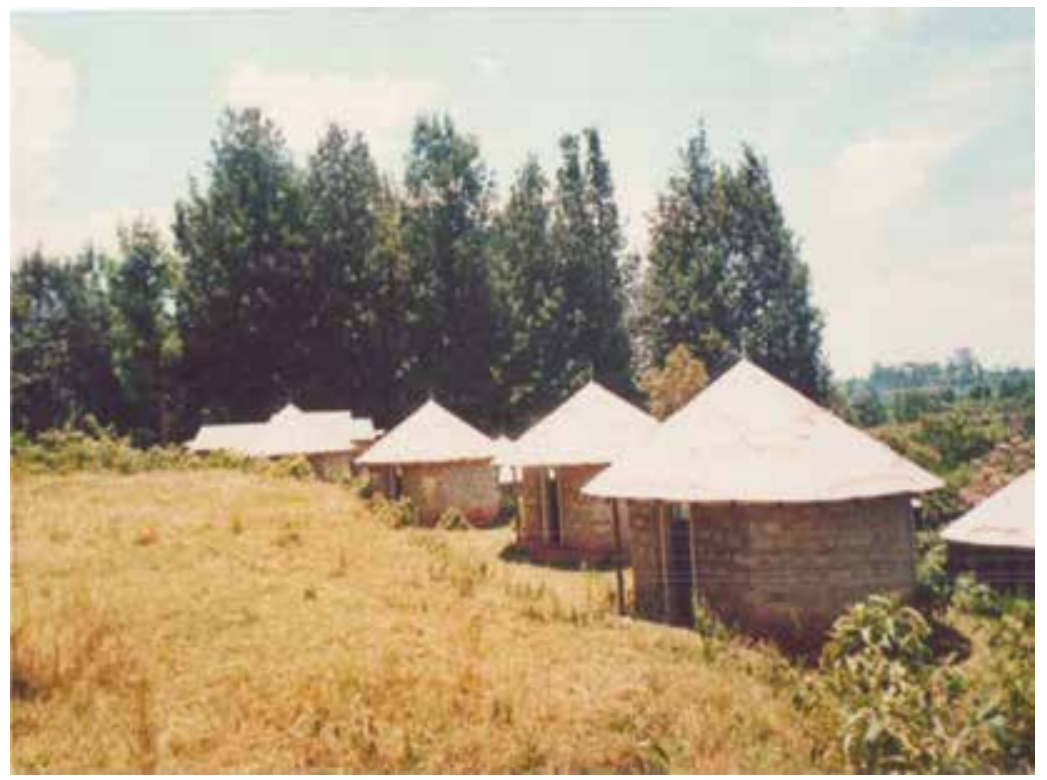

Figure 12.5 Mukurwe wa Nyagathanga: the pseudo-Kikuyu traditional forms of the stalled tourist hotel at the mythical site (Rukwaro 2015)

\section{Stakeholder interest in the restoration and conservation of the Agikuyu shrine}

Initial group of stakeholders under the leadership of the Green Belt Movement included National Museums of Kenya, the defunct provincial administration and Murang'a municipal council, the local community, University of Nairobi Department of Architecture, members of parliament and Mau Mau Research Center (USA). Two members of each institution were selected to form the steering committee. The committee met at site and at Murang'a County Council offices at Murang'a town on several occasions from 1999 to 2002.

The conservation programmes were coordinated by a secretariat located at the Agikuyu shrine office. The stakeholders had a shared vision of the project and carried their activities in a transparent and coherent manner as shown in Table 12.1. The main activities carried out were civic education, fundraising, tree planting and end-of-year annual meetings in 2000, 2001 and 2002. Religious groups including the Akorino and traditionalists who visited the site prayed and offered sacrifices to God at the shrine. Traditional groups organized performances 
Table 12.1 Summary of conservation activities carried out by different stakeholders at the Agikuyu shrine during the Wangari Maathai period (Rukwaro 2015)

\begin{tabular}{|c|c|}
\hline Stakeholders & Conservation activities \\
\hline $\begin{array}{l}\text { National Museums of } \\
\text { Kenya (NMK) }\end{array}$ & $\begin{array}{l}\text { Trained and employed local curator } \\
\text { Managed curative office } \\
\text { Repaired structures on site } \\
\text { Provided conservation skills e.g. curator } \\
\text { Custodian of the site }\end{array}$ \\
\hline $\begin{array}{l}\text { Muranga County } \\
\text { Council (MCC) }\end{array}$ & $\begin{array}{l}\text { Managed the shrine activities e.g. cleaning } \\
\text { Site trustee } \\
\text { Rehabilitated the site } \\
\text { Updated NMK status of the site } \\
\text { Employed guards }\end{array}$ \\
\hline $\begin{array}{l}\text { Green Belt Movement } \\
\text { (GBM) }\end{array}$ & $\begin{array}{l}\text { Coordinated stakeholders and network } \\
\text { Provided tree seedlings and material for fencing } \\
\text { Provided civic education } \\
\text { Tree planting }\end{array}$ \\
\hline $\begin{array}{l}\text { Local community } \\
\text { (elders) }\end{array}$ & $\begin{array}{l}\text { Provided artefacts to be preserved at the shrine } \\
\text { Planted indigenous trees with cultural meaning } \\
\text { Provided labour } \\
\text { Provided Kikuyu sages } \\
\text { Marketing } \\
\text { Protected the site from vandals, land grabbers }\end{array}$ \\
\hline Kikuyu diaspora & $\begin{array}{l}\text { Made pilgrimage to the site as tourists } \\
\text { Contributed funds and ideas } \\
\text { Marketed the shrine }\end{array}$ \\
\hline $\begin{array}{l}\text { Provincial administration } \\
\text { (DO, chief, DC, councillors) }\end{array}$ & $\begin{array}{l}\text { Created awareness of the project } \\
\text { Organized barazas }\end{array}$ \\
\hline $\begin{array}{l}\text { Members of parliament } \\
\text { (MP) }\end{array}$ & $\begin{array}{l}\text { Created awareness } \\
\text { Fundraised }\end{array}$ \\
\hline $\begin{array}{l}\text { University of Nairobi } \\
\text { (UON) }\end{array}$ & $\begin{array}{l}\text { Master planned and prepared architectural } \\
\text { designs of site facilities }\end{array}$ \\
\hline $\begin{array}{l}\text { Relevant government } \\
\text { institution ministries }\end{array}$ & $\begin{array}{l}\text { Kenya Power \& Lighting Co. provided electricity } \\
\text { Ministry of Transport constructed access roads } \\
\text { Ministry of Water provided water }\end{array}$ \\
\hline
\end{tabular}

such as drama, traditional dances, riddles, proverbs, poems and tales to entertain visitors to the site. The annual cultural festivals were held every 29 December to 1 January. The steering committee that was organizing restoration and conservation programme ceased to be functional 
after Wangari Maathai, who spearheaded them, was elected a Member of Parliament in 2002. She died in 2011.

\section{Further efforts to restore and conserve the Agikuyu shrine site}

In the effort to revive management of Mukuruwe wa Nyagathanga, the Green Belt Movement organized the elders from different counties to meet at the shrine site in July 2012. During the meeting some elders were selected to spearhead the formation of a trust for Mukuruwe wa Nyagathanga. After working closely with a lawyer, they developed and registered the Mukuruwe wa Nyagathanga (Kihumo) Trust. The mission of the trust was to uphold, protect, nurture, develop and/or teach Agikuyu culture, traditions, preserve cultural properties, spiritual life, offer guidance to develop and protect the Agikuyu shrine at Mukuruwe wa Nyagathanga. The board of trustees has been meeting and has advocated for restoration of the site. The group has not effected much change on the shrine site, though it has created a structured way of how restoration should happen.

\section{Murang'a county government initiatives on restoration of the Agikuyu shrine}

On 5 December 2014, the Murang'a county government revisited the restoration of the shrine site by inviting Agikuyu people at Ihura stadium in Murang'a town. Arising from this meeting two committees were formed to look at means of restoring the site. One committee was referred to as the operation committee and was mainly constituted of Murang'a county officials. The other committee was referred to as the national steering committee board. Each committee was composed of eleven members. The national steering committee board drew its membership from different institutions: Kihumo Trust, Council of Kikuyu Elders (Kiama Kia Maa), Mau Mau Research Centre, University of Nairobi, National Museums of Kenya (Trustees), Green Belt Movement, local community (Aramati), Kenyatta University and Murang'a county government (trustees). A technical committee was also formed and its members were drawn from Murang'a county government, University of Nairobi, National Museums of Kenya, Kihumo Trust and Kikuyu Council of Elders selected officials. These committees have had four meetings at 
diverse dates in 2014 and 2015 at Golden Palm Hotel at Kenol, Murang'a County and Kenyatta University. Arising from these meetings, it has been agreed that the interest of all members of Agikuyu would be served through a consensus.

Murang'a county government, the national steering committee board and the technical committee have developed the programme for restoration of Agiguyu shrine at Mukurwe wa Nyagathanga. Murang'a county government and the board outlined the main objectives of the conservation and restoration of Mukurwe wa Nyagathanga site: to protect the Agikuyu culture natural heritage, to promote Agikuyu culture and art, to safeguard the process and practice of cultural heritage, to interpret the cultural forms into architectural expression, to reflect on local culture, context and principles of sustainable development and to integrate and accommodate the visitors and the displayed collections within selected medium.

Murang'a county government and the national steering committee board outlined the patent issues considered in the restoration and conservation of Mukurwe wa Nyagathanga as follows:

1. The site is to have a porous fence made of natural hedge, and grills and concrete columns.

2. The design of the site must consider public space as its dominant expression.

3. The shrine of a size of 0.2 acres would be defined by the already growing fig (mugumo) tree. This sacred space is to be maintained in its natural state. Around it, planting of natural traditional hedge for privacy of the people praying within has been recommended. Further, a piped water place is to be located at the entrance of the shrine for the cleansing of elders' and pilgrims' feet.

4. A main entrance gate to symbolically and sculpturally capture the impression of Mount Kenya (kirinyaga) is be erected at the entrance to the site.

5. The 4.05 acres left after declaring the shrine area are to house a botanical garden, a cultural centre, a medium-sized museum, parking for twenty cars, statues and homestead of Mumbi and Gikuyu, the nine daughters' houses, and a place for the elders' rituals (Kiama kia athuri/maruta ma mburi).

6. At the periphery of the site, the proposed activities are a tower (munara) and commercial activities such as shops and hotels. 
The planning and architectural design of the traditional man's house (thingira) and woman's house (nyumba) was to be fully equipped with the traditional artefacts. Each of the daughters' houses was to emphasize and recognize the different Agikuyu clans' peculiarities. The houses were to be planned according to the traditional Agikuyu homestead principles.

\section{Further suggested areas of interest of material and non-material cultural knowledge}

Most of the activities the Agikuyu community were interested in seeing carried out at the shrine site were captured by the Murang'a county government and the national steering committee board proposal. Table 12.2 shows further the proposed areas of material and nonmaterial cultural knowledge that promote cultural tourism within the region and would lead to employment of local community. The local community stated that conserving the cultural heritage would instil a sense of pride in Agikuyu heritage and would bring a sense of identity and unity when the local community and Agikuyu diaspora visited the site.

The other proposed social, economic and cultural activities to be incorporated at the site in the traditional houses within the homestead

Table 12.2 Suggested areas of material and non-material cultural knowledge (Rukwaro 2015)

Areas of material and non-material cultural knowledge

Traditional religions and legal systems

Traditional crops

Traditional foodways, cuisine

Medicinal trees and treatment

Traditional entertainments: dance, games, sports, storytelling, drama, music

Traditional rites: circumcision, marriage, funerals

Warfare (tools/items) and crafts

Language expression and meaning: riddles, proverbs, literature

Social stratification

Clothing

Type of livelihood

Means of sustenance 
were embroidery (kiondo), tailoring, weaving, wood carving, craftsmanship in buildings, blacksmithing, leather work, brass-making and bead making.

\section{Local community participation in conservation programmes}

During Wangari Mathaai's period, more local community elders participated in the meetings than at any other time. Community members contributed tangible and intangible resources, within their ability and means, for the success of the conservation project. During this period, the local community members were keen to contribute labour for digging the latrines and planting trees at the site, and provide items such as building materials for traditional houses and traditional artefacts.

The main channels of communication used to disseminate information about development of the site were meetings, the chiefs' barazas (57\%), leaflets (14\%) and leaders' meetings (29\%). Barazas were more effective than the other channels in creating awareness and reporting happenings at the shrine site. Local administrative government officials such as divisional officers and chiefs helped to spread civic education on ownership of the shrine and its restoration to local community members. The main messages communicated were on the role of stakeholders, contribution of cultural materials and attendance of major cultural festivals at the shrine. The local committee liaised with the defunct Murang'a County Council and steering committee on the message communicated during the public fora. This level of involvement was expected to create a sense of ownership and belonging around the project with different groups - locally and abroad. Regularly, all groups could meet at the site to make major decisions on developments of the shrine site. This was a very effective way, during the Wangari Mathaai period, for local community members to participate in the conservation of the shrine. Table 12.1 lists the activities which were organized during this period.

During the Kihumo Trust and Murang'a County Government initiative from 2014 to 2015, the involvement of local community members changed since the committees that were formed had very few members, if any, from the locality of the shrine site. Most of the meetings were held away from the site. There have been very few activities undertaken on the site since the end of the Wangari Mathaai period.

This study established that local community members were not fully involved during this period in the conservation effort initiated 
by these stakeholders. They demanded effective communication at all stages of the projects being initiated by stakeholders, especially at planning and implementation stages. They stressed that their representatives in the stakeholder committees should be elected but not selected, to avoid infighting and factions within the community. During this period, negative politics played out a lot in the revival of the shrine. It was not the spirituality and cultural preservation of the shrine that drove the conservation efforts but political expedience and the commercial interests of different institutions involved.

\section{Challenges faced in management of the Agikuyu shrine site}

During Wangari Mathaai's period, conservation programmes at Agikuyu shrine were carried out by the curator and community elders. The workers and volunteers at the site were not paid for services rendered. The collected tourist revenue at the shrine was mismanaged because of lack of accountability by those involved. There was no appropriate pricing mechanism of Agikuyu curios to generate better revenue. The programme did not enhance the hospitality services at the site and it did not train the workers on how to manage conservation activities at the site. Fifty-seven percent of the elders involved were primary school leavers, $40 \%$ were fourth form graduates and the rest had university education. $60 \%$ of those interviewed were over 50 years old. Most elders were concerned with immediate direct benefits arising from the conservation project. The education and age of elders was an impediment to the planning and implementation of the stakeholders' vision of the conservation of the shrine site.

During 2002-13 when there was no clear stakeholder involved in the protecting and preservation of the site, it was observed that intruders and vandals would come to the site to destroy and steal the fencing and stalled buildings materials, fell trees and carry out anti-social activities, among other things. There were cultural by-laws to be enforced at the Agikuyu shrine. The site was unkempt. Further, a religious group wanted to put up a church at the sacred site, but this was put on hold by a High Court judge when a member of local community sued the church. The case is still pending in court.

During the period of conducting this study, there was a cartel operating without authority from the Murang'a county government, demanding money from pilgrims and visitors to the site, including 
schoolchildren. The money they raised was shared among themselves. The cartel considered themselves as the owners of the shrine site.

The site has very little visibility since only one signboard of the heritage site was erected along Murang'a Road, at the Kaweru shopping centre which is six kilometres away. The signboard read 'National Museums of Kenya, Murang'a County Council and local community Mukurwe wa Nyagathanga National Protected Site'. The locals said they had not experienced the social-economic benefits of development at the site.

\section{Conclusion}

As the conservation programme evolved, attempts to involve, strengthen and empower community institutions and local authorities were somewhat neglected. The Murang'a county government have a major role to play and must interact with relevant national government ministries in dealing with infrastructure provisions for the site. Adapting to a new institutional environment will require significant adjustment on the part of those involved in the programme. Allowing a new administration to modify the current community-based approach without dismantling it is the desired outcome. This study found that it was easy for strategies to become politicized after so much neglect of the Agikuyu shrine as some stakeholders were already talking of providing free services - a move that, whilst being politically popular in the short term, would merely delay the establishment of a sustainable conservation strategy in the medium to long term.

Community groups have a role to play in the development of future conservation programmes and should be moulded to govern the project. These local groups include elders and marketing groups. It is much easier for the local groups to come together to deal with local issues since they are informed about their needs and how to meet them within their resource-base. These groups can together improve their access to resources. They can also demand policy changes and effectively lobby for the provision of effective and appropriate services from involved stakeholders. For instance, where the mechanisms for enforcing regulations and standards are still relatively weak, the community can easily monitor the implementation of the conservation project and ensure quality service is being delivered.

This study has expanded on the role and participation of the local community in the conservation of the Agikuyu shrine. It has revealed 
how the local community members are involved in the conservation of the heritage site according to their needs and limited resources within the locality, and also pointed out the challenges stakeholders encounter in the process of delivering their services.

\section{Recommendations}

To empower local people to become active in the development, there is need for them to have relevant education and appropriate conservation skills. Stakeholders should make resources available to facilitate the implementation of conservation programmes and the community should be involved at all stages.

Cultural values and norms as well as social relations must be seen as the strength of local community participation in the conservation projects. Hence there is need to formulate policies, programmes and actions with the aim of addressing the local community economic and cultural concerns.

The conservation approach for the Agikuyu shrine should seek to understand and incorporate the traditional processes and to guarantee continuity of its cultural identity, thereby retaining relevance of the Agikuyu culture.

There is need to strengthen the community-based system in the management of the conserved Agikuyu shrine in order to better attract the local community to engage with its programmes. The management committee should always be inclusive in its operations of planning and managing the restoration of the site. Additionally, more cultural items and activities need to be added to the Agikuyu shrine to give meaning to the continuity and identity of Agikuyu traditions and practices. This would enable the shrine to provide the historical perspective and educate pilgrims on the heritage value of Agikuyu life.

There should be more integration of the roles of the local community and stakeholders to set realistic conservation goals for the proposed programmes. Any accepted and formalized steering committee should be empowered to identify the core and supportive projects in the conservation programmes, and to take decisive positions on how to implement them.

Resource mobilization should be strengthened for continuity of the conservation programmes. All stakeholders should participate in the conservation efforts and it should be emphasized that contribution should be based on the ability and willingness to commit to the project. 
There is need to establish a foundation to mobilize resources for restoration and encourage investment to put in place the infrastructure, such as a police post, tarmac road and piped water installations, required to enhance the new image of site.

The cartel group should be dismantled immediately and the sacred site should be manned by county government employees. The impending cases in court should be settled to allow development of the shrine site.

One of the pillars of success for any project is the establishment of an institutional framework for the Agikuyu community involved in conservation management of the shrine. All Agikuyu have a share in the shrine and nobody should be left behind in the conservation effort, during consultation or decision-making, and nobody should be seen to dominate in participating to the project. More consultation should go into establishing a matrix of stakeholders and their functions.

Arising from the challenges at the site, there is need for workers and volunteers to be properly selected, trained and supervised. A curator should be hired and trained in Agikuyu culture. One or two competent elders can be employed to assist the curator. They should be vetted by a competent panel.

Favourable marketing policies and registration need to be formulated to encourage tourists to visit the shrine, thus generating more revenue. The tourism industry should develop tours through the site. The local community should be encouraged to see how proper management of the site would lead to cultural tourism, turning it into a main source of revenue with knock-on effects on their local economy.

The steering committee should develop by-laws (migiro) to control and regulate the use of the sacred site based on the Agikuyu traditions. This should be intended to make the local community view the site as a reverence place with immovable cultural heritage, and therefore worthy of conservation and protection.

For visibility, Murang'a county government and the national steering board should create awareness of the site restoration activities, erect signs from Murang'a town to the site and construct a tower that can be seen from a distance. For cultural symbolism, there is need to construct a monument to the Agikuyu ancestral parents, Gikuyu and Mumbi, and a perimeter fence using local material. Further, a botanical garden should be planted on the 4.05 acres remaining after demarcating the shrine. 


\section{Fisheries as heritage: indigenous methods of fishing and conservation among the Luo fishers of Lake Victoria, Kenya}

Paul Opondo

\section{Introduction}

This chapter examines the Luo fishing practices in Lake Victoria, Kenya, during the pre-colonial and post-colonial epochs. It looks into the types of fishing gear used and those prohibited, the conservation and management approaches applied, threats and challenges to fisheries as a heritage, especially in light of globalization, and the application of new technologies and the introduction of new species of fish. Rural Kenyans are becoming increasingly aware of the great need to conserve nature through sound environmental management, education, appreciation of culture and their involvement as ordinary citizens in conservation policies engendered by the state. There is a growing need to engage history with natural heritage and to relate culture with nature. Heritage landmarks in Kenya include lakes, rivers, caves, the 'crying stones' of western Kenya, beaches along the Indian Ocean and Lake Victoria and the largest fresh water lake in Africa, among many other sacred sites. The objective of the chapter is to investigate the traditional methods of fishing and conservation used by the fishers of Lake Victoria, and to understand how they exploited fish sustainably. It is critical to incorporate some of these methods into the government policy on the exploitation of fisheries so as to ensure sustainability. The Luo's fishers are a good example of how social life was, and still is, closely intertwined with their environment and economic system of survival. 
According to James McCann (1999), Africa is the richest continent in terms of the biodiversity of its fresh water lakes with over $90 \%$ of cichlid species being endemic to Lakes Malawi and Tanganyika. Recent rapid changes in the climate and land use practices in Africa have resulted in endangering specific parts of the continent's biodiversity, most dramatically in lake fish species where eutrophication and anoxia have sharply reduced species numbers (McCann 1999). In the pre-colonial era, the mesh size and catch of traditional papyrus nets were carefully controlled so that only a certain number of particular fish species were allowed to be caught. During floods and rainy season, Luo fishers did not have to go very far into the lake for fish. The closed season and other restrictions allowed the resource to reproduce, ensuring abundant catches. A fisher could catch enough fish of a good size to meet his subsistence needs within a short time. In Jansen's opinion, Jo-Lupo (fishers) had developed clan-based rules for fishing (chike-lupo) that had to be observed by all fishers.

Among the Luo fishers, there were rules governing the use of nets, hooks, baits and canoes, which further ensured the sustainable use of the lake's fish resources. There was adherence to the closed season, which was also facilitated by its coinciding with the period of working the farms. Clan elders controlled access to the lake and during the closed season canoes were forbidden to go beyond a certain distance on the lake.

The Luo fishers believed that soaps and lemons polluted the rivers, damaging the ecosystem and ultimately killing fish. There was also an element of cooperation in the setting up of the boats. In modern times, the government spells out rules, imposes taxes, licenses and decrees on seasonal closures to protect juvenile fish and also supports the Beach Management Units (BMU) on each beach.

The colonial state, from the 1950s, halted the 'free access' system hitherto used by Luo fishers. The colonial state's main concern was to control fishing for purposes of developing it for both internal and external markets. Oguyo, a fisherman for many years, commended the decision to restrict access between April and August, for it allowed fish to breed. According to him, 'free access' had encouraged people to fish juvenile fish, which put future breeding at risk. 'Free access' had allowed too many people to practise fishing, and this encouraged the use of smaller mesh size nets which at times scooped fish eggs, catching the young fish together with the mature fish, as well as fish that were yet to breed (Opondo 2012). It is believed that the introduction of a closed season and minimum mesh sizes guaranteed the future supply of fish 
by protecting the eggs and the underage fish, and thus ensured the sustainability of the lake fish resource. The post-colonial government has, since 1963, pursued and maintained the same policy of closed season as opposed to the open access paradigm.

\section{The contemporary situation}

Fish population in Lake Victoria is affected by several variables and elements such as fishing effort, use of technology, hatcheries, temperature, wind direction and predator populations, all of which influence abundance and distribution (Glantz 1992). Yet human activities can also affect the sustainability of these populations through, for instance, the application of a variety of different management schemes or new technology, each of which could have a different consequence on the state of fishery.

Lake Victoria is the largest lake in Africa and the world's third largest with an area of $69,000 \mathrm{~km}^{2}$. The catchment area of the lake covers an area of $46,000 \mathrm{~km}^{2}$. Fishery is today worth an estimated US $\$ 600$ million annually, with US \$350 million in export earnings alone. About $75 \%$ of Nile perch caught is exported, mainly to Europe, the United States and the Middle East creating more employment, income, GDP and foreign exchange earnings. Rising demand has led to increased capitalization and competition for more catches for the export market, thus creating unsustainable exploitation; hence the need for controlled use of the fisheries for future posterity. In the 2013/2014 financial year, the East African Community (EAC) allocated US \$3 million to the Lake Victoria Fisheries Organization (LVFO) to support sustainable management of fisheries and harmonization of national fishery policies and regulations on fishing gear to avoid over-exploitation and future shortage (LVFO 2013). The fisheries are governed by a series of control measures designed to maintain stocks and increase benefits to resource users. According to the LVFO, the technical control mechanisms include minimum gillnet mesh size of five inches for Nile perch and tilapia. Some fishing gear and methods are prohibited. These include trawling, beach seines, monofilament nets, cast nets, drift nets, tycooning, use of chemicals and explosives, vertical joining of nets and gillnets more than 26 meshes deep. The EAC governments use the BMUs in efforts to reduce illegal and destructive fishing and to promote participatory management.

Goldschmidt (1998) points out that before the human factor began to play a role, the life expectancy of fish species was approximately one 
million years, but today the chance of extinction among species has become 1,000 to 10,000 times greater. Goldschmidt informs us that on the Tanzania side of Lake Victoria, biologists and limnologists have become actively involved in the conservation of fisheries through the Lake Victoria Research and Conservation Team. Through the work of this group, endangered species such as furu (the Swahili name given to the species haplochromines) have been recognized by the International Union for Conservation of Nature (IUCN). A captive breeding programme has been launched and some 40 species sent to Europe and the United States for conservation and kept in European zoos to continue breeding there. It is believed that one day it will be possible to release several species of furu in Lake Victoria or in the smaller lakes of East Africa. In addition, Goldschmidt (1998) asserts that there were plans to create fish reserves in which the endangered species could be protected from the greedy Nile perch.

\section{The indigenous systems of conservation}

Resources that need to be preserved in the lake region include fisheries, the Gwassi forest, the fresh water, the wetlands and indigenous fish types such as oreochromis, barbus, mormyrus, labeo, gnathoremus, rastrinebola, bagrus, schilbe and alestes, which were depleted after the introduction of the predatory Nile perch (mbuta) in the 1950s. Today, only three types of fish - Nile perch (Lates niloticus), and silver cyprinid (Rastrineobola argentea) and tilapia (Oreochromis niloticus) dominate the fishery, making up $98 \%$ of the catch. The Luo had, for many years, practised their unique mode of fishing and management distinctively different from the colonial ones. They had their own indigenous methods of fishing. William Ochieng' (1974) asserts that by 1850 the Lake Victoria region had a rich village culture, based on fishing, simple crop production and increased craft specialization. He further suggests that the Bantu civilization in Yimbo, which influenced the Luo near the lake, was based on fishing and the communities' lives were oriented purely towards Lake Victoria. Over the same period, the local people had their own ethics and rules of fishing (chike-lupo), which were adhered to religiously by all fishers. There existed conservation efforts by the fishers to protect the lake's habitat to allow for the regeneration and reproduction of fish. In the words of Doug Wilson (1987), fishers had 'certain [common] assumptions about how environmental issues should be defined'. Bokea (2000) explains that this is linked to 
the fact that the fishing community had traditional and territorial rules and regulations which ensured that fishery was exploited in a sustainable manner. They further point out that the use of simple traditional technology such as traps and spears kept fishing intensity and pressure in check. It was not common for fishers to take underage fish from the lake. There were rules and procedures on the use of nets, hooks, baits, boats and seasonality, which ensured sustainability in the use of fishery resources.

Fishers thus knew when and how to fish. They respected the closed season and this was made easier by the fact that it coincided with the period of working the farms. Fishing access was under the leadership of clan elders. During the closed season, fishing canoes were only allowed to reach certain distances on the lake. One of the fishermen, Mireri, points out that there was a closed period when elders decreed that there would be no fishing along the beach (wath). This coincides with the season from February to June when fishers would turn to crop farming. He asserts that one could not fish and at the same time farm. However, those households that had adequate labour resources could easily straddle fishing and farm cultivation, depending on seasonality, though they could not go beyond a few metres from the shoreline. The fact that the farming season from planting to harvest coincided with the closed season for fishing allowed for conservation of juvenile fish, also because the rainy season overlaps with the months when fish breed. Thus, breeding zones were afforded protection. To this end, only certain fish sizes and species could be fished at certain seasons and locations. The elders would punish those fishers who failed to adhere to the closed season by banning them for many months. A total ban on fishing at certain times of the year was practised to protect fishing grounds under pressure and give certain species of fish a chance to multiply.

The Luo were skilled fishers who used appropriate and environmentally friendly techniques such as fishing lines, hooks, nets, traps, baskets made from papyrus reeds and spears, depending on the type of fish to be caught - very innovative methods used in catching and preserving fish in the Lake Victoria region. The local population had learnt how to control fisheries using methods of management and conservation they had learnt from their environment and later, the colonial modes of management. The amount of fish and mesh size of traditional papyrus nets were carefully controlled so that only the correct fish size of the right species could be caught. Fishing was often a communal activity though individuals also had their own plans on how to go fishing. In the 1850s, fishers did not have to go very far into the lake to find fish because 
closed seasons allowed plenty of fish to breed and grow to maturity. A fisherman could catch enough big sized fish to feed the family.

Communal ownership was an appropriate method for conserving the fisheries. Organized around clans, fishing activities were well managed and controlled to allow sustainability. The various clans, rather than individuals, 'owned' the beaches adjacent to their homes and land. There were neither boundaries nor hurdles to their movements. Fishers freely roamed the lake catching fish and preparing it for sale. In the words of Lazarus Ogwire, a fisherman for over 40 years, 'there were no borders indicating Uganda or Tanzania'. Ouko Okullo expressed similar sentiments: 'we believed that the Lake belonged to God'. This assertion indicates that Jo Nam, the people of the lake, interacted freely across the lake before the advent of colonialism. There was freedom to enter and exit at will on condition that one was a member of a given clan. During this era, Ngege (Nile tilapia) was a highly valued catch. It was traded with neighbouring communities such as the Samia and the Abagusii for grains, pots and iron implements such as the nyagot, a hoe used for farming (Kitching 1980). During this period, the metal hoe was an important factor in increasing agricultural productivity. Cattle were also used in a bartering system and by selling fish one could acquire cattle which could then be exchanged for this important farming implement.

\section{Conservation, threats and regulations}

The factors that affect the conservation of Lake Victoria beaches include intervention by government agencies, waste disposal mechanisms from around the towns in the lake region and increased fishing activities due to the rise in population along the Dunga, Uhanya and Luanda Kotieno beaches in Kisumu County (University of Nairobi 2014). In the precolonial period, Luo fishers had traditional, communal and territorial rules and regulations which ensured that the fishery was exploited in a sustainable manner by limiting access to specific stock areas. Communal fishing was based on clan or kin membership. This view is supported by Jansen (1973) who states that entry to fishery was on open access and exit (but strictly on the basis of kinship). In his opinion, Jo-Lupo had developed clan-based rules and regulations (chike-lupo) that had to be observed by the fishers. In most cases these rules were vague and not explicitly expressed but they were followed and enforced by clan elders all the same. In fact, it seems there were no preconditions or fees charged on joining the fishing fraternity. In essence, everyone had his 
own fishing plan. However, there were religious prerequisites to be observed by the fishers.

In the words of fisherman Oracho Wire, the lake god had to be respected. Before a canoe could go on a fishing voyage, the team leader, Mwasiamar Yie, had to take some water into his mouth and spray it on the canoe, beseeching the lake god for blessings. Besides, there were gifts given to the sea god. The first fish to be caught was handed over to Mwasia to offer to the god. Using strong-smelling bathing soaps while going fishing was considered taboo, and a person who had eaten lemon was allowed not into the canoe. Oracho Wire's explanation underlines the link between cultural beliefs and conservation. Pollutants rarely entered the lake's ecosystem due to such precautions. The prohibition on the use of such things as soap was probably because fish could detect strong smelling substances and thus escape being caught. Luo fishers believed that soaps polluted the rivers and damaged the ecosystem and ultimately killed fish. Joyce Oruko, a fisherwoman for more than 40 years, explains that most fishers sold their fish to a limited number of fishmongers with whom they developed trade links which were longstanding. There was limited outside interference, little penetration of outside capital and less colonial government intervention during this era. This system of local management and adherence to chike-lupo (rules) was later to be threatened by the introduction of commercial fishing after the First World War.

The nature of fishery management and conservation in the precolonial period enhanced the participation of local people. The lake and its fishing grounds were as important to early fishers as land is to the farmer. The lake was not only a major source of food but had customary value as well. Jane Awino explains that there were practical rules that were adhered to in order to protect the lake's habitat from damage. Besides, there were candid efforts and regulations on fishing seasons so as to allow the lake's fauna to regenerate and ensure sustainability. This shows that fishers shared their concern in conserving fish by adhering to local rules. The fishing community commonly shared issues of environmental protection, conservation and justice. The fishers understood their fishing seasons well. In the words of Ogwire, 'juvenile fish were bred in April during the heavy rains and floods, so allowing the lake to rest during this period was good because it allowed young fish to grow'. Aware that taking young fish was a bad practice for future fishery, the fishers allowed the lake to rejuvenate naturally. He observed that, 'during this season one could see several fish jumping near the beach'. This opinion corroborates that of Agola Okullo who asserts that sustainability was 
ensured. 'During the rainy season, we fished with very little effort, by taking floating fish near the lake shore, and left the juvenile fish to grow'. In effect, the closed season in the pre-colonial period ensured a future supply. The lake also experienced a cold season, a kind of winter 'when marshes (yugni) covered the lake surface. In June, it became very cold and movement became very difficult on the lake surface and it was said that the lake had closed itself'.

Prominent species, which were considered important by the Luo community included ngege (tilapia), fuani, ningu (ray-finned fish), soga, okoko (synodontis), sote, suma (mormmyrus kanume), mumi (catfish). But of all these species, tilapia was the most common and abundant. It was also the most popular commodity for both traders and consumers alike. It was caught and sold fresh or split, smoked or dried as obambla (dried fish). Henry Ondiek avers that before the introduction of mbuta (Nile perch), which is a predator fish, there were many varieties of fish. At the same time, fish was plentiful. It is argued that nets tended to lead to overfishing or over-exploitation of fishery. Traditional papyrus nets could catch hundreds of fish within a short time, which were however, sold very cheaply. For instance Oracho explains that 30 pieces of tilapia were sold for as little as Ksh 1 (Kitching 1980). Amos Amollo confirms that the 'traditional' indigenous species had less commercial value but provided the much needed source of protein. Furthermore, conservation was made easy due to minimal capitalist competition, hence the level of conservation was high and fish was plentiful.

In the pre-capitalist era, conservation was probably more sustainable. According to Manas Osur, a long-time fisher, 'the indigenous methods of fishing necessitated the use of only a few canoes, as these were scarce. One canoe could, for instance, be used by up to five people or more, each with his nets'. This implies that fishers cooperated rather than competed during this era. This view is confirmed by Lazarus Ogwire who asserts that fishers cooperated a lot at work. They shared fishing secrets like which islands to go to for fish and on sighting the position of the moon, which was an important factor in ocean fishing. They did the same things and discussed similar issues such as which beach had a type of a given species, all for the betterment of their trade. There was even harmony at the end of a fishing trip as the day's catch was shared among the fishers. The owner of the canoe had to be given $10 \%$ of the catch by everyone who had used the boat. There was also an element of cooperation in the setting up of the boats.

This illustrates the egalitarian nature of the fishing community as far as sharing was concerned. Lazarus Ogwire further explains that 
the setting of a fishing trap such as gogo was a communal affair. He adds that the Luo fishers set the nets on the canoe together. After the net caught enough fish, they jointly pulled it with eight young men on either side of the gogo. He appreciates the efficiency of the gogo nets when he asserts that 'it was good and could catch lots of fish, hence it was referred to as machoka (generous collector)'. But this view is contrasted by Abila, who argues that the gogo nets were not generous and that the amount they caught was not so excessive as to threaten the fishery reproduction (Abila 1992). Fishing traps were set very early in the morning at around four o'clock and checked for catches the following day. Fishing was a communal affair predominantly done by men. This avoided the severe competition that would have jeopardized fisheries.

Another aspect of cooperation, according to Oracho, was the system of sharing catches inherent within the fishing economy. There was reciprocity at two levels. Firstly, he points out that the colleagues who had had a good catch gave out a few pieces of the fish caught to those fishers whose nets had not caught any fish that day. Secondly, orphans and the destitute could also wait for the fish to land and they too, were assured of a few donations. This system of sharing ensured that all families within the fishing community would not starve.

One fundamental reason why fishing in the pre-colonial era was sustainable was that it remained a subsistence activity practised by those who lived near the shores of the lake. But this is not to say that surplus fish was not sold. On the contrary, marketing of dry fish was done within the locality as buyers came from nearby centres and villages. By 1895, when Kenya became a British protectorate, Oguyo Mahira (who learnt from his grandfather) asserts that 'there were no marketing agents like we have today. Everybody sold his own fish. You fished and took your commodity to the market or gave it to your wife to sell it for you'. After a fishing voyage (kilua), fishers set up small huts (kiru) where they stored their catch as they waited for buyers to come to the beach to buy.

Implicit in this statement is the fact that in the pre-colonial era, before the introduction of the colonial economy and the monetary system and taxation, and before transport had been improved, the selling of fish was done locally, especially by women. However, it was not the exclusive domain of women as they only sold fish in the nearby markets; men too participated in the selling of fish, especially when it involved travelling long distances to faraway centres (Abila 1992). For instance, Abila points out that a typical artisanal fish processor-trader 
in pre-colonial Kenya was likely to be female, with nearly half of them engaged in subsidiary activities to supplement the income from the fish trade.

In 2015, overfishing and pollution remain the greatest threats to fisheries as a national heritage. Commercial fishing picked up from the 1950s onwards. Fish production in Lake Victoria is now between 400,000 and 500,000 tonnes per annum with Tanzania accounting for $40 \%$, Uganda $25 \%$ and Kenya $35 \%$ of all the catches (Ong'ang'a 2005, 67). Each of these three East African countries has a government policy framework through which fisheries resources are managed. Yet the greatest threats to fisheries remain trawling, the use of undersized nets, human overpopulation, the water hyacinth and the HIV/AIDS virus which is increasingly prevalent among fishers. Towns such as Kisumu, Homa Bay, Busia and Migori have become centres of trade with fish being the main commodity. Ochieng' (1974) suggests that fish was a common commodity of trade, adding that most of the people who lived along the lake exported smoked fish to those who lived in the interior and fish was usually exchanged for grain. Writing on the existence of trade on Lake Victoria islands by 1890, Ochieng' asserts that:

It [trade] was possible along the lake islands such as Mageta, Rusinga and Mfang'ano for ruoth (a leader) benefited due to riches that accrued from trade and these islands [were] very much influenced by Buganda political ideas. A ruler was supposed to be a rich man who could freely provide food for the needy in his society. $(1974,70)$

He further points out that by 1890, one of the richest families of fishers was the Gaunyas. That family exported fish to neighbouring territories such as Sakwa and Alego, and got grains and cattle in return. Women played an active role in the fish trade because trading centres were near the beaches. Naturally, women had a longer day than men. This was because apart from trade, women also had domestic duties as well as child raising tasks.

Kitching (1980) states that labour was underutilized in precolonial Africa. But this assertion is not right. The view that Africans were idle was propagated by apologists of colonialism who needed to utilize African labour to serve the colonial state. This was the justification used by colonial rulers to force Africans to work on colonial settler farms and mines. Kitching further asserts that there was more emphasis on the production of annual cereal crops, mainly millet and simsim, 
and that the African farmer was mostly a peasant, subsistence farmer. Africans worked on their beaches as fishers, on farmlands as farmers and looked after their livestock. As cattle grazed along the lake, Luo fishers used this so-called 'free' time to engage in fishing activities. Fishing was a full-time productive activity, unlike hunting and raiding. As a productive activity, asserts Vercruijsse (1987), canoe fishing required a substantial amount of time and equipment such as nets and gear, when compared to other pre-capitalist branches of production such as farming. It is thus incorrect to claim that African labour (Luo labour in this case) was underutilized where fishery as an economic activity was concerned.

Farming and fishing activities were significant in the economic life of the Luo. Lazarus Ogwire, once again, asserts that fishing was done on a seasonal basis. This was because fish, by their nature, were more plentiful in certain seasons than others. Ogwire argues that between February and June, fish went upstream to hatch in the adjacent rivers. Fish were more abundant during the low moon and less so when the moon was high, probably because during the low moon there was darkness and so the fish could not see the fishers due to poor visibility. He further states that seasonality was paramount to the fishers for they had to organize their labour and that of their families accordingly. This arrangement ensured efficient use of local resources such as land and lake. As Ocholla-Ayayo $(1976,22)$ points out, by practising a pastoralagrico-fishing economy, the Luo society was largely a self-sufficient group. This tri-economy ensured that labour was adequately used. He reinforces this point further by stating that 'the economy meant that the Luo had adequate means of production, such as land and water, and their three main economic activities provided strong interactions that enabled them to accumulate and widen their normative and ideological beliefs'.

\section{Conclusion}

Overfishing, which is a threat to the fisheries of Lake Victoria, is a product of an unsustainable exploitation of the Nile perch and other species. Major threats to the lake's ecosystem include accelerated soil erosion which creates siltation, deforestation, air and water pollution from the factories in Kisumu City, declining fish catches and loss of biodiversity. These challenges have in turn led to the escalation of environmental degradation, declining food security, rising health problems, reduced 
incomes and deepening poverty; all of which call for increased government vigilance over issues of licensing and closed seasons. All these measures will lead to increased fish productivity and incomes for the small-scale fishermen. Moreover, increased commercial exploitation of fishery such as the Nile perch, which is highly prized in Europe, the Middle East and the USA, has led to its over-exploitation, thus threatening the survival of the lake and its people. The lake is a profound and authentic heritage and should be conserved, especially by riparian communities such as the Luo, Samia and Suba, who associate the lake with deep cultural, aesthetic and religious significance. Indeed these people have always valued the lake for its endowments since it serves both ritualistic and economic purposes. The lake is not only a source of livelihood for thousands of families, but is also a tourist attraction. However, for conservation to be sustainable there is need to involve the local people - the main agents of overfishing - in the development of conservation practices and management methods of fisheries. This will ensure sustainability in the exploitation of fishery resources for posterity as an important element of the Kenyan natural and intangible heritage. 


\section{4}

\section{Tracing a forgotten heritage: the place of Mau Mau memory and culture in Kenya}

Ephraim Wahome, Felix Kiruthu and Susan Mwangi

\section{Introduction}

The origins of the Mau Mau have been discussed by many scholars including Kanogo (1987), Anderson (2005) and Elkins (2005), who generally agree that the Mau Mau uprising had something to do with British colonial oppression. In 1915, the colonial government enacted the Crown Lands Ordinance which effectively relegated the Africans into a state of perpetual tenancy on their own land. Lonsdale (1992) intimates that Mau Mau grievances date back to the Resident Native Labourers Ordinance of 1918 which systematically reduced indigenous land owners to squatters and sources of labour for the emergent settler economy. These events altered the history of Kenyan communities significantly, culminating in the declaration of a state of emergency in 1952.

Unfortunately, the Mau Mau struggle against the British colonists in Kenya has not been given the attention it deserves. It is not only important for scholars to conduct studies on the movement, but to also document it for the benefit of memorialization and posterity. The Mau Mau sites in Kenya are many and varied, including their complex communication networks, trenches, caves, gun factories, oaths sites, offices, detention camps and burial places. Conserving this heritage would give the general public a chance to appreciate the place of fighters in the history of Kenya.

Unfortunately, unless prodded to do so, the ordinary people who participated in the movement rarely open up on issues about it. This 
leaves historians and other scholars with many unanswered questions with regard to the memory of the Mau Mau experience. The reasons behind this are open to conjecture:

- Is the memory of humiliation, emotional and physical pain silencing the veterans?

- Is it the fear of exposing the secrets of the many oaths that were administered to the fighters?

- Is it the fear of widening the existing rift between the freedom fighters and the loyalists?

- Is it the game played by the political class to forge a united nation at the expense veterans?

According to Anderson (2005), political independence was followed by suppression of public memories on the Mau Mau experiences by the elite in Kenyatta's government. Kenyatta himself was alive to the fact that the division between the Mau Mau supporters and the loyalists was real and a major threat to national unity. Consequently, at independence, he was quick to remind Mau Mau supporters not to retaliate.

In spite of the Kenyatta regime's efforts to suppress Mau Mau memories, the movement's supporters continued with their clamour for recognition. In 2003, the Kibaki regime recognized the Mau Mau as a legal movement which had contributed significantly to the independence of Kenya. This recognition and lifting of the silent state of proscription contributed much to the revitalization of the Mau Mau associations and activities, resulting in a compensatory financial award by the British government a decade later for the atrocities meted on freedom fighters. It also stimulated further research into the myth of the Mau Mau.

\section{The concept of memorialization}

In this chapter, memorialization refers to a process that satisfies the desire to honour those who suffered or died during the Mau Mau conflict. Memorialization is a means to examine the past and address the issues related to that past. In all human societies, governments and the political elite have the power to determine which collective memory of a nation is to be revisited, reconstructed and remembered from time to time. For this reason the collective memories of any given event are never static but constantly changing and dynamic enough to respond to new situations and circumstances. Memory is subject to alteration and 
re-emphasis to justify emerging trends and ideologies or to accord prestige to a set of new ideas within the political elites (Maloba 1994). As for the Mau Mau, the evolution of memories has largely been determined and dominated by consecutive governments with presidents selecting themes that most appropriately benefit their interests.

Memorialization of the Mau Mau is important for a number of reasons. As Williams (1999) underscores, it is crucial to understand what remedial action needs to be taken to address what were gross violations of human rights and ensure that such abuses do not recur. It is also necessary to provide a historical overview of those violations and to suggest reasons as to why they emerged on such a scale (Williams 1999). Lessons learnt about the violations by the British against the Mau Mau fighters are not only important for historical purposes, but could also inform the current government, police and the armed forces on human rights issues.

Mazrui (1963) observes that next to forgetting past enemies, the most important element in building up national consciousness and healing is perhaps the faculty of remembering past heroes. This act of recognition is tantamount to an exercise in national self-identification (Mazrui 1963). This is important given that the idea of a nation can at times be too abstract to command ready-made allegiance. Therefore, it becomes easier and necessary to personify nationhood metaphorically or to give it specific human form in national heroes. Mazrui concludes that it is precisely due to this complexity that ancestor worship is an important exercise in all nations. The Americans, for example, glorify their heroes of the American Revolutionary War, such as George Washington and Thomas Jefferson.

According to Mackay $(2013,44)$ heritage properties are important for the society as part of humanity's inheritance which 'we have an obligation to pass ... to the current generation and transmit... to future generations'. This gives a concise justification for memorialization and conservation. However, support for this memorialization process is usually influenced by the direct engagement of stakeholders who relate with values being conserved (Talbot 2013). In the case of the Mau Mau, lack of sensitization and poor identification of the cultural values attached to the heritage combine with changing political perceptions to complicate the memorialization process. In spite of the contribution made by the Mau Mau, politicians conspired to deny them official recognition due to the neocolonial tendencies that followed political independence (Munene 2012). Both Kenyatta and Moi treated the memorialization of 
the Mau Mau as both a liability and an asset which they could switch on and off whenever needed, but never elevating it to national status.

Mau Mau sites play a critical role in the social construction of the past and, by extension, enhance memorialization and reconciliation among members of the community. Barsalou and Baxter (2007) have observed that the meaning of reconciliation has become one of the key components of transitional justice, which assumes that truth telling and justice, which includes holding perpetrators accountable through restorative measures such as compensation, promote reconciliation.

\section{Kenyatta and the Mau Mau legacy: 1963-1978}

The Mau Mau legacy has shaped Kenya's political discourse (Buijtenhuijs 1973; Lonsdale 1992; Friedmann 1995; Clough 1998; McClellan 2000; Odhiambo 2003). Since the 1960s there has been an ongoing debate over the interpretation of the Mau Mau movement (Friedman 1995), its nature and legacy. Often the official discourse on the Mau Mau depends on the intentions and motivation of different groups and the prevailing political dynamics. Due to the diversity in the above factors, the collective memories on the movement have been more exclusivist than integrationist (Friedman 1995). At the national level, debate on whether the movement was all-inclusive and intended to liberate all Kenyans from white domination, and whether it represents a proudly resistant past in which all Kenyan ethnic groups can claim some share, has remained potentially explosive, and silence has thus remained the chosen language in dealing with Mau Mau memories. At the ethnic level, especially among the Kikuyu where the insurgency took place, the rebellion divided the community between fighters and loyalists, making it politically destructive. In remembering the movement and its heroes, freedom fighters have continually demanded justice and recognition of their efforts through awards, medals and land compensation, the commodity that they spiritedly fought for.

Buijtenhuijs (1973) gave the three major interpretations of the Mau Mau in Kenya's historiography; the European myth, the African myth and the Euro-African myth. The European myth, largely presented by the British colonizers and their sympathizers, constructed Mau Mau insurgence as a regression to the past, condemned them as savages and maniacs, and justified counterinsurgency, detention and rehabilitation as necessary antidotes to this political and spiritual sickness. 
The movement was presented as atavistic, backward, subversive and closely related to the cults (dinis) that were quickly sprouting in the squatter farms in rejection of mainstream Christianity and the Western values that the British believed they had laboured for two generations to inculcate in the African minds. According to Lyttelton, the revolt was neither 'the direct child of economic conditions nor was it intended or designed to improve them' (cited in Buijtenhuijs 1973). This presentation was based on the belief that Africans were not only backward, but also incapable of organizing political groups capable of challenging the white hegemony.

In the attempt to correct this myth (which had been controlled by the enemies of the Mau Mau), African scholars of the Mau Mau in the 1960s began writing and reconstructing the memories of the movement afresh. Many dismissed the regression as well as the primitive discourse, arguing that Africans were not only capable of organizing and articulately presenting their grievances, but that they were also aware of their rights and freedoms in the face of external aggression and attack on their being. Memoirists thus presented their versions of the movement noting that rather than the perverted and inimical movement that the British had portrayed, the Mau Mau was indeed a movement composed of heroes, patriots and nationalists.

Wachanga (1975) revitalized the debates on the movement by creating an alternative version that largely captured the mood of most Africans, especially the Kikuyu. Such cleansing histories portrayed the revolt as a rational response to colonial oppression, similar to other violent struggles for liberation (Clough 1998). Since 1964 the discourse on the Mau Mau began assuming a decidedly nationalistic character. The British and their African collaborators were branded as brats, thugs and traitors. But like the European narrative, this corrective version created a counter-mythology and certainly reflected its own political objectives.

Historians and literary writers soon took up the debate. Borrowing from Marxist-Leninist theory, literary intellectuals on their part argued that were it not for the mobilization and the activities of peasants and the 'wretched of the earth', among the Kikuyu, Kenya would not have attained her independence. That it was as a result of the challenge that Mau Mau fighters posed to the colonizers that the latter came to vacate the White Highlands and relinquish their positions of power, leaving the country in the hands of Africans. The revolution that was staged by the Mau Mau was equated to the ones launched by Guineans, Algerians and Mozambicans in countering colonial rule. The movement was presented 
as not only heroic, but also patriotic in its approach to the fight for independence.

Anderson (2005) and Elkins (2005) give various reasons why Kenyatta's government pushed the Mau Mau myth into the rear in the official discourse, choosing instead to emphasize constitutional advance towards majority rule. In the face of ethnic diversity, the founder president had to adopt the language of national integration. The new regime thus considered it important to build and forge interethnic unity, an endeavour which would have been complicated had Kenyatta only rewarded and praised the Kikuyu role in the fight for liberation. In his famous quote, Kenyatta noted 'we all fought for freedom' and during the Kenyatta Day celebrations of 1964 he buttressed the point by adding that:

Let this be the day on which all of us commit ourselves to erase from our minds all the hatreds and the difficulties of those years which now belong to history. Let us instead unite in all our utterances and activities, in concern for the reconstruction of our country and the vitality of Kenya's future. (McClellan 2000)

Through this statement, Kenyatta was indirectly asking the ex-fighters to embrace the communities which had not taken part in the Mau Mau revolt, especially on the issue of land ownership. Here the president was also insinuating that he was not ready to prosecute those who had mistreated the ex-fighters such as the settlers, home guards, district and provincial officers, chiefs and headmen, as well as other colonial agents. His stance was to deal equally with anyone threatening peace and the progress of the nation, regardless of tribe or prior affiliation. True to his words, by the end of 1964, Kenyatta had detained a number of 'rebels' associated with either Kiama kia Muingi (the Society of the People) or the Kenya Land and Freedom Army (McClellan 2000).

Secondly, the independent government had to deal with the complicated phenomenon of the British presence in Kenya. During the ensuing decolonization debates, Kenyatta and KANU had vowed to uphold the dignity of the settlers by not flashing them out of the country and it was thus imperative for Kenyatta to prove to Europeans in Kenya and abroad that his system of governance was all-inclusive and not bent on witch-hunting.

Thirdly, Kenyatta was aware of the divisive wounds that had emerged during the fight for liberation between loyalists and fighters. The post-independence presence of these loyalists within the ruling 
party, the civil service and the boardrooms of the private sector and Kenyatta's inner circle of advisors required Mau Mau memories to be suppressed as a subject for public discussion. The inclusion of loyalists in the decolonization debate and the benefits that had accrued from their friendly relations with the settlers and the colonial administrators was also a delicate issue that Kenyatta was well aware of (McClellan 2000).

Finally, the new regime was keen on emphasizing the role of Kenyatta in the liberation struggle and bringing in the Mau Mau would have weakened this individual contribution. It is notable that Mau Mau veterans posed a serious threat on their return from the forest in 1964. This threat is particularly seen in their demand for free land, which undermined Kenyatta's clarion call for uhuru na kazi (freedom and work) where everyone was required to work for the benefit of the nation. In any case, granting free land would have introduced inequality and weakened the economy against Kenyatta's appeal.

Throughout 1961-65 Mau Mau's discourse in public life thus remained in the rear and attempts to revive it by a few individuals and groups were discouraged by the political and economic elites whose fortunes continued to swell with the economic boom that was occasioned by purchase of land in the highlands. But the situation began changing from 1965 when Kenyatta began adopting a benign attitude towards the movement and its members. This change had been occasioned by two major factors; the president had by now entrenched himself into the system and therefore had little worry about a few 'hooligans' out to destabilize his government. However, the emergence of a new party, Kenya People's Union (KPU), led by Oginga Odinga and Bildad Kaggia, two champions of the ex-freedom fighters, meant that he had to find a way of uniting the Kikuyu by discrediting these leaders as tribalists out to usurp the swelling wealth of the Kikuyu. By invoking the Mau Mau memory and accusing Kaggia of betrayal, Kenyatta thus succeeded in uniting the community and for some time having the ex-fighters on his side.

From 1965 Kenyatta allowed ex-veterans to form old comrades associations as a way of remembering their past. However, creative remembering and selective amnesia were to become clear in 1969 when Kenyatta, in need of political support from the Kikuyu community, openly invoked the memories of Mau Mau (Friedman 1995). This memorialization followed the assassination of Tom Mboya when Kenyatta's government suffered a big blow with many politicians putting pressure on the government to explain the circumstances of the slaying and apprehend the killers of the vocal politician. To counter 
this wave, Kenyatta successfully demarcated a usable history of Mau Mau oaths by calling on the Kikuyu community to rise against external aggression from unsatisfied communities. Odinga, though an avowed enemy of Mboya, was presented as the enemy while his community, the Luo, were seen as the aggressors who intended to destabilize the government. Kenyatta thus invited the Kikuyu from all walks of life to his home in Gatundu for a tea party intended to galvanize their support for his regime. During the party, 'oathing' was revived to keep the nation's flag in the house of Gikuyu and Mumbi (Friedman 1995).

Ex-veterans also played a role in relegating the memory of their sacrifice into the cupboard of forgetfulness. To begin with, they were unable or unwilling to work under one authority, which would have preserved the unity of those who survived the war. Ethnicity and intraethnic politics played a great role in this. Veteran associations emerged from different sections of Central Region, representing diverse interests and often competing against each other, thereby blocking the possibility of forging a common identity for the movement.

\section{Moi and the Mau Mau memory, 1978-2002}

The demise of Kenyatta in 1978 and the takeover by President Daniel Arap Moi saw a new reconstruction of the Mau Mau memory in Kenya's historiography. Though a Kalenjin, Moi could not ignore the role that had been played by the Mau Mau in the fight for independence. For the majority of Kikuyu, who by then occupied a majority of seats in the government, Moi had to devise a way of pleasing and working with them. He also had to appear to be the champion of the poor and his announcement in 1979 was that in recognition of Kenyan heroes, a major monument was to be erected at a suitable place in Nairobi. Moi was, however, careful not to mention the role of the Mau Mau directly, choosing instead to highlight the role of Kenyan freedom fighters in general.

As a populist and 'defender' of human rights, Moi also released twenty-six political detainees who had been imprisoned by Kenyatta for their support of the landless and insistence on a renewed revolution, after the abortion of the first one (the Mau Mau insurgency) when loyalists took over power from the colonialists. The released political prisoners included Ngugi wa Thiong'o and Maina wa Kinyatti, two popular intellectuals who have remained instrumental in helping shape the Mau Mau narrative in Kenya's public discourse. By associating with the Mau Mau 'activists', Moi was well aware that the problematic historical 
memory of the Mau Mau required careful treatment if one was to avoid conflicts with other communities. Moi's immediate and strategic concern was thus to appease the Kikuyu elite who had, since 1960, dominated the political, administrative and economic life of the country, and later to damp them once he had asserted his rule.

After years of relegating the Mau Mau legacy to the margins of history, the year 2000 attracted an upswing in the support of Mau Mau as heroes and victors. Both the opposition and the Moi government projected Mau Mau fighters as patriots and the movement as a pillar of hope. This change of tact, especially for Moi, was necessary as the elections were just around the corner and it was apparent that the opposition was more powerful than he had imagined. To counter the opposition, he had to seek ways of enticing any group that was associated with the movement, including the Mungiki and members of the veterans associations. In 2001 Moi thus declared that sites linked to the Mau Mau rebellion would be memorialized as national heritage. This notwithstanding, Moi's party, KANU, was trounced by the opposition in 2002 and the Mau Mau contribution was officially recognized by the new Kibaki regime. Kibaki took up the challenge of lifting the proscription on Mau Mau and recognizing the veterans followed by a process of identifying heroes and heroines as a form of memorialization (Coombes 2014, 145).

\section{Mau Mau heritage sites}

The Mau Mau rebellion created a complex culture within the forests, forest fringes and reserves which culminated into a new form of heritage. This culture extended between 1952, when the state of emergency was officially declared, and 1964, when the forest hide-outs were completely vacated. In Nyeri County, this culture is celebrated through sites such as the Nyeri Peace Museum and the Peace Garden in Othaya (Anderson 2005). Conservation of such sites contributes to the memorialization of the contribution of freedom fighters if the stakeholders are properly consulted (Coombes 2014).

In cases of mass killings, such as the Rwanda genocide (1994), memorialization often involves the displaying or preservation of human remains. This then becomes a central way of educating people about the scope of suffering and death (Barsalou \& Baxter 2007). In Kigali, Rwanda, visits to genocide sites are becoming popular, with interpretations such as the Gisozi photo exhibitions on massacred children serving as reconciliation points and historical memorialization. This indicates 
that battle and death sites have a crucial role in the society, hence the need for their conservation as heritage. On the First World War museum in Kansas City, Murphy $(2014,17)$ intimates that 'the museum tells stories of heroism, heartbreak and the brutal reality of trench warfare in Europe using one of the world's largest collection of artefacts'.

This implies that war heritage has an important role in the memorialization of a people's history, which can be exploited as in the case of Mau Mau. For example, when the Othaya Memorial Hall was being established, some Mau Mau remains were discovered in a mass grave. However, it is alleged that a certain politician organized for the remains to be collected and subsequently buried in an unknown location (Anderson 2005). Discussing this phenomenon, Anderson (2005) observes that this is yet another sign of the fear that Kenya leaders have of the power of Mau Mau memory. Even in death, it is believed that the bones of the fighters haunt the living who betrayed the Mau Mau. The fear has obscured a rich heritage that would provide important lessons on the Mau Mau movement, especially for the future generations.

When the Mukurwe-ini Dairy Society was re-established in 1990, following the collapse of its predecessor in 1980, a number of events took place that rekindled the Mau Mau memory in the area. The management of the revamped dairy identified a site for the construction of a milk plant near a former Mau Mau prison/detention centre. Some of the elders were aware of the existence of a burial ground at the site and quickly organized for the bones of the dead to be reburied near Kiriti Stadium. However, these activities troubled the elders in the area who still felt that it was wrong to exhume the remains of the dead Mau Mau. When the preparation of the site for construction started, a landslide buried some of the construction workers and the accident was interpreted as having been triggered by interference with the dead Mau Mau fighters. No one died in the incident. Construction work continued, but as it reached an advanced stage, another landslide was experienced in 2011, this time killing some of the workers. In the eyes of some members of the community, this was proof that the Mau Mau ancestors were unhappy with the way they were being dishonoured. Such incidences have deterred attempts to preserve the Mau Mau war heritage. The same challenges have befallen the trenches which were meant to contain the Mau Mau at the Aberdare and Mount Kenya forests who fell during operations within the protected area during the war (Clayton 2006). Shooting on sight within the protected area was allowed, leading to many of the deaths recorded during the Mau Mau uprising (Elkins 2005). 
Such atrocities make the heritage suitable for conservation as an important component in the memorialization process. The trenches were huge moats 15 feet wide by 10 feet deep with spikes at the bottom meant to deter any attempts to jump from the forests to Kikuyu reserves.

\section{Challenges in conservation: the case study of war trenches}

Looking at Mau Mau trenches today, one can only see a shadow of what they were in the past. Part of the reason is their exposure to natural and anthropogenic deterioration. Anthropogenic deterioration is prompted by the population increase and subsequent agricultural expansion of the last fifty years. Backfilling of the trenches for agricultural purposes and infrastructural development is a common practice which has led to their systematic demise.

It is important to note, for example, that a large population of landless people was banished from the Mount Kenya forest in the 1990s as a way of preserving the water tower. The population settled just outside the forest by the roadside, which came to be known as Muoroto. These settlements became ideal as the former forest settlers could go on with their conventional activities in the forest without breaking the law through permanent settlement. However, basic needs such as food drove them to use every open space available. This is a common challenge for heritage sites globally, even in areas where listed sites have been identified, like Lamu (Lynn 2013). This challenge emanates from poor sensitization of those affected by the conservation of heritage, or stakeholders, who may destroy other heritage on the 'wrong impression' that listed heritage is 'the only heritage worth saving' (Lynn 2013). It becomes more complicated in areas where conservation has never been attempted, like in the case of trenches. This could be a sign of historical amnesia or suppression of memory on the event which exposes the heritage to systematic destruction (Coombes 2014, 141).

It is against this background that sections of the Mau Mau trenches, which are essentially on no man's land, were divided up and converted into agricultural plots. The deep trenches were soon flattened and agricultural products like maize and beans sprouted in them. For dairy needs, fodder crops benefitted from the rich alluvial deposits of the trenches (Figure 14.1). In 2012, the former forest dwellers were slowly relocated from their temporary structures to new government land. 


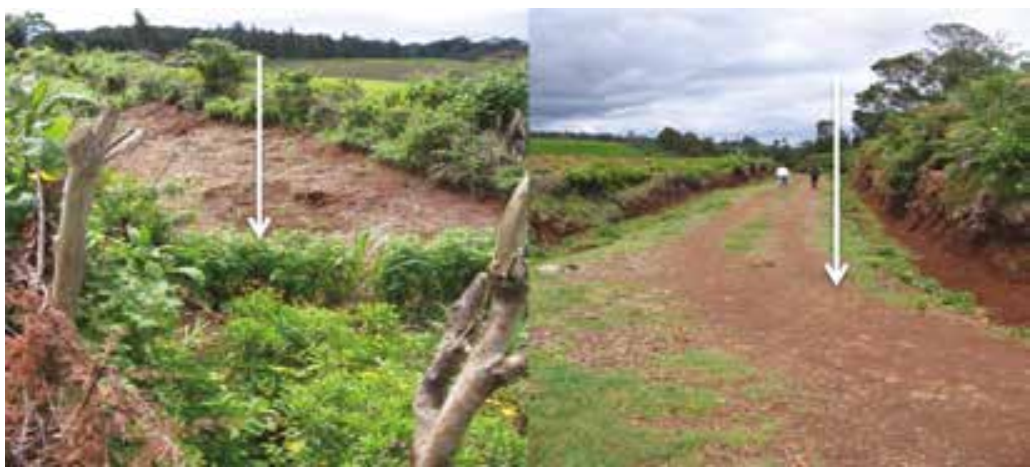

Figure 14.1 Transformation of war trenches (Wahome 2013)

This gave conservators an opportunity to protect what remains of the trenches without impacting socio-economic activities.

Besides agriculture, construction of roads through the trenches is a common practice as the overburden has already been removed, leaving a firm foundation behind. By adding quarry chips for stability, smooth access roads are easily prepared. This has increased the rate of trench deterioration in a number of areas. The trenches have also made water piping easy as pipes are easily passed through them.

These practical uses, combined with ignorance of their historical significance, have exposed the trenches to further anthropogenic degradation. Planting of eucalyptus trees along the edges of the trenches during the colonial period had both positive and negative impacts. The eucalyptus roots penetrate into the trenches, hastening their collapse or, in some cases, buttressing the structure. Eucalyptus seedlings also grow inside the structures, literally obscuring the trenches over time Significant human settlements in the vicinity in 1990s fueled a hunger for seedlings, timber and fencing poles that led to over-exploitation of the trees and further destruction of the features.

The construction of trenches formed a landscape barrier that separated animals and humans up to the early 1990s. Through time, especially due to population explosion, this relationship has changed significantly as destruction of the trenches continues unabated, thereby providing entry points which are readily exploited by animals, like elephants, as they systematically enter into settled areas and facilitate the collapse of the heritage in the process. Wild and domestic animals are known to graze inside the trenches, causing more deterioration. Parts of the structures have been completely lost and some are beyond feasible repair. 
Areas that have been spared from destruction are exposed to dense vegetation growth, which has taken its toll on the trenches as well. A combination of different shrubs and standing tree vegetation, including fig trees, have sprouted inside the trenches after the demise of eucalyptus, creating a vegetative cover which is both protective and destructive depending on its use and appeal to the surrounding communities.

Trenches represent the evils of colonial administration; they were used to oppress and humiliate the local population. The aim was to stem the possibility of agitation for political independence. In the memory of those who died or suffered the atrocities, monuments such as trenches represent the height of cruelty in a way that written words cannot express. For their progenitors and other nationalists, such monuments represent the conquering spirit that distinguishes Mau Mau as an irrepressible people.

The protection of monuments of war, like the trenches, conforms with the mandate of the National Museums of Kenya (NMK), as stipulated in the National Museums and Heritage Act (NMHA 2006), in identifying and declaring objects of historical, cultural of historic interest, especially where they are threatened and likely to continue deteriorating as monuments (NMHA 2006 Section 32). The declaration can be made by the cabinet minister dealing with culture or the director general on behalf of NMK.

In view of the reputation of the movement, the trenches and other Mau Mau monuments represent a phenomenon of key domestic and international tourism. Communities, as the real custodians, will also benefit as more and, hopefully, properly managed tourism is generated from the heritage. Tourism expenditure has the potential of developing the regions which suffered this menace through the multiplier effect.

Currently, the push for integrated conservation and community involvement in forest protection could be effectively extended to cover the protection and promotion of the monuments in the Aberdare and Mount Kenya forests, which were the hotbeds of the war campaigns. Furthermore, the Mount Kenya ecosystem was inscribed as a World Heritage site in 1997, and extended in 2013 by the United Nations (UNESCO 2013). The trenches and other forms of Mau Mau heritage around them could be added to the list for ease of conservation with proper justification. The monuments contributed to the transformation of the population socially, economically and politically from traditional to multicultural ways of life. It also led to the transformation of their 
cultural landscape in an irreversible manner. The trenches, therefore, qualify for conservation within the legal definition as:

architectural works, works of monumental sculpture and painting, elements or structures of an archaeological nature, inscriptions, cave dwellings and combinations of features which are of universal value from the point of view of history, science and art... ancient earthworks or other immovable objects attributable to human activity (NMHA 2006 Part 1).

Under the current circumstance of continued anthropogenic deterioration, the only realistic hope for the monuments lies with Sections 43 and 59 of the National Museums and Heritage Act, where heritage is ensured continued protection with the benefit of police and heritage guard inspection from time to time (NMHA 2006). The Constitution of Kenya Chapter 2 (Section 11) provides for the 'recognition', 'promotion', 'compensation' and 'use' of communal cultural heritage (CoK 2010). However, successful conservation will always depend on proper identification of cultural values and direct engagement of the communities living with the heritage (Muñoz Viñas 2005; Talbot 2013). Successful and sustainable conservation also requires proactive repair and salvaging of the extant heritage (Tayler \& Dilcher 2010).

\section{Conclusion}

This chapter has shown that the Mau Mau freedom fighters suffered continued atrocities since the declaration of a state of emergency in Kenya in 1952. They suffered at the hands of both colonial and post-colonial governments in equal measures. The former criminalized and humiliated them while the latter used, abused and demonized them. This implies that the freedom fighters never enjoyed the glory and recognition for which they so gallantly fought. The emergence of NARC government, therefore, served as a turning point in the fortunes of freedom fighters and also shaped the current scholarly discourse.

The efforts being made by the government of Kenya to recognize its heroes are important and in line with the Constitution of Kenya (2010), which entrenches national values. This will be important for the memorialization of the Mau Mau and possible compensation, by the national government, for their sacrifices. Efforts to preserve Mau Mau history, tangible and intangible heritage, is crucial in engendering interest in 
national reconciliation that never was. In light of this, the construction of a Mau Mau monument in Nairobi, by the British government, is a welcome gesture.

As a way forward, it is recommended that inventorying of the Mau Mau repertoire be fast-tracked as a national agenda to mitigate memory and physical loss. This will guard against further anthropogenic and natural destruction of national heritage. The government must pay attention to the universal value of some Mau Mau sites and urgently approach UNESCO for their listing as heritage of humanity to enhance their sustainable conservation as global tourist attractions.

In a nutshell, the reconstruction of the Mau Mau tangible and intangible heritage is an important stage in its memorialization process and in easing the tension that has characterized Kenya's post-colonial political dispensation. There is urgent need to use a variety of disciplines to study the Mau Mau phenomena for proper documentation and conservation. 


\section{References}

Abdullahi, A. (2002). Cultural Transformation and Human Rights in Africa. London: Zed Books.

Abila, R. (2000). The Development of Lake Victoria Fishery: A Boon or Bane for Food Security? Nairobi: IUCN East African Office.

Abila, R. (2005). Impacts of International Fish Trade: a Case Study of Lake Victoria Fisheries. Kisumu: KMFRI.

Abila, R. \& Jansen, E. (1997). From Local to Global Markets: the Fish Exporting and Fishmeal Industries of Lake Victoria - Structures, Strategies and Socio-economic Impact in Kenya. Nairobi: IUCN.

Abungu, L. (2005). Museums and communities in Africa: facing the new challenges. Public Archaeology, 4(2-3), 151-4.

Adam, H. (2012). Recognizing sacred natural sites and territories. In Institute for Culture and Ecology (Kenya), African Biodiversity Network \& the Gaia Foundation Kenya (eds), An Analysis of How the Kenyan Constitution, National and International Laws Can Support the Recognition of Sacred Natural Sites and Their Community Governance Systems. Nairobi: Institute for Culture and Ecology.

Agrawal, A. (2008). The Role of Local Institutions in Adaptation to Climate Change. Paper prepared for the Social Dimensions of Climate Change, Social Development Department, The World Bank, Washington, DC, 5-6 March.

Akama, S. (2002). The role of government in the Development of Tourism in Kenya. International Journal of Tourism Research 4(1), 1-14.

Akande, W. (2002). The drawback of cultural globalization. Yellow Times. Available from: https://www.globalpolicy.org/component/content/article/162/27594.html (Last accessed 15 September 2015).

Aloo, P. \& Ngugi, C. (2005). Participatory approach: the key to aquaculture development in Kenya. Aquaculture Association of Southern Africa, 12-16 September.

Alpers, E. (1992). The ivory trade in Africa: an historical review. In D. Ross (ed.), Elephant: the Animal and its Ivory in African Culture. Los Angeles: University of California, 349-60.

Amareswar, G. (2009). The 'first voice' in heritage conservation. International Journal of Intangible Heritage (3), 10-25.

Ambrose, S. (1984a). The introduction of pastoral adaptations to the highlands of East Africa. In J. Clark \& S. Brandt (eds), From Hunters to Farmers: Considerations of the Causes and Consequences of Food Production in Africa. Berkeley: University of California Press, Berkeley, 212-39.

Ambrose, S. (1984b). Excavations at Deloraine, Rongai, 1978. Azania 19, 79-104.

Ambrose, S., Kyule, M. \& Hlusko, L. (2007). History of paleontological research in the Narok District of Kenya. Kirtlandia 56, 1-37.

Anderson, D. (2005). Histories of the Hanged: the Dirty War in Kenya and the End of Empire. New York: W. Norton.

Appadurai, A. (1986). Introduction: commodities and the politics of value. In A. Appadurai (ed.), The Social Life of Things. Cambridge: Cambridge University Press, 151-70.

Appleyard, D. (1979). Introduction. In D. Appleyard (ed.), The Conservation of European Cities. Cambridge: MIT Press.

Aseto, A. \& Ong'ang'a, O. (2003). Lake Victoria (Kenya) and its Environs. Kisumu: OSIENALA (Friends of the Lake).

AU. (1981). African Charter on Human and Peoples'Rights. Addis Ababa: African Union. 
AU. (2006). Charter for African Cultural Renaissance. Addis Ababa: African Union.

Appelbaum, R. \& Robinson, W. (2005). Critical Globalization Studies. New York: Routledge.

Arnold, E. (1989). Patterns of learning, residence and descent among potters in Ticul, Yucatan, Mexico. In S. Shennan (ed.), Archaeological Approaches to Cultural Identity. London: Unwin Hyman, 175-84.

Asoka, M. (2007). The role of the Kenyan diaspora in Kenya's development, international conference held at Kennesaw State University, Georgia, 22-24 March.

Ayton-Shenker, D. (1995). The challenge of human rights and cultural diversity, United Nations background note. New York: United Nations Department of Public Information. Available from: http://www.un.org/rights/dpi1627e.htm (Last accessed 5 November 2013).

Baker, A. (2011). Ethical considerations in Web 2.0 archives. SLIS Student Research Journal, $1(1), 4$.

Barsalou, J. \& Baxter, V. (2007). The Urge to Remember. Washington DC: USIP.

Batibo, H. (2005). Language Decline and Language Death in Africa: Causes, Consequences and Challenges. New York: Multi Lingual Matters Ltd.

Bell, R. (1979). Board and Table Games from Many Civilizations. New York: Dover Publications.

Ben-Ali, A.M. (1998). Shaping Benghazi centre plan: Benghazi centre plan for year 2014. (MA dissertation) Manitoba: University of Manitoba.

Bennet, G. (1963). A Political History of Colonial Kenya. Oxford: Oxford University Press.

Berman, B. \& Lonsdale, J. (1992). Unhappy Valley: Conflict in Kenya and Africa. London: James Currey.

Bokea, C. \& Ikiara, M. (2000). The microeconomy of the export fishing industry in Lake Victoria (Kenya). Socio-Economics of the Lake Victoria Fisheries Project no. 7. Nairobi: IUCN East African Regional Programme.

Bouchenaki, M. (2003). The interdependency of the tangible and intangible cultural heritage. In C. Sevilla, \& M. Grywnow (eds), ICOMOS 14th General Assembly and Scientific Symposium: Place, Memory, Meaning: Preserving Intangible Values in Monuments and Sites, Victoria Falls, Zimbabwe, 27-31 October. Paris: ICOMOS, 9-14.

Bowdich, T. (1819). Mission from Cape Coast Castle to Ashantee. London: John Murray. Reprint edited with notes and introduction by E.W.F. Ward, 3rd ed., 1966, Frank Cass and Co. London.

Bower, J., Nelson, C., Waibel, A. \& Wandibba, S. (1977). The University of Massachussett's later stone age/pastoral Neolithic comparative study in central Kenya: an overview. Azania 12, $119-46$.

Bower, J. \& Nelson, C. (1978). Early pottery and pastoral cultures of the central Rift Valley, Kenya. Man (N.S.) 13, 554-66.

Boyd, A. (1977). The game of bao Lamu-style. Mila 6(1), 81-9.

Boyd, R. \& Richerson, P. (1995). Why does culture increase human adaptability? Ethology \& Sociobiology 16, 125-43.

Brandi, C. (2001). Théorie de la restauration. Paris: MONUM Edition du Patrimoine.

Brandi, C. (2005). Theory of Restoration. Rome: Instituto Centrale per il Restauro.

Britz, J. \& Lor, P. (2004). A moral reflection on the digitization of Africa's documentary heritage. IFLA Journal 30(3), 216-23.

Brodie, N. (2011). The market in Iraqi antiquities 1980-2009 and academic involvement in the marketing process. In S. Manacorda \& D. Chappell (eds), Crime in the Art and Antiquities World: Illegal Trafficking in Cultural Property. New York: Springer, 117.

Bruun, M. (1988). Nature and culture in the rural landscape - a nordic project on rural landscape planning and management. In IFLA Year Book. Poland: International Federation of Landscape Architects, 50-1.

Buijtenhuijs, R. (1973). Mau Mau: Twenty Years After, the Myth and its Survivors. The Hague: Mouton.

Bulpett, G. (2001). John Boyles: King of the Wa-Kikuyu. New York: Alexander Books.

Business Daily (2015). Coastal communities prepare for battle with encroachers over sacred, ecologically-rich kayas. 26 June, 12-13.

Carlson, A. (1977). On the possibility of quantifying scenic beauty. Landscape Planning 4, 131-72. Available from: http://www.sciencedirect.com/science/article/pii/0304392477900156 (Last accessed 23 June 2011).

Cass, G \& Jahrig, S. (1998) Heritage tourism: Montana's hottest travel trend. Montana Business Quarterly 36, 8-18.

Chapman, S. (1966). A Sirikwa hole on Mount Elgon. Azania 1, 139-48. 
Chen, B. (2009). Assessment of aesthetic quality and multiple funtions of urban green space from the users' perspective. Landscape Urban Planning 93, 76-82.

Chongwa, M. (2012). The history and evolution of national parks in Kenya. The George Wright Forum 29(1), 39-42.

Churchill, W. (1908). My African Journey. London: Hodder \& Stoughton.

City of Chicago (1995). An inventory of architecturally and historically significant structures. Available from: http://webapps1.cityofchicago.org/landmarksweb/web/historicsurvey. htm (Last accessed 2 March 2015).

Clavir, M. (2002). Preserving What is Valued: Museums, Conservation, and First Nations. Vancouver: UBC Press.

Clavir, M. (2009). Conservation and cultural significance. In A. Richmond \& A. Bracker (eds), Conservation: Principles, Dilemmas and Uncomfortable Truths. London: ButterworthHeinemann in association with the Victoria and Albert Museum, 139-49.

Clayton, A. (2006). The Killing Fields of Kenya 1952-1960: British Military Operations Against the Mau Mau. Nairobi: Transafrica Press.

Clough, M. (1998). Mau Mau Memoirs: History, Memory and Politics. Boulder: Lynne Rienner.

Coe, C. (2002). Educating African leadership: Achimota and the teaching of African culture in the Gold Coast. Africa Today 49(3), 23-44.

Coen, D., Nassauer, J. \& Tuttle, R. (1987). Landscape architecture in the rural landscape. Landscape Architecture Technical Information Series 10, Volume 7, No. 1. Washington, DC: American Society of Landscape Architects.

Cohen, M. (1970). A reassessment of the stone bowl cultures of the Rift Valley, Kenya. Azania $5,27-38$.

CoK (Constitution of Kenya) (2010). Kenya Gazette Supplement, No. 55. Nairobi: Government Printer.

Condominas, G. (2001). Introduction. In O. Salemink (ed.), Viet Nam's Cultural Diversity: Approaches to Preservation. Paris: UNESCO Publishing.

Constantine, M. (1998). Preserving the legacy of 20th century art. Conservation. The Getty Conservation Institute Newsletter 13(2), 4-9.

Coombes, A. (2014). Monuments and memories: public commemorative strategies in contemporary Kenya. In A.E. Coombes, L. Hughes and Karega-Munene (eds), Managing Heritage, Making Peace; History, Identity and Memory in Contemporary Kenya, 139-83.

Coombes, E. (2011). Monumental histories: commemorating Mau Mau with the statue of Dedan Kimathi. Heritage, History and Memory: New Research from East and Southern Africa 70(2), 202-23.

Council of Europe. (1979). European charter of the architectural heritage. In D. Appleyard (ed.), The Conservation of European Cities. Cambridge: MIT Press.

Crown, P. (2007). Learning about learning. In N. Skibo (ed.), Archaeological Anthropology Perspectives on Method and Theory. Tucson: University of Arizona Press, 198-217.

Crystal, D. (2000). Language death. New York: Cambridge University Press.

D'Andrade, R. (1996). The Development of Cognitive Anthropology. Cambridge: Cambridge University Press.

Deisser, A. (2007). Investigating partnership between local and institutional communities for the preventive conservation of cultural heritage in East Africa. ( $\mathrm{PhD}$ dissertation), University of Southampton.

Deisser, A. (2008). Community management of cultural heritage at Ankober, Ethiopia: a partnership in preventive conservation. In Bridgland, J. (ed.), Diversity in Heritage Conservation: Tradition, Innovation and Participation - Preprints of the ICOM-CC 15th Triennial Conference, Vol. 2, 1029-34.

Deisser, A. (2009). The socio-cultural impact of the preservation of an historical site on the conservation of tangible and intangible heritage: the case of the citadel of Erbil and the Kurdish Textile Museum. In F. Leduc (ed.), Culture as a Tool for Development: Challenges of Analysis and Action. Brussels: Arcade, Acted \& European Commission, 128-35.

Deisser, A. (2015). The Culture of Nature and Nature of Culture: an Introduction to Crossdisciplinary Perspectives in Conservation. Forthcoming publication.

De La Torre, M. (2002). Assessing the Values of Cultural Heritage. Los Angeles: Getty Conservation Institute.

de Voogt, A. (1995). Limits of the mind: towards a characterisation of Bao. (PhD thesis) Research school CNWS, Leiden, The Netherlands. 
Dickinson, K. (1996). Heritage is hot. American Demographics 18(9), 13-4.

Dietler, M. \& Herbich, I. (1998). Habitus, techniques style: an integrated approach to the social understanding of material culture and boundaries. In T. Miriam (ed.), The Archaeology of Social Boundaries. Washington, DC: Smithsonian Institution Press, 232-63.

Dobby, A. (1978). Conservation and Planning. London: Hutchinson and Co. Ltd.

Donders, Y. (2008). The legal framework of the right to take part in cultural life. In Y. Donders \& V. Volodin (eds), Human Rights in Education, Science and Culture: Legal Developments and Challenge, 232-72. New York: United Nations.

Donohungh, A.C.L. (1935). Essentials of African culture. African Journal of the International African Institute 8(3), 329-39.

Dorfman, E. (2012). Intangible Natural Heritage. London: Routledge.

Driedger, W. (1972). The game of Bao or Mankala in East Africa. Mila 3(1), 7-20.

Dudley, N. (2005). Beyond Belief: Linking Faith and Protected Areas to Support Biodiversity Conservation. Gland, Switzerland: Equilibrium and the alliance of religions and conservation.

Durrenberger, P. \& Palsson, G. (1987). Ownership at sea: fishing territories and access to sea resources. American Ethnologist 14(3), 508-22.

Eastop, D. (2002). Conservation as a democratising practice: learning from Latin America. ICOM UK News 63, 22-4.

Eastop, D. (2006). Conservation as material culture. In C. Tilley, et al. (eds), Handbook of Material Culture. London: Sage, 516-33.

Elkins, C. (2005). Britain's Gulag: The Brutal End of Empire in Kenya. London: Pimlico.

Elkins, C. (2005). Imperial Reckoning: the Untold story of Britain's Gulag in Kenya. New York: Henry Holt.

Emerton, L., Ndugire, N. \& Bokea, C. (1997). The costs of environmental degradation to the Kenyan economy: a review of the literature. Report prepared for the World Bank. Policy Research Group (PRG) and Research and Development Services (RDS), Nairobi.

Erickson, F. (2001). Culture in society and in educational practices. In J.A. Banks and C. McGee Banks (eds), Multicultural Education: Issues and Perspectives 4th Edition. New York: John Wiley \& Sons, 31-58.

Esikot, F. (2012). Globalization versus relativism: the imperative of a universal ethics. Journal of Politics and Law 5(4), 129-35.

Fanana, A. (2002). Measures of safeguards under the Banjul Charter on Human and Peoples' Rights. A comparative study. Lesotho: Institute of Southern African Studies.

Farah, P. \& Tremolada, R. (2014). Intellectual property rights, human rights and intangible cultural heritage. Journal of Intellectual Property Law 9(2).

Feilden, B. (1994). Conservation of Historic Buildings. Johannesburg: Reed Educational \& Professional Publishing Ltd.

Fitch, J. (1990). Historic Preservation: Curatorial Management of the Built World. Virginia: University Press of Virginia.

Flacourt, E. (1661). Histoire de la Grande Isle Madagascar, Paris. Reprint 1962. Monumenta Ethnographica Band I. Graz, Austria: Akademische Druck-u.Verlagsanstalt.

Forsyth, M. (2007). The past in the future. In M. Forsyth (ed.), Understanding Historic Building Conservation. Oxford: Blackwell, 1-8.

Fraser, S. (1983). Status of Asian and African elephants in North American zoos - 1983. In Proceedings of the Fourth Annual Elephant Workshop Held at Kansas City, 14-16 October 1983, 66-75.

Friedmann, G. (1995). The Mau Mau myth: Kenyan political discourse in search of democracy. Cahiers d'Études Africaines 35(137).

Galzer, R. (1988). Landscape planning in rural areas in Austria. In IFLA Year Book. Poland: International Federation of Landscape Architects, 68-71.

Gao, Y. \& Clark, S. (2014). Elephant ivory trade in China: trends and drivers. Biological Conservation 180, 23-30.

Geheb, K. (1997). 'The regulators and the regulated': fishery management options and dynamics in Kenya's Lake Victoria Fishery (Unpublished thesis). Brighton: University of Sussex.

Geheb, K. \& Binns, T. (1997). Fishing farmers' or 'farming fishers'? The quest for household income and nutritional security on Kenyan shores of Lake Victoria. African Affairs 96(38), 73-93.

George Phillip Ltd. (1991). Atlas. Nairobi: General Printers Limited. 
Getty Conservation Institute (2002). Assessing the values of cultural heritage (research Report). Los Angeles: Getty Conservation Institute.

Gill, W. \& Gilson, L. (1994). Reforming health sector in developing countries: the central role of policy analysis in health policy planning. In Health Policy and Planning. London: Oxford University Press, 353-70.

Githitho, A. (2005). The sacred Mijikenda Kaya forests of coastal Kenya. In T. Joffroy (ed.), Traditional Conservation and Management Practices. Rome, ICCROM, 61-7.

Glantz, M. (1992). Climate Variability, Climate and Fisheries. London: Cambridge University Press.

Goldschmidt, T. (1998). Darwin's Dreampond: Drama in Lake Victoria. Amsterdam: MIT Press. (Translated from Dutch by Sherry Marx Macdonald.)

Gosselain, O. (1998). Social technical identity in a clay crystal ball. In T. Miriam (ed.), The Archaeology of Social Boundaries. Washington, DC: Smithsonian Institution Press, 78-106.

Gosselain, O. (2000). Materializing identities: an African perspective. Journal of Archaeological Method and Theory 7(3), 187-217.

Gosselain, O. (2010). Exploring the dynamics of African pottery cultures. In R. Barndon et al. (eds), Case studies from the Palaeolithic to the Age of the Vikings. Lewiston: Edwin Mellen Press, 193-224.

Greaves, T. (1996). Tribal rights. In S. Brush \& S. Stabinsky (eds), Valuing Local Knowledge: Indigenous People and Intellectual Property Rights. New York: Island Press, 25-40.

Greenwood, D.J. (1977). Culture by the pound: an anthropological perspective on tourism as cultural commoditization. In V.L. Smith (ed.), Hosts and Guests: the Anthropology of Tourism. London: Blackwell, 129-38.

Hamilton, C. (1962). Notes on some newly found Bau petroglyphs and the Maasai Game 'Ngeshui'. Journal of East Africa Natural History Society 24(1), 50-3.

Harrison, R. \& Hughes, L. (2010). Heritage and post colonialism. In R. Harrison (ed.), Understanding the Politics of Heritage. Manchester: Manchester University Press, 234-69.

Herzog, T. (1988). A cognitive analysis of preference for field-and-forest environments. In J. Nasar (ed.), Environmental Aesthetics: Theory, Research and Applications. Cambridge: Cambridge University Press, 343-56.

Hill, M. (1976). Permanent Way: the Story of the Kenya \& Uganda Railway (Vol. I). Nairobi: EALB.

Hirst, T. (2006). Articulating Identities Jahazi. Twaweza communications, Nairobi, 3-6.

Hitchcock, R.K. (1996). Kalahari Communities: Bushmen and the Politics of the Environment in Southern Africa. Copenhagen: International Work Group for Indigenous Affairs (IWGIA).

Hodder, I. (2010). Cultural heritage rights: from ownership and descent to justice and well-being. Anthropology Quarterly 83(4), 861-82.

Hunter, J. (1952). Hunter. London: Hamish Hamilton.

Hyde, T. (1694). De Ludis Orientalis (Vol. 2). Oxford: n.p.

ICOMOS. (1998). Declaration of ICOMOS Marking the 50th Anniversay of the Universal Declaration on Human Rights. Stockholm: ICOMOS.

ICOMOS. (2013). The Burra Charter. The Australia ICOMOS Charter for Places of Cultural Significance.

International Federation of Library Association (IFLA) (2002). Guidelines for digitization projects for collections and holdings in the public domain. Paris: UNESCO publishing.

IUCN. (2006). An Introduction to the African Convention on the Conservation of Nature and Natural Resources. Gland: IUCN.

Ivanovic, M. (2008). Cultural Tourism. Cape Town, SA: Juta and Company.

Iwatani, Y. \& Wanjiku, E. (2010). A Brief Tour of Buildings in Nairobi. Nairobi: UNON Publishing Services Section.

Jacobs, A. (1969). New light on interior peoples - the Sirikwa phenomenon. East Africa and the Orient, a Diagnostic Research Seminar, Paper No. 5. Nairobi: Cultural Division I.D.S., University College.

Jaja, J. (2012). Globalization, culture and the great disruption: an assessment. International Journal of Academic Research in Business and Social Sciences, February 2(2), 78-86.

James, P. (2007). Heritage, identity, cultural heritage, cultural diversity and human rights: professional challenges - human rights, cultural heritage conservation and cultural tourism conflict or collaboration? Paper presented at the AICOMOS 2007 Conference, Extreme 
Heritage. http://www.aicomos.com/wp-content/uploads/petercjames.pdf (Last accessed 5 November 2013).

Jansen, E.G. (1973). The Fishing Population in the Kenyan Part of Lake Victoria; A Report to the East African Freshwater Fisheries Research Organisation. NORAD, University of Bergen, Norway.

Jansen, E.G. (1997). Rich Fisheries-Poor Fishfolk. Some preliminary observations about the effects of trade and aid in the Lake Victoria fisheries. IUCN Report no. 1. Nairobi: The World Conservation Union, IUCN.

Jansen, E., Abila, R. \& Owino, J. (1999). Constraints and Opportunities for Community Participation in the Management of Lake Victoria. Report No. 6. Nairobi: IUCN East African Office.

Jenje, B. (2015). Reps reject 180bn coal project over health risks. Daily Nation, 18 June, 20.

Jobson, R. (1623). The Golden Trade, or a Discovery of the River Gambra, and the Golden Trade of the Aethiopians. Tiegmouth: E.E. Speight and R.H. Walpole.

Johnson, H. (2002). Balinese music, tourism and globalization: Inventing traditions within and across cultures. New Zealand Journal of Asian Studies 4(2), 8-32.

Joliffe, B. (2005). Strengthening livelihoods secures future for forest. In focus. Conservation international Available from: http://www.cepf.net/xp/cepf/news/infocus/2015/aprilfeature.xtml (Last accessed 25 July 2016.

Juma, C. \& Ojwang, J.B. (1996). In Land We Trust: Environment, Private Property and Constitutional Change. Nairobi: Initiatives Publishers.

Kalron, N. \& Crosta, A. (2012). Africa's white gold of Jihad: Al-Shabaab and conflict ivory. Elephant action league, 2011-2012. Available from: http//elephantleague.org/project/ africas-white-gold-of-jihad-al-shabaab-and-conflict-ivory/ (Last accessed 15 September 2015).

Kameri-Mbote, P. (2005). A critical analysis of the legal, policy and institutional frameworks. IELRC working paper. Geneva: International Environmental Law Research Centre.

Kanogo, T. (1987). Squatters and the Roots of Mau Mau. London: James Currey.

Kaplan, S. (1995). The restorative benefits of nature: toward an integrative framework, Journal of Environmental Psychology. Available from: http://www.esf.edu/for/schuster/FOR\%20 475/Restorative\%20environs.pdf (Last accessed 31 May 2011).

Karanja, S. (2009). Designing a Land Restitution Programme in Kenya's Emerging Transitional Justice. Oslo: University of Oslo, Norwegian Centre of Human Rights.

Karega, M. (2009). Toward recognition of the right to a cultural past in the twenty-first century: an example from East Africa. In P. Schmidt (ed.), Postcolonial Archaeologies in Africa. Santa Fe: SAR Press, 77-94.

Karega, M. (2014). Expressions of nationhood in Kenyan museums. In A. Coombes, L. Hughes \& M. Karega (eds), Managing Heritage, Making Peace: History, Identity and Memory in Contemporary Kenya. London: IB Tauris, 17-51.

Katz, C. (1998). Whose nature, whose culture? Private productions of space and the 'preservation' of nature. In B. Braun and N. Castree (eds), Remaking Reality: Nature at the Millennium. London: Routledge, 46-64.

Keith, M.B. (1990). Inventing the French Revolution (Vol. 16). Cambridge: Cambridge University Press.

Kenyatta, J. (1938). Facing Mount Kenya. London: Mercury Books.

Kiamba, M. (ed.) (1995). Conservation of Historic Towns in Kenya. Nairobi: University of Nairobi.

Kimathi, L. (2012). Contesting local marginalisation through international instruments: the Endorois community case to the African Commission on Human and Peoples' Rights. Available from: http://africapeacepoint.net/pubs/Endoroispaper.pdf (Last accessed 30 May 2016).

Kitching, G. (1980). Class and Economic Change in Kenya: The Making of an African Petite Bourgeoisie, 1905-1970. London: Yale University Press.

KLR (2006). The National Museums and Heritage Act. Revised ed. Nairobi: The National Council for Law Reporting.

KLR (2009). The National Museums and Heritage Act. Revised ed. Nairobi: The National Council for Law Reporting.

KNBS (Kenya National Bureau of Statistics) (1999). Kenya population and housing census. Nairobi: Government Printer. 
KNBS (Kenya National Bureau of Statistics). (2009). Kenya population and housing census. Nairobi: Government Printer.

Koichiro, M. (2001). Masterpieces of the Oral and Intangible Heritage of Humans. Paris: UNESCO. Kreps, C. (2003). Liberating Culture. London: Routledge.

Kunkel, R. (1982). Elephants. New York: Harry N. Adams.

KWS (2012). KWS Security Database Law enforcement statistics. Unpublished data. Nairobi: KWS.

Kyule, D. (1992). Economy and subsistence of iron age Sirikwa culture at Hyrax Hill, Nakuru: a zooarchaeological approach (MA thesis). University of Nairobi, Kenya.

Kyule, M. (1993). Hyrax Hill: 50 years of archaeological research. Kenya Past and Present 25, 47-53.

Kyule, M. (1997). The Sirikwa economy: further work at site II on Hyrax Hill, Nakuru. Azania $32,21-30$.

Kyule, M., Ambrose, M., Noll, M. \& Atkinson, J. (1997). Pliocene and Pleistocene sites in southern Narok District, southwest Kenya. Journal of Human Evolution 32, A9-10.

Kitching, G.N. (1980), Class and Economic Change in Kenya: the Making of an African Petite Bourgeoisie, 1905-1970. London: Yale University Press.

Lake Victoria Environmental Management Programme (2005). Knowledge and Experiences Gained from Managing the Lake Victoria Ecosystems. Nairobi and Kampala: WB.

Lake Victoria Fisheries Organisation (LVFO 2013) Report: http://www.stopillegalfishing.com/ news.php?country=Tanzania (Last accessed 15 May 2016).

Lang, J. (1987). Creating Architectural Theory: the Role of Behavioural Sciences in Environmental Design. New York: Van Nostrand-Reinhold.

Langenkamp, A. (2000). Structural Changes of the Potters' Craft in Kenya. Regional and Gender Based Disparities. Osnabruck: Universitätsverlag Rasch.

Larkham, P. (1996). Conservation and City. 1st ed. London: Routledge.

Larsen, L. (2013). Power, politics and public monuments in Nairobi, Kenya. Available from: www. opendemocracy.net.

Lau, C., Drinkwater, R., Yusoff, K., Tan, S., Hetzel, D. \& Barker, J. (1998). Genetic diversity of Asian water buffalo (Bubalus bubalis): mitochondrial DNA D-loop and cytochrome b sequence variation. Animal Genetics 29, 253-64.

Laws of Kenya (2010). The Constitution of Kenya. 2010. Revised ed. Nairobi: National Council for Law Reporting.

Layton, R. (1989). Who Needs the Past? Indigenous Values and Archaeology. London: Unwin Hyman.

Leakey, M. (1945). Report on the excavations at Hyrax Hill, Nakuru, Kenya Colony 1937-8. Transactions of the Royal Society of South Africa 30(4), 271-409.

Leiper, N. (1995). Tourism Management. Reprint. RMIT Publishing, 168-80.

Lewis, P. (1975). The future of the past our clouded vision of historic presentation. Pioneer America Society 7(2), 1-20.

Limb, P. (2004). Digital Dilemmas and Solutions. Oxford: Chandos Publishing.

Little, D. (2006). Levels of the social. In S. Turner \& M. Risjord (eds), Handbookfor Philosophy of Anthropology and Sociology. New York: Elsevier.

Livingstone-Smith, A. (2000). Processing clay for pottery in Northern Cameroon: social and technical requirements. Archaeometry 42(1), 21-42.

Logan, W. and Craith, N. (2010). Cultural Diversity, Heritage and Human Rights: Intersections in Theory and Practice. London: Taylor \& Francis.

Lonsdale, J. (1992). The moral economy of Mau Mau: wealth, poverty and civic virtue in Kikuyu political thought. In B. Berman, and J. Lonsdale (eds), Unhappy Valley: Conflict in Kenya and Africa. London: James Currey.

Lotte, H. (2014). The production and transmission of national history: some problems and challenges. In E.A. Coombes, H. Lotte and Karega-Munene (eds), Managing Heritage, Making Peace. New York: J.B. Tauris, 185-226.

Luxmoore, R. (1991). The ivory trade. In S. Eltringham (ed.), The Illustrated Encyclopedia of Elephants. Salamander: London, 148-57.

Lynch, G. (2012). Becoming indigenous in the pursuit of justice: the African Commission on Human and Peoples' Rights and the Endorois. African Affairs 111.442, 24-45. 
Lynn, M. (2013). UNESCO World Heritage at 40: Challenging economic and political order of international heritage conservation. Current Anthropology 54(4). Available at: www.jstor/ stable/10.1086/671136 (Last accessed 5 October 2013).

Mabulla, A. (2000). Strategy for cultural heritage management: a case study. African Archaeological Review 17(4): 211-33.

MacCannell, D. (1973). Staged authenticity: arrangements of social space in tourist settings. American Journal of Sociology 79(3), 589-603.

Mackay, R. (2013). Setting best standards for world heritage management. In P. Figgis, A. Leveringon, A. Maclean \& P. Valentine (eds), Keeping the Outstanding Exceptional: the Future of World Heritage in Australia. Sydney: Australian ICUN National Committee, 42-7.

Madman, M. (2005). Political identity, citizenship and ethnicity in post-colonial Africa. Keynote address in Arusha World Bank sponsored conference on New Frontiers of Social Policy: Development in a Globalizing World, December 12-15.

Maghenda, M. and Mwanza, O.W. (2014). The trends and consumption patterns of cultural heritage tourism by domestic tourists in Kenya: an approach to understanding cultural heritage as a symbol of Kenyan national identity. Paper presented at the Conference on Understanding oneself and the others: new domestic and international tourism practices and the promotion of tourism and heritage in East Africa, held 16-17 July at the Louis Leakey Auditorium, National Museums of Kenya.

Makagon, J., Jonas, H. and Roe, D. (2014). Human Rights Standards for Conservation Part I: to Which Conservation Actors do International Standards Apply? London: International Institute for Environment and Development.

Malinowski, B. (1943). The Pan-African problems of culture contact. American Journal of Sociology 48(6), 649-65.

Maloba, W. (1994). Mau Mau and Kenya: an Analysis of Peasant Revolt. Indianapolis: Indianapolis University Press.

Manek, M. (2001). Kenya's implementation of biodiversity-related conventions. UNEP/BPSP Project. Nairobi: UNEP.

Martinez-Cobo, J. (1981). Study on the problem of discrimination against indigenous populations. United Nations Economic and Social Council, E/CN.4/Sub.2/476.

Martinez-Cobo, J. (1986). United Nations working group on indigenous populations. Study of the problem of discrimination against indigenous populations. United Nations Commission on Human Rights, E/CN.4/RES/1986/35.

Matson, A. (1962). Bau Petroglyphs. Journal of East Africa Natural History Society 14, 43-9.

Mawere, M. \& Kadenge, M. (2010). Zvierwa as African indigenous knowledge systems: epistemological and ethical implications of selected Shona taboos. INDILINGA-African Journal of Indigenous Knowledge Systems 9(1), 29-44.

Mazama, M. (2002). Afrocentricity and African spirituality. Journal of Black Studies 33(2), 218-34.

Mazrui, A. (1963). On heroes and Uhuru-worship. Transition, no.11 November, 23-8.

Mbiti, J. (1990). African Religion and Philosophy. Oxford: Heinemann.

McCann, J. (1999). Green Land, Brown Land, Black Land: An Environmental History of Africa, 1800-1990. Oxford: James Currey.

McClellan, C. (2000). Mau Mau memoirs: history, memory and politics. International Social Review Journal September 22.

McGranahan, D. (2008). Landscape influence on recent rural migration in the U.S. Landscape and Urban Planning 85(3-4), 228-40. Available from: http://www.sciencedirect.com/science/article/pii/S0169204607002976 (Last accessed 19 March 2014).

McHarg, I. (1969). Design with Nature. Philadelphia: Falcon Press.

McIntosh, J. (2009). Elders and frauds: commodified expertise and politicised authenticity among the Mijikenda. Africa: Journal of the International African Institute 79(1), 35-52.

Meredith, M. (2001). Elephant Destiny: Biography of an Endangered Species in Africa. New York: Public Affairs.

Merrick, H. (1983). Visitors' guide to the Hyrax Hill site. Nairobi: National Museums of Kenya.

Miller, C. (1971). The Lunatic Express. London: Penguin.

Mire, S. (2011). Somali archaeological remains are in danger. Somali Heritage and Archaeology September. Retrieved from: http://www.somaliheritage.org/endangered.php (Last accessed 15 September 2015). 
Mitullah, W. (2003). Understanding slums: case studies for the global report on human settlements 2003: the case of Nairobi, Kenya. UNHABITAT, Nairobi.

M'Mbogori, F. (2006). Late iron age economies of Mt. Kenya region: a case study of Kiburu, Kangai and Kanyua Archaeological Sites (MA thesis). Bergen, University of Bergen.

M'Mbogori, F. (2015). Population and ceramic traditions: revisiting the Tana ware of Coastal Kenya (7th-14th Century AD). Cambridge Monographs in African Archaeology, BAR International series 2717.

Moore, D. (2005). Suffering for Territory: Race, Place and Power in Zimbabwe. Durham, NC: Duke University Press.

Moore, R. (2006). Disappearing, Inc.: glimpsing the sublime in the politics of access to endangered languages. Language and Communication 26(3/4), 296-315.

Moseley, C. (2010). Atlas of the World's Languages in Danger. Paris: UNESCO Publishing.

Muhoro, T. (2004). Public open space in the transformation of a city - the case of Nairobi (master's thesis). Katholieke Universiteit Leuven, Leuven.

Mumma, A. (2009). Framework for legislation on immovable cultural heritage in Africa. In W. Ndoro, A. Mumma \& G. Abungu (eds), Protecting Immovable Heritage in English Speaking Countries of Sub-Saharan Africa, ICCROM Conservation Studies, 8.

Munene, M. (2012). Historical Reflections on Kenya: Intellectual Adventurism, Politics and International Relations. Nairobi: UONP.

Muños Viñas, S. (2005). Contemporary Theory of Conservation. London: Elsevier.

Murang'a County Council (1985). Proposed Museum and Hotel Complex. Murang'a: Murang'a County Council.

Muriuki, G. (1987). The History of Kikuyu 1500-1900. New York: Oxford University Press.

Murphy, K. (2014). 100 years on, World War One resonates at museum. Business Daily 28 July.

Murray, H. (1952). A History of Board Games Other than Chess. New York: Oxford University Press.

Murray-Brown, J. (1973). Kenyatta -Vol. 3453. Dutton Adult.

Muthuma, L. (2013). Nairobi in Pictures: Political Icons, 1899-2000. Nairobi: Focus Publishers.

Mutua, M. (2008). The Banjul Charter: the case for an African cultural fingerprint. In A. Abdullahi (ed.), Cultural Transformations and Human Rights in Africa. New York: Zed Books, 68-107.

'Nai ni Who' City Festival, May to August 2013. Go Down Arts Centre, Nairobi, Kenya.

Nasar, J. (1988). Environmental Aesthetics: Theory, Research and Applications. Cambridge: Cambridge University Press.

Nassauer, J. (1989). The aesthetic benefits of agricultural land. Renewable Resources Journal 7(4), 17-8. Available from: http://www.researchgate.net/publication/251850648_The_ Aesthetic_Benefits_of_Agricultural_Land (Last accessed 12 June 2014).

National Coordinating Agency for Population and Development (2010). State of population report - population dynamics and climate change: implications for the realization of the MDGs and the goals of Vision 2030. Nairobi: NCAPD.

National Environment Management Authority (NEMA) (2005). State of the environment report 2004.

Ndeti, K. (1975). Cultural Policy in Kenya. Paris: UNESCO Press.

Ndoro, W. (2009). Legal definitions of heritage. In W. Ndoro, A. Mumma \& G. Abungu (eds), Protecting Immovable Heritage in English-Speaking Countries of Sub-Saharan Africa, ICCROM Conservation Studies 8.

Ndoro, W. \& Kiriama, H. (2009). Management mechanism in heritage legislation. In W. Ndoro, A. Mumma \& G. Abungu (eds), Protecting Immovable Heritage in English Speaking Countries of Sub-Saharan Africa, ICCROM Conservation Studies 8.

Ndua, C. (2013). Challenges facing the implementation of policies in the culture sector in Kenya (MA thesis). University of Nairobi.

Nelson, F. (2010). Community Rights, Conservation and Contested Land: the Politics of Natural Resource Governance in Africa. London: Earthscan.

Ngugi, R. (1999). Use of indigenous and contemporary knowledge on climate and drought forecasting information in Mwingi district, Kenya. Consultancy report. UNDP/UNSO. p. 28.

NMHA (National Museums and Heritage Act) (2006). Kenya Gazette Supplement, No. 63 (Acts No. 6). Nairobi: Government Printer.

Nyaupane, G.P. (2009). Heritage complexity and tourism: The case of Lumbini, Nepal. Journal of Heritage Tourism 4(2), 157-72. 
Nyaupane, G., White, D. \& Budruk, M. (2006). Motive-based tourist market segmentation: An application to native American cultural heritage sites in Arizona, USA. Journal of Heritage Tourism 1(2), 81-99.

Obiakor, F. (2004). Building patriotic African leadership through African-centred education. Journal of Black Studies 34(3), 402-20.

Ochieng', W. (1974). An Outline History of Nyanza up to 1914. Nairobi: KLB.

Ocholla-Ayayo, A.B.C. (1976). Traditional Ideology and Ethics among the Southern Luo. Uppsala: S.I.A.S.

Odhiambo, E., Atieno and Lonsdale, J. (2003). Mau Mau and Nationhood: Arms, Authority and Narration. Oxford: James Currey.

Oduwole, E. (2012). Globalisation as universalization: rethinking the philosophy of globalisation in Africa. Humanity \& Social Sciences Journal 7(2), 87-95.

Omolewa, M. (2007). Traditional African models of education: their relevance in the modern world. International Review of Education 53, 593-612.

Ong'ang'a, O. (2005). Lake Victoria and its Environs: Resources, Opportunities and Challenges. Kisumu: OSIENALA.

Onwauch, P. (1966). African traditional culture and Western education. The Journal of Negro Education 35(3), 289-92.

Onyango-Abuje, J. (1977). A contribution to the study of the neolithic in East Africa with particular reference to the Nakuru - Naivasha Basins. (PhD thesis). University of California, Berkeley.

Opondo, P. (2012). Colonial policy and the development of fish production in Kenya, 1880-1978 ( $\mathrm{PhD}$ thesis). UNISA.

Pannel, S. (2006). Reconciling nature and culture in a global context. Lessons from the World Heritage List. Rainforest CRC.

Papageorgiou, A. (1971). Continuity and Change: Preservation in City Planning. London: Pall Mall Press.

Patel, Z. (2002). Alibhai Mulla Jeevanjee. Nairobi: East African Educational Publishers, Kenya.

Pattullo, P. (2005). Last Resorts: the Cost of Tourism in the Caribbean. New York: Monthly Review Press.

Paudel, G. and Ojha, H. (2007). Human rights - a guiding principle or an obstacle for conservation? Policy Matters 15, 299-310.

Pavitt, N. (2008). Kenya: A Country in the Making 1880-1940. New York: W.W. Norton \& Company.

Peters, R. (2008). Approaches to access: factors and variables. IIC London Congress: Conservation and Access.

Peters, R. (2008). The brave new world of conservation. In Diversity in Heritage Conservation: Tradition, Innovation and Participation, ICOM-CC 15th Triennial Conference, 1.

Petrie, F. (1927). Objects of Daily Use. London: British School of Archaeology.

PIC (Public Investment Committee) (2009). National Assembly eighteenth report of the public investments committee on accounts of state corporations, Vol. 1. Available from: www.49.91.136index.php?option=docman (Last accessed 3 May 2014).

PIC (Public Investment Committee) (2012). National Assembly eighteenth report of the public investments committee on accounts of state corporations, Vol. 1. Available from: www.49.91.136index.php?option=docman (Last accessed 3 May 2014).

Poria, Y., Butler, R. and Airey, D. (2004). Links between tourists, heritage and reasons for visiting heritage sites. Journal of Travel Research 43, 19-28.

Porter, P. \& Sheppard, E. (1998). The management of tropical and subtropical ecosystems: the Pokot of West Central Kenya - an indigenous knowledge system. In P. Wayland Porter \& E. Sheppard (eds), The Worlds as Differentiated Resource. New York: Guilford Press, 263-303.

Posey, D. (1999). Cultural and Spiritual Values of Biodiversity. London: Intermediate Technology.

Posey, D. \& Dutfield, G. (1996). Beyond Intellectual Property. Ottawa: International Development Research Center.

Posnansky, M. (1967). Excavation at Lanet, Kenya, 1957. Azania 2, 89-114.

Potter, B., Barker, D., Conway, D. and Klak, T. (2004). The Contemporary Caribbean. Harlow: Pearson Education, UK.

Pramukh Swami Maharaj (2002). Quoted in swaminarian.org. Available from: http://swaminarayan.org/news/2002/03/nairobi/index.htm (Last accessed 27 May 2016). 
Primack, R. \& Kobori, H. (2001). Conservation for Satoyama, the traditional landscape of Japan. Available from: http://www.bioone.org/doi/abs/10.1579/0044-7447-32.4.307 (Last accessed 27 May 2016).

Rakodi, C. (1997). The Urban Challenge in Africa: Growth and Management of its Large Cities. Tokyo: United Nations University Press.

Rees, E. (1989). Defining Sustainable Development. Vancouver: Center for Human Settlements.

Reid, D. (2002). Cultural tourism: learning from the past. In J. Akama and P. Sterry (eds), Cultural Tourism in Africa: Strategies for the New Millennium. Proceedings of the ATLAS Africa International Conference, December 2000, Mombasa, Arnhem: ATLAS.

Republic of Kenya (1934). Preservation of Objects of Archaeological and Paleontological Interest Act. Nairobi: Government Press.

Republic of Kenya (1983). National Museum Act (Cap 216). Nairobi: Government Printers.

Republic of Kenya (1984a). Antiquities and Monuments Act (Cap 215). Nairobi: Government Printers.

Republic of Kenya (1984a). The National Museums Act. Nairobi: Government Press.

Republic of Kenya (1984b). The Antiquities and Monuments Act. Nairobi: Government Press.

Republic of Kenya (1986). Public Health Act (Cap 242). Nairobi: Government Printers.

Republic of Kenya (1987). Building code. The local government (Adoptive by-Laws (Building) order 1968 and (Grade II Building) order 1968. Nairobi: Government Printers.

Republic of Kenya (1996). Physical Planning Act (Cap 286). Nairobi: Government Printers.

Republic of Kenya (1999). Environmental Management and Co-ordination Act. Nairobi: Government Printer.

Republic of Kenya (2001). Industrial Property Act. Nairobi: Government Printer.

Republic of Kenya (2005). Kisumu district strategic plan (2005-2010) for implementation of the national population policy for sustainable development. Nairobi: National Coordination Agency for Population and Development.

Republic of Kenya (2006). National Museums and Heritage Act. Government Printer.

Republic of Kenya (2007). Kenya Vision 2030. Nairobi: Government Printer. Nairobi.

Republic of Kenya (2009a). National Policy on Culture and Heritage. Nairobi: Government Printer.

Republic of Kenya (2009b). National Policy on Traditional Knowledge, Genetic Resources and Traditional Cultural Expressions. Nairobi: Government Printer.

Republic of Kenya (2010). Constitution of Kenya, 2010. Nairobi: Government Printer.

Republic of Kenya (2011). Urban Areas and Cities Act. Nairobi: Government Printers.

Republic of Kenya (2012a). Land Act. Nairobi: Government Printer.

Republic of Kenya (2012b). Kenya Cultural Centre Act. Nairobi: Government Printer.

Republic of Kenya (2013). National Environment Policy. Nairobi: Ministry of Environment, Water and Natural Resources.

Retschitzki, J. (1990). Stratégies des joueurs d'Awale. Paris: L'Harmattan.

Richards, J. (2002). Digital preservation and access. Journal of Archaeology 5(3), 343-66.

Richards, G. (2004). Textile tourists in the European periphery: new markets for disadvantaged areas? Tourism Review International 8(4), 323-38.

Rodwell, D. (2007). Conservation and Sustainability in Historic Cities. Oxford: Blackwell.

Roncoli, C., Ingram, K. \& Kirshen, P. (2002). Reading the rains: local knowledge and rainfall forecasting in Burkina Faso. Society \& Natural Resources 15(5), 409-27.

Rouard, J. (2001). Discovering, knowing and identifying the rural heritage. Operation 'Rural Heritage': an example of co-operation between civil society and the authorities. Naturopa 95(102), 4-6.

Roux, V. (2007). Ethnoarchaeology: a non-historical science of reference necessary for interpreting the past. Journal of Archaeological Method and Theory 14(2), 153-78.

Roux, V. (2011). Anthropological interpretation of ceramic assemblages: foundations and implementations of technological analysis. In S. Scarcella (ed.), Archaeological Ceramics: a Review of Current Research, B.A.R International Series 2193. Oxford: Archaeopress, 80-88.

Russ, L. (1984). Mancala Games, Reference Publications. Michigan: Algonac.

Ruther, K. (2004). Sekukuni, listen! Banna! And to the children of Frederick the Great and our Kaiser Wilhelm: documents in social and religious history of the Transvaal 1860-1890. Journal of Religion in Africa 34(3), 207-34.

Ryszkowski, L. (1988). Ecological principles of formation of agricultural landscape. In IFLA Year Book. Poland: International Federation of Landscape Architects, 52-3. 
Salvadori, C. (1996). We came in Dhows (Vol. I). Nairobi: Paperchase Kenya Ltd.

Sanderman, M. (2002). Omweso: Uganda's national game. Abstract Games 11.

Sanders, D. (1999). Indigenous peoples: issues of definition. International Journal of Cultural Property 8, 4-13.

Schwimmer, E. (2001). Sustainable tourism management at World Heritage Sites. Enhancing inter-agency and stakeholders for joint action conference, 24-27 March. Huangshan, China. Available from: http://sdt.unwto.org/en/content/publication-1 28.1.2014 (Last accessed 15 September 2015).

Sethi, P. (2005). Heritage Tourism. Anmol Publications, New Delhi.

Silva, E. (1995). Jogos de quadrícula do tipo mancala com especial incidencia dos praticados em Angola. Lisboa: Instituto de Investigaço Científica Tropical.

Silverman, H. and N. Ruggles. (2007). Cultural Heritage and Human Rights. New York: Springer. Sindima, H. (1990). Liberalism and African culture. Journal of Black Studies 21(2), 190-209.

Singh, J. (2011). United Nations Educational, Scientific and Cultural Organization (UNESCO): Creating Norms for a Complex World. New York: Routledge.

Smart, J. (1950). Nairobi: A Jubilee History of Nairobi 1900-1950. Nairobi: East African Standard.

Smith, M. (2003). Issues in Cultural Tourism Studies. London: Routledge.

Sommer, G. (1992). A survey on language death in Africa. In M. De Gruyter (ed.), Language death: factual and theoretical explorations with special reference to East Africa. International Journal of Humanities and Social Science 3(7), 258-66.

Spear, T. (1978). The Kaya Complex: a History of the Mijikenda Peoples of the Kenya Coast to 1900. Nairobi: Kenya Literature Bureau.

Spierenburg, M. (2004). Strangers, Spirits and Land Reforms: Conflict about Land in Dande Northern Zimbabwe. Leiden: Brill.

Spirn, A. (1998). The Language of Landscape. New Haven \& London: Yale University.

Sponsel, L. (2001). Do anthropologists need religion and vice versa? Adventures and dangers of spiritual ecology. In New Directions in Anthropology and Environment: Intersections. Walnut Creek: Alta Mira Press.

Springer, J. (2009). Addressing the social impacts of conservation: lessons from experience and future directions. Conservat Soc 7, 26-9.

Stark, M.T. et al. (1998). Social boundaries and technical choices in Tonto Basin Prehistory. In M. Stark (ed.), The Archaeology of Social Boundaries. Washington, DC: Smithsonian Institution Press, 208-31.

Stephenson, J. (2008). The cultural values model: an integrated approach to values in landscapes. Landscapes and Urban Planning 84, 127-39.

Stiebel, L. (2000). The land in Africa: Space, Culture, History workshop transformation. Critical Perspective in South Africa 44, 1-8.

Strachan, G. (2002). Paradise and Plantation: Tourism and Culture in the Anglophone Caribbean. Charlottesville: University of Virginia Press.

Strathern, M. (1980). No nature, no culture: the Hagen case. In C. MacCormack and M. Strather (eds), Nature, Culture and Gender. Cambridge: Cambridge University Press, 174-223.

Sukumar, R. (1992). The Asian Elephant, Ecology and Management. Cambridge: Cambridge University Press.

Sullivan, S. (2004). Local involvement and traditional practices in the world heritage system. In World heritage paper 13, linking universal and local values: managing a sustainable future for world heritage. Paris: UNESCO World Heritage Centre, 49-58.

Sunderlin, W., Hatcher, J. \& Liddle, M. (2008). From Exclusion to Ownership? Challenges and Opportunities in Advancing Forest Tenure Reform. Washington, DC: Rights and Resources Initiative.

Survey of Kenya (1968). Central Province, Muranga District, Gaturi Location, Gakuyu Unit Sheet No. 4. Nairobi: Cadastral Overprint.

Sutton, J. (1973). The archaeology of the western highlands of Kenya. Memoir 3. Nairobi: British Institute in Eastern Africa.

Sutton, J. (1987a). Hyrax hill and the Sirikwa. Azania 22, 1-36.

Sutton, J. (1987b). Deloraine and the Rift Valley sequence. Nyame Akuma 29, 34-6.

Sutton, J. (1990). A Thousand Years of East Africa. Nairobi: British Institute in Eastern Africa.

Symonids, J. (1998). Cultural rights: a neglected category of human rights. International Journal of Science 50(158), 559-77. 
Tajfel, H. and Turner, J.C. (1978). An integrative theory of inter-group conflict. In J.A. Williams and S. Worchel (eds), The Social Psychology of Inter-Group Relations. Belmont, CA: Wadsworth, 33-47.

Tajfel, H. and Turner, J.C. (1986). The social identity theory of intergroup behavior. In S. Worchel \& W. Austin (eds), The Social Psychology of Intergroup Behavior. Chicago: Nelson-Hall, 7-24.

Takeuchi, K. et al. (2003). Satoyama: the Traditional Rural Landscape of Japan. Tokyo: Springer-Verlag.

Talbot, L. (2013). Engaging indigenous communities in world heritage declarations: Processes and practice. In P. Figgis, A. Leverington, A. Maclean \& P. Valentine (eds), Keeping the Outstanding Exceptional: the Future of World Heritage in Australia. Sydney: Australian ICUN National Committee, 134-9.

Tayler, I. \& Dilcher, A. (2010). Sustainable heritage conservation: Pere Marquette Railroad Depot in Michigan. APT Bulletin Journal of Preservation Technology 14(1), 21-6.

Taylor, K. \& Lennon, J. (2011). Cultural landscapes: a bridge between culture and nature? International Journal of Heritage Studies 17(6), 537-54.

Thevenot, J. (1976). Voyages. Paris: Hachette.

Thomas, J. (1999). Time, Culture and Identity: an Interpretive Archaeology. London: Routledge.

Thompson, D. (1990). The Concise Oxford Dictionary. New York: Oxford University Press.

Tillotson, M. (2010). A critical location of the contemporary black church: finding a place for the word church formation. Journal of Black Studies 40(5), 1016-36.

Timothy, D. and Boyd, S. (2006). Heritage tourism in the 21st century: valued traditions and new perspectives. Journal of Heritage Tourism 1(1), 1-16.

Tiwari, R. (1981). The origin, growth and the functional structure of the Central Business District of Nairobi. In R.A. Obudho (ed.), Urbanization and Development Planning in Kenya, Nairobi: Kenya Literature Bureau.

Townshend, P. (1986). Games in culture: a contextual analysis of the Swahili board game and its relevance to the variation in African mankala. ( $\mathrm{PhD}$ thesis). University of Cambridge.

Tribble, J. (2015). Antiquities trafficking and terrorism: where cultural wealth, Political violence, and criminal networks intersect. Available from: http//www.miis.edu/media/ view/37908 (Last accessed 10 September 2015).

Udvardy, M., Giles, L. and Mitsanze, J. (2003). The transatlantic trade in African ancestors: MijiKenda memorial statues (Vigango). American Anthropologist 2003, 566-58.

Ulrich, K. (2006). Creation of artifacts in society. Available from: http://opim.wharton.upenn. edu/ ulrich/publications.html (Last accessed 26 May 2011).

UN (2001). Sustainable development of tourism, report of the Secretary-General (Document No. E/CN.17/2001/ PC/21), New York: UN.

UNCTAD (2008). Creative Economy Report. UNDP. Available from: http://unctad.org/en/ Docs/ditc20082cer_en.pdf (Last accessed 15 September 2015).

UNESCO (1954). Convention for the Protection of Cultural Property in the Event of Armed Conflict. Paris: UNESCO. Available from: http://whc.unesco.org/en/news/453 (Last accessed 5 November 2013).

UNESCO (1972). Promotion and implementation of the Convention concerning the Protection of the World Cultural and Natural Heritage/world heritage convention on nature and cultural heritage. Paris: UNESCO.

UNESCO (1982). Mexico City Declaration of the World Conference on cultural policies, 26 July-6 August. Available from: http://www.unesco.org/culture/lawa/maxicohtm/page1. shtml (Last accessed 20 February 2014).

UNESCO (2001). Universal Declaration on Cultural Diversity. Paris: UNESCO.

UNESCO (2003). Convention for the Safeguarding of Intangible Cultural Heritage. Paris: UNESCO.

UNESCO (2007). Report of the sub-regional meeting in the Pacific on the convention for the safeguarding of the intangible cultural heritage from 12-14 December. Nadi, Fiji.

UNESCO (2012). Culture: a driver and enabler of sustainable development. Thematic Think Piece. Available from: https://en.unesco.org/post2015/sites/post2015/files/Think\%20 Piece\%20Culture.pdf- 26.3.2014 (Last accessed 15 September 2015).

UNESCO (2013). Intangible cultural heritage. A force for sustainable development. Available from: http://www.unesco.org/new/en/media services/in-focus-28.1.2014 (Last accessed 15 September 2015).

UNESCO (2013). Mount Kenya national park/forest: UNESCO World Heritage Centre. Available from: http://whc.unesco.org/en/list/800 (Last accessed 27 November 2013). 
UNESCO (2013). The Hangzhou Declaration. Placing culture at the heart of sustainable development policies. Presented at the Hangzhou International Congress China, Hangzhou, and People's Republic of China. Available from: http://www.unesco.org/new/en/culture/themes/cultureanddevelopment/hangzhoucongress/- 24.5.2014 (Last accessed 15 September 2015).

UNESCO (2013). The World Heritage Committee meeting, 32nd session, inscribing new sites on UNESCO's World Heritage List on 8 July.

UNESCO (2014). Heritage and identity. Available from: http://portal.Unesco.org/geography/ en/er.Php-URI-ID=92, 15.03.2014. (Last accessed 15 September 2015).

UNESCO (2015). State of Conservation (SOC): Lamu Old Town (Kenya). whc.unesco.org/en/ soc/241 (Last accessed 18 June 2015).

United Nations (1948). United Nations Universal Declaration of Human Rights. New York: United Nations.

United Nations (1979). Convention on the Elimination of All Forms of Discrimination against Women. New York: CEDAW.

United Nations (2008). United Nations Declaration on the Rights of Indigenous Peoples. New York: United Nations.

United Nations Environmental Program (1999). Cultural and Spiritual Values of Biodiversity. London: Intermediate Technology Publications. Available from: http://www.unep.org/ pdf/Cultural_Spiritual_thebible.pdf (Last accessed 30 May 2016).

Van Eetvelde, V. (2009). Indicators for assessing changing landscape character of cultural landscapes in Flanders, Belgium. Land Use Policy 26, 901-10.

Van Eetvelde, V. \& Antrop, M. (2009). Indicators for assessing changing landscape character of cultural landscapes in Flanders (Belgium). Land Use Policy 26(4), 901-10.

Van Zwannenburg, R.M.A. \& King, A. (1975). An Economic History of Kenya and Uganda 1800 1970. London: MacMillan.

Vassanji, M.G. (2007). The In-between World of Vikram Lall. London: Random House.

Vercruijsse, E. (1987). The Penetration of Capitalism: A West African Case Study. London: Zed Books.

Von Lewinski, S. (2004). Indigenous Heritage and Intellectual Property: Genetic Resources, Traditional Knowledge, and Folklore. New York: Kluwer Law International.

Wachanga, K. (1975). The Swords of Kirinyaga. Nairobi: East Africa Literature Bureau.

Wahome, E. (2013). An assessment of the challenges associated with the loss of intangible heritage in Kenya. International Journal of Arts and Commerce (2), 77-92.

Wahome, E. \& Gathungu, J. (2013). Brand personality and the evolution of destination Kenya during the colonial period. Thought and Practice: A Journal of the Philosophical Association of Kenya (PAK) New Series 5(1), 91-119.

Wahome, W. Mugwima, B. and Nyachwaya, W. (2013). Reflections on the conservation of urban heritage attractions: the case of Nairobi 1898-1948. Global Built Environment 8(3), 1-34.

Waithaka, J. (2012). Historical factors that shaped wildlife conservation in Kenya. The George Wright Forum 29(1), 21-9.

Wakhungu, J., Waruingi, L., Agwanda, B., Awori, P., Isiche, J., Itela, S. and Njumbi, S. (2010). Towards a national biodiversity conservation framework: policy implications. Proceedings of the International Conference on Biodiversity, Land-use and Climate Change, 15-17 September. Nairobi, Kenya.

Walker, R. (1990). Sculptured mancala game boards of sub-Saharan Africa. (PhD thesis). Indiana University.

Wamicha, W. \& Mwanje. J. (2000). Environmental management in Kenya - have the conservation plans worked. OSSREA Environmental Forum Publications Series 2.

Wandibba, S. (1977). An attribute analysis of the ceramics of the early pastoralist period from southern Rift Valley, Kenya. (MA thesis). University of Nairobi.

Wanyonyi, E.W. (2012). Mobilizing resources for wildlife conservation in Kenya beyond the 21st century. The George Wright Forum 29(1), 118-25.

Wasuna, B. (2015). Chinese company renews battle for $164 \mathrm{bn}$ Lamu power plan project. Business Daily 17 June, 7.

Wayland, E. (1936). Notes on the board game known as 'Mweso' in Uganda. Uganda Journal 4, 84-9.

Waziri, M. \& Swazuri, M. (2012). Sustainable Swahili architecture; reconciling urban conservation, tourism and sustainable development. Africa Habitat Review 6, 431-8. 
Wekundah, J. (2012). Why protect traditional knowledge? Bio-technology Trust Africa Special Paper Series, No 44. African Technology Policy Studies Network.

Were, S. and Wilson, A. (1968). East Africa Through a Thousand Years. Evans Brothers: Ibadan, Nigeria.

Western, D., Russel, S. \& Mutu, K. (2006). The status of wildlife in Kenya's protected and nonprotected areas. A paper commissioned by Kenya's wildlife policy review team presented at the first stakeholders symposium of the wildlife policy and legislation review 27-28 September 2006, ACC, Nairobi.

White, T., Silberman, L., \& Anderson, P. (1948). Nairobi master plan for a colonial capital - a report prepared for the Municipal Council of Nairobi. London.

Wild, R., McLeod, C. (2008). Sacred Natural Sites: Guidelines for Protected Area Managers. Gland, Switzerland: IUCN.

Williams, P. (1999). Ngugi wa Thiong'o. Manchester: Manchester University Press.

Wilson, A. (1991). The Culture of Nature: North American Landscape from Disney to the Exxon Valdez. Toronto: Between the Lines.

Wilson, D. et al. (1987). The Implications for Participatory Fisheries Management on Intensified Commercialization on Lake Victoria. Rural Sociology 64(4), 554-72.

Winterbottom, T. (1803). An Account of the Native Africans in the Neighbourhood of Sierra Leone (Vol. 1). 2nd Edition, 1969. London: Frank Cass \& Co.

Wolski, P. (1988). Landscape planning process as the use of the information - as the system. In IFLA Year Book. Poland: International Federation of Landscape Architects, 38-40.

Wynne-Jones, S. \& Mapunda, B. (2008). 'This is what pots look like here': ceramics, tradition and consumption on Mafia Island, Tanzania. Azania XLIII, 1-17.

Yim, H. (2002). Cultural identity and cultural policy in South Korea. International Journal of Cultural Policy 8(1), 37-48.

Zhu, L. (2013). Cultural performance in tourism: liminality and authenticity. In Jiuxia Sun (ed.), Anthropology of Tourism: Theory and Experience. Publisher House of China Social Science (in Chinese). 



\section{Index}

Page numbers in italics are figures; with ' $t$ ' are tables.

'1918' building $86,88 \mathrm{t}$

Abila, R. 208-9

Abu'l Faraj, Kitab al Aghani 100

access $4,17,27,29$

and bao games 8

and fishing $200-11$

aesthetics 11,146

African Charter on Human and Peoples'

Rights (Banjul Charter) 19, 20

African Union (AU) 4

conservation policies 27

and human rights 17

and Kenyan legal standards 19-21

African War Memorial see Carrier Corps

African Wildlife Foundation 140

Agikuyu people 131, 180, 185, 186

and Christianity 187

Agikuyu shrine $13,180-3,181-2$

and cultural knowledge 194-5, 194t

management of 186-7

recommendations for 198-9

restoration/conservation 190-4, 191t

study $185-8$

All Saints Cathedral 78, 80, 81

Al-Shabaab 2

Alvares, Francesco 100

Anderson, D. 15, 212, 217, 221

anthropology 36, 38, 93, 124

antiques/antiquities

defined 35,39

legislation on $40-1$

Antiquities and Monuments Act (1984) 32, $43,90,184$

Appleyard, D. 183

archaeology

and bao boards 94, 96-7, 101-2

Hyrax Hill Pre-Historic

Sites (Nakuru) 8

legislation on $36,37-41,42,43$

resources 30,33

architecture

Asian influences $84-5,85$

European influences 78-84, 79-83

building materials $76-8$

conservation 89-90

and heritage $6,7-8$

legislation on 36

recycling 22 status of historic buildings $85-9,87-8 \mathrm{t}$

and tourism $160-3,161-2$

art/arts

and bao games 104

and culture 155

performing 45,50

and trafficking 2

see also monuments

Art Deco 83-4, 83

artefacts 2

archaeological 35

Vigango 22, 25

Asoka, M. 48

Atlas of the World's Languages in Danger 54 attitude formation 146

Australia 129

authenticity 159

ayo 104

Ayton-Shenker, D. 18

Baden-Powell, Robert, 1st Baron Baden-Powell 134

Banjul Charter (African Charter on Human and Peoples' Rights) 19, 20

Bank of India building 77

bao game 8-9, 93-107, 95-6

and contemporary society 104-6

cultural aspects 103-4

study of $100-3$

sustainability/conservation 106

'bao Naligwa' (poem) (Muyaka bin Haji) 101

Batibo, H. 53

bazaars, Indian Bazaar 84

Beach Management Units (BMU) 14, 201

belief systems 45

Bell, R. 94

Ben-Ali, A.M. 184

Bennet, G. 71

Berman, B. 15

'Big Hunt' 133-4

biodiversity $11,12-13,52,144,173$

of Africa's freshwater lakes 201, 210

blue granite $77-8$

Bokea, C. 203-4

Bowdich, T. 101

Boyles, John 131, 132

Brandi, Cesare 1

Britain see colonialism/colonial period 
British East Africa Protectorate 60

Britz, J. 57

Bronson, Edgar Beecher 134

Brown, R.D. 144

Bruun, M. 143

bubonic plague 134

Buijtenhuijs, R. 215

building materials $76-8,84$

buildings see architecture

Bullpett, G. 131

capital rights $127,127 \mathrm{t}$

Carlson, A. 146

Carrier Corps monument 7, 59, 61t, 62, 67, 67, 70-4

cartel groups 196-7, 199

Central Business District (CBD) 6-7, 59, 61, $61 \mathrm{t}, 62,68-70$

Chama cha Bao (Bao Society) 105, 106

Chama cha Michezo ya Jadi cha Dar es Salaam (CHAMIJADA) 105, 106

Charter for African Cultural Renaissance 18

Chiromo Mansion 87t

Chonyi, pottery 119-21

Christianity 9

and the Agikuyu people 187

and traditional technologies $110-13$

CHRM see Cultural Heritage Resources Management (CHRM)

Church, Arthur 76

Churchill, Winston 133

City Hall $79,79,87 \mathrm{t}$

civilization $2,18,34,111$

classical revival style $78-9$

Clavir, Miriam 1

claystone 78

climate 51, 52, 56, 75, 169t, 201

Coastal Bantu speakers, pottery of 119-23, $121,122 \mathrm{t}$

Coastal Forests Conservation Unit (CFCU) 52

coast of Kenya 21-8

cognition 146

collectors, art 2

colonialism/colonial period $6,10,13,15$

and the Agikuyu shrine 182, 187

and architecture 7-8, 75, 77

and fishing access to Lake Victoria 201-2

and the Mau Mau war 13, 15, 68, 212-26

and wildlife heritage $132-7,141$

see also monuments

communities

and cultural rights 20

ethnic 163

fishing 207-8

and rural heritage 152

and tourism 171

and wildlife heritage $129,130-2$, 138-40, 142

Community Game Scout Program 140

Community Museums of Kenya 40

conflict 2,5

conservation practices $3-4$

Constantine, M. 89

Constitution of Kenya 4, 43-4

and cultural heritage 225

on culture 18 and human rights 17

and intellectual property rights 35

Convention for the Safeguarding of the Intangible Cultural Heritage (2003) 21, 34

Coombes, E. 64

Copyright Act 34

corruption 28

Council of Europe 183

crafts $8-9,45$

see also pottery

Crown Lands Ordinance 15

Crystal, D. 53

cuisine see food/cuisine

Cultural Heritage Resources Management (CHRM) 5, 30, 35-41

Cultural Intellectual Property Rights (CIPR) 5

cultural knowledge 13

and the Agikuyu shrine 194-5, 194t

and language 173

cultural landscapes 4, 12, 42, 225

Kit-Mikayi site $172-9$

cultural properties 173

cultural services, and Kit-Mikayi 177, 179

culture, defined 7, 18-19, 155

in Kenyan constitution 4

Cushitic speakers, pottery of 114-19

custodians $4,17,21,22,29$

communities as 224

custom/customary laws 5

Darkhana Jamatkhana (Khoja Mosque) $87 \mathrm{t}$

deforestation 147, 148, 151, 151, 210

Delamere, Lord (Hugh Cholmondeley, 3rd Baron Delamere) 61, 61t, 62, 63,133

Deloraine 101

democracy 4, 9, 17

design see architecture

destruction, of heritage 3-4

development 3

and intangible heritage 49-51

legislation on 20

and rural landscapes 151-2

sustainable 6

de Voogt, Alexander Johan 94, 98, 105

Dickinson, K. 156

digitization $6,55,56,57$

Digo community 52, 53, 115, 119, 122t, 161

distributive justice 57

documentation 56

Downey, Sid 134

Dunga beach 14

ecology

legislation on 20

and population 23

economic development, and intangible heritage 49-51

economic rights $127,127 \mathrm{t}$

ecosystems 12,140

coastal $24,25,28,52$

and culture 173,179

Lake Victoria 201, 206, 210

Mount Kenya 224

rural 144 
education

and the bao game 105

Western 110-13

elders

and the Agikuyu shrine 13, 187, 191t, 192, 196,199

and the bao game 104

Kaya 52

and the Luo fishers 201, 204-5

and Mau Mau memory 221

elephants 128, 138, 139

see also ivory

Elite House $87 \mathrm{t}$

Elizabeth II, 136

Elkins, C. 15, 212, 217

empowerment of communities 4, 183, 185, 197, 198

English Gothic revival style 80

environment 4, 51-2, 145

coastal 23-4, 26

and intangible heritage 156

and Kit-Mikayi site 179

laws/legislation on 33,38

and the Luo fishers 200, 204

and spaciousness $152-3$

and tourism 11, 145

Esikot, F. 48, 49

ethics 3

and intangible cultural heritage 55, 57

ethnicity 163

and intraethnic politics 219

exhibitions 9, 103, 107, 220

farming 47, 144, 150, 151, 209-10

and the Mau Mau war trenches 222

and traditional technologies 205

festivals 45, 50, 158, 191

fishing 14, 200-11

Flacourt, Etienne de 101, 135-6

folklores, and identity 176-7

food/cuisine $45,50,52$

food security 52,210

forests/forestry 11, 14, 25, 136

building materials 78

coastal 26, 52

deforestation 147, 148, 151, 151, 210

Gwassi forest 203

Kakamega forest 47

Kaya forests/ceremonial sites 25-6, 28, $47,52,53$

Kaya Kinondo 45

Kaya Waa 52

and the Mau Mau 220, 221-5, 223

Mount Kenya 131

Satoyama (Japan) 11

see also Karura Forest

freedom fighters 136-7, 215

freedom and work (uhuru na kazi) 218

funerary rites, and the bao game 103, 104

games

mankala 8, 93, 94, 107

see also bao game

Gaunyas family 209

genocide 220-1

George V, 61, 61t, 62, 65, 65, 68, 69, 70
George VI, 61, 61t, 62, 66, 66, 68, 69

Georgian architectural style $80-1$

Gikuyu 180, 187, 189, 193, 199, 219

Giles, L. 22

globalization $2,41,48-50$

Goldschmidt, T. 202-3

Gosselain, O. 113-14

Green Belt Movement (GBM) 14

and the Agikuyu shrine $182,186,188$, 191t, 192

Greenwood, D.J. 159

Griffin, Geoffrey W. 134

Gwassi forest 203

Hamilton, C. 102

Hemingway, Ernest 134

heritage

war 221

see also intangible heritage; tangible heritage

heritage conservation 59-60

and human rights $17-29$

'heritage inspection/investigation' 42

heritage products $11-12,163,164 t$, $165,169 \mathrm{t}$

Herzog, T. 147

Hirst, T. 63

human remains, display of $220-1$

human rights $4-5,33-4$

and heritage conservation 17-29

and the Mau Mau 214

hunting wildlife

as sport $133-5$

traditional subsistence 136

Hyde, Thomas 100

Hyrax Hill Pre-Historic Sites (Nakuru) 8, 94, $97,101,102-3,158$

IBEA building 85-6

ICH (intangible cultural heritage) see intangible heritage

ICOMOS (International Council on Monuments and Sites) 12, 33, 34

'identifiability' 152-3

identity 6,214

cultural 33, 198

and folklores $176-7$

and ICH 46-8

and landscapes 12

and material culture 155

and monuments 59, 60-7, 74

Imperial Chambers $88 \mathrm{t}$

inclusiveness 73

independence 10

and the Mau Mau war 13, 212-26

and wildlife conservation 137-8, 141-2

Indian Bazaar 84

Indigenous Knowledge (IK) 5, 12, 28, 50

and ICH 55

and Kaya elders 52

indigenous knowledge systems (IKSs) 52

indigenous peoples 1

UN Declaration on the Rights of Indigenous Peoples 21

indigenous traditional knowledge 52

Industrial Property Act 34 
Information and Computing Technologies (ICT) 105

intangible heritage 5-6, 9, 12, 45-6, 156

coastal region 22

Convention for the Safeguarding of the Intangible Cultural Heritage (2003) 6, 21, 34

and development 49-51

and environmental conservation $51-2$

ethical issues 57

and globalization 48-9

and identity 46-8

Intangible Cultural Heritage (UNESCO) instruments $6,21,34,45$

and language 45

safeguarding/preservation of $52-5,54 \mathrm{t}$

intellectual property $5,34-5,55,57$

International Council on Monuments and Sites (ICOMOS) 12, 33, 34

Ismail Rahimtulla Walji Trust Library $87 \mathrm{t}$

Isukha 56

Ivanovic, M. 156

ivory $131-2,160,167$

Jamia Mosque $87 \mathrm{t}$

Jansen, E. 201, 205

Jareer community 114, 114, 116, 116

Jeevanjee Gardens 63

Jobson, Richard 101

Johnson, H. 156

Joliffe, B. 52

Jomvu community $115,120-1$

Kaggia, Bildad 218

Kakamega forest 47

Kamahi, Dedan 47

Kameri-Mbote, P. 137

Kanogo, T. 15, 212

Karen Blixen Museum $87 \mathrm{t}$

Kariokor grounds 70

Karue Hill, Embu County 148-51, 149, 150, 151,153

Karura Forest 28, 163

tourism study $163,165-70,165-6,167$, $168 \mathrm{t}, 169 \mathrm{t}$

Kaya forests/ceremonial sites 25-6, 28, $47,52,53$

Kaya Kinondo (Kaya Ngalaani) 45, 161

Keith, Michael Baker 173

Kenya African National Union (KANU) 14, 188, 217

Kenya Industrial Property Institute (KIPI) 34, 55

Kenya Land and Freedom Army 217

Kenya People's Union (KPU) 218

Kenyatta International Conference Centre (KICC) 161, 162, 164t

Kenyatta, Jomo 61, 61t, 62, 65-7, 68, 69, 70, 134,138

and the Mau Mau 214-19

Kenyatta, Uhuru 138

Kenya Uganda Railway 7,163

Kenya Vision 203050

Kenya Wildlife Service (KWS) 138

Ker, Donald 134

Kiama kia Muingi (the Society of the People) 217
Kiamba, M. 183

Kibaki, Mwai 64, 138

Kikuyu community 131, 132, 215, 216 , 218, 219

Kimathi, Dedan 61, 61t, 62, 63-4, 64

King, A. 76

Kinondo Kaya 51

Kinyatti, Maina wa 219

Kipande House $81,87 \mathrm{t}, 89$

Kipling, Rudyard 71-2

Kitab al Aghani 100

Kitching, G. 209

Kit-Mikayi site 13, 172-9, 174

Kivoi, Chief 132

knowledge 26

cultural 13,176

transfer of 53

see also Indigenous Knowledge (IK)

Koichiro, M. 48

Krapf Memorial Museum 160

lakes, biodiversity 201

Lake Turkana 45, 50

Lake Victoria 202-3

and the Luo fishers 200-11

Lamu 22-3, 50, 160, 161, 222

Lamu Port-Southern Sudan-Ethiopia Transport (LAPSSET) 22-3, 28

land grabbing 188

landscapes 14

as restorative $144-5$

and symbolism 12

see also cultural landscape; rural heritage

Lanet 101-2, 103

Lang, J. 146

language 13

and cultural knowledge 173, 179

as intangible heritage $45,53-5,54 \mathrm{t}$

LAPSSET see Lamu Port-Southern SudanEthiopia Transport (LAPSSET)

Larkham, P. 183-4, 184-5

Larsen, L. 69, 71

Law Courts 79

laws/legislation $3,5,30-44$

and the African Union 19-21

and conservation $90-2$

and heritage sites $184-5$

intellectual property 35,57

and wildlife conservation 134-6, 137-8, 139

see also rules/regulation

Legio Maria sect 178

Leiper, N. 155

Leopold II, King of Belgium 128

Likwepa, Monday 105

Limb, P. 57

listing of historical buildings $90-1$

local culture 159

Lonsdale, J. 15, 212

Lor, P. 57

Luhya 47-8

Luo fishers 14, 200-11

luzolo game 104

Maasai community 132,163

Maathai, Wangari 185, 188, 192 
McCann, James 201

McClellan, C. 217

Mackay, R. 214

McMillan Memorial Library 88t

Madman, M. 46

Malinowski, B. 111

management

of Agikuyu shrine 186-7

of cultural heritage 41-3

cultural landscape 173

management rights $127,127 \mathrm{t}$

mankala games 8, 93, 94, 107

Maputo Convention 19, 20

marketing

and fishing 208

and tourism 199

material culture 155

Mau Mau 13, 15, 68

and the Agikuyu shrine 187

heritage sites 220-2

historical interpretations 215-17

war trenches 222-5, 223

and wildlife hunting 137

Mazama, M. 111

Mazrui, A. 214

Mboya, Tom 47, 61, 61t, 62, 67, 218-19

medicine, traditional 50,52

memorialization 213-15, 218

memory

collective $6,59,74$

and the Mau Mau 15, 213-15

Merrick, H. 103

Mijikenda ('the Nine Tribes') 22, 25, 47, 52, 56

Miller, C. 130, 133

missionaries 111

Mitsanze, J. 22

Moi, Daniel Arap 138

and the Mau Mau 214-15, 219-20

Mombasa 160

monuments 6-7, 45, 59-60, 68

Carrier Corps 7, 59, 61t, 62, 67, 67, 70-4

Central Business District (CBD) as $68-70$

and identity 47

International Council on Monuments and Sites (ICOMOS) 12

legislation on 36

Mau Mau 226

removal of $69-70$

Mount Kenya ecosystem 131, 224

Mukurwe-ini Dairy Society 221

Mukurwe wa Nyagathaga see Agikuyu shrine

Mumbi 180, 187, 193, 199, 219

Muños Viñas, S. 89

Murphy, K. 221

museums, and preservation 1

Muyaka bin Haji, 'bao Naligwa' (poem) 101

Nairobi 6-7

architecture 7

cultural heritage tourism 163, 164t, 165

Nairobi Club 87t

Nairobi National Park (NNP), tourism study $163,165-70,165-7,168 t, 169 t$

naqala 93

Nasar, J. 146

Nassauer, J. 144
National Council for Culture 38

National Council for Culture and the Arts 42

National Culture Bill 32, 35, 38, 42, 44

National Environment Management Authority (NEMA) 33, 38

National Environment Policy 33

National Museum Act (1983) 184

National Museums and Heritage Act (2006) 4, $17,18-19,25,43,90,185,224,225$

National Museums of Kenya (NMK) 2, 5 , $34,42,89$

and the Agikuyu shrine $13,191 \mathrm{t}$

and Cultural Heritage Resources

Management (CHRM) 35-41

and monuments of war 224

tourism study $163,165-70,165-6,167$, $168 \mathrm{t}, 169 \mathrm{t}$

nation-building 4, 7, 18, 34, 46, 48, 57

and memorialization 213, 214, 217

see also monuments

nature/natural 45

conservation 173

defined 27

Ndorobo community 131

NEMA see National Environment Management Authority (NEMA)

Ngugi, R. 52

Njonjo, Charles Mugane 63

nomads/nomadic 2

Norfolk Hotel 82, 83

normative theory 146,147

Nyaupane, G. 155

Nyeri Peace Museum 220

'oathing' 219

Ochieng', William 203, 209

Ocholla-Ayayo, A. 210

Odinga, Oginga 218, 219

Oduwole, E. 49

Ojijo cultural property 28

Old Provincial Commissioner's Office building $81,82,87 \mathrm{t}, 89$

Ondetto, Melkiah 178

open access wildlife heritage regime 129

Organisation of African Unity (OAU) see African Union (AU)

Othaya Memorial Hall 221

owari 104

ownership

antiquities 39

Crown Lands Ordinance 15

of fisheries 205

intellectual property 55

local 30

and wildlife $10,128-9$

Panafric House 79, 80, 87t

Parliament Buildings 84

participation/partnership in conservation 183-4, 195-6, 197-8

and conservation practices $13,73-4$

and historic buildings 91-2

and Lake Victoria 206-7

in rural landscape 147-8

and wildlife heritage $138-40$

Patel, Z. 63 
patents 55

paternalism 72

Pattullo, P. 160

peace, promotion of 19

Peace Garden (Othaya) 220

perception 146

visual 146

Petrie, Sir Flinders 100

philosophy, globalization 49

planning $3,13,21,84$

laws/legislation 33, 152, 185

plants 51

policy

and cultural heritage $5,27,31-3,41$

for intangible heritage 52

see also laws/legislation

pollution, and Lake Victoria 206, 210

population 23-4, 23, 24, 26, 28

and effect on landscape 145,173

and Lake Victoria 205, 209

and the Mau Mau war trenches 222

Poria, Y. 165, 167

positive theory 146

and rural heritage 145-7

Posnansky, M. 103

Potter, B. 160

pottery 9-10, 109, 110, 113-24

Coastal Bantu speakers 119-23, 121, $122 \mathrm{t}$

of Cushitic speakers 114-19, 116-17

Lanet ware 101-2

Sirikwa 101-2

poverty 145

preservation 1

of ICH $52-5,54 \mathrm{t}$

legislation on 19,20

preventive approach to conservation 1,20 , 51

products, cultural tourism $157-8,163,164 t$

properties, cultural 173

property rights $127-8,127 \mathrm{t}, 139$

protection 1

Public Investment Committee (PIC) 28

quarrying 150

railway $76,89-90$

Kenya-Uganda 133

Railway Headquarters 79

regulation see rules/regulation

religion 7,12

Christianity 9

Legio Maria sect 178

sacred sites $3,25-6,172-9,174$

see also ritual

Renaissance revival style $79-80$

repatriation, cultural heritage material $36,41,55$

Resident Native Labourers Ordinance (1918) 15, 212

Ribeiro, Rosendo 134, 135

rights

cultural 20,21, 42

property $127-8,127 \mathrm{t}, 139$

see also human rights ritual 9,45

and the bao game 103,104

and Karue Hill 150

and Kit-Mikayi 177-8, 179

and Lake Victoria fisheries 206

and traditional technologies $108,110,111$,

rivers 163 $113,116,118-19,118 \mathrm{t}, 123$

Roosevelt, Theodore 133

Rouard, J. 47

rules/regulation

and fisheries 14, 205

see also laws/legislation

rural heritage $11-12,143-53,146-7,149-51$

Ruther, K. 111

Rwanda genocide 220-1

sacred sites $3,172-9,174$

Satoyama (Japan) 11

science $25,27,34,35,38,39,55$

seasonality, and fishing 14, 201-2, 204-5, 206-7, 210-11

self-identification 214

Sethi, P. 155

Sheria House 84,85

shrines see Agikuyu shrine

Sindima, H. 111

Singh Sabha Sikh Temple 84, 86

Sirikwa culture 103

pottery 101-2

skills see traditional technologies

slave trade 160

Smart, J. 76

Smith, M. 157-8

social identity theory 159

socio-cultural development $49-51$

socio-economic cultural practices $178-9$

Sommer, G. 53

Spirn, A. 148

Standard Chartered Building $87 \mathrm{t}$

Statement on Future Wildlife Management Policy in Kenya, A 137-8

status, of potters 119, 120

Strachan, G. 160

supernatural powers see ritual

Surat District Association Building 88t

sustainability $6,27,158-9$

and the bao game 106

and fishing communities 208

and Lake Victoria 202

and population 23

and tourism 160

sustainable development 20

sustainable tourism 160

Sutton, J. 101

Swaminarayan Temple 161-3, 162

Swazuri, M. 183

SWOT analysis of tourism in Nairobi 169-70, $169 t$

symbolism/symbols $35,39,44,46,47,155$ and the Agikuyu shrine 180, 186, 188, 193, 199

and the bao game $98,104,107$

and landscapes 12

and monuments $7,13,61,68,72-3,79$ 
Takeuchi, K. 144

Tangible Cultural Heritage (TCH)/tangible heritage $6,9,46$

coastal region 22

technology 2

Information and Computing Technologies (ICT) 105

see also traditional technologies

TEK see traditional ecological knowledge (TEK)

terrorists

antiquities trafficking 2

and the Kenyan coastal region 24

theory see normative theory; positive theory; social identity theory

Thevenot, Jean de 100

Thiong'o, Ngugi wa 219

Thompson, D. 180

Tillotson, M. 113

tourism 3, 10-11

and Agikuyu shrine 187-8, 189-90, 199

and artistic heritage 50

cultural heritage $11,12,154-5,170-1$

defining 155-6

Kenya $160-3,161-2$

Nairobi $163-5,164 t$

and sustainability $158-9$

typology $156-8$

eco- $13,178-9$

and the Mau Mau war trenches 224

rural $145,150,152$

wildlife 126,134

Townshend, Philip 105

traditional cultural practices 9

traditional ecological knowledge (TEK) 28

traditional knowledge (TK) 28, 35, 45, 51, 52 and traditional technologies 109

traditional resource rights 39,41

traditional technologies 9, 108-9

and fishers 204, 205, 207, 209

pottery making $113-24$

traffic/trafficking 2, 4

transfer rights $127,127 \mathrm{t}$

trenches, Mau Mau 221, 222-5, 223

tribes see communities; individual tribes

Tsunekawa, A. 144

Tudor revival style $81-2,82$

Udvardy, M. 22

uhuru na kazi (freedom and work) 218

Ulrich, K. 146
UNESCO 4, 155, 156

Intangible Cultural Heritage (ICH)

instruments $6,34,45,46$

and intangible heritage 5-6, 52-3

World Heritage sites 25, 51

United Nations (UN)

Declaration on the Rights of Indigenous Peoples (2008) 21

World Tourism Organization (UNWTO) 158-9

Universal Declaration of Human Rights 18 , 26-7

urban heritage 6

value, added 3, 9, 108

Van Zwannenburg, R.M.A. 76

Vercruijsse, E. 210

Vessella, Nino 105-6

Victoria, Queen 61, 61t, 62, 62, 63

vigango $22,25,55$

visual resources 143, 146, 150

Wachanga, K. 216

Waithaka, J. 130, 136

war heritage 221

Washitani, I. 144

water buffalo 128

Waziri, M. 183

wellbeing 11,144

Westminster House $87 \mathrm{t}$

West Pokot 56

Whitehouse, Sir George 76

wildlife heritage 51

ownership 10, 127-9

history of $130-8$

trafficking of 2

Williams, P. 214

Wilson, Doug 203

Winterbottom, T. 101

women

and bao 104

and fishing 14, 208, 209

and Kit-Mikayi study 176

and pottery making $115,119-20,121,123$

and ritual 150

World Heritage Convention 156

World Heritage sites 51

Kenyan coastal region 25

worship, and tourism 166-7, 167

Yokohari, M. 144 

In Kenya, cultural and natural heritage has a particular value. Its prehistoric heritage not only tells the story of man's origin and evolution but has also contributed to the understanding of the earth's history, via fossils and artefacts spanning over 27 million years that have been discovered and conserved by the National Museums of Kenya (NMK). Alongside this, the steady rise in the market value of African art has also affected Kenya: demand for African tribal art has surpassed that for antiquities of Roman, Byzantine, and Egyptian origin, and in African countries currently experiencing conflicts, this activity invariably attracts looters, traffickers and criminal networks.

This book brings together essays by heritage experts from different backgrounds, including conservation, heritage management, museum studies, archaeology, environment and social sciences, architecture and landscape, geography, philosophy and economics to explore three key themes: the underlying ethics, practices and legal issues of heritage conservation; the exploration of architectural and urban heritage of Nairobi; and the natural heritage, landscapes and sacred sites in relation to local Kenyan communities and tourism. It thus provides an overview of conservation practices in Kenya from 2000 to 2015 and highlights the role of natural and cultural heritage as a key factor of social-economic development, and as a potential instrument for conflict resolution.

ANNE-MARIE DEISSER is Research Associate at the Department of History and Archaeology of the University of Nairobi and Honorary Research Associate at UCL's Institute of Archaeology, London.

MUGWIMA NJUGUNA is an architect and planner, and director of the Centre for Urban Studies at Jomo Kenyatta University of Agriculture and Technology.

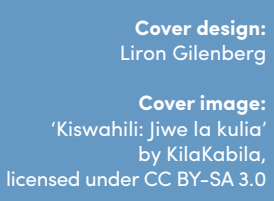

$£ 18.99$

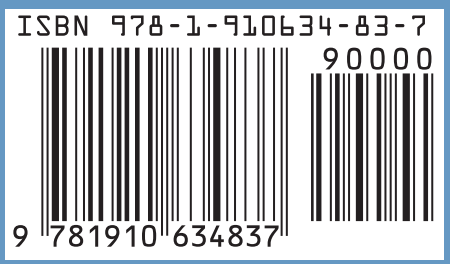

